Florida International University FIU Digital Commons

6-12-2014

\title{
Stakeholder Perceptions and Preferences for Coral Reef Restoration and Sustainable Resource Management
}

James Wilkinson Harper

jharp002@fiu.edu

DOI: $10.25148 /$ etd.FI14071138

Follow this and additional works at: https://digitalcommons.fiu.edu/etd

\section{Recommended Citation}

Harper, James Wilkinson, "Stakeholder Perceptions and Preferences for Coral Reef Restoration and Sustainable Resource Management" (2014). FIU Electronic Theses and Dissertations. 1486.

https://digitalcommons.fiu.edu/etd/1486 


\section{FLORIDA INTERNATIONAL UNIVERSITY}

Miami, Florida

\section{STAKEHOLDER PERCEPTIONS AND PREFERENCES FOR CORAL REEF RESTORATION AND SUSTAINABLE RESOURCE MANAGEMENT}

A thesis submitted in partial fulfillment of the requirements for the degree of MASTER OF SCIENCE in ENVIRONMENTAL STUDIES by

James W. Harper 
To: Interim Dean Michael R. Heithaus

College of Arts and Sciences

This thesis, written by James W. Harper, and entitled Stakeholder Perceptions and Preferences for Coral Reef Restoration and Sustainable Resource Management, having been approved in respect to style and intellectual content, is referred to you for judgment.

We have read this thesis and recommend that it be approved.

Ligia Collado-Vides

Mahadev Bhat

Pallab Mozumder, Major Professor

Date of Defense: June 12, 2014

The thesis of James W. Harper is approved.

Interim Dean Michael R. Heithaus

College of Arts and Sciences

Dean Lakshmi N. Reddi

University Graduate School

Florida International University, 2014 


\title{
ABSTRACT OF THE THESIS \\ STAKEHOLDER PERCEPTIONS AND PREFERENCES FOR CORAL REEF RESTORATION AND SUSTAINABLE RESOURCE MANAGEMENT
}

\author{
by
}

James W. Harper

Florida International University, 2014

Miami, Florida

\section{Professor Pallab Mozumder, Major Professor}

The Florida Reef and associated human community form a unique socioecological system. While this system represents great value to society, it is exposed to high levels of vulnerability. Despite intense study of its elements, the system lacks conceptual integrity, its management is fragmented, and user valuation remains unclear. A survey using contingent valuation methods investigated stakeholders' attitudes and how much they are willing to pay for sustainable seafood, coral reef restoration, and research funding for coral reefs in southeastern Florida. Respondents expressed angst about climate change and reef conditions, and they connected reef degradation to land-based pollution and water quality. Regression analysis revealed status (income, education) as weak, indirect predictors of behavior, age as a moderating influence, and environmental and emotive factors as strong, direct predictors. One's relative attachment to ecosystems, such as coral reefs, is theorized as a motivation that displaces the expectations of traditional economic theory. 


\section{TABLE OF CONTENTS}

CHAPTER

PAGE

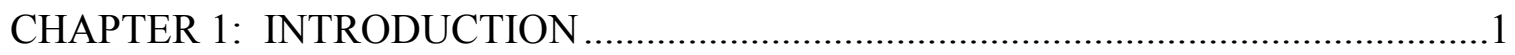

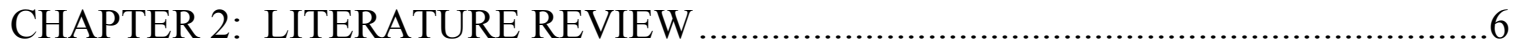

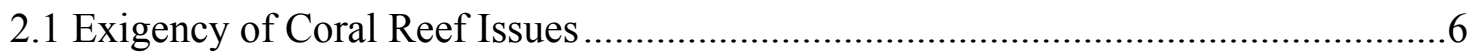

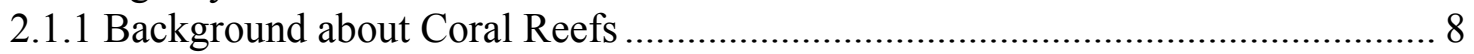

2.1.2 Endangered Corals ................................................................................. 10

2.2 U.S. Attitudes about Climate Change and Coral Reefs ............................................. 16

2.3 Public Attitudes and Willingness To Pay for Coral Reefs in Florida .......................... 21

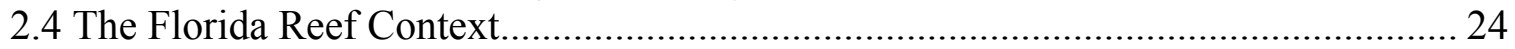

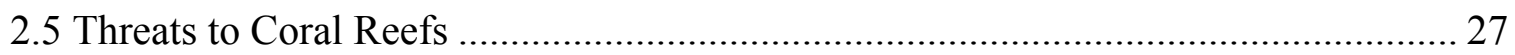

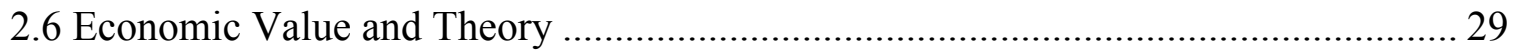

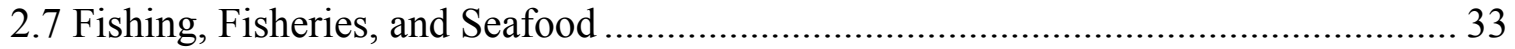

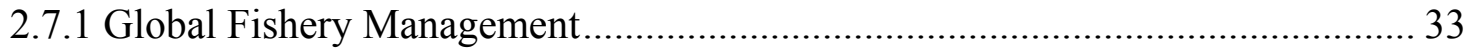

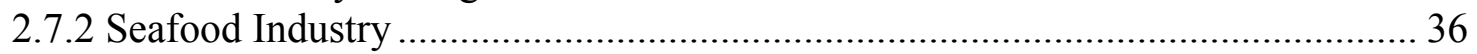

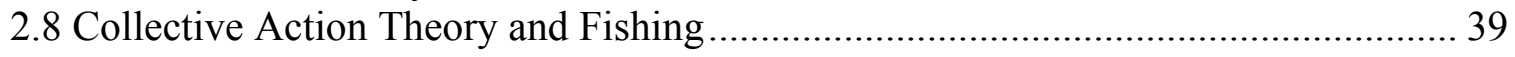

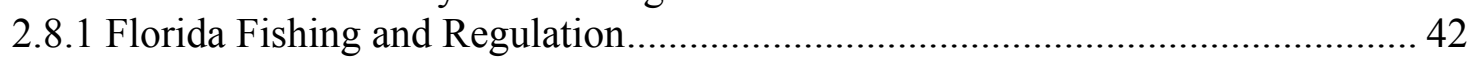

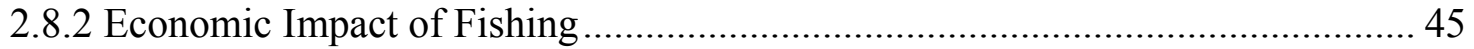

2.8.3 Florida's Commercial Fishing Industry …….................................................. 48

2.8.4 Florida Recreational Fishing Industry ……….................................................. 49

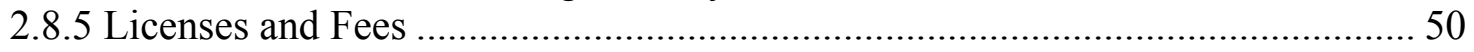

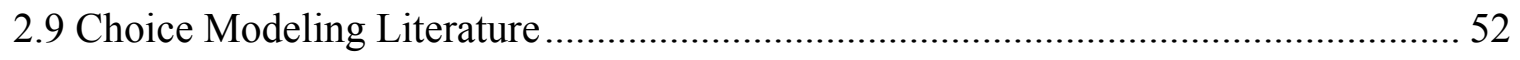

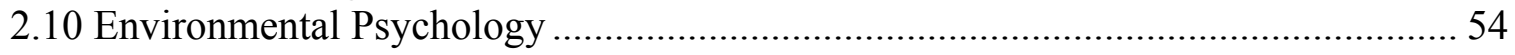

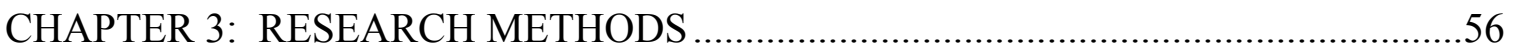

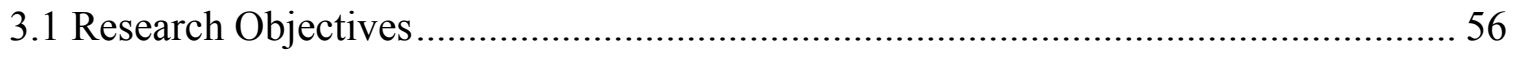

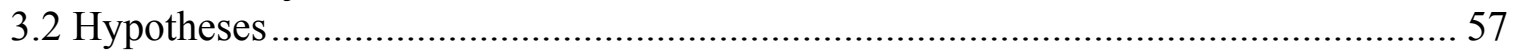

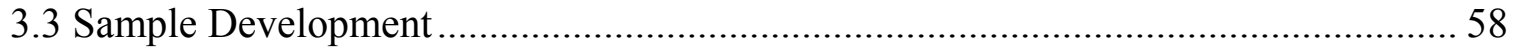

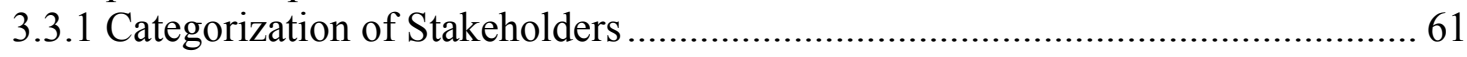

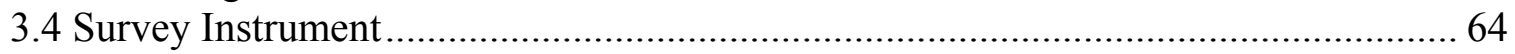

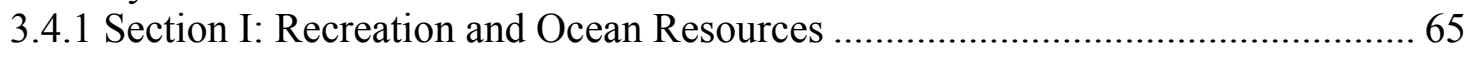

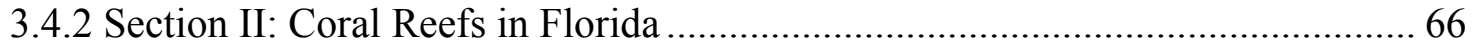

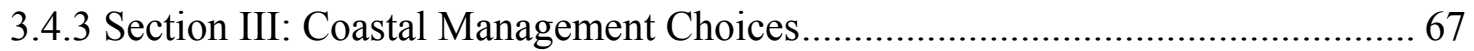

3.4.4 Section IV: Climate Change and Reef Values ................................................... 73

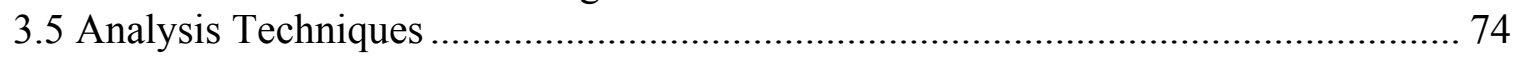

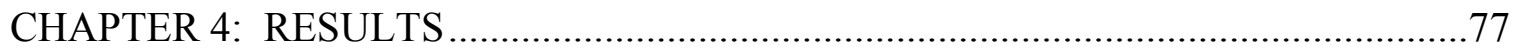

4.1 Description of Sample Respondents ..................................................................... 77

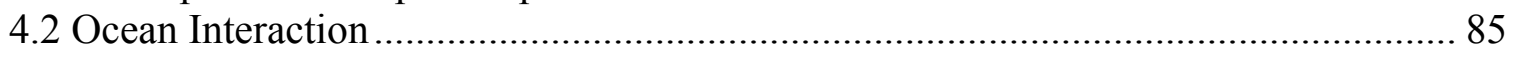

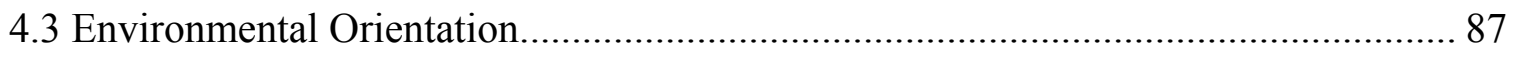

4.4 Scales for Climate Concern and Coral Concern ...................................................... 88

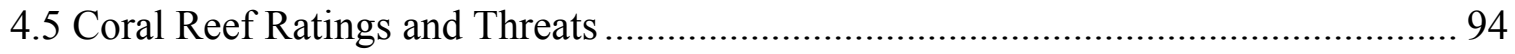

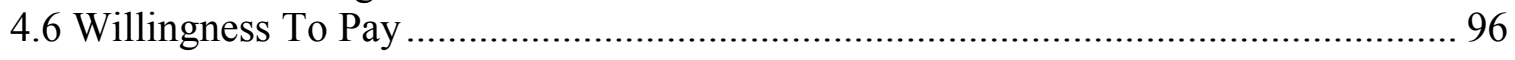




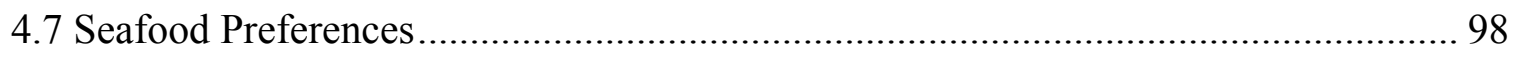

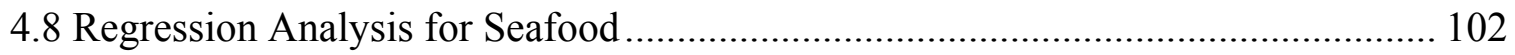

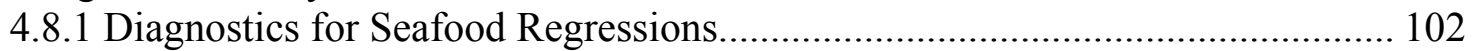

4.9 Management Choice Preferences...................................................................... 106

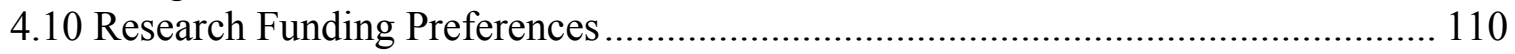

4.10.1 Regression Analysis for Research Funding ................................................. 110

4.10.2 Diagnostics for Research Funding Regressions............................................ 115

4.11 Summary of Extended Regression Models............................................................ 115

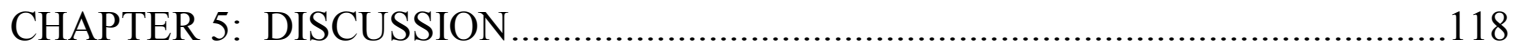

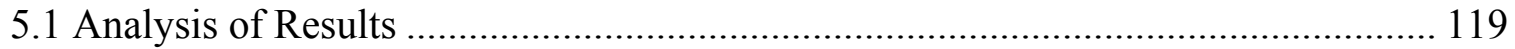

5.1.1 Comparison to Previous WTP Studies........................................................ 124

5.1.2 Climate Change and Other Perceptions ..................................................... 128

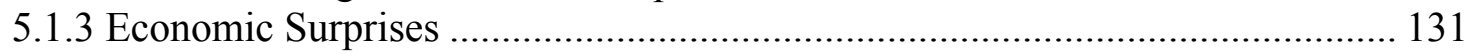

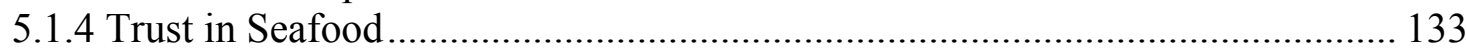

5.1.5 High Fees Supported in Choice Modeling ................................................. 137

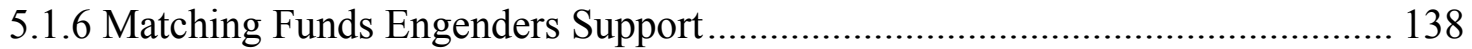

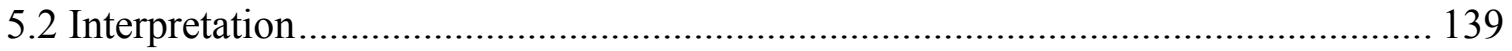

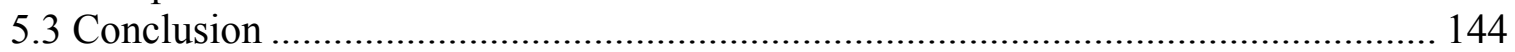

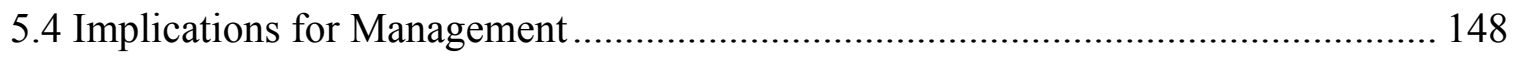

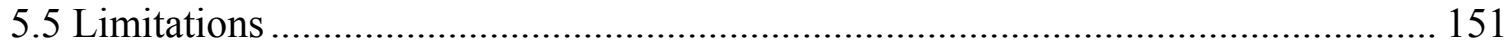

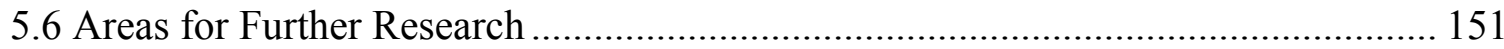

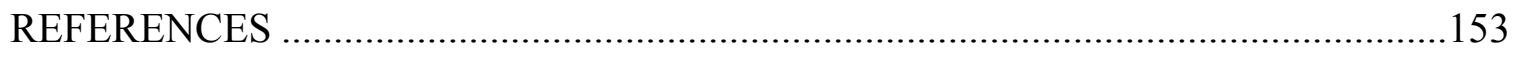

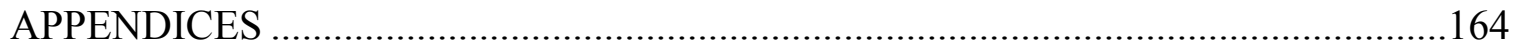




\section{LIST OF TABLES}

TABLE

PAGE

Table 1: Contrasts in U.S. Attitudes about Coral Reefs ............................................17

Table 2: Differences in U.S. Coral Reef Attitudes within Five Years.............................20

Table 3: Economic Impact of Commercial Seafood and Recreational Fishing ................46

Table 4: Population of Southeastern Florida and State.................................................59

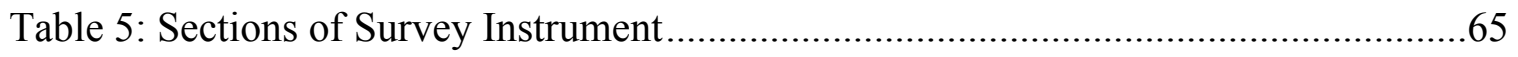

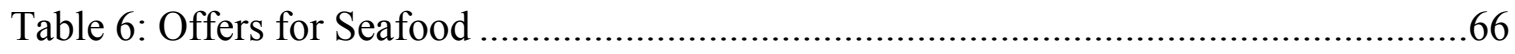

Table 7: Attributes and Levels in Choice Experiment...............................................69

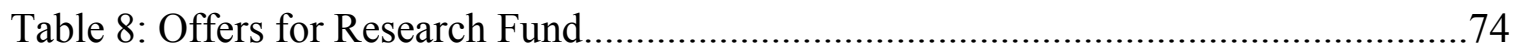

Table 9: Sample Frequencies and Survey Completion ..............................................77

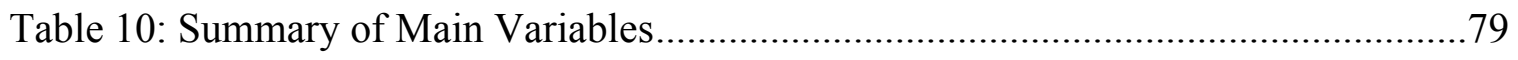

Table 11: Scales and Related Variables for Climate Change and Coral Reefs ................92

Table 12: Summary of Willingness To Pay (WTP) Scenarios .....................................96

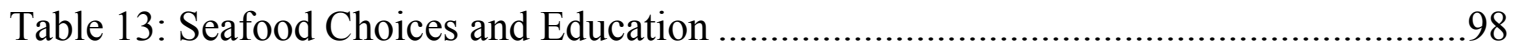

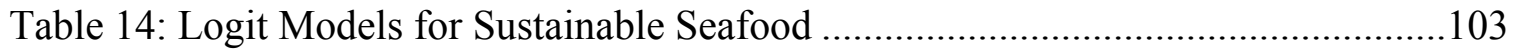

Table 15: Diagnostics for Regression on Sustainable Seafood …...............................103

Table 16: Logit Models For Local Seafood ................................................................... 104

Table 17: Diagnostics for Regression on Local Seafood ...........................................104

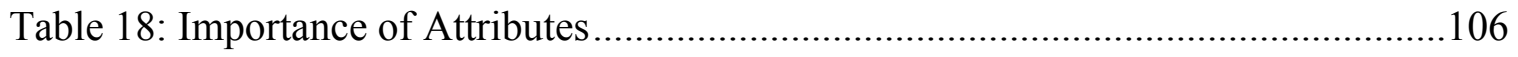

Table 19: Management Plan Choices by Variables Revealing Environmental Concern.107

Table 20: Logit Models for Research Fund 1 .........................................................114 
Table 21: Diagnostics for Regression on Research Fund 1

Table 22: Logit Models for Research Fund 2 (Matched) .........................................112

Table 23: Diagnostics for Regression on Research Fund 2 .....................................112

Table 24: WTP For Research Fund 1 and Political Identity .......................................113

Table 25: WTP For Research Fund 2 and Political Identity .....................................113

Table 26: Contrast of Assessment and Perception of Reef Threats ..............................130 


\section{LIST OF FIGURES}

FIGURE

PAGE

Figure 1: Comparison of Extinction Risk .....................................................................

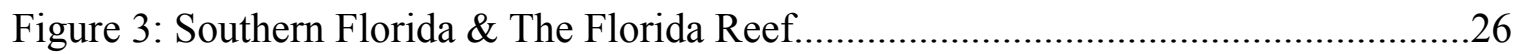

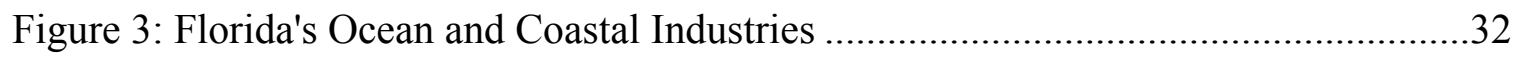

Figure 4: Global Fish Catch Data Over Decades................................................................34

Figure 5: Areas with Endangered Corals and Fishing Restrictions ...................................44

Figure 6: Decline of Fishing Landings and Growth of Seafood Imports in Florida...........47

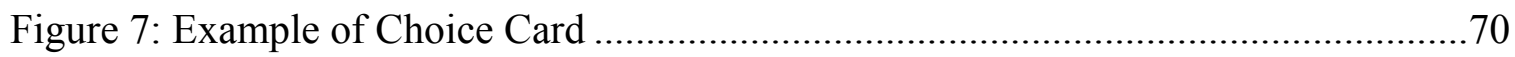

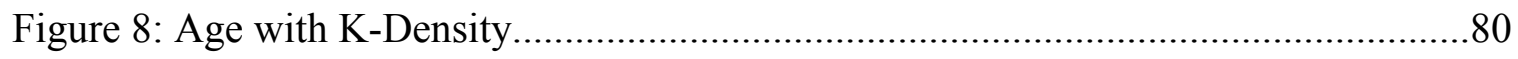

Figure 9: Household Annual Income ................................................................................

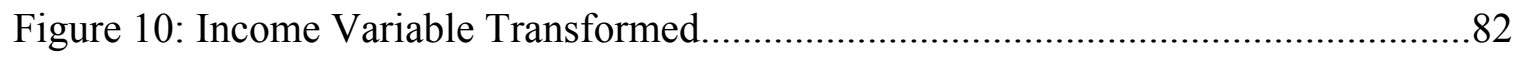

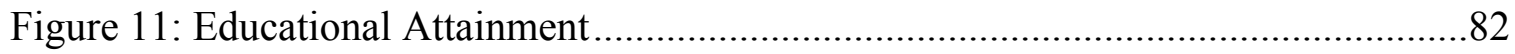

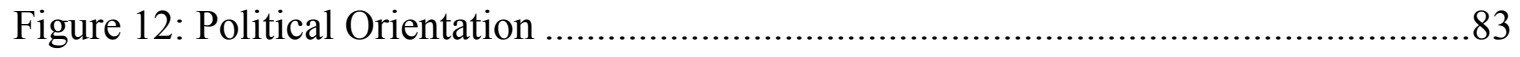

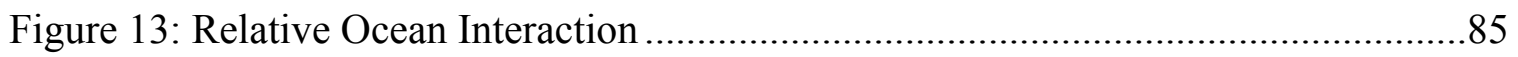

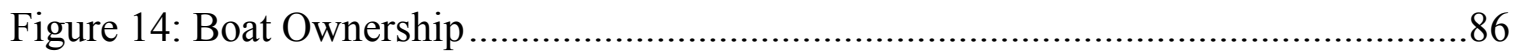

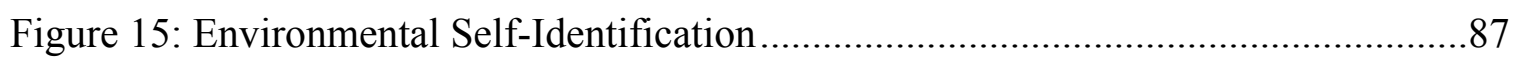

Figure 16: One Variable of 5 Used in Scale of Climate Concern........................................88

Figure 17: One Variable of 7 Used in Scale of Coral Concern ..........................................89

Figure 18: Scales of Climate Concern and Coral Concern .............................................91

Figure 19: Arrival of Climate Change Impacts..............................................................92

Figure 20: Rating of Mainland Reefs in Florida .............................................................93

Figure 21: Ranked Threats to Florida's Coral Reefs ......................................................94 
Figure 22: Favorable Willingness To Pay ….......................................................... 96

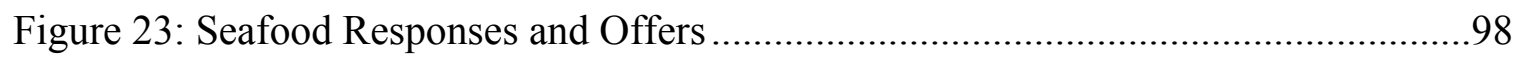

Figure 24: Seafood WTP Based On Income......................................................... 100

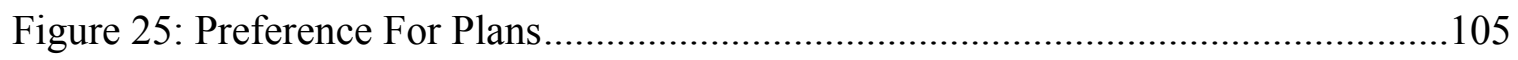

Figure 26: Management Plan Responses based on Fee Offered...................................106

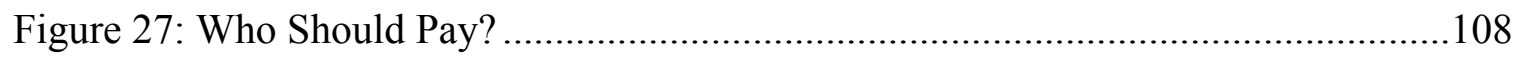

Figure 28: Research Fund 1 and Fund 2, By Income ...........................................110

Figure 29: Summary of Extended Models' Significant Variables ................................115

Figure 30. Mean Age by Income Category.......................................................... 120

Figure 31. Research Fund Choices per Offer...................................................... 125

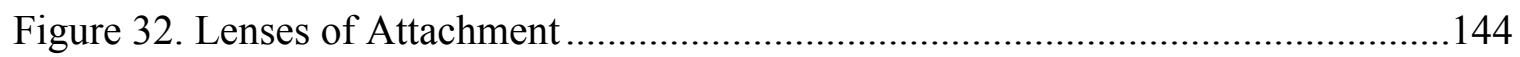

Figure 33: How Attachments Interact to Influence Decisions ......................................14 


\section{CHAPTER 1: INTRODUCTION}

Seven billion people are consuming the world's resources, and by tomorrow the world's population will have experienced a net growth of 219,000 people (Brown 2012). This global population expansion rate is the equivalent of creating a new City of Miami in two days. A new United States is created in four years (U.S. Census 2014).

Population growth is a root cause of pressures that are degrading the ocean and its coral reefs (Bradbury 2009). Coral reefs are exceptionally diverse, beautiful, and valuable ecosystems that have been studied extensively, and their global degradation within a few decades has stunned seasoned biologists (Veron 2009). Stress from population growth and climate change is pushing coral reefs to their biological limits, and they have become one of the world's most imperiled ecosystems (Hoegh-Guldberg 2011). Once considered abundant beyond quantification and models of stability, coral reefs are now candidates for global extinction (Keith \& Spalding 2013; Veron 2008).

The very concept of extinction is being recalibrated. Ecosystems are being evaluated by the International Union for the Conservation of Nature in a manner that had previously been applied to singular, endangered species (Keith et al. 2013), and this novel approach re-imagines multitudes of coral reefs in the Caribbean as if they were one endangered system (Keith \& Spalding 2013). The loss of such a vast ecosystem would represent an unparalleled tragedy of the commons (Wilkinson 2012).

How well is this unfolding tragedy understood by stakeholders, and does it inspire change? One means of measuring how concern for coral reefs translates into action, and 
into funding for solutions, is contingent valuation, whereby people are asked to assign monetary values to various coral reef-related scenarios (Van Beukering 2011). Such studies offer the benefits of quantification, replication, and application to ecosystem-wide management.

The present investigation uses contingent valuation to assess preferences of residential reef users who live within the region adjacent to the coral reefs of Florida. The Florida Reef is one of the world's most popular coral reef systems in terms of tourism, and it is the only such ecosystem within the continental United States. Its popularity and its proximity to a large population are reflected in the ranking of the entire system as being under threat (Burke 2011).

Although several relevant technical reports have been published within the past decade, sparse scientific literature addresses preferences and public perceptions of the Florida Reef. These reports reveal trends also appearing in the broader social science literature; namely, people lack an understanding of oceanic ecosystems; despite this knowledge deficit, they express support for oceanic conservation; and they are willing to pay more than current levies for the protection of coral reefs.

The conception of the Florida Reef as one socio-ecological system is relatively new. In the academic arena, physical and social sciences traditionally have been segregated by discipline; likewise, the Florida Reef itself has been segregated into discontinuous segments to facilitate study. Mapping technology has enhanced an ability to portray both coral reef segments and the system as a whole; the first comprehensive, integrated GIS map of the Florida Reef was published the by Florida Fish and Wildlife Conservation Commission in 2013 (FWRI). Even the system's name is unclear, as the 
scientific community uses "Florida Reef Tract" to refer to either the system or a northern sub-section. Hence, the current study avoids that term and favors adoption of the term "Florida Reef."

Commonly associated with the Florida Keys, the Florida Reef forms an arc that parallels the Atlantic shoreline of southeastern Florida and extends north of Palm Beach County. This northern region lacks protection in comparison to the comprehensive Florida Keys National Marine Sanctuary.

Re-conceived of as one socio-ecological system, southeastern Florida and its coral reefs appear as twin arcs of human cities and coral cities--one above water, the other below. The arc of human cities--from Palm Beach to Fort Lauderdale to Miami to Key West--displays increasing density in a southern direction, and near the southeastern tip of the Florida peninsula it transitions into the land-poor, coastal-rich archipelago of the Florida Keys. Underwater, the density and complexity of the Florida Reef's coral communities also increase in a southern direction. With the exception of the isolated and undeveloped Dry Tortugas National Park, pressure on the system is high.

Pressures have been studied extensively, and they range from non-point pollution, such as fossil fuel emissions, to point pollution, such as sewage disposal, and from nonextractive activity, such as scuba diving, to extractive activity, such as fishing. Fishing has been practiced in southeastern Florida for centuries, but most other pressures arrived after 1912 and the completion of the Florida Overseas Railroad by Henry Flagler, which connected the mainland to the Florida Keys and facilitated the entire region's population growth (McClenachan 2013). The population of Miami at this time was about 5,500; until 
the 1890 s, all of mainland southeastern Florida had less than 1,000 residents, making it "one of America's last frontiers" (George 1996).

With more than six million residents compressed into its coastline today, southeastern Florida has transitioned very rapidly into a major metropolitan region. Its residential users of the Florida Reef are the targeted population for this study, because their ecosystem awareness and personal investments enable an engagement with coral reef issues that might elude visitors and the general public. Preferences of these stakeholders serve as indicators of future commitments, because they are likely to lead political efforts for this system's conservation.

How much are these stakeholders willing to pay for sustainability, and what factors influence their decisions? Answering such questions would be informative to various sectors engaged with this resource, ranging from establishments of tourism to centers of political power and from coral reef managers to the angler on the dock. Based on relevant literature, the current study employed best practices for economic valuation studies for coastal ecosystem services as summarized in Waite (2014). For example, the study's choice experiment is similar to studies conducted for other reef systems, but it has never applied to the Florida Reef. Moreover, instead of relying on one metric or one technique, the study employs three distinct scenarios that investigate stakeholder willingness to pay for seafood, for management plans, and for research funds. This diversification facilitates the examination of both market and non-market goods.

The current study intends to reveal if stakeholders of the Florida Reef have the will to conserve this unique, natural resource. They may or may not be aware of the many factors affecting its demise, yet their direct interaction and residential proximity to the 
resource means that they are connected to it. If they are willing to pay for it, other people may be willing to follow their lead. 


\section{CHAPTER 2: LITERATURE REVIEW}

\subsection{Exigency of Coral Reef Issues}

Coastal ecosystems have been ranked as the world's most valuable habitats, and among them, coral reef values are especially high for recreation and disturbance regulation (Costanza 1997). An updated global valuation study found that coral reef ecosystem services had been exceptionally undervalued, and per unit they represent the most valuable ecosystem in the world (Costanza 2014). Coral reefs provide $10 \%$ of global fish catch and protect 15\% of the world's coastline (Miller 2008). The goods and services they provide have been estimated as between $\$ 172$ billion to $\$ 375$ billion per year (Brainard 2011), although the updated Costanza study places their current annual value at $\$ 9.9$ trillion. If coral reefs were as extensive as in 1997 , their annual value today would be $\$ 21.7$ trillion (Costanza 2014).

Dubbed the "rainforests of the sea," coral reefs provide the ocean's clearest demonstration of the four pillars of sustainability: biodiversity; solar energy reliance (most uniquely in photosynthesis by the symbionts that live in coral tissues); nutrient recycling (within an oligotrophic environment); and population control through a complex food web (Miller 2008). Once considered models of stability, coral reefs have been rapidly transformed by anthropogenic forces (Hoegh-Guldberg 2011).

The entire coral reef ecosystem of the wider Caribbean, including Florida, has been classified as "endangered" by the International Union for the Conservation of Nature (Keith 2013). This regional designation adds to a broad consensus that warm- 
water coral reefs are one of the most threatened ecosystems in the world (Burke 2011). The urgency to conserve coral reefs is growing alongside the literature on how climate change is decimating these habitats. Worldwide, the loss of coral reefs is estimated at $1 \%$ to $2 \%$ per year (Hoegh-Guldberg 2011). The consensus of thousands of coral reef scientists from 90-plus countries is that most reefs will not persist after 2100 , by which time harmful atmospheric and oceanic conditions are projected to exceed those of the previous mass extinction 55 million years ago (Palumbi 2012). In short, all corals and the reefs they build are on a trajectory towards extinction within a human timeframe (Veron 2008).

A distinction between the projected extinction of coral reefs and many other extinctions attributed to the Anthropocene is the magnitude: instead of referring to a stepwise disappearance, species by species, scientists are referring to a collapse of the entire system. In the 2008 opus, A Reef in Time, coral geologist Veron says that the only way to save reefs is to deal with greenhouse gas emissions within a decade-meaning before 2018. Otherwise, levels of emissions by that time will impel reefs into an accelerating death spiral that will end within a few decades or less. The timeframe projected by different methods varies, but they all point in the same, dire direction.

The idea to examine both climate change impacts and social attitudes follows from a growing concern that societal responses lag far behind physical observations of climate change (Flugman 2012; Maibach 2009). Essentially, scientific evidence is expanding while attitudes in the U.S. are stagnating (Barker 2013). Moreover, perceptions and social norms function as one of several social feedback systems that affect the status of ecosystems such as coral reefs (Kittinger 2012). These dynamic 
interactions, while difficult to characterize, provide a holistic approach to sustainability issues.

\subsubsection{Background about Coral Reefs}

In the U.S., warm-water coral reefs occur in the two states of Florida and Hawaii and in five territories across the Caribbean and the Pacific. In addition to being concealed underwater, the geography of reefs may reinforce an "out of mind" mentality due to their relatively isolated locations that are far from political and economic centers of power. Even in Florida and Hawaii, where reef-related industries qualify as big business, other forms of tourism and recreation may overshadow concerns about the health of coral reefs. The status of reefs in the Pacific is somewhat better than in the Caribbean: Hawaii's reefs in highly protected and uninhabited areas qualify as some of the most robust, whereas all reefs in Florida are labeled as threatened (Burke 2011).

Shallow coral reefs are marine ecosystems constructed by sessile, Scleractinian or stony corals that secrete a calcium carbonate skeleton onto hospitable benthos (Veron 2008). Warm-water coral reefs exist in tropical and semi-tropical seawater around the globe and mostly on the eastern side of continents and archipelagos. They provide primary food sources for many millions of people, especially in developing island nations; at least 500 million people use reef-related resources, and an estimated 850 million people live within 100 kilometers of coral reefs (Hoegh-Guldberg 2011; Burke 2011). In addition to fisheries, coral reefs offer significant service values in terms of storm protection, erosion control, and tourism (Costanza 2014). Various reef types form 
in various habitats; in this study, the term "coral reef" refers to shallow, benthic structures created by reef-building corals.

Coral reefs are biological hotspots. Within a small percentage of oceanic area, they contain more than 25 percent of the ocean's diversity, 31 of the world's 33 animal phyla, and potentially multitudes of unknown species (Appeltans 2012; Hannah 2012). Although investigated more than most of the ocean, coral reefs are not as well studied as terrestrial ecosystems, and they may contain several million species new to science (Hannah 2012). Without a doubt, they offer some of the most stunningly beautiful places on earth. Losing them would be an unparalleled calamity in human history.

Reefs are assemblages of slow growing coral species that form structures over long time scales and that attract a huge variety of other species. Stony corals are typically individual assemblages or colonies of individual polyps, visible to the naked eye, and most of them form a symbiotic relationship with zoozanthellae, an algae that feeds the coral animal through photosynthesis. The structure of the reef comes from the calcareous, limestone skeleton that is secreted by the coral colonies.

Coral species are not limited to the tropics, as some cold and deep water corals can live in temperatures as low as 2 degrees Celsius (Veron 2008), yet conservation biology focuses on warm-water reefs due to their importance and proximity to humans, extreme diversity, and vulnerability to climate change. For a coral reef to persist, it needs a suitable environment that allows corals to build their skeletons at a rate that exceeds the accretion of sediment (Precht 2006). A typical reef-building coral grows at the slow rate of 0.6 meters per century, and most corals are very $\mathrm{pH}$ sensitive, although some Porites species can manage a pH level between 7.9 and 8.2 (Veron 2008). Individual corals 
depend upon a host of variables, "including temperature, irradiance, calcium carbonate saturation, turbidity, sedimentation, salinity, $\mathrm{pH}$, and nutrients" (Crabbe 2009). Climate change can affect all of them directly or indirectly, and it has been well established that corals in proximity to human populations suffer additional threats (Brainard 2011; Wilkinson 2012).

Before going further, consider that the term "climate change" is being used in this paper to refer to multiple effects, including ocean acidification, while the term "global warming" isolates temperature increase as a distinct variable. Climate change includes global warming and serves as an umbrella term for many observed patterns.

\subsubsection{Endangered Corals}

In 2006, the first two coral species were listed under the U.S. Endangered Species Act. They are related, primary reef-building corals of the Caribbean: the elkhorn coral (Acropora palmata) and the staghorn coral (Acropora cervicornis). Their hybrid species (Acropora prolifera) was not eligible for listing (Brainard 2011). In 2008, these two corals were listed as Critically Endangered by the IUCN, and both were noted for their susceptibility to disease and for population declines in excess of 80 percent during the past 30 years (IUCN 2012). Interestingly, the hybrid form has been increasing, and its viability was found to surpass the parent species (Fogarty 2012). It even persists in the highly degraded environment of the Port of Miami (personal communication).

In Florida, reef decline has been documented for at least 30 years. A study of $A$. palmata in the Florida Keys between 2004 and 2010 measured a 50\% reduction in live tissue and attributed this loss to three main causes: fragmentation, disease, and predation 
by snails (namely, Coralliophila abbreviata) (Williams 2012). Coral bleaching of $A$. palmata was not observed during this period. Half of the overall decline was attributed to the active hurricane season of 2005 .

Many more corals may be joining the U.S. endangered species list based on a petition for 82 coral species. A preliminary report from NOAA indicates that 56 coral species are likely candidates for extinction by 2100 (Brainard 2011).

A growing awareness of the effects of climate change has shifted the conversation of policymakers away from local point source pollution, such as sewage, to global nonpoint pollution threats—-primarily carbon dioxide emissions (Wilkinson 2012). The seminal Coral Reef Conservation Program at NOAA refined its priorities to focus on three primary threats: climate change, land-based pollution, and overfishing (NOAA Implementation 2011). Similarly, the NOAA study for the listing of 82 corals identified 19 threats, but only four ranked at a level of medium or above: Ocean Warming (High), Disease (High), Ocean Acidification (Medium-High), and Reef Fishing-Trophic Effects (Medium) (Brainard 2011).

Three decades ago, it was unthinkable that even a single coral species could go extinct because of their very broad ranges across stable, tropical habitats (HoeghGuldberg 2012). Today, at least one-third of species are threatened with extinction, and all 838 known reef-building coral species are assessed by CITES and the IUCN (Huang 2012; IUCN 2012). Thirty years ago, most reefs were considered robust, although there were pockets of unhealthy reefs associated with nearby, dense human populations (Wilkinson 2012; Williams 2012). Currently in Florida, all reefs are considered threatened by a combination of local and global pollution, and worldwide 75 percent of 
reefs are likewise threatened (Burke 2011). Some relatively pristine reefs exist in remote locales; for example, the reefs far from human populations in Hawaii, protected since 2006 in the Papahānaumokuākea Marine National Monument, are some of the world's healthiest. Yet global climate change is expected to make all reefs vulnerable to collapse in less than 50 years (Burke 2011).

By 2050, atmospheric carbon dioxide levels are estimated to reach $500 \mathrm{ppm}$, much higher than today's level of just over $400 \mathrm{ppm}$, and the rate of increase would be at its highest level in 300 million years (Rau 2012; Tans 2014). Ocean temperatures will continue rising, and acidification is predicted to surpass bleaching as the primary threat to corals (Rau 2012; Veron 2008).

Some coral species may have the capacity to adapt to increased shifts in temperature, although research on adaptation remains inconclusive (Baker 2008). A 2011 review in Science demonstrates that reefs in the geological past existed under more severe conditions than today, with very high levels of temperature, carbon dioxide and acidification (Pandolfi 2011). While the researchers accept these indicators as eventually causing mass extinctions, they argue that "current projections of global-scale collapse of reefs within the next few decades probably over-estimate the rapidity and spatial homogeneity of the decline." In response to this article, a letter in Science cautioned that the current rate of change overwhelms a reef system's ability to adapt through evolution, and that the visual evidence of expanding coral bleaching leads to pessimistic conclusions (Riegl 2011).

Over geological time, reefs have faced five mass extinction events, with the most recent occurring 56 million years ago (Harnik 2012; Veron 2008). With the exception of 
the first extinction event, reef crises have been characterized by both global warming and acidification, although a debate within the literature continues about the magnitude of their effects (Harnik 2012; Pandolfi 2011). The term "event" is misleading, because systemic extinction occurred over a period of more than one million years; afterwards, it took as many as of 10 million years for reefs to recover (Veron 2008).

Within the modern historical era, no coral species has been confirmed as going extinct; however, their rapid descent into endangerment appears unparalleled within the animal kingdom (IUCN Summary 2013). Before 1995, corals were considered highly stable species, but by 2008 they nearly equaled amphibians in their vulnerability to extinction (see Figure 1).

In the historical record, only 19 extinctions of marine species have been confirmed, although a much higher number can be inferred (IUCN 2013; Regnier 2009; Turvey 2009). Despite perceptions to the contrary, no whales and no commercially important fish have been declared extinct, and the singular reef-associated species, the green wrasse (Anampses viridis) from Mauritius, is data deficient (IUCN 2013). Missing data should not be surprising, because until recent decades, extinction and the ocean were considered oxymoronic. Why would you track something that does not happen?

Employing geological timeframes, geologist Veron concludes that the rate of change of both ocean temperatures and acidification is too rapid to allow for genetic adaptation of corals $(2008 ; 2009)$. He observes that the past five mass extinction "events" actually took place over millions of years and that reefs required millions of years to recover, making today's pace of accelerating change incompatible with the very slow transitions observed in geological time. He is likewise clear about the singular action that 


\section{Figure 1: Comparison of Extinction Risk}

Explanation: The IUCN Red List Index assesses extinction risk trends among taxonomic groups on a scale of 0 to 1 , with 0 equal to extinction and 1 equal to least concern (Source: IUCN Summary 2013).

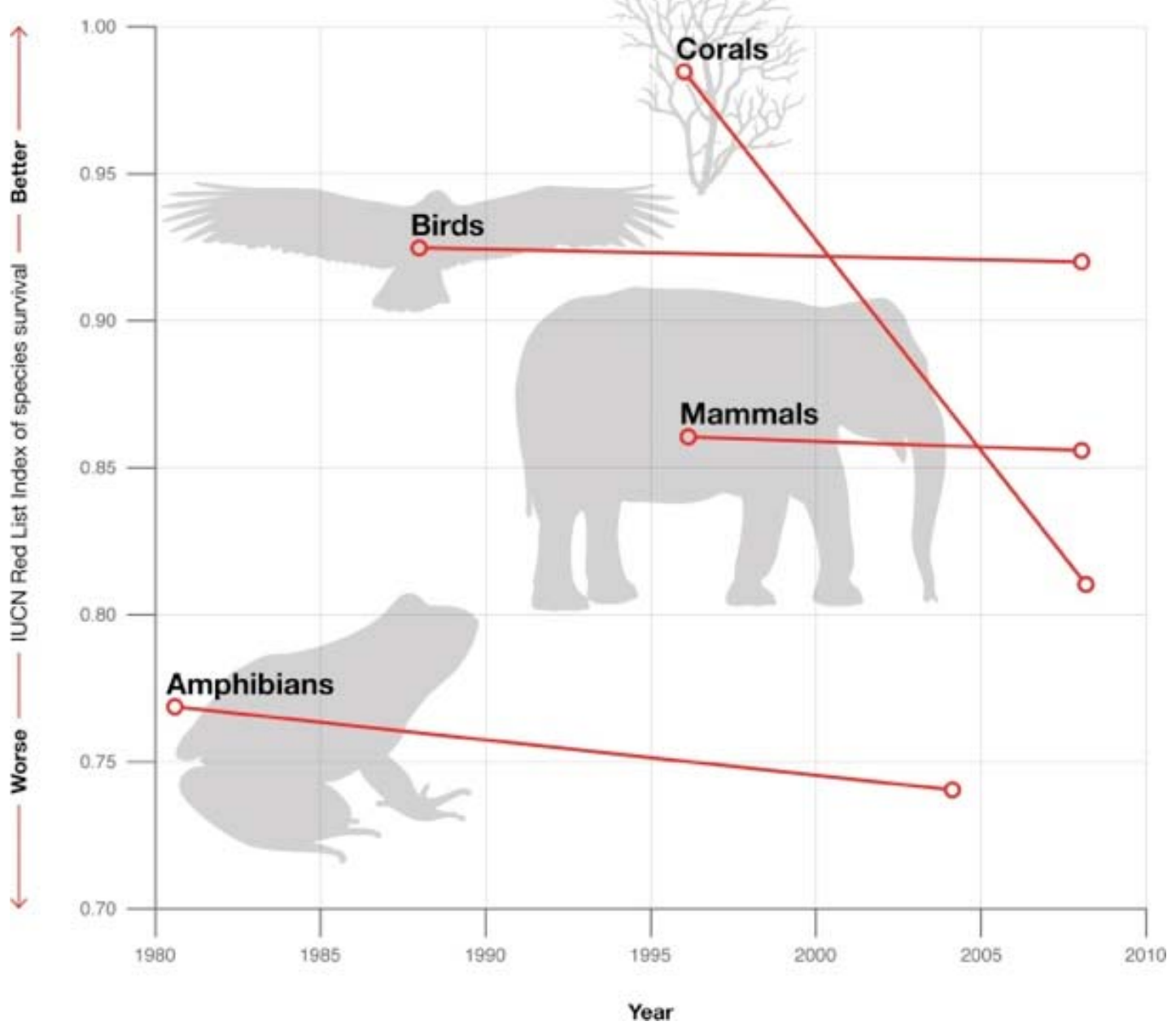

can address the singular greatest cause of a mass extinction on coral reefs: “... It has happened before and it not only can happen again, it will happen again unless adequate intergovernmental action is taken on $\mathrm{CO}_{2}$ emissions now... The time frame and severity of acidification, as well as its long-term consequences, have no equal" (2008). Such predictions urge natural resource managers to move quickly beyond the rule of precaution. Another reason for heightened concern is the time lag between the release of 
emissions and their effect in the ocean (Brainard 2011). Because effects cannot be seen immediately, protective action may be delayed until crucial tipping points have been passed. Not only are existing threats high, but also the rate of atmospheric change is increasing and outpacing the capacity for evolutionary change (Rau 2012; Riegl 2011).

Direct, recent evidence of thermal stress on coral reefs is well documented in mass bleaching events. Bleaching refers to the white appearance of the coral skeleton after it expels its algal symbiont due to stress. Mass bleaching, as opposed to isolated bleaching, was first recorded in 1978, when atmospheric carbon dioxide levels were at $336 \mathrm{ppm}$ (Veron 2009). The largest mass bleaching event occurred during 1997 to 1998 , when carbon dioxide registered at $365 \mathrm{ppm}$, and it coincided with an El Nino event that elevated ocean temperatures (Veron 2009). Corals can recover from bleaching if favorable conditions return, although mass mortality may result if tipping points or thresholds are passed. An estimated 16\% of all reef-building coral populations perished within the year following the 1998 mass bleaching event (Hoegh-Guldberg 2011). The Caribbean region experienced its most severe bleaching event in 2005, and recovery has been minimal (Burke 2011).

While the subsistence of corals depend on many variables, such as irradiance, turbidity, and salinity, the growth of a coral colony depends on a calcification rate that exceeds erosion (Veron 2008). In laboratory experiments, calcification of corals fell between 11\% to 37\% when carbon dioxide levels were doubled (Brainard 2011). Acidification is the process that begins with the absorption of carbon dioxide by the ocean, and it results in the suppression of calcification rates. By the year 2050, acidification is predicted to overcome bleaching and disease as the leading threat to 
corals (Veron 2008). Under severe acidification, corals lose their skeletal structure. A 2009 study predicted that reefs would begin to dissolve when carbon dioxide levels exceed 560 ppm (Brainard 2011). This level is expected after the year 2075 (Veron 2009).

When considering the observed and predicted threats to coral reefs, it becomes understandable why scientists are publishing very urgent and uncharacteristically stark appeals for conservation measures of all varieties (Hoegh-Guldberg 2011; Rau 2012; Veron 2009). What becomes puzzling, however, is that these dire warnings and pleas to save entire ecosystems have not captured pervasive public attention.

\subsection{U.S. Attitudes about Climate Change and Coral Reefs}

Attitudes about climate change in the United States can be considered first from the point of view of general attitudes about the environment. Over decades, citizens have consistently ranked the environment as a low-level priority, with only 2 percent ranking it as the most important issue in an April 2000 Gallup poll (Guber 2003). Interestingly, when ranking concerns for 25 years into the future, citizens in the same poll placed the environment first. Many studies have shown a generally sympathetic view of the environmental movement and its concerns, but at the same time its prioritization seems suppressed by other concerns considered more immediate and influential. A possible root cause of such apathy may be a lack of knowledge about the environment.

A major study of global warming attitudes determined that Americans fall within six general groupings of concern, ranging from dismissive to alarmed (Maibach 2009). Responses fall along these lines for many related issues, and generally higher levels of 
concern correlate with greater action. Some actions garner widespread support, such as increasing vehicle fuel efficiency, and a majority of U.S. citizens plan to take consumer action in the form of energy-efficient purchases. Political action, on the other hand, registers weakly.

Various studies show that U.S. citizens do not connect climate change, or global warming, to the degradation of coral reefs. The most recent national survey about attitudes in relation to coral reefs was conducted in December 2007 by Edge Research, and it was principally a replication of the first national study by the same company in 2002 (Edge). With 1,019 interviews completed by telephone, the 2007 survey found a high level of concern for coral reefs alongside low levels of knowledge and information. Some contrasts discovered within the two studies are summarized in Table 1.

Table 1: Contrasts in U.S. Attitudes about Coral Reefs

\begin{tabular}{|l|l|}
\hline \multicolumn{1}{|c|}{ High Levels } & \multicolumn{1}{c|}{ Low Levels } \\
\hline Ocean ethic & Knowledge of reefs \\
\hline $\begin{array}{l}\text { Support for protection, Marine } \\
\text { Protected Areas, and increased } \\
\text { enforcement of water pollution laws }\end{array}$ & $\begin{array}{l}\text { Connection of reefs and climate } \\
\text { change }\end{array}$ \\
\hline $\begin{array}{l}\text { Willingness to pay, per vacation: } \\
\text { 2002: 72\% WTP at least \$10; }\end{array}$ & $\begin{array}{l}\text { Belief that personal actions and } \\
\text { consumer choices will make a } \\
\text { significant impact }\end{array}$ \\
2007: 65\% WTP \$50 or more & \\
$33 \%$ WTP \$50 or more & \\
\hline
\end{tabular}

Overall, U.S. citizens demonstrated high levels of stated concern for the ocean environment, although basic knowledge was lacking. At least $65 \%$ in both surveys 
demonstrated a willingness to pay an additional fee for conservation purposes when planning a vacation to regions with coral reefs. In addition, willingness to pay or alter purchases was also supported by majorities in terms of tourism, fish consumption, and coral products.

Other key findings included a correspondence between interaction with reefs and higher levels of belief in scientific statements about them. This distinction emerged from survey questions about coral reefs and climate change: whereas the general population expressed little awareness of a connection between the two, the two categories of "visitors" (to reefs) and "donors" (to conservation) demonstrated higher awareness. Overall, climate change was ranked as the lowest among eight threats to coral reefs, with the top two ranked threats being water pollution and destructive fishing. Worth noting in the 2002 survey, the average person ranked themselves as 6.3 on a 0 to 10 "Environmentalist" scale; in addition, the primary source of information about coral reefs was television. In the 2007 survey, a majority expressed a willingness to change their fish consumption to support greater reef health. These findings indicate that sympathy exists even when awareness is lacking.

Accurate knowledge of coral reefs registered at a low level, and only a minority of $39 \%$ of U.S. citizens could identify coral correctly as an animal. This level held even for the sub-sample of "donors" to conservation, noted above as having higher awareness of climate change along with reef "visitors." Even for concerned citizens and stakeholders, knowledge of coral reefs cannot be assumed.

Considering that the vast majority of U.S. citizens live at a great distance from tropical coral reef ecosystems, they have surprisingly high levels of interaction with 
them. Within the five years previous to the Edge Research 2007 survey, a considerable $25 \%$ of the population had visited a U.S. territory with reefs (Florida, Hawaii, U.S. Virgin Islands, Puerto Rico or U.S. Territories in the Pacific, such as American Samoa or Guam), and the majority of them visited a reef while there. Fully $50 \%$ of those visitors had been to the Florida Keys. This popularity among U.S. tourists suggests that coral reef territories generate high demand for tourism, and very large numbers of citizens have interacted with a coral reef ecosystem directly. This opportunity for educating the public is ripe for expansion.

In the same years that the scientific literature was blossoming with studies about coral reef degradation, a comparison between the 2002 and 2007 studies shows a trend of decline in concern. Although it is unknown if these declines would be statistically significant, as the original data was unavailable, an inference can be made based on the reported margin of error $+/-3.1$ percentage points at the $95 \%$ confidence level. For example, the threat from global warming registered as at least "somewhat serious" by $80 \%$ in 2002 , but the same question registered at $68 \%$ in 2007 . When respondents were asked a series of questions to test their levels of belief and of concern about threats to coral reefs, the lowest believability score of $62 \%$ was for the statement "Water temperature change can cause coral to die" (Edge 2007). Some other considerable declines are noted in Table 2 .

With only five years separating the nearly identical surveys, it appears that a shift in attitudes has occurred. Many questions remain about the causes of such a shift. As for demographics and related attitudes, one apparent change during this period was the 
Table 2: Differences in U.S. Coral Reef Attitudes within Five Years (Edge 2002, Edge 2008)

\begin{tabular}{|l|l|l|l|l|}
\hline Survey Question or Statement & $\begin{array}{l}\text { Response } \\
\text { Level }\end{array}$ & 2002 & 2007 & Difference \\
\hline $\begin{array}{l}\text { "In the last few decades, human } \\
\text { activity has destroyed more than } \\
35 \text { millions acres of coral, which is } \\
\text { 25\% of reefs worldwide." }\end{array}$ & $\begin{array}{l}\text { some } \\
\text { concern }\end{array}$ & $90 \%$ & $75 \%$ & $-15 \%$ \\
\hline $\begin{array}{l}\text { Healthy ocean, with plentiful and } \\
\text { diverse marine life and habitat }\end{array}$ & $\begin{array}{l}\text { some } \\
\text { importance }\end{array}$ & $93 \%$ & $83 \%$ & $-10 \%$ \\
\hline Threat from global warming & $\begin{array}{l}\text { somewhat } \\
\text { serious }\end{array}$ & $80 \%$ & $68 \%$ & $-12 \%$ \\
\hline Threat from water pollution & $\begin{array}{l}\text { somewhat } \\
\text { serious }\end{array}$ & $95 \%$ & $78 \%$ & $-17 \%$ \\
\hline
\end{tabular}

growth of political ambivalence, as in 2007 there was a higher percentage of respondents refusing to choose a political category (21\%) than in $2002(13 \%)$, and the only category to gain in 2007 was a 6 point increase for "Independent, leans Republican." Although the timeframe between surveys is relatively short, these differences indicate that public sympathy for coral reef degradation was declining at the very same time that concern among coral scientists was rising (Edge 2007).

For all respondents, $83 \%$ stated that a healthy ocean is important to them personally, and groups with even higher levels of agreement were older adults $(45+)$, Democrats, visitors to reef areas, divers and snorkelers, and conservation donors. For willingness to pay, fully $65 \%$ were willing to pay at least $\$ 10$ per person as a vacation fee that would fund reef research and conservation, and nearly half offered $\$ 50$ to $\$ 100$ per person. Divers and snorkelers offered the most generous financial support. 


\subsection{Public Attitudes and Willingness To Pay for Coral Reefs in Florida}

Residents of southern Florida were surveyed extensively for DeHaven-Smith's 1991 book Environmental Concern in Florida and the Nation. South Floridians

demonstrated high levels of satisfaction with their communities and high levels of generalized empathy for environmental issues. However, per national trends, environmental concern did not translate into a willingness to pay. One trend found was that environmental issues were much more closely associated with local elections and issues rather than with national concerns, where it lagged in comparison to concern about security and economic issues.

In mainland southeastern Florida, a beach visitor study by Shivlani in 2006 found that both visitors and residents were willing to pay a tax to support healthy reefs. The visitors' mean amount equaled $\$ 3.14$ in additional bed tax, and resident willingness to pay for a reef management fund registered at $54.9 \%$ approval and an average rate of $0.77 \%$ sales tax. A similar study by Shivlani in 2003 found a higher willingness to pay for beach area visitation with sea turtle conservation, equivalent to $\$ 2.12$ per visit, versus $\$ 1.69$ per visit without conservation.

Trip valuation studies offer one method to assess an ecosystem's worth to visitors. A study by Bhat (2003) of non-marketed values in the Florida Keys determined that marine reserves would inspired more visits and increase the user's value by $69 \%$, or $\$ 523$ per capita per visit. It also concluded that an entrance fee policy could sustain the reserve with as little as 2\% of annual recreational benefits. As reported by Park (2002), a 1999 study by Bhat found a reef visitation value of $\$ 1,087$. Park's study of snorkeling in the 
Florida Keys found a trip expenses value of $\$ 481.15$ per person and a willingness to pay of \$735 per trip, and this study reports Leeworthy and Bowker's average finding of $\$ 653.94$ per trip. Influential factors were not consistent across studies. In comparison to international studies, these values are very high (Londono 2012). Comparisons of research find that travel cost methods inflate coral reef values, whereas contingent valuation may underestimate them (Ghermandi 2011; Londono 2012).

The most extensive economic valuation studies of the Florida Reef were conducted by Johns et al. in 2001, updated in 2003, and expanded in 2004. Focusing on boaters that fish or dive, and using a contingent valuation technique within a survey, the 2003 study found a lack of support for artificial reefs from stakeholders: "It is of interest that slightly over 75 percent of the respondents refused to pay the amount given to them in the question for additional artificial reefs. Of course, these amounts varied from $\$ 10$ to $\$ 100$ per year. Those answering "NO" to the increased annual cost felt that government should fund this program out of general revenue ( 15.5 percent) rather than levy a specific tax on reef users." This rejection by the majority could reflect a disdain for artificial reefs, for taxes, for fee levels, or for a combination of various factors. It contrasts sharply with the Shivlani 2006 study showing majority approval for sales tax for a reef management fund. Such differing conclusions indicate that findings are relative expressions of each study's context and methods.

Considered by county, the Johns et al. study found that Broward County reef users are willing to pay $\$ 126$ million per year to maintain current quality. In Miami-Dade County, willingness to pay was $\$ 46.9$ million per year. A consistent finding was a higher 
WTP for natural versus artificial reefs. It is worth noting that the majority of residents supported no-take zones for natural reefs.

This preference for natural reefs also appears in international studies (Londono 2012). Through meta-regression models, this study found only three themes that consistently increase willingness to pay: natural reef type, percentage of live coral cover, and Marine Protected Area status.

In southern Florida, five recent studies provide a baseline for stakeholders' attitudes about the Florida Reef (Berry 2011; Shivlani 2011; Shivlani 2008; Shivlani 2007; Shivlani 2006). Most notably, climate change or global warming was not a major concern. It only registered as a serious threat in the 2006 study, although this study discusses doubts that respondents understood its connection with coral reefs. In the two most recent studies from 2011, panels of stakeholders downplayed climate change and ranked it behind more immediate threats of water quality, coastal construction, and landbased sources of pollution. In the 2008 study, commercial fishers, dive operators, and environmental group members did not mention climate issues. In the 2007 summary of several studies of the mainland region, global warning ranked as the least important threat.

These studies found a convergence in the perceptions of coral reefs. Stakeholders consistently portrayed them as declining resources, and they likewise perceived deterioration in water quality, which ranked as a major threat. These perceptions align with long-term observational studies, yet they contrast with some short-term biological surveys, such as Gilliam 2010's assessment of relative stability in the mainland reefs' coral cover during the course of a decade. 
As for climate change attitudes, a 2008 study in Florida found that $71 \%$ accepted the reality of global warming (Leiserowitz). They mainly considered it a threat to distant locations instead of within Florida, although 30\% acknowledged current, dangerous impacts within the state. Action to address climate change within Florida was wellsupported: $65 \%$ agreed with a $\$ 100$ annual household increase in utilities; $65 \%$ agreed with $\$ 5$ per month in additional taxes; $63 \%$ agreed with increased costs for state buildings to use solar power; and $51 \%$ agreed with a $\$ 2.50$ surcharge per month on electricity. For the 2008 presidential election, $60 \%$ planned to give consideration to the issue of global warming, and 37\% would disregard it. As for damage to coral reefs in Florida, 61\% agreed (26\% strongly) that global warming is causing damage. This survey shows that Florida residents have considerable concern about the effects of global warming, and they are willing to pay for new measures to address it.

\subsection{The Florida Reef Context}

At the northern boundary of the Caribbean Sea is the Florida Reef Tract, heralded as the world's third longest reef system (ONMS 2011). Instead of calling it the Florida Reef Tract, this study favors the inclusive term of "Florida Reef."

The Florida Reef is a subtropical Atlantic system and part of the Caribbean Basin of associated coral reefs, and it extends alongside the arc of southeastern Florida. Situated within the Florida Current and Gulf Stream, it extends from the southernmost points in the continental U.S. in Monroe County and continues north along the coastline of MiamiDade, Broward, Palm Beach, and Martin counties. Highly developed along the coastline, this region of 6.1 million residents contains $31 \%$ of the state's population (Census 2013). 
Excluding Monroe County, more than $46 \%$ of residents surveyed in the four mainland counties remain ignorant of the reef's existence within less than one mile of their shoreline (Shivlani 2006). Such ignorance excludes citizens from participating in informed cooperative behavior or even discussions about this resource. Therefore, studies of social interactions with the Florida Reef tend to focus on stakeholders who have acquired a requisite baseline of knowledge.

The northern one-third of this reef system is biologically less developed than the southern two-thirds alongside the archipelago of the Florida Keys, and these sections have been managed distinctly, with few protections covering the northern section, and the Florida Keys National Marine Sanctuary covering the entire southern section since 1997 (Banks 2008; Florida 2010). It should be noted that seagrasses predominate within the Sanctuary's borders, especially in the Gulf of Mexico, and this habitat provides essential, integrated functions for the reef system in the Atlantic. Scientific literature segregates the Florida Reef's northern and southern sections based on geomorphology and differences in reef-building corals, yet the reef-building staghorn coral (A. cervicornis), one of the two coral species federally listed as "threatened," persists across the system, and the relatively cooler waters of the northern region may prove more conducive to future growth (see Figure 2 and Figure 5; NOAA 2012).

As with any regional ecosystem, gradations in species richness and productivity exist, and some divisions in management may be warranted; still, the Florida Reef deserves to be recognized as one socio-ecological system in a manner similar to the conception of the adjacent Florida Everglades (see Figure 2). These related systems, which share many similarities in terms of size and economic impact, deserve comparative 
Figure 2: Southern Florida \& the Florida Reef (Source: Florida Ocean Alliance 2013)

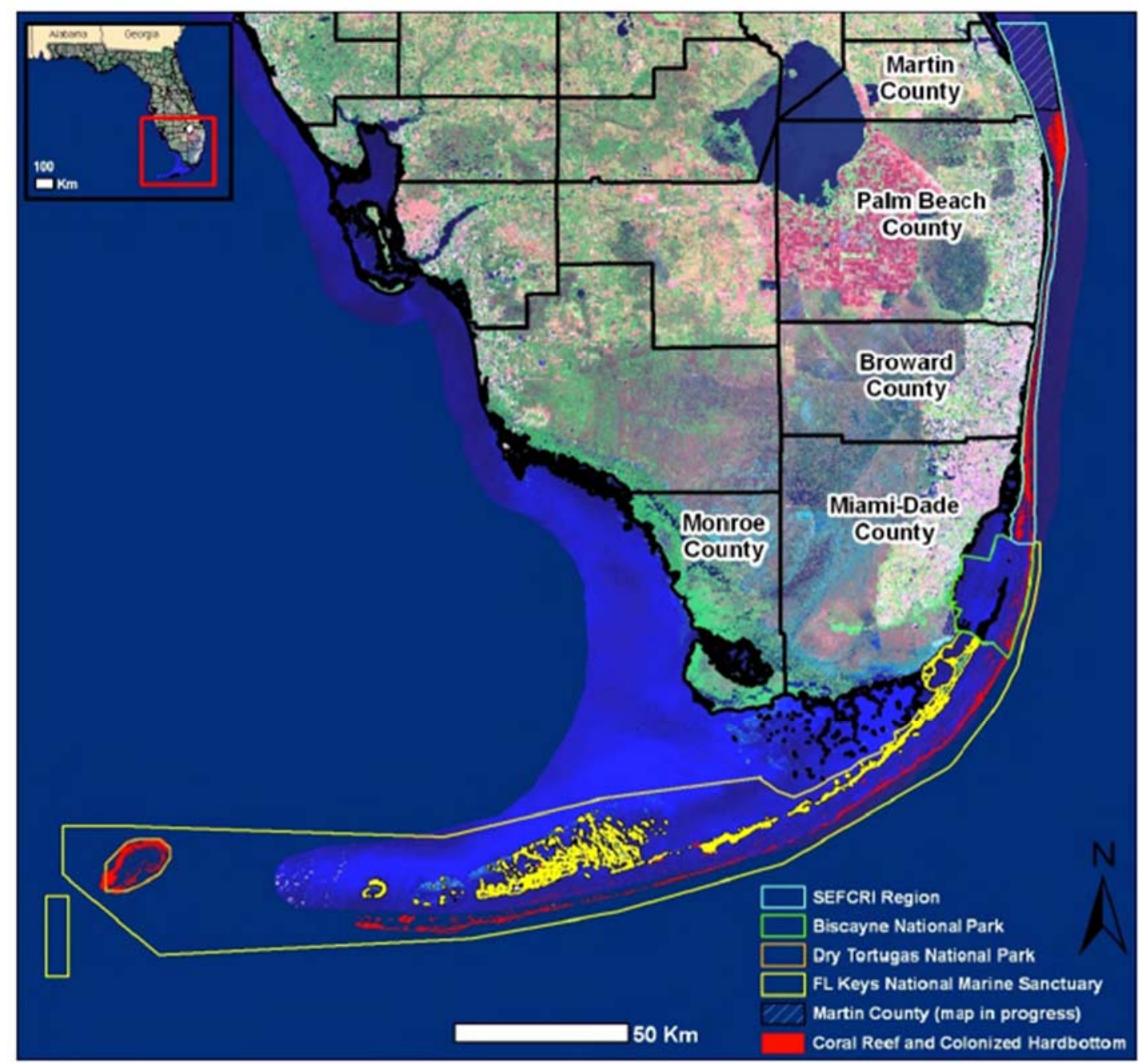

study, and as a degrading common pool resource with many users, the Florida Reef begs the creation of a new, comprehensive institution or framework for its management that would complement the Comprehensive Everglades Restoration Plan. Naming such a framework the "Great Florida Reef Restoration Plan" would simultaneously christen the region with the highly symbolic name of the Great Florida Reef. 
Of the Florida Reef's 560 kilometers in length, the 169 kilometers along the mainland is monitored by a state-level agency that does not have powers of enforcement (see SEFCRI Region in Figure 4 map). Regarding these mainland reefs, more than 100 reports and projects have been produced since 2004 by the Southeast Florida Coral Reef Initiative (SEFCRI), a regional project of the Coral Reef Conservation Program of the Florida Department of Environmental Protection. Budgets for such management agencies limit their scope; the state's Coral Reef Conservation Program has an annual budget of approximately $\$ 1.3$ million, funded equally by state and NOAA funds; the Florida Keys National Marine Sanctuary's total annual budget from NOAA is approximately $\$ 5$ million (personal communication; ONMS 2011).

Human use of the Florida Reef is pervasive, and although cultural and economic divisions exist between the mainland and the Florida Keys, there are no barriers within the ocean, and travel across the region is convenient and ubiquitous. The reef system's recent degradation is well documented; for example, the decline in the Keys' stony coral cover from 1996-2007 was 47\% (ONMS 2011). Water quality within the Sanctuary has decreased, while overfishing, boat groundings, and other direct impacts have increased (Ruttenberg 2011). The perception of a degrading and threatened ecosystem is justified.

\subsection{Threats to Coral Reefs}

The current study's survey instrument lists nine threats to coral reefs in a random order. If these were ranked according to the prioritized threats for corals being considered under the Endangered Species Act (NOAA 2012), the threats from the questionnaire could be prioritized in this order: 
1. High Water Temperatures

2. Air Pollution

3. Fishing

4. Sewage \& Runoff

5. Dredging \& Construction

6. Hurricanes \& Natural Disasters

7. Shipping \& Boating

8. Scuba Diving \& Snorkeling

9. Invasive Species

These items could be reordered depending on translations of terms; most notably, the term "air pollution" needs to be understood as inclusive of invisible greenhouse gases that cause acidification and other climate change effects. In common parlance, "air pollution" may be understood to mean visible smog and particulate matter than remains in the air, without dissolving in water, and from this perspective it becomes a negligible threat in the NOAA study, which lists the two lowest threats as "African/Asian Dust" and “Changes in Insolation.” The NOAA study's second highest threat, disease, is not listed separately in the questionnaire because of a correlation with high water temperatures.

Ranking these threats based on the context in Florida is quite difficult, given the many physical factors involved and the highly politicized debate surrounding them. As with so many environmental problems, the root cause of most of these threats is an increasing human population.

The survey instrument also requests the ranking of six coastal resources within southeastern Florida's mainland region. It would be very difficult to rank the six items according to scientific literature, although the items "drinking water" and "beaches" consistently lack major health warnings and have earned commendations. Moreover, respondents may have personal working definitions that do not correspond to the 
literature. Respondents may equate the item "wetlands" with Everglades National Park or the massive Comprehensive Everglades Restoration Plan, although the broad term "wetlands" would include patchy and urban locations as well. The items "canals," while prevalent across the region, holds relevance for boat owners and canal residents while lacking relevance for other residents. Likewise, "coral reefs" may lack relevance for people without direct engagement. Such considerations should be kept in mind when reviewing this study's methods and results.

\subsection{Economic Value and Theory}

Many concepts in economics apply to the current study. The law of demand stipulates that prices and demand are linked in a negative association (Mankiw 2001). This law assumes that a good is normal, which means that demand increases as income increases. The theory of consumer choice provides models of decision-making, and one assumption is that consumers strive to maximize their utility, or satisfaction, by optimization. They make choices between competing goods and services by considering each one's utility in relation to their ability to make purchases. Budgets place limitations on consumption, and consumers consider both these limitations and personal preferences to determine the optimal way to spend their income (Mankiw 2001).

Environmental economics considers the environment as an asset that is subject to depreciation, typically due to pollution (Tietenberg 1988). In the normative approach, which considers an ideal economy, the market attempts to maximize the value of the asset, yet environmental goods and services are often subject to externalities that lead different consumers to differing values and allocations (Tietenberg 1988). An externality 
means that the actions of one consumer affect the welfare of another consumer, and in the case of coral reefs, fishers who extract resources affect the welfare of non-extractive users such as divers; furthermore, disruption or reduction of the ecosystem reduces its indirect and non-use benefits. Such benefits include coastal protection, reduction of wave action and erosion, potential medical advances, preservation for future generations, and the existence value of a highly-esteemed ecosystem.

According to a literature review on values of U.S. coral reefs, a total economic value of the Florida Reef is not possible, because no authoritative study has assessed its non-use, future use, and indirect use values (Brander 2013). Total economic value combines use and non-use values, and they would include existence, bequest, shoreline protection, and support for fisheries (Waite 2014). Most studies in Florida have assessed only part of the reef system. One study (Johns 2001) was used within Brander's literature review to estimate the total coral reef value, in 2007 prices, at $\$ 174$ million. In comparison, values for Puerto Rico's reefs are \$1.1 billion, and Hawaii's reefs are \$1.7 billion. These latter estimates, incorporating tourism and non-use values, offer a proxy of the value of Florida's system. This same review showed that per hectare ecosystem services in Florida were higher than in Hawaii for snorkeling, diving and snorkeling combined, and much higher for other tourism/recreation. In comparison to both Hawaii and the U.S. Virgin Islands, the tourism values for Florida are approximately eight times higher (Brander 2013).

This literature review by Brander laments the lack of peer-reviewed literature and the low quality of coral reef valuation studies, and this finding is echoed in a metaanalysis of willingness to pay for coral reef values (Londono 2012). The Brander review 
excluded artificial reefs, which are substantial in southeastern Florida, and it did not mention a supplementary study to the 2001 study (Johns 2004). When combined, these two studies credit coral reefs in southern Florida with creating 94,000 jobs and generating $\$ 8$ billion annually (Johns 2001; Johns 2004). By another account, the marine industry within only the three counties of Miami-Dade, Broward, and Palm Beach generates $\$ 8.9$ billion (Florida Ocean Alliance 2013).

Six percent of all jobs in Florida have an indirect link to an ocean-based economy. Tourism is the state's leading industry, with nearly 90 million visitors in 2012, and they contribute nearly 25 percent of all state tax revenue (Florida Ocean Alliance 2013). For the inclusive ocean and coastal industries, Figure 3 shows the dominance of southeastern Florida and of Miami-Dade County in particular.

Interactions with an ecosystem can be either non-consumptive, such as scuba diving, or consumptive, such as fishing for food. A meta-analysis of coral reef valuation studies found a mean, non-consumptive recreational value of $\$ 700.40$ per year per capita, which was higher than beach-related values (Ghermandi 2011). It also found that a reef's value rose along with greater ecosystem size and number of visits. Another meta-analysis by Brander et al. (2007) of 52 studies found a similar correlation of diving area and numbers of visits that influences willingness to pay (WTP). Reviews of Marine Protected Areas found a wide range of WTP values, from $\$ 4.70$ to $\$ 223.80$ per capita per visit (Ghermandi 2011). A problem facing such valuation studies is the divergence of findings between different methods, especially between contingent valuation methods and the travel cost method. Brander et al. calculated average coral reef recreation values per capita per year, and the contingent valuation method resulted in WTP estimates of 
Figure 3: Florida's Ocean and Coastal Industries (Source: Florida Ocean Alliance 2013)

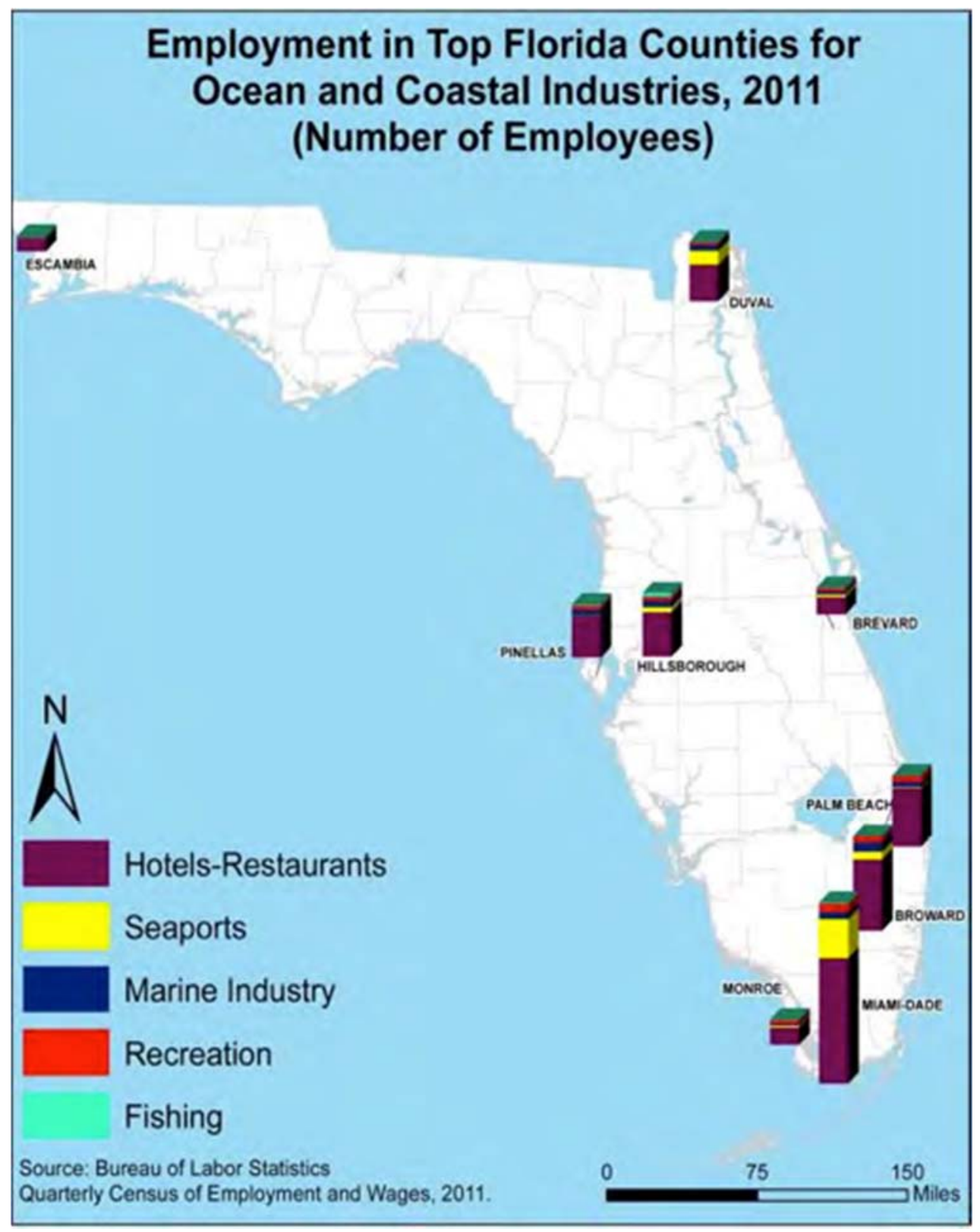

$\$ 59.80$, choice experiments resulted in $\$ 94.30$, and travel cost method resulted in $\$ 1,147.40$ (Ghermandi 2011). The current study employs contingent valuation methods and a choice experiment. 


\subsection{Fishing, Fisheries, and Seafood}

While many issues affect coral reefs and their users, the fundamental threat of climate change must be addressed if they are to have any chance at long-term survival (Burke 2011; Frieler 2012). The issues of fisheries and fishery management, while important, assume the position of secondary concerns.

Fisheries provide classic examples of common pool resources that are vulnerable to the tragedy of the commons (Hardin 1968). Yet relatively few fisheries have collapsed, and both small-scale and large-scale fisheries provide examples of sustainable management, including many coral reef fisheries applying co-management strategies in developing countries (Cinner 2012; Hilborn 2012). Instead of a straightforward application of Hardin's tragedy of the commons and Olson's view of the rational egoist acting on purely selfish interests, the idea of collective action and actors that exhibit more than self-interest deserves further investigation as it applies to fisheries and related common pool resources (Ostrom 2000). Building upon evolutionary theory, Ostrom explains how cooperative behavior has enhanced survival and become institutionalized for common pool resources such as fisheries (Ostrom 1990). The management of fisheries provides a market-based window into the management of ocean habitats, such as coral reefs.

\subsubsection{Global Fishery Management}

Fisheries in the U.S. are managed regionally, with 45 active management plans as of 2008, and these plans tend to restrict access by limiting commercial licenses (Ohashi 
2010). Globally, fisheries are less regulated than in the U.S.; in fact, the U.S. ranks as one of only four nations successful at regulating major fisheries to avoid overfishing (Hilborn 2012). This global tragedy is often referred to as the "race for fish" (Fenner 2012).

During the past fifty years of increasingly effective technology, globalized industrial fishing operations have pushed further south, towards Antarctica, and cast their nets ever deeper and deeper (Cooke 2006; Roney 2012). Wild fisheries appear to have reached "peak seafood" around the late 1980s, and many studies document the loss of top predators and the phenomena of fishing down the food web (see Figure 4; Hilborn 2012).

\section{Figure 4: Global Fish Catch Data Over Decades} (Source: UN 2005).

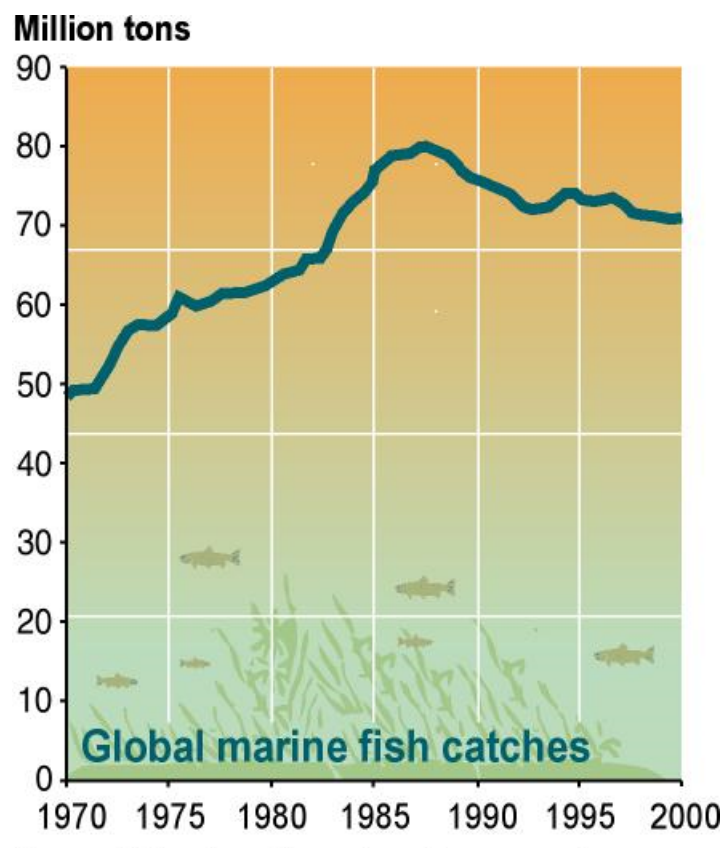

Source: Millennium Ecosystem Assessment

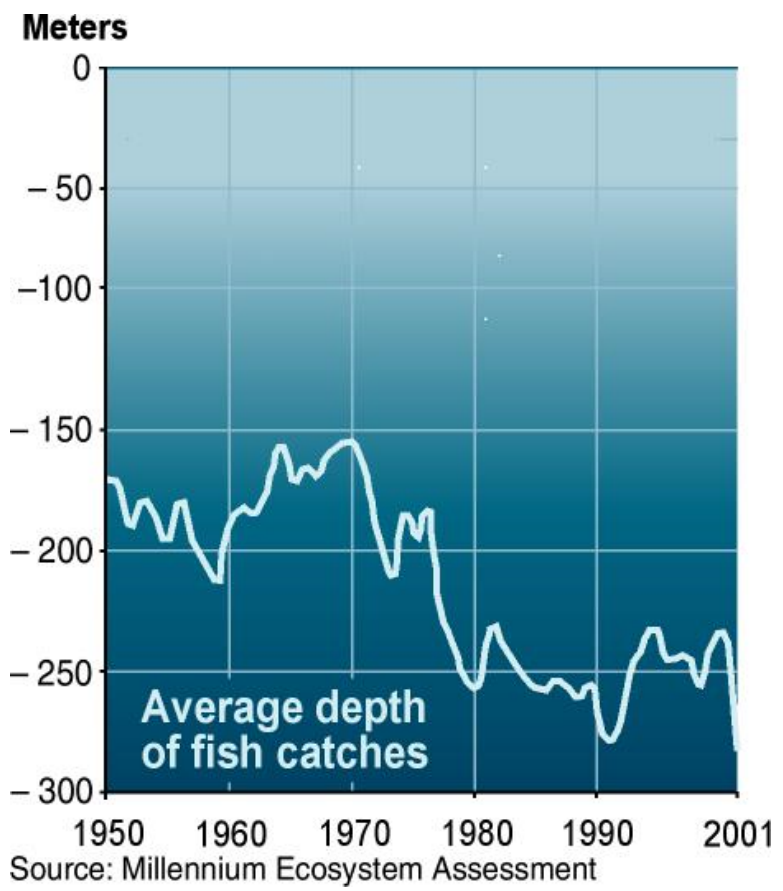


The globalization of fisheries presents a complicated bundle of issues, and a special edition of the Journal of Agrarian Change in 2012 summarizes its 11 studies with the following insights:

1. Fisheries worldwide are highly exploited and valuable:

a) Three-fourths operate at full exploitation levels.

b) Most fish are caught in the wild (62\%), while aquaculture has grown rapidly $(38 \%)$.

c) FAO data show that seafood exports from developing countries are more valuable than the combined value of coffee, bananas, cocoa, tea, sugar and tobacco.

d) Fisheries supply nearly $16 \%$ of human animal protein consumption.

e) Wild fisheries support 120 million people's livelihoods.

2. Relevant social science needs more development:

a) Studies of fisheries obfuscate economic systems.

b) Gender and race issues have received considerable attention.

c) Economic inequality remains opaque.

d) Academic work "fetishizes" fishery management as efficiency (Campling 2012).

Extreme exploitation of marine resources often results in localized population crashes, yet they rarely lead to global extinctions. Historically, overfishing has caused extinctions of four mammals, namely the Steller's sea cow (Hydrodamalis gigas), sea mink (Neovison macrodon), Caribbean monk seal (Monachus tropicalis), and Japanese sea lion (Zalophus japonicus), and it could lead to more (Turvey 2009). Under the U.S. Endangered Species Act, $81 \%$ of marine species listed or considered for listing experienced overexploitation (Harnik 2012). These species manifest tragedies of the commons.

The rapid rise of global fishery exploitation coupled with the lack of social investigation creates a huge knowledge gap. As for solutions, a common management strategy across heterogeneous contexts is Marine Protected Areas. These vary greatly by size and by regulation, and fishers often oppose their creation (Salz 2004). Globally, 
studies of commercial fishers find that they tend to disapprove of no-take zones, and they are more likely to approve of a Marine Protected Area with the purpose of fishery management instead of conservation management, while this view was reversed for scuba divers and researchers (Pita 2011). As a relatively new and rapidly developing conservation strategy, MPAs require further study.

\subsubsection{Seafood Industry}

The Marine Stewardship Council certifies fisheries as sustainable, and it labels seafood products with its blue stamp of approval. As of 2011, the U.S. had 16 of the 102 worldwide fisheries that are certified by MSC, located mostly in the North Pacific, and its only Atlantic representative was the Mid-Atlantic deep-sea red crab fishery (NMFS 2010). The first and only Florida-based operation was MSC certified in 2012 (Zwerdling 2013). Such certifications tend to address large-scale fisheries and overlook small-scale, local operations.

The average U.S. citizen consumed 16.6 pounds of seafood in 2005, and the U.S. ranks third in total consumption behind Japan and China (Ohashi 2010). The per capita amount is likely much higher in coastal regions such as southeastern Florida, where residents may also have significant anecdotal knowledge about fishing and seafood. In southeastern Florida, overfishing is considered the oldest and largest local impact on coral reefs (McClenachan 2009; Fenner 2012). Of the top 10 harvested species in the U.S., none are coral reef-dependent species, and only shrimp is commonly harvested in southeastern Florida (NMFS 2010). However, reef-related species from Florida retain 
high value within the state. In Florida, the most valuable fisheries are, in order, shrimp, lobster, stone crabs, and grouper (Ropicki 2010).

Seafood fraud is a related issue. High levels have been documented in mass media and have included the vast majority of sales in the U.S. of red snapper (Ropicki 2010). In Florida, 62 percent of consumers showed an awareness that grouper had been sold under false identities, and they expressed a willingness to pay a premium of $\$ 0.83$ to $\$ 3.18$ to guarantee a "Florida caught grouper" (Ropicki 2010). Consumers with awareness of such fraud may be reluctant to trust labeling schemes and the fishing industry in general.

Despite attempts at clarification, the concepts of sustainable and local seafood may elude shoppers. Most notably, labels of seafood sustainability remain uncommon in the region. A 2012 investigation in the City of North Miami of the seafood section of a Publix grocery store, a large Florida-based chain, revealed that none of 26 items could be confirmed as local, and only 19 percent were labeled as originating in the U.S. (personal observation). Seven products were labeled "wild," nine were labeled "farmed," and ten were not labeled. Moreover, shoppers may interpret existing labels in ways that do not correspond well with concepts of sustainability.

Even the term "seafood" lacks clarity, as it functions as a catchall term for fresh and saltwater creatures, vertebrates and invertebrates. This term becomes further obscured by the rise of tilapia, a freshwater, herbivorous fish that has been domesticated like none other, turning it into a "chicken of the sea" (but not from the sea). We may falsely assume that seafood is for human consumption, yet the majority of the world's largest wild fishery, the Peruvian anchovy, is destined for farm animals, including other 
fish (Roney 2012). The term seafood is both necessary and totally inadequate, as if we could describe the many other animals that people eat as "landfood."

The term "sustainable" may have a clearer, working definition as a level of exploitation that allows a resource to persist indefinitely, but when attached to "seafood," it may lose much of that meaning - especially the connotation that local origination is preferable. Representing its emergence as a neoliberal commodity, both Walmart and McDonalds sell only sustainable seafood (McDonalds 2012; Parkes 2009). A report by Greenpeace gave its top seafood sustainability ranking to Target (Trenor 2011).

Sustainable seafood labels remain suspect. The London-based Marine Stewardship Council was established in 1997 through cooperation between the World Wildlife Fund and Unilever, one of the world's largest dealers in seafood, and it began independent certifications in 2000 (Ponte 2012). One analysis concludes: "MSC has so far failed to convincingly show that its certification system has positive environmental impacts, and it has marginalized Southern fisheries, especially in low-income countries. As an institutional solution to the global fishery crisis, the MSC seems to be better tuned to the creation of a market for 'sustainable fish' rather than 'sustainable fisheries"'(Ponte 2012). In other words, MSC's net environmental impact remains questionable.

Another self-appointed, primary source of information about sustainable seafood are lists published by about one dozen non-governmental organizations (URI 2012). Similarly to sustainability labels, these lists tend to use international fisheries data from the FAO. A popular listing program from the Monterey Bay Aquarium, called Seafood Watch, began in the year 2000 as a means of informing customers at the aquarium's café about what they were eating. It expanded to offer national and regional lists that include 
logos from the MSC and the Environmental Defense Fund (Ponte 2012; Monterey 2014).

One study of Seafood Watch found that it had no significant effect, and an experiment in California supermarkets found that sustainability labels suppressed overall sales of seafood (Hallstein 2013).

Despite various caveats and questions about seafood, including its origins from an environment that is less studied and understood than the terrestrial environment, seafood offers an unmatched societal connection to the ocean that is intuitive to understand and precisely valued in the marketplace.

\subsection{Collective Action Theory and Fishing}

Various institutions have attempted to manage or protect the Florida Reef, and the establishment of John Pennekamp Coral Reef State Park in 1963 was the world's first underwater park (ONMS 2011). Ostrom elucidated eight design principles of institutions that are effective for sustainable management of common pool resources. Those principles are:

1. clearly defined boundaries

2. rules appropriate to the context

3. participation in rule-making

4. accountable monitoring

5. fair, graduated sanctions

6. conflict-resolution mechanisms

7. rights to organize

8. nested enterprises for large systems (Ostrom 1990).

These principles cannot be applied to the mainland region of the Florida Reef, because it has no enforceable boundary and no restrictions specific to that area. On the other hand, applying Ostrom's eight design principles of effective common pool resource institutions 
to the Florida Keys National Marine Sanctuary, it is arguable that the Sanctuary fulfills several of these principles, yet with many complications. The Sanctuary has clear rules and physical boundaries in theory, as seen in Figure 2, and it has deployed at least 790 demarcation buoys, although its immense size and oceanic horizon makes it difficult to enforce and to delineate from its surroundings (ONMS 2011). Given the Sanctuary's limited funding, it is not surprising that research assesses the Sanctuary as understaffed, unable to monitor and enforce its provisions, and reliant on voluntary compliance (Keller 2005). These weaknesses violate the design principles of effective monitoring, graduated sanctions, and conflict resolution. Still, local stakeholders were engaged in its development, although some lacked trust due to its federal origins from a Congressional mandate, and a majority of commercial fishers opposed its creation (Shivlani 2008; Suman 1999).

Such distrust undermines the development of effective cooperative institutions. Trust is the foundation of collective action, and evolutionary theory posits that the trait of using trust wisely increases over time. Ostrom also summarizes evidence that cooperation is a learned behavior that increases with repetition (1990). In the Sanctuary, distrust eased over time, and a ten-year comparison study found that attitudes among fishers and other users had become more favorable by 2007 (Shivlani 2008). This agrees with the finding across studies worldwide that older marine protected areas engender more support (Pita 2011).

In Florida, fishers and other interest groups are free to self-organize, and some are engaged as citizen monitors of the Sanctuary, indicating at least some adherence to Ostrom's categories of participation in rule-making and monitoring (Keller 2005). Even 
so, tension remains about the Sanctuary's legitimacy. One strikingly unusual development of self-organization has been the growth of the "right to fish" movement among marine anglers, who lobby against closed areas or other restrictions designed to preserve habitat, and they stand in opposition to the tradition of hunters and other sportsmen who typically support habitat preservation (McClenachan 2013).

Being a relatively large system in a developed economy, the Florida Keys National Marine Sanctuary requires the eighth design principle of a nested system, especially in consideration of how the Sanctuary protects the foundation of the economy in the Keys. Tourism associated with ocean recreation accounts for $\$ 2.3$ billion in annual sales and 58 percent of the local economy (ONMS 2011). Here, diving and snorkeling outpace recreational fishing. In 2008, divers spent $\$ 450$ million in Monroe County (covering the Florida Keys) and recreational fishers spent \$262 million (FKNMS 2007). Lesser industries include commercial fishing for seafood and the aquarium trade. Conflict among such industries is inevitable.

Interestingly, the economic value of the much smaller, non-Sanctuary mainland reef region, estimated at $\$ 2.3$ billion in sales, is equivalent to the sales value within the Sanctuary (Gregg 2013). This economic equivalence reinforces the conception of the Florida Reef as one socio-economic system, and it challenges the non-Sanctuary status of the northern section. Stakeholders in this populous mainland region value the ecosystem, and two survey-based studies in this region found that divers, snorkelers and recreational fishers were willing to pay to $\$ 255.8$ million per year to protect these reefs (Johns 2003). The collection of such fees and their fair distribution might necessitate a nested system of 
smaller jurisdictions within a comprehensive institution for the entire Florida Reef, but such technicalities are beyond the scope of this study.

\subsubsection{Florida Fishing and Regulation}

Apart from tourism, fishing is arguably the most important industry associated with the Florida Reef. Yet research of its social institutions is lacking. Fishing regulation is exceeding complex, highly time and space dependent, and distributed across a web of agencies, and this complexity may undermine the efficacy of its localized institutions.

The primary federal law concerning commercial fisheries is the MagnusonStevens Fishery Conservation and Management Act; no equivalent law exists for recreational fishing. Within the main geographic jurisdictions of the Florida Reef, fishing access ranges from very open to very closed (see Figure 5). State and federal rules apply in all marine zones; state waters extend three nautical miles offshore, and federal waters in general extend 200 miles.

An imposing number and variety of agencies operate within the Florida Keys National Marine Sanctuary:

- 5 federal agencies, with separate NOAA jurisdictions for the Gulf of Mexico and for the Atlantic

- 3 national parks, with special zones limited to research, no-take, and no anchor

- 4 national wildlife refuges

- 3 state agencies, with fishing licenses originating from the Florida Fish and Wildlife Conservation Commission

- 6 state parks

- numerous county and municipal agencies (Ruttenberg 2011).

Moreover, the regulations for fishing vary by season and by zone, creating a labyrinth of fluctuating access and permitted harvesting within the Sanctuary. In contrast, the Florida 
Reef's mainland area has almost no place-based restrictions or marine protected areas and remains a broadly open pool resource.

Marine restrictions vary within the Dry Tortugas, Everglades, and Biscayne national parks, and a few relatively small zones are designated as no access or no take zones where fishing is fully prohibited. On the map in Figure 5, the slanted line areas refer to an assemblage of limitations on species, captures per person, gear, or other regulations that vary by season and by type of fishing, and such regulations are common techniques in developed countries (Fenner 2012). Despite the appearance of wide restrictions, they apply more comprehensively to commercial than to recreational fishing, and the reality is that most of the Florida Reef remains open to fishing. Strictly nonfishing areas or no take zones within the Sanctuary cover only $6 \%$ of the hard bottom area (Ruttenberg 2011). They have proven effective at increasing reef fish populations (ONMS 2011).

All rated "living resources" within the Sanctuary are assessed as fair or poor, and none are improving, with key species such as corals and groupers ranking in the lowest category of "poor" (ONMS 2011). The lack of improvement persists despite a documented reduction in human population and fishing activity. Many impacts remain weakly documented, such as the effects of recreational fishing and lost gear, which includes large numbers of derelict lobster traps. Regarding debris, $84 \%$ of impacts are attributed to hook-and-line gear (ONMS 2011; Cooke 2006).

In Biscayne National Park, located immediately north of the Sanctuary, the majority of studied reef species are overfished (Fenner 2012). A 2006 replication of a 1981 habitat and fishery study in the park found a 64\% reduction in frequency of reef fish 
Figure 5: Areas with Endangered Corals and Fishing Restrictions Note: Prohibited, no-take areas are named.

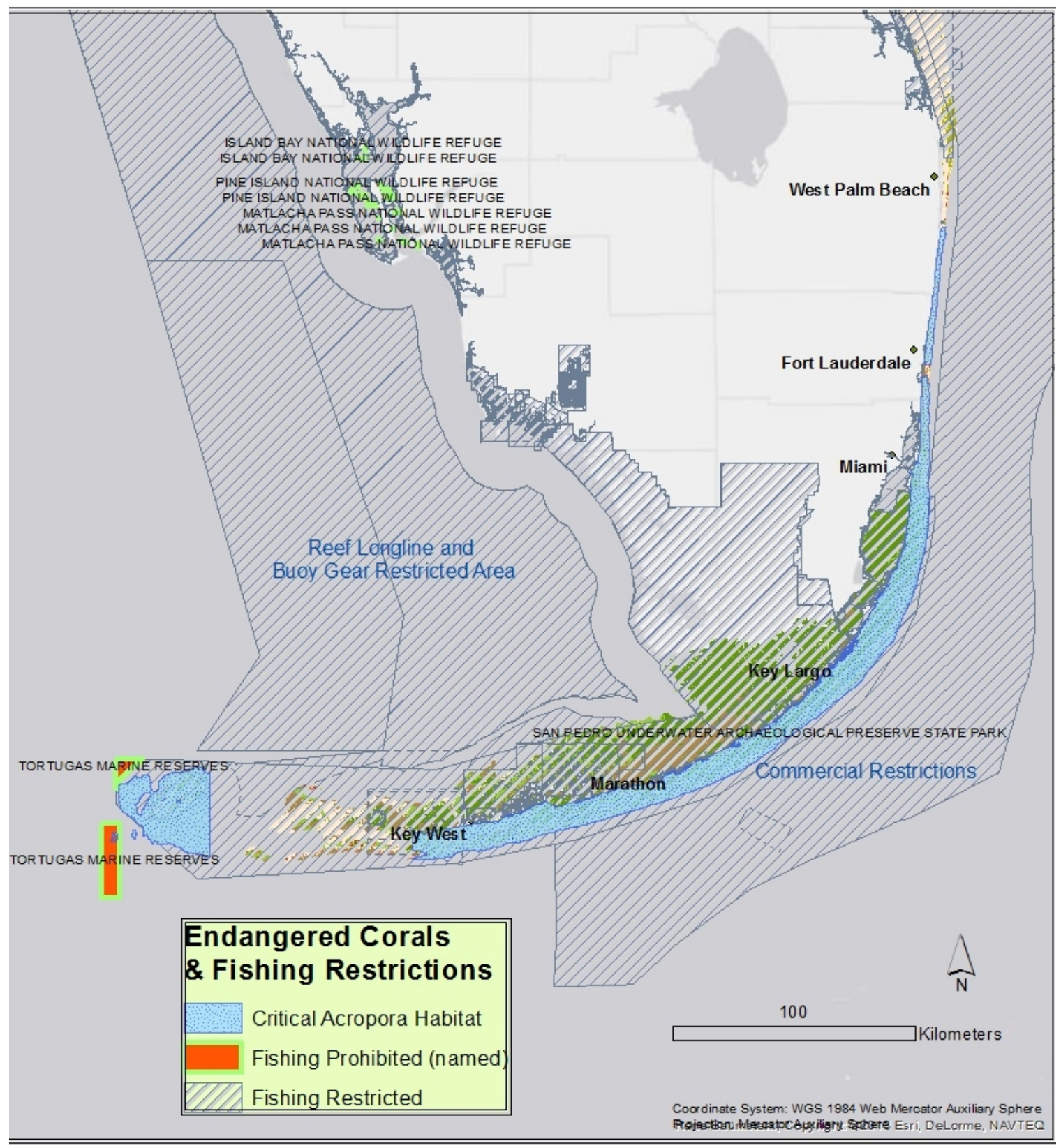


species and habitat-wide declines across an assemblage of species, including a 75\% decline of omnivores (Kellison 2011). As in indicator of a regime shift, two studied sites of elkhorn coral (A. palmata) shifted from abundant to absent (Kellison 2011). During these 25 years, fishing pressure grew and visitation to the park increased 2.5 fold to more than 500,000 visitors per year (Kellison 2011). Despite this habitat's location within a national park, the degradation documented in this study is greater than similar declines documented across the Caribbean.

\subsubsection{Economic Impact of Fishing}

Cooke (2006) argues that recreational and commercial fishing should be considered as essentially equivalent in global impact. Commercial seafood in the U.S. is much a larger and more profitable industry than recreational fishing; however, this view obfuscates the fact that commercial harvesting (often conflated with "fishing") is only one aspect of the commercial seafood industry, and harvesting has a lesser economic impact than recreational fishing. This distinction of commercial fishing and recreational fishing is especially pronounced in Florida. Table 3 summarizes economic impacts for the U.S. and for Florida, and recreational data is reported separately for East Florida and for West Florida. Individually, both regions of Florida rank higher than any other state for recreational fishing. For the state as a whole, the value of commercial harvesting represents a small fraction of the value of recreational fishing.

The U.S. seafood industry's economic impact is inflated by imports. Of the seafood industry's $\$ 116$ billion total sales impacts, importers account for $\$ 49$ billion

while U.S. harvesters account for only $\$ 10$ billion. Moreover, the U.S. harvest is highly 
concentrated in Alaska at 53\% of landings. Based on the statistic that U.S. fishers generated $\$ 3.9$ billion from 7.9 billion pounds of landings in 2009, fish caught in the U.S. generate a value that averages approximately $\$ 2$ per pound (NMFS 2010). The effect of imports is especially keen in Florida, where the balance of local and imported seafood has shifted dramatically in the past two decades. Consumers in Florida may believe that their seafood comes from Florida, but the vast majority does not (see Figure 6).

Table 3: Economic Impact of Commercial Seafood and Recreational Fishing (combines NMFS 2010 \& Lovell 2013; or only Lovell*)

Note: Commercial seafood includes: importers, retail, wholesalers, harvesters, processors (ranked in that order in Florida). Lovell arrived at higher numbers than NMFS by different methodology and cannot combine East/West Florida due to overlap.

\begin{tabular}{|l|l|l|l|l|l|l|}
\hline Region & Sector & Jobs & $\begin{array}{l}\text { Sales / } \\
\text { Output } \\
(\$ 1,000 \text { 's })\end{array}$ & $\begin{array}{l}\text { Income } \\
(\$ 1,000 \text { 's })\end{array}$ & $\begin{array}{l}\text { GDP } \\
\text { Value } \\
\text { Added } \\
(\$ 1,000 \text { 's })\end{array}$ & $\begin{array}{l}\text { State } \\
\text { Rank } \\
\text { (NMFS) }\end{array}$ \\
\hline \multirow{2}{*}{ U.S. } & $\begin{array}{l}\text { Commercial } \\
\text { Seafood: }\end{array}$ & $1,029,542$ & $116,224,548$ & $31,556,643$ & $48,282,319$ & \\
\cline { 2 - 6 } & - Harvesters & 135,466 & $10,349,446$ & $3,435,027$ & $5,340,116$ & \\
\cline { 2 - 6 } & $\begin{array}{l}\text { Recreational* } \\
(2011 \text { data) }\end{array}$ & 363,932 & $55,843,020$ & $18,176,957$ & $29,100,691$ & \\
\hline Florida & $\begin{array}{l}\text { Commercial } \\
\text { Seafood }\end{array}$ & 64,744 & $12,988,379$ & $2,426,410$ & $4,341,208$ & $\begin{array}{l}3 \\
\text { (jobs); } \\
2 \\
\text { (sales, } \\
\text { value) }\end{array}$ \\
\cline { 2 - 6 } & $\begin{array}{l}\text { - Harvesters } \\
\text { Recreational } \\
(2006 \text { data) }\end{array}$ & 4,775 & 312,239 & 97,964 & 130,331 & 12 \\
\hline $\begin{array}{l}\text { East } \\
\text { Florida }\end{array}$ & $\begin{array}{l}\text { Recreational* } \\
(2011 \text { data) }\end{array}$ & 32,118 & $7,481,461$ & $2,578,576$ & $4,019,198$ & 1 \\
\hline $\begin{array}{l}\text { West } \\
\text { Florida }\end{array}$ & $\begin{array}{l}\text { Recreational* } \\
(2011 \text { data) }\end{array}$ & 66,237 & $8,054,526$ & $2,954,453$ & $4,629,218$ & 1 \\
\hline
\end{tabular}


Figure 6: Decline of Fishing Landings and Growth of Seafood Imports in Florida (Source: Florida Oceans Council 2013)

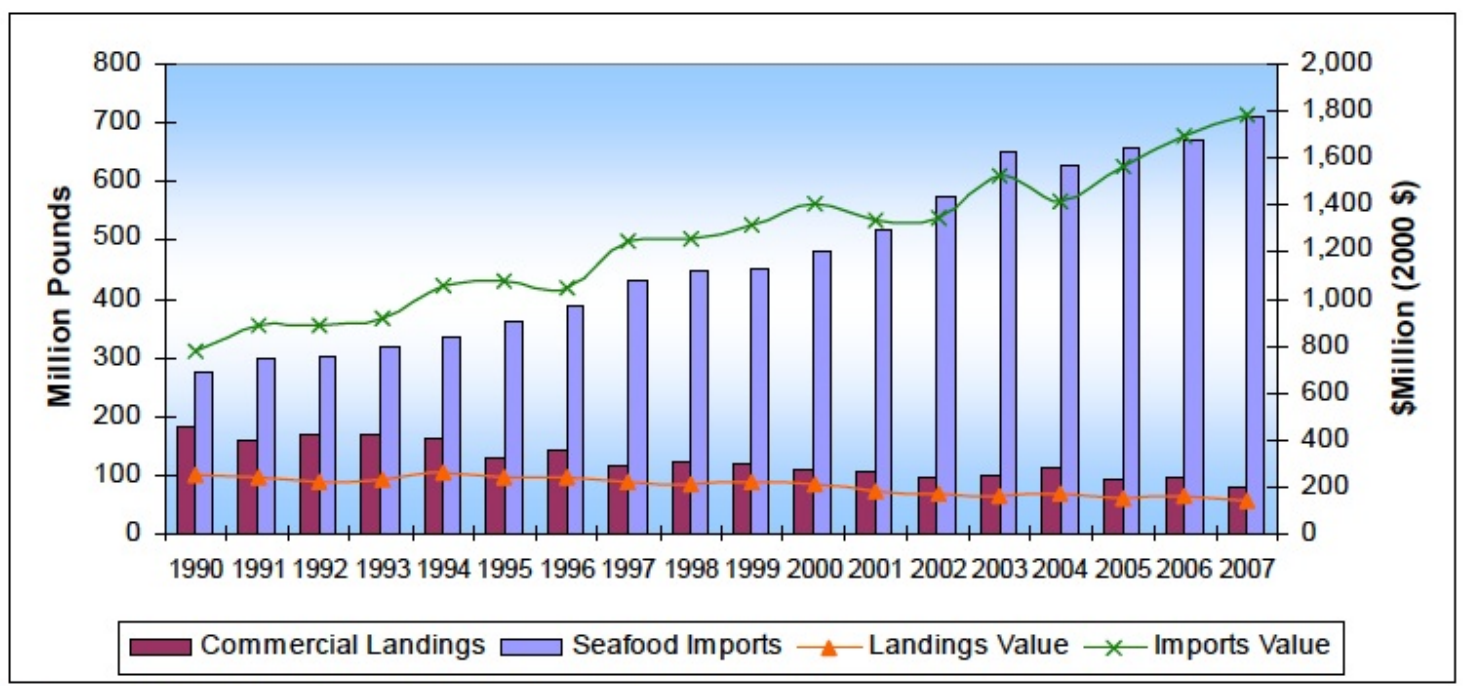

All aspects of recreational fishing in Florida are much larger than commercial fishing. Florida dominates the marine recreational sector in the U.S.; for the seafood industry, it ranks third behind California and Massachusetts for the number of jobs $(64,744)$, and second in sales, at $\$ 13$ billion (NMFS 2010). Confusion results from other studies that compile vastly different numbers, reporting Florida's seafood industry in 2006 supporting more jobs (103,000 employees) and lesser sales, at $\$ 5.2$ billion (Ropicki 2010). One clear trend is that fishing jobs and revenue are concentrated in the Gulf of Mexico. In 2009, West Florida recreational fisheries supported nearly twice as many jobs, at 42,314 versus East Florida's 27,445 jobs, and the landing revenue was nearly triple for West Florida at $\$ 116$ million versus East Florida’s $\$ 41$ million (NMFS 2010). All in all, commercial fishing or harvesting in Florida ranks as a lesser industry. In contrast, sales from Florida's $\$ 7$ billion-plus recreational fishing industry rival the entire 
nation's sales from commercial fishing or harvesting at $\$ 10$ billion (NMFS 2010). The economic power of Florida's recreational fishing industry is undeniable.

\subsubsection{Florida’s Commercial Fishing Industry}

Historical fishing has been identified as the earliest major impact on coral reef ecosystems in Florida, and its effects appear even at relatively low human population levels (McClenachan 2009). The history of reef fishing in Florida shows explosive growth following World War II, although sponge and green turtle fisheries had previously peaked in the 1880 s (McClenachan 2012). A turning point was 1912, when the new Flagler railroad connected the Florida Keys to the mainland, and development led to greater fishing pressures. Catch of the endangered sawfish peaked in 1928, as did catch of conch, although catch of spiny lobster did not peak until in 1996 (McClenachan 2012). In terms of biomass in relation to the number of fishers, the catch per unit effort peaked in the 1930's, and fisheries for most reef species peaked in the 1970s and 1980s (McClenachan 2009).

Even with such loss, a majority of commercial fishers in the mainland region believe that reef fisheries are improving (Shivlani 2011). This apparent contradiction may be partially explained by the reduction of effort within the industry, because the number of regional commercial fishers declined 38\% from 1994 to 2009 (Shivlani 2011). Moreover, these fewer fishing operators are less likely to target reef species, and they may be pleased with pelagic captures in contrast to reef captures (Shivlani 2011). 


\subsubsection{Florida Recreational Fishing Industry}

Since 2010, all marine anglers have been required to register with a state or federal agency (Lovell 2013). Even so, no comprehensive national policy exists, and this year NOAA Fisheries announced its intention to develop standards for the nation's 11 million saltwater anglers (Cocking 2014). Distinct from marine commercial fishing, recreational fishing has been defined as "fishing for finfish in the open ocean or any body of water that is marine or brackish for sport or pleasure" (Lovell 2013). This definition should be expanded to include invertebrates.

In southeastern Florida, the impact of recreational fishing on coral reefs is considered much larger than commercial fishing; for example, within a two-day mini season, more than 50,000 divers remove an estimated 80 to 90 percent of the spiny lobster stock (Fenner 2012). This trend is observed in both the Florida Keys and the mainland region (Shivlani 2011). The total harvest of recreational fishing is likely much lower in biomass than commercial fishing, especially considering that approximately half of fish caught recreationally are not landed in the common practice of catch and release, a rate similar to a national estimate at $60 \%$ (Fenner 2012; Cooke 2006). Yet impacts to an ecosystem involve more than harvesting. The incremental growth of recreational fishing in Florida during the same period that commercial fishing contracted means that its current effect on coral reefs must be considered much greater than commercial fishing (McClenachan 2009). 
The number of Florida's recreational fishers, or anglers, quadrupled between 1964 and 2000 (McClenachan 2009). Today, more than one million people hold a license for saltwater fishing in Florida (FFWCC 2013, personal communication). Related to fishing, the number of recreational vessels has skyrocketed in the region, and Monroe County witnessed a 1000\% increase between 1964 and 2010 (ONMS 2011).

\subsubsection{Licenses and Fees}

A central problem for common pool resources is the issue of free-riders (Ostrom 2000), and one means to reduce this effect is to charge fees or licenses for access to the resource. In Florida's fisheries, such licenses and fees may be insufficient to allow for adequate monitoring and enforcement of regulations. Some annual fees include:

- boating vessel of 18 feet: $\$ 51.08$

- saltwater fishing resident: $\$ 17.00$

- fresh \& saltwater fishing: $\$ 32.50$

- spiny lobster fishing: $\quad \$ 5.00$ (FFWCC 2014)

Other fees also raise funds within the Sanctuary. A construction permit costs $\$ 1.06$ per square centimeter of affected coral (Watson 2013). Entrance to the Dry Tortugas National Park is $\$ 5$ per week, and this fee raised $\$ 694,514$ in 2010 (Watson 2013). Biscayne National Park charges no entry fee. With its coral reefs and its reef fisheries degrading, this park has neither the authority nor the ability to enforce measures to improve these resources. Currently it faces stiff resistance from the fishing community and from elected officials as it attempts to create restrictions on reef access and fishing (Wadlow 2014). North of Biscayne National Park, the Florida Reef has few regulations or means of raising funds for conservation. 
Managers of the Florida Reef face the dilemmas of an increasing population, divided stakeholders, a declining resource, and meager bank accounts to deal with expanding problems. A bundle of complicated issues surround the Florida Reef, and arguably the most important issues relate to recreational fishing. These stakeholders are large in number and accustomed to uninhibited access to the reef and the ocean at large. Attempts to restrict their access, such as the current plans for Biscayne National Park, have met stiff resistance. Recreational fishers in Florida have organized to demand the "right to fish" based on tradition and in defiance of the condition of resources (McClenachan 2013). Research has mostly let them "off the hook," although awareness is growing that their impact can equal or surpass commercial fishing in certain fisheries and habitats (Cooke 2006).

Could institutions be designed according to Ostrom's principles that could address these problems? Neither the commercial nor the recreational fishing sector has demonstrated sufficient self-regulation to allow for resource recovery. Instead, they appear resistant to regulation and resigned to the whims of the marketplace, and this capitulation to the status quo induces unsustainability. The area's main attempt at comprehensive, ecosystem-based regulation, the Florida Keys National Marine Sanctuary, represents a mostly top-down approach that has improved its image during the past 17 years. Yet this growing support is not guaranteed. To function more effectively, it may require expansive, localized organizing that would increase its legitimacy and enable better monitoring and enforcement of rules. The Sanctuary could remain the large system within Ostrom's eighth principle that coordinates its layers, but it appears only partially successful in attempts to develop the other aspects of an enduring institution. Although it 
has reached out to the community, it needs to find other ways of allowing the community to reach out to embrace it.

For the full ecosystem of the Florida Reef, the outlook for its effective management is sabotaged by climate change and associated regional and global degradation of all coral reefs. It remains to be seen if stakeholders and managers will unite to save the reef in the same manner that various constituents have united to restore the Everglades. The fishing community, both commercial and recreational, needs to provide leadership to give any conservation measure a chance of success. Even with such leadership, the future of this common pool resource appears grim; without it, it seems hopeless.

\subsection{Choice Modeling Literature}

One distinction from previous studies is that the current survey includes a choice experiment. A discrete choice experiment follows principles of choice modeling and stated preference research methods, and it has gained preference for determining economic value over similar approaches, such as the contingent valuation method (Van Beukering 2011). A choice experiment examines trade-offs between multiple attributes that mimic a complex, multi-tiered decision-making process. The results could be used for benefit-cost analyses.

Choice modeling builds upon conjoint analysis, as developed from marketing theory, and it assesses non-market benefits (Gazzani 2007). More recently it has been applied to environmental studies of willingness to pay for conservation and remediation, 
including for coral reefs, such as a 2011 socioeconomic study of the U.S. Virgin Islands that calculated total economic value at $\$ 187$ million per year (Van Beukering).

Choice modeling is considered a cost-effective means for ascertaining consumer behavior because it assesses multiple attributes efficiently (Gazzani 2007). It also reduces bias of strategic response behavior by confounding a respondent's ability to ascertain preferred answers (Van Beukering 2011). Its foundation in Random Utility Theory, developed in the 1920 s, posits that utility is a combination of an observable valuation and a random error component. Utility does not equal the goods and services directly but rather the attributes that they contain (Tawfik 2010). It assumes that when respondents are forced to choose between a collection of different attributes contained in alternative A or B, they will choose the alternative with greater total utility (Shoyama 2013).

Within the current study's choice experiment, the four attributes considered are: beach size, water quality, coral restoration, and fee per month. The experiment's development is discussed further in the Methods section. Considering coral restoration, one of its greatest failures took place near the shoreline of Broward County from 1967 to 1973, when more than one million tires were dumped to create Osborne Reef. Not only did they fail miserably to create new reefs, the tires moved and crushed existing coral structures. This failure remains as a stark reminder of what not to do (Precht 2006; personal communication).

Legitimate coral gardening is a relatively pro-active approach to the coral reef crisis. Most reef conservation efforts to date have focused on less controversial, passive methods such as reducing point-source pollution from sewage and creating Marine Protected Areas. While beneficial to the ecosystem, these indirect approaches have been 
criticized as inadequate to the urgency at hand, especially in view of escalating climate change (Rau 2012). Coral gardening has its own complications. When moved to a permanent substrate in the wild, Acroporid transplants from nurseries face the threats of disease, fragmentation, and predation from snails (Williams 2012). The latter two issues can be managed by hand, but reef managers are essentially helpless in the face of rising rates of disease. Likewise, acidification is accelerating and may bring unpredictable and unmanageable stress.

\subsection{Environmental Psychology}

An individual's reaction to the degradation of coral reefs demonstrates a clear example of a social dilemma, whereby one's immediate choices may conflict with principles of sustainability (Van Lange 2013). For example, activities such as recreational boating and fishing near southeastern Florida's coral reefs offer immediate gratification, yet the cumulative effect of hundreds of thousands of boaters and anglers using the ecosystem creates stress that degrades the system. Such loss eventually impacts immediate gratification, because regular users will become discouraged by perceptions of impoverished water quality and fishing opportunities. This dilemma may motivate them to contribute financially or otherwise to protect and improve the ecosystem's condition.

A willingness to sacrifice one's immediate gratification for the sake of a place, such as a coral reef, likely increases with one's attachment to that place, and people with such connections report more pro-environmental behavior (Scannell 2013). But divergent findings and insufficient research confound these issues. A 2013 review by DevineWright of place attachments and place identities concluded that place attachments occur 
at diverse, multiple, and non-linear scales that do not necessarily correspond to distance; for example, national identity in the U.S. is stronger than regional identity, and internationally, national identity tends to supercede neighborhood identity. Moreover, people may hold equal attachments to local places and global places, although smallscale attachments are often assumed to be stronger than large-scale identities. A recent study the effect of messages about climate change found that localized messages inspired more engagement, whereas global messages had no discernable effect (Scannell 2013). 


\section{CHAPTER 3: RESEARCH METHODS}

\subsection{Research Objectives}

The purpose of this study is to investigate preferences and attitudes that demonstrate stakeholders' willingness to pay for the preservation of a threatened ecosystem. The two main research questions for this study are the following:

1. How much are stakeholders in the region willing to pay to protect coral reefs?

2. How much does the global issue of climate change influence the willingness to pay for the localized issue of coral reef conservation?

The latter question borrows from the popular slogan of "think globally, act locally" that serves as a reference point for many environmental campaigns. Could this wellintentioned slogan be misguiding campaigns for coral reefs and other environmental issues? If so, it would require the revision of many assumptions within the environmental movement.

Instead of general citizens or visitors, residential stakeholders who consciously interact with the coral reef are the target population. The choice of stakeholders reflects the difficultly of finding citizens with enough basic knowledge to respond decisively to questions about the Florida Reef ecosystem. The 2006 study by Shivlani identifies a lack

of a connection to coral reefs as the major stumbling block: "This is in many ways the central problem facing an outreach and awareness program, which must not only attempt to improve the understanding of coral reefs among residents and visitors in southeast Florida but also explain why coral reefs are important to the region, how all groups affect 
and are affected by coral reefs (either directly or indirectly), and the need to protect this otherwise deteriorating resource." The study found that most residents of Southeastern Florida lack the motivation to answer questions about coral reefs in Florida. This problem is avoided by focusing on stakeholders.

The 2006 study by Shivlani surveyed visitors, residents, and stakeholders, and it included the following findings:

- While seafood ranks as a major benefit, fisheries are not considered a threat to reefs by the majority.

- Nearly half of respondents identify the Florida Keys as the only location of coral reefs in Florida.

- Stakeholders rate the reefs of southeastern Florida as declining and/or poor.

- Stakeholders disagree about the main cause for coral reef decline.

The current study will seek to draw comparisons to these and other major findings from four other surveys within the region, which provide useful benchmarks for assessment. The five reference surveys with number of respondents are: Shivlani 2006: 3,218; Shivlani 2007: 1,962; Shivlani 2008: 801; Berry 2011: 298; Shivlani 2011: 270. The average sample is 1,310 . It should be noted that these studies were commissioned by government agencies and not conducted for academic purposes.

\subsection{Hypotheses}

On the basis of the literature and the two research questions, three main hypotheses are proposed:

Hypothesis 1: Willingness to pay to protect coral reefs is moderately high.

Hypothesis 2: Local concern for coral reef conservation influences willingness to pay. 
Hypothesis 3: Global concern for climate change does not influence willingness to pay.

Willingness to Pay is operationalized by three metrics that corresponds to hypothetical payments for sustainable seafood, for a research fund, and for management regimes. Local concern for coral reefs and global concern for climate change are both operationalized as scales, called Coral Concern and Climate Concern respectively.

Willingness to pay is a well-developed measurement of contingent valuation, and it applies well to externalities such as ecosystem benefits from coral reefs (Brander 2013; Ghermandi 2011). As with any large system, willingness to pay for the Florida Reef and its benefits is neither universal nor uniform, and this study investigates its contextual expression.

\subsection{Sample Development}

The sampling universe is all residents in southeastern Florida within a contiguous, five-county region that encompasses Monroe, Miami-Dade, Broward, Palm Beach, and Martin counties (see Table 4). This region of 6.1 million residents contains $31 \%$ of the state's population in very dense concentration along the coastline, while the interiors of the four mainland counties have very low density and vast protected areas within the historical Everglades watershed (Census 2013). Excluding Monroe County, more than $46 \%$ of residents surveyed in the four mainland counties remain ignorant of the reef's existence within less than one mile of their shoreline (Shivlani 2007).

A dilemma exists between the center of population within the four mainland counties, representing $98.7 \%$ of the region's population, and the majority of the reef 
system located within Monroe County, which represents only $1.3 \%$ of the region's population (Census 2013). The peninsular mainland counties have relatively large and contiguous landmasses in comparison to the extended archipelago of the Florida Keys within Monroe County. Cultural and economic factors are heterogeneous on the mainland, while the Keys maintain an "island mentality" and independent spirit (Suman 1999). Economically, the Keys are enmeshed with the ocean. Moreover, there are noticeable differences between the Keys/Monroe and the mainland region in terms of the Hispanic and foreign-born populations.

\section{Table 4: Population of Southeastern Florida and State}

(2013 estimates from U.S. Census)

\begin{tabular}{|l|r|r|r|r|r|}
\hline & \multicolumn{1}{|l|}{$\begin{array}{l}\text { Foreign } \\
\text { born }\end{array}$} & \multicolumn{1}{l|}{$\begin{array}{l}\text { Hispanic or } \\
\text { Latino }\end{array}$} & $\begin{array}{l}\text { Growth } \\
2010-13\end{array}$ & Population & \multicolumn{1}{l|}{$\begin{array}{l}\text { Percentage } \\
\text { of Region }\end{array}$} \\
\hline Monroe County & $18.0 \%$ & $21.4 \%$ & $4.5 \%$ & 76,351 & $1.3 \%$ \\
\hline $\begin{array}{l}\text { Miami-Dade } \\
\text { County }\end{array}$ & $51.2 \%$ & $64.3 \%$ & $4.8 \%$ & $2,617,176$ & $43.2 \%$ \\
\hline Broward County & $31.4 \%$ & $26.5 \%$ & $3.4 \%$ & $1,838,844$ & $30.4 \%$ \\
\hline $\begin{array}{l}\text { Palm Beach } \\
\text { County }\end{array}$ & $22.4 \%$ & $20.1 \%$ & $3.9 \%$ & $1,372,171$ & $22.7 \%$ \\
\hline Martin County & $9.8 \%$ & $12.7 \%$ & $3.4 \%$ & 151,263 & $2.5 \%$ \\
\hline 5-county total & $19.3 \%$ & $23.2 \%$ & $4.0 \%$ & $19,552,860$ & State: $31 \%$ \\
\hline State & \multicolumn{2}{|l|}{} & & & \\
\hline
\end{tabular}

Although cultural and economic divisions exist between the mainland and the Keys, there are no barriers within the ocean, and travel across the region is convenient and pervasive. Hurricane evacuation from the Keys onto the mainland is customary. It can safely be assumed that reciprocal knowledge exists between the two regions. 
Because this study is concerned with human intentions, an effort was made to focus on representation from centers of population, a method employed in a relevant Australian study (Zander 2010). The region's tax base is centered in the mainland region's heterogeneous economy, while coral reef stakeholder concentration is high the Florida Keys, where the economy is clearly ocean-centric. By sampling a large database of stakeholders across the entire region, the dual concentrations of population and of highly invested stakeholders are addressed.

A stratified sample was built by multiple methods to represent stakeholders of the entire Florida Reef. The sample's two primary sources are: 1) regional holders of saltwater fishing licenses, provided by the Florida Fish and Wildlife Conversation Commission, and 2) stakeholders compiled by the author in consultation with the Southeast Florida Coral Reef Initiative, an entity of the Florida Department of Environmental Protection that operates within the four mainland counties. The limitations of the secondary, compiled sample are compensated by the exhaustive primary sample of fishing licensees.

Stakeholders are defined as people with a cultural or economic dependence on coral reefs. They are financially invested in coral reefs in terms that include recreation, employment, and social connections. Non-stakeholders are people without a direct financial or other major interest associated with coral reefs, and they would include casual beach visitors and scientists in non-related fields. Non-stakeholders may interact with the marine environment, benefit from it, or have knowledge about it, but they lack direct dependence on coral reefs. 
A spreadsheet was developed to create a representative sample of various communities, including operations of fishing, diving, boating, and other relevant institutions, such as university research, non-profit groups, and media. Previous counts for stakeholder communities provided benchmarks that were considered in order to represent them proportionally.

\subsubsection{Categorization of Stakeholders}

How many stakeholders are there? A comprehensive tally does not exist, and five directly relevant regional studies vary widely in their construction of stakeholder samples (Berry 2011; Shivlani 2011; Shivlani 2008; Shivlani 2007; Shivlani 2006). The range of participants in these surveys was from 270 to 3,218 . Two studies of mainland coral reef stakeholders for the Florida Department of Environmental Protection categorize stakeholders respectively into fifteen groups (Shivlani 2011) and eight groups (Berry 2011). Berry's more restricted grouping does not include clubs, conservation groups, educators, tourism agencies, ports, and the construction industry. Two studies by Shivlani $(2007 ; 2011)$ identify the following populations of stakeholders in the mainland southeast Florida region (excluding Monroe County):

- 166 dive operations

- 377 charter fishing operations

- 900 surfers

- 1,247 commercial fishing license holders

- 87,000 recreational fishing license holders

- 159,441 vessels registered

o recreational vessels: 151,109

o commercial vessels: 4,332

This compilation of nearly 250,000 entities provides a baseline of the mainland 
stakeholder population. Recreational fishing is identified as the most important fishery sector by both effort and number of participants (Shivlani 2011), yet from among the five studies referenced above, only the Shivlani 2007 study sampled them heavily. Because licenses are issued specifically for saltwater fishing, they offer a highly valid means of identifying coral reef stakeholders. Freshwater interests may distort vessel registration; therefore, vessel owners' representation will be confirmed within the survey based on questions about boat ownership and boating activity.

The current study's categorization of stakeholders divides them into four broad interest groups with 22 sub-categories:

1. Fishing: Recreational Saltwater License Holders, Commercial Saltwater License Holders, Clubs (Spearfishing, Freediving, and General), Tournaments

2. Diving: Recreational, Commercial, Clubs

3. Boating: Schools, Clubs (Boating and Yacht) and Paddling Clubs (Kayak and Rowing)

4. Education and Other: Environmental Organizations, Research Universities, Parks, Museums, Aquariums, Government, Media, Recreationalists.

As identified within the survey instrument, recreationalists may participate in: Fishing, Scuba Diving, Snorkeling, Freediving, Boating by motor, Surfing, Paddling, Swimming/Exercise, and Sailing. The activity of "Visiting the beach" is included as a control. The sample of stakeholders does not include ports, tourism agencies, and coastal construction, as these categories are considered too broad and likely lacking a direct engagement with coral reefs.

Lists of commercial and recreational saltwater fishing licenses were obtained from the Florida Fish and Wildlife Conservation Commission. Types of licenses include Resident 1-year or 5-year, Freshwater/Saltwater, Charter Captain, Lobster Permit, Snook 
Permit, and Gold Sportsman for multiple sports. With few exceptions, and free licenses available for onshore fishing only, all anglers are required to obtain a license from the state (FFWC 2014). The commercial list for the five-county region, obtained on September 13,2013, contained 2,668 unique names, of which 1,277 had an associated email addresses. The recreational list, obtained on October 17, 2013, included 1,048,575 licenses, of which 141,637 were not Florida residents. Within the five-county region, recreational saltwater fishing licenses totaled 132,021, of which 88,809 had an associated email address. The total of commercial and recreational licenses with an email address was $90,086$.

Of licenses from the five counties of interest, with individuals in alphabetical order, a random selection was made of email addresses, using the technique of beginning with a random number under 10 and selecting every $10^{\text {th }}$ individual until meeting the desired quota. The resulting sample included 33,940 licensed individuals associated with an email address. Due to bounced emails, the actual number contacted was lower (see Table 9 in Results).

Respondents were contacted only by email. An initial email was sent on November 13, 2013 (see Appendix 2), and three follow-up emails were sent after one week, three weeks, and the morning of December 13, the day when the survey link expired at 6 p.m. Due to a low response rate, the sample quota was expanded and additional emails and reminders were sent in mid-December, with a closing date of January 3, 2014.

The compilation of the samples for Diving, Boating, and Education and Other, is explained in Appendix 1. 


\subsection{Survey Instrument}

The survey instrument posed 41 questions to each respondent, and the survey instrument is presented in Appendix 3. This questionnaire was developed following similar coral reef stakeholder studies (Edge 2002; Edge 2008; Shivlani 2006; Shivlani 2011; Van Beukering 2011), and it features a choice experiment to assess willingness to pay. Because several questions request multiple answers, the number of responses per completed questionnaire is much higher than 41 .

A pilot study was conducted with several experts and more than 20 respondents to confirm the survey's legitimacy and operability. The online software program Qualtrics was used to develop and distribute the questionnaire. It sophisticated programming options enhanced reliability and the user's experience through such techniques as question randomization, content randomization, interactive graphics, and a variety of question formats. Users are assigned a unique identification, and the location of their online access is specified by latitude and longitude data.

A unique survey link provided for each email address cannot be forwarded; it must be accessed within that opened email. Furthermore, each link is limited to the completion of one questionnaire. The selected or pasted link opens directly within the user's browser. The Qualtrics email program reports email failure and success and stores the history of communication. Email addresses were removed from stored data files to protect anonymity.

Several questions confirm each respondent as a stakeholder. The most direct question asks what percentage of the respondent's household income is generated in 
association with the marine environment, and it directs the respondent to include the fields of ocean-related tourism, hospitality, resources, and environmental science and management jobs. Stakeholders are also identified directly as owners of a boat, as visitors to coral reefs, and as participants in ocean recreation.

As shown in Table xx, the questionnaire divides into five sections: 1) Recreation and Ocean Resources, 2) Coral Reefs in Florida, 3) Coastal Management Choices, 4) Climate Change and Reef Values, and 5) About You (demographics). Each section is discussed below. Six questions were skipped if irrelevant to the respondent.

\section{Table 5: Sections of Survey Instrument}

\begin{tabular}{|c|c|c|}
\hline Section number & Section description & $\begin{array}{l}\text { Number of questions } \\
\text { displayed }\end{array}$ \\
\hline Section I & $\begin{array}{l}\text { Recreation and Ocean } \\
\text { Resources }\end{array}$ & $\begin{array}{l}9 \text { (4 if non-seafood } \\
\text { consumer) }\end{array}$ \\
\hline Section II & Coral Reefs in Florida & 5 \\
\hline Section III & $\begin{array}{l}\text { Coastal Management } \\
\text { Choices }\end{array}$ & 5 \\
\hline Section IV & $\begin{array}{l}\text { Climate Change and Reef } \\
\text { Values }\end{array}$ & 8 \\
\hline Section V & About You & 14 (13 if non-donor) \\
\hline
\end{tabular}

\subsubsection{Section I: Recreation and Ocean Resources}

After a question about activities in the ocean, a series of six questions relates to Willingness to Pay (WTP) for seafood. A preliminary question excludes people who do 
not eat seafood from the other five questions. The two payment questions are illustrated with icons respectively for sustainable seafood, showing the label from the Marine Stewardship Council, and for local seafood, showing an image of mahi-mahi that is locally abundant and called dolphin (fish). These two questions contained a randomized display of payment premiums or offers, as shown in Table 6. Each respondent was shown only one of the four potential offers.

\section{Table 6: Offers for Seafood}

The amount is a premium that would be added to a weekly seafood budget.

\begin{tabular}{|l|c|c|}
\hline Offer & Sustainable Seafood & Local \& Sustainable \\
\hline 1 & $\$ 2$ & $\$ 1$ \\
\hline 2 & $\$ 4$ & $\$ 2$ \\
\hline 3 & $\$ 6$ & $\$ 4$ \\
\hline 4 & $\$ 10$ & $\$ 5$ \\
\hline
\end{tabular}

A follow-up question asks respondents to indicate the certainly of their answers. The final seafood-related question asks them to rate the credibility of labeling schemes for sustainable seafood.

Before subsequent sections relating to the context in Florida, respondents were asked about coral reefs in terms about their visitation and their assessment of reef conditions in general.

\subsubsection{Section II: Coral Reefs in Florida}

For the remainder of the questionnaire, respondents are instructed to refine their answers based on awareness of coral reefs located within Florida. Nine threats to these 
reefs are assessed with a Likert scale that ranges from Minimally Destructive to Extremely Destructive. A related question displays a map that excludes the Florida Keys and asks respondents to rank the quality of natural resources in the mainland region. A map of the entire state was divided into 9 boxes covering the coastline, and respondents were asked to select boxes that contained coral reefs.

\subsubsection{Section III: Coastal Management Choices}

One major distinction from previous studies is that the current survey includes a choice experiment. A discrete choice experiment follows principles of choice modeling and stated preference research methods, and it has gained preference for determining economic value over similar approaches, such as the Contingent Valuation Method (Van Beukering 2011). It examines trade-offs between multiple attributes that mimic a complex, multi-tiered decision-making process. The results could be used for benefit-cost analyses.

Choice modeling builds upon conjoint analysis, as developed from marketing theory, and it assesses non-market benefits (Gazzani 2007). More recently it has been applied to environmental studies of willingness to pay for conservation and remediation, including for coral reefs. A 2011 socioeconomic study of the U.S. Virgin Islands that contains a discrete choice experiment provides a useful parallel to the current study (Van Beukering).

Choice modeling is considered a cost-effective means for ascertaining consumer behavior because it assesses multiple attributes efficiently (Gazzani 2007). It also reduces bias of strategic response behavior by confounding a respondent's ability to ascertain 
preferred answers (Van Beukering 2011). Its foundation in Random Utility Theory, developed in the 1920 s, posits that utility is a combination of an observable valuation and a random error component. Utility does not equal the goods and services directly but rather the attributes that they contain (Tawfik 2010). It assumes that when respondents are forced to choose between a selection of different attributes contained in alternative A or B, they will choose the alternative with greater total utility (Shoyama 2013).

For such choice experiments, the multinomial logit model is commonly applied, and it assumes that choices are independent of irrelevant alternatives. Orthogonality, or a lack of correlation between variables, has been applied to choice modeling with an Orthogonal Main Effect Plan (Street 2005; Shoyama 2013).

The current choice experiment offers multifaceted scenarios that are illustrated on a choice card in the form of a menu with three options (see Figure 7). Each option combines several attributes into Plan A, Plan B, or Plan C. The construction of 20 choice cards began with the selection of attributes to represent various stakeholder concerns. The four selected attributes were: 1) the size of beaches, 2) the quality of navigable water, 3) the effect of restoration projects on coral reefs, and 4) a monthly fee for reef management. The fee was assigned seven levels, while the other attributes had three levels each (see Table 7). The intention was to create a series of scenarios with contrasting attributes.

On the choice cards, attributes are identified by comparable symbols and explanatory text, as in the example provided in Figure 7. The attribute of water quality was held constant for the three plans at levels of "Significant (30\%) Improvement" for Plan A, "Slight (10\%) Improvement" for Plan B, and "Poor" for Plan C. The control plan, 
Plan C, has a fee of $\$ 0$ and attributes that are explained to respondents as representing the status quo. Besides the fee, Plan C contained the least desirable attributes (Beach size: 10\% Smaller; Water quality: Poor; Coral restoration: Current Level).

Table 7: Attributes and Levels in Choice Experiment

Note: Areas outlined in bold were held constant.

\begin{tabular}{|c|c|c|c|c|c|c|c|}
\hline & \multicolumn{7}{|c|}{ Levels } \\
\hline Attribute & \multicolumn{6}{|c|}{ Plan A or B } & Plan C \\
\hline $\begin{array}{l}\text { 1. Beach } \\
\text { size }\end{array}$ & \multicolumn{3}{|c|}{ 10\% Larger } & \multicolumn{3}{|c|}{ Current Size } & $\begin{array}{c}10 \% \\
\text { Smaller }\end{array}$ \\
\hline $\begin{array}{l}\text { 2. Water } \\
\text { quality }\end{array}$ & \multicolumn{3}{|c|}{$\begin{array}{l}\text { Significant }(30 \%) \\
\text { Improvement }\end{array}$} & \multicolumn{3}{|c|}{$\begin{array}{l}\text { Slight }(10 \%) \\
\text { Improvement }\end{array}$} & Poor \\
\hline $\begin{array}{l}\text { 3. Coral } \\
\text { restoration }\end{array}$ & \multicolumn{3}{|c|}{$\begin{array}{l}\text { Significant (30\%) } \\
\text { Improvement }\end{array}$} & \multicolumn{3}{|c|}{$\begin{array}{l}\text { Slight }(10 \%) \\
\text { Improvement }\end{array}$} & $\begin{array}{c}\text { Current } \\
\text { Level }\end{array}$ \\
\hline $\begin{array}{l}\text { 4. Fee per } \\
\text { month }\end{array}$ & $\$ 30$ & $\$ 25$ & $\$ 20$ & $\$ 15$ & $\$ 10$ & $\$ 5$ & $\$ 0$ \\
\hline
\end{tabular}

A full factorial was generated for the combinations of attributes, resulting in 729 potential scenarios. Because this number of choice cards is impractical, as explained in the literature, 20 cards were selected that avoided dominant plans and that demonstrated compelling trade-offs for the respondent (Van Beukering 2011). These 20 cards were matched into 10 pairs that demonstrate divergence, with Plan A and Plan B varying by at least two attributes. A matched pair was randomly selected to be shown to each respondent. The randomization and the pairing increase reliability. 
Figure 7: Example of Choice Card

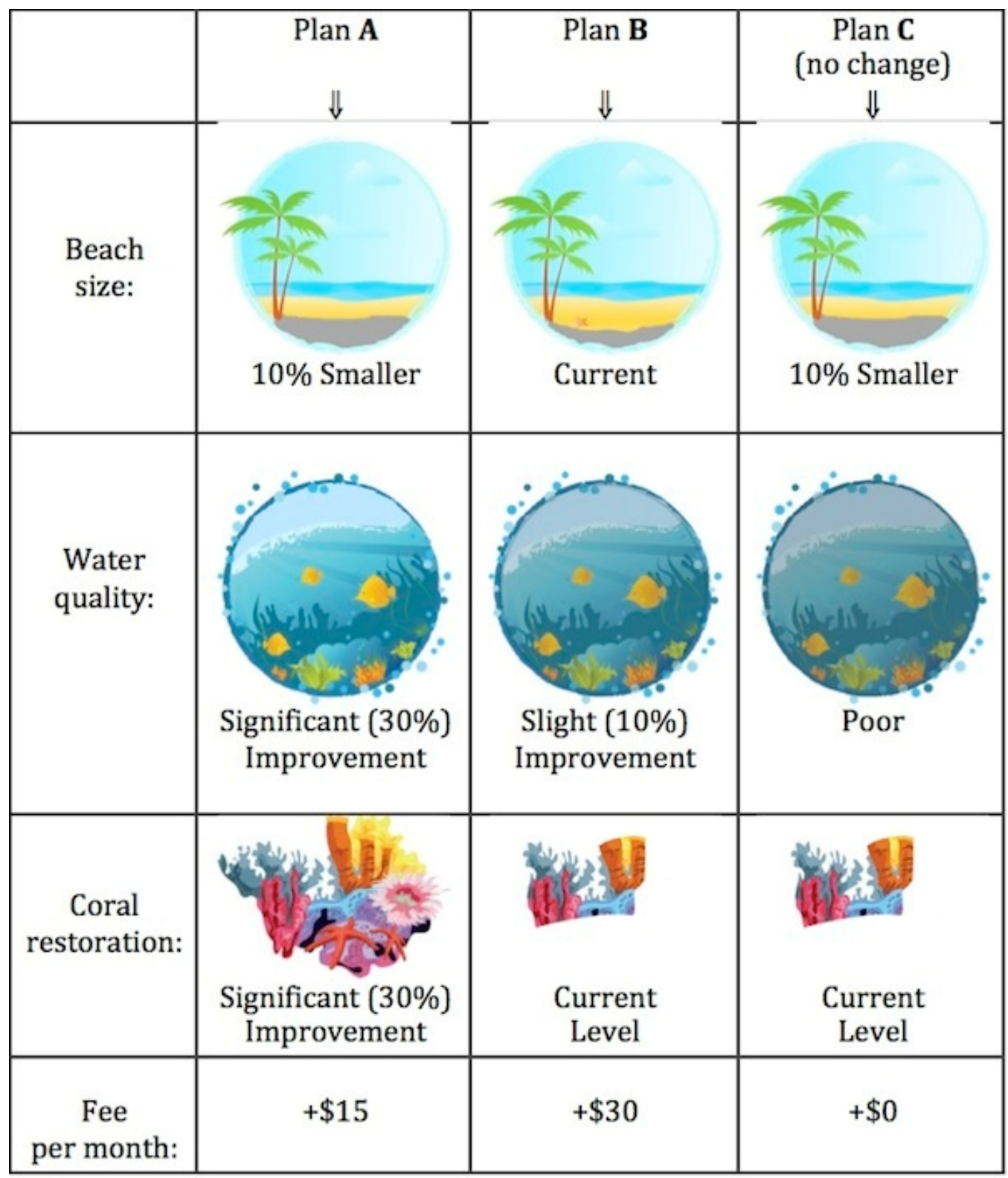

Except for water quality, Plan B tended to have more favorable attributes than Plan A. The average fee for Plan B was $\$ 2.75$ less than for Plan A. For Plan B, beach size 
averaged 1.2 times better, and coral restoration averaged 1.5 times better. For the full set of differences in the choice cards, see Appendix 4.

The choice experiment is an efficient method to assess willingness to pay for the management of a complex ecosystem, namely coral reefs, while considering a variety of socio-economic factors that interact (Van Beukering 2011; Kittinger 2012). Because regional stakeholders generally do not support user fees for marine resources (Shivlani 2011), the fee on the choice cards is proposed as part of a utility bill for all residents. The fee considers the combined costs of the other three attributes at a modest level, as explained below.

Beach nourishment is a common practice in southeastern Florida. As for costs per household, a 2009 study from Brevard County, Florida proposed household assessments that range from $\$ 16$ to $\$ 626$ per year for 18 years, with shorefront property owners paying the highest fees (Brevard). A moderate fee of $\$ 120$ would be equivalent to $\$ 10$ per month.

Water quality is considered the most comprehensive and most costly of the three attributes. A major expense for maintaining nearshore ocean water quality is wastewater treatment, and significant cost increases are anticipated within the coming decade due to legislation that affects the three counties of southeast Florida (Miami-Dade, Broward, and Palm Beach) that dispose of partially-treated sewage through ocean outfalls. A state law passed in 2008 (The Leah Shad Memorial Ocean Outfall Program) decommissions the outfalls by 2025 , and a fee structure in the bill states that "treatment upgrades and continuing operation and maintenance costs would be borne by certain utility customers in the three counties through monthly rates, impact fees, connection fees, assessments, or 
other mechanisms" (FDEP 2008). Citing a University of Florida study, the bill concludes that "a household using 7,500 gallons per month would have an additional average cost of $\$ 19.80$ per month.” This amount influenced the choice cards' median fee of $\$ 15$ per month.

As for percentage of water quality improvement indicated on the cards, the reference selected is the mid-range improvements to water reuse in Broward County after outfall decommissioning, which under alternative scenarios result in improvements of $24 \%$ or $11 \%$ (Koopman 2006). These estimates were rounded to $30 \%$ (Significant Improvement) and 10\% (Slight Improvement) for the choice cards.

This cost of coral reef restoration to the individual is difficult to calculate, as it involves diverse actors and environments that range from ex-situ aquaculture in laboratories to in-situ coral gardening (Precht 2006). For the Coral Restoration Foundation, based in the Florida Keys, an individual Acroporid coral costs $\$ 75$ to $\$ 135$ per year to generate and manage (Watson 2013). This foundation is funded through grants and donations. One existing fee for coral restoration is the $\$ 1.06$ per square centimeter of affected coral due to construction within the Florida Keys National Marine Sanctuary (Watson 2013). Another source of income is Florida's Coral Reef Protection Act of 2009, which penalizes coral damage anywhere within the Florida Reef with fees that range from $\$ 150$ to $\$ 1,000$ per occurrence (SEFCRI 2014). Regardless of its funding source, reef-wide restoration in Florida is at least a multi-million dollar prospect (Watson 2013). If such costs were spread across the utility bills of all households in southeastern Florida, the monthly fee would be small. 
Summing potential fees for beach nourishment programs, water quality upgrades, and coral reef restoration projects, and comparing them to the monthly fee attributes on the choice cards, the highest level of $\$ 30$ seems moderate and the lowest level of $\$ 5$ seems inadequate for full implementation. Respondents are not provided with a detailed account of the fee structure; they must choose rapidly based on their current level of understanding and their preferences, and the fee may or may not be the deciding factor.

\subsubsection{Section 4: Climate Change and Reef Values}

Having made choices for seafood and for management options, the respondent faces a third scenario of voting for a local sales tax for a statewide coral reef research fund. In a series of four questions, the first question is illustrated with an image of the "Protect Our Reefs" specialized Florida license plate, and it explains that the license plate costs $\$ 25$ and raises funds for one research center (Mote 2014). These questions build upon similar questions from the Shivlani 2006 survey:

- Should corals and coral reefs be protected?

- IF YES and resident, then would you be willing to pay an additional $1 \% / 2 \% / 3 \%$ sales tax (on all items) into a coral reef protection fund that would be used EXCLUSIVELY to manage and protect South Florida reefs?

Responses resulted in an estimated preferred sales tax of $0.77 \%$. Hence, the current study capped the tax rate at $2 \%$ and created a range of nine offers that were displayed randomly to respondents, as shown in Table 8 .

Similar to the scenario for seafood, the respondent answers two related questions, and within this study they are abbreviated as "Fund1" and "Fund2." The second question refines the proposed tax into an alternative that includes new, matching funds from the 
National Oceanic and Atmospheric Administration. The tax rate offer is held constant across the two questions. To help respondents interpret percentages, their potential to raise funds is explained as a dollar amount per $\$ 25,000$ of taxable spending.

\section{Table 8: Offers for Research Fund}

\begin{tabular}{|l|l|l|}
\hline Offer & Tax rate & Explanatory text \\
\hline 1 & $0.1 \%$ & raises $\$ 25$ per $\$ 25,000$ spent \\
\hline 2 & $0.25 \%$ & raises $\$ 63$ per $\$ 25,000$ spent \\
\hline 3 & $0.5 \%$ & raises $\$ 125$ per $\$ 25,000$ spent \\
\hline 4 & $0.75 \%$ & raises $\$ 188$ per $\$ 25,000$ spent \\
\hline 5 & $1 \%$ & raises $\$ 250$ per $\$ 25,000$ spent \\
\hline 6 & $1.25 \%$ & raises $\$ 313$ per $\$ 25,000$ spent \\
\hline 7 & $1.5 \%$ & raises $\$ 375$ per $\$ 25,000$ spent \\
\hline 8 & $1.75 \%$ & raises $\$ 438$ per $\$ 25,000$ spent \\
\hline 9 & $2 \%$ & raises $\$ 500$ per $\$ 25,000$ spent \\
\hline
\end{tabular}

After each question, respondents were asked to rank the certainty of their answer.

In this section, six items within two questions addressed climate change, and seven items within one question addressed coral reef concerns.

\subsection{Analysis Techniques}

Data were transferred from the online Qualtrics program to the software program Stata 13.1 for Mac. Data were cleaned and coded so that higher scores reflect greater environmental awareness or concern. Many new variables were created, and preference was given to binary representation; when appropriate, the response option of "don't know" was combined with "no" to result in only negative or positive responses. 
An error was discovered in the randomized presentation of the two questions about seafood preferences, and the result is that no respondents were shown one matched pair of the intended offer levels ( $\$ 8$ and $\$ 4$ respectively). This error is being addressed by obtaining additional responses for future analysis; however, it did not corrupt the data, and the results for those two questions are presented and analyzed comprehensively.

Respondents under the age of 18 were removed from the data set. Univariate analysis of the data confirmed the internal consistency of each variable, and spreadsheets were developed to report of each variable in terms of the number of responses, maximum and minimum values, mean, and standard deviation. Bivariate analysis was conducted using cross tabulations or contingency tables for potentially associated variables, although most of these results are not reported.

Extensive time was devoted to multivariate analysis. Due to the complexity of the choice experiment, it was analyzed outside of the Stata program by using Excel spreadsheets. It was decided to delay multivariate analysis of this experiment for the future. All other variables were analyzed within Stata.

As a process, multiple regression analysis involves seven major steps:

1. Hypothesize the model's deterministic component by selecting independent variables to include.

2. Collect sample data.

3. Estimate the unknown parameters (beta coefficients) using the method of least squares.

4. Estimate the variance of the random error component.

5. Assess the model against the hypothesis.

6. Modify if necessary.

7. Estimate or predict the parameter (Mendenhall 2012). 
These steps were followed, and nonlinear logistic regression analysis was performed for the four scenarios representing seafood and research funding. Nonlinear logistic regression is useful for describing relationships between binary qualitative dependent variables and predictor, independent variables. For a logistic regression, the general model uses the sum of the exponents of the independent variables. The resulting betas quantify the change in the log-odds for every one-unit change in that independent variable (Mendenhall 2012). The logit transformation uses odds ratios and finds their natural logarithm (Acock 2012). Given the difficulty of interpreting the coefficients in such models, the log odds technique was also employed. All models were run with the robust command to adjust for potential outliers and non-normal distributions (Mendenhall 2012).

The postestimation diagnostics used for goodness of fit and homoscedasticity are those recommended for logit models by Stata, and the commands used are "estat gof" and "estat classification," with the latter command reported as the percentage correct for all observations. The goodness of fit is reported for the default Pearson chi-squared, and for a grouping of 10 for the Hosmer-Lemeshow chi-squared, as recommended by the Stata 13 manual (StataCorp 2013).

The same parsimonious model was used for both sustainable and local seafood to allow for easier comparison, and the extended model for local seafood was developed on its own merits. The same process was followed for the two research funds. For all models, the first independent variable, the offer, was maintained at a significant level, because the relationship between cost and benefit is theoretically sound. 


\section{CHAPTER 4: RESULTS}

\subsection{Description of Sample Respondents}

Following successful contact by email, sample respondents included 1,923 who opened the survey, 1,651 individuals who agreed to begin the survey, and 1,157 who answered at least one question. Most questions had more than 800 responses, and 812 respondents completed the survey's final question. Questionnaires were considered complete if the respondent answered a question in each of the five sections. Based on questionnaires completed by 824 respondents from a total sample of 32,151 , the response rate was $2.6 \%$. Table 1 shows the tally of completed surveys.

Table 9: Sample Frequencies and Survey Completion

Note: The Received Email column excludes bounced emails.

\begin{tabular}{|c|c|c|c|c|}
\hline $\begin{array}{l}\text { Stakeholder } \\
\text { Group }\end{array}$ & Subgroup & $\begin{array}{l}\text { Received } \\
\text { Email }\end{array}$ & Started & Completed \\
\hline \multirow{3}{*}{ Fishing } & $\begin{array}{l}\text { Recreational } \\
\text { Saltwater License } \\
\text { Holder }\end{array}$ & 30,576 & 1,676 & 703 \\
\hline & $\begin{array}{l}\text { Commercial License } \\
\text { Holder }\end{array}$ & 1115 & 134 & 45 \\
\hline & $\begin{array}{l}\text { Clubs \& } \\
\text { Tournaments }\end{array}$ & 36 & 7 & 5 \\
\hline Diving & & 82 & 14 & 11 \\
\hline Boating & & 75 & 9 & 4 \\
\hline \multirow{3}{*}{ Edu / Other } & Various & 109 & 20 & 10 \\
\hline & $\begin{array}{l}\text { Our Florida Reefs } \\
\text { participants }\end{array}$ & 71 & 25 & 19 \\
\hline & SEFCRI referrals & 87 & 38 & 27 \\
\hline \multicolumn{2}{|c|}{ Total Sample } & 32,151 & 1,923 & 824 \\
\hline \multicolumn{3}{|l|}{ Return Rate } & $6.0 \%$ & $2.6 \%$ \\
\hline
\end{tabular}


The stakeholder groupings in Table 9 are based on the pre-identification process of how an email address was obtained, and by this method, $85 \%$ of completed respondents qualify as recreational anglers. Within the questionnaire, respondents identified themselves based on several variables that are reported subsequently, and many belong to multiple stakeholder groups.

The highest response rate was 1,157 for the question asking if the participant consumes seafood. The lowest response rate was 507 for the question asking if the participant holds a degree in science.

Because each respondent is associated with a unique email address and survey link, the assumption that each respondent represents a unique individual maintains high validity. It is certainly possible that an individual could be represented by more than one email address, but the randomized selection for the vast majority of email addresses makes such duplication highly unlikely.

More than 200 variables were generated, and a summary of the main variables appears in Table 10. Other variables are organized into groups in Appendix 6. All variables were coded so that high scores represent greater environmental concern. For universal results, a file with Stata commands is available electronically.

Participant ages range from 18 to 85 years old (see Figure 8 ). Only 10 respondents reported a residential zip code outside of Florida. Modes (and percentages) indicate that the typical respondent was white (81.6\%), male (82.5\%), age 48 , a motorboat owner (68.3\%), with a 4-year college degree $(36.3 \%)$, and with an annual household income of greater than $\$ 200,000$ (17.2\%). The income distribution is shown in Figure 9 . 


\section{Table 10: Summary of Main Variables}

\begin{tabular}{|c|c|c|c|c|c|c|}
\hline \multirow[b]{2}{*}{ Description } & \multicolumn{6}{|c|}{$\mathrm{Ma}$} \\
\hline & Abbreviation & $\mathrm{N}$ & Min & $\mathrm{x}$ & Mean & St. Dev. \\
\hline \multicolumn{7}{|c|}{ Seafood Willingness to Pay (WTP)* } \\
\hline Consumer of Seafood & food & 1157 & 0 & 1 & $\begin{array}{l}0.973206 \\
6\end{array}$ & $\begin{array}{l}0.161549 \\
1\end{array}$ \\
\hline Offer for Sustainable Seafood & foodoffer1 & 1651 & 2 & 10 & $\begin{array}{l}5.4149 \\
0.645813\end{array}$ & $\begin{array}{l}2.969623 \\
0.478496\end{array}$ \\
\hline Sustainable Seafood Choice & foodsust & 1039 & 0 & 1 & 3 & 4 \\
\hline Offer for Local Seafood & foodoffer2 & 1651 & 1 & 5 & $\begin{array}{l}2.70745 \\
0.804642\end{array}$ & $\begin{array}{l}1.484812 \\
0.396667\end{array}$ \\
\hline Local Seafood Choice & foodlocal & 1034 & 0 & 1 & 2 & 8 \\
\hline Certainly of Seafood Choices & foodcert & 1033 & 1 & 11 & 9.281704 & 2.228477 \\
\hline Trust in Seafood Labels & foodtrust & 1034 & 1 & 11 & 7.340426 & 2.908773 \\
\hline Weekly Seafood Budget & foodbudget & 977 & 1 & 11 & 4.221085 & 2.728163 \\
\hline \multicolumn{7}{|c|}{ Management WTP } \\
\hline Management Plan Choice1 & v117-126 & 861 & 1 & 3 & & \\
\hline $\begin{array}{l}\text { Management Plan Choice } 2 \\
\text { Certainty of Management Plan }\end{array}$ & v128-137 & 847 & 1 & 3 & & \\
\hline Choices & plancert & 629 & 2 & 11 & 8.489666 & 2.703849 \\
\hline Importance of Fee Attribute & planfee & 834 & 1 & 5 & 3.079137 & $\begin{array}{l}1.459652 \\
0.978324\end{array}$ \\
\hline Importance of Coral Attribute & plancoral & 834 & 1 & 5 & 4.374101 & $\begin{array}{l}9 \\
0.919611\end{array}$ \\
\hline Importance of Water Attribute & planwater & 834 & 1 & 5 & 4.414868 & 4 \\
\hline Importance of Beach Attribute & planbeach & 834 & 1 & 5 & 2.730216 & 1.261822 \\
\hline Funding Source Preference & resp & 833 & 1 & 6 & 2.581032 & 1.470373 \\
\hline \multicolumn{7}{|c|}{ Research WTP } \\
\hline Offer for Research Fund & & 847 & 0.1 & 2 & $\begin{array}{l}1.004782 \\
0.656019\end{array}$ & $\begin{array}{l}0.597075 \\
4 \\
0.475326\end{array}$ \\
\hline Research Fund1 Choice & $\operatorname{tax} 1$ & 814 & 0 & 1 & $\begin{array}{l}7 \\
0.732098\end{array}$ & $\begin{array}{l}7 \\
0.443139\end{array}$ \\
\hline $\begin{array}{l}\text { Research Fund } 2 \text { Choice } \\
\text { Certainty of Research Fund } 1\end{array}$ & $\operatorname{tax} 2$ & 810 & 0 & 1 & 8 & 5 \\
\hline $\begin{array}{l}\text { Choice } \\
\text { Certainty of Research Fund2 }\end{array}$ & taxcert1 & 819 & 1 & 11 & 9.332112 & 2.109956 \\
\hline Choice & taxcert 2 & 820 & 1 & 11 & 9.537805 & 1.997504 \\
\hline \multicolumn{7}{|c|}{ Other Variables } \\
\hline Rate Health of World Reefs* & health & 944 & 1 & 5 & 3.549788 & 3 \\
\hline Interaction with World Reefs* & visit & 1044 & 1 & 5 & 4.272989 & 1.210056 \\
\hline Ocean Interaction* & see Appen & 6: recf & & eac & & \\
\hline
\end{tabular}




\begin{tabular}{|c|c|c|c|c|c|c|}
\hline Interaction with Florida Reefs & flvisit & 1025 & 0 & 1 & $\begin{array}{l}0.938536 \\
6\end{array}$ & $\begin{array}{l}0.240295 \\
6\end{array}$ \\
\hline Coral Reef Concern Scale & coral & 817 & 5 & 35 & 25.27907 & 5.150239 \\
\hline Rate Reef Threats & \multicolumn{6}{|c|}{ see Appendix 6: tscuba - ttemp } \\
\hline $\begin{array}{l}\text { Climate Concern Scale } \\
\text { Climate Change Arrives in }\end{array}$ & climate & 829 & 1 & 25 & 17.10977 & 5.151686 \\
\hline Florida & when & 825 & 1 & 6 & 4.721212 & 1.753595 \\
\hline $\begin{array}{l}\text { Source of Reef Information } \\
\text { Environment vs. Economy }\end{array}$ & \multicolumn{6}{|c|}{ see Appendix 6: personal - scilit } \\
\hline Priority & efirst & 800 & 0 & 1 & 0.75125 & 0.432559 \\
\hline Environmental Orientation & enviro & 771 & 1 & 10 & 6.089494 & 2.396649 \\
\hline Age in Years & age & 811 & 18 & 85 & 46.61159 & $\begin{array}{l}12.18006 \\
0.616710\end{array}$ \\
\hline Birthplace & born & 813 & 1 & 3 & $\begin{array}{l}1.810578 \\
0.824539\end{array}$ & $\begin{array}{l}1 \\
0.380593\end{array}$ \\
\hline Sex & $\operatorname{sex}$ & 815 & $\begin{array}{l}0 \\
142\end{array}$ & $\begin{array}{l}1 \\
902\end{array}$ & 9 & 7 \\
\hline Zip Code & zip & 815 & 40 & 09 & 33377.06 & $\begin{array}{l}2682.729 \\
0.833081\end{array}$ \\
\hline Boat Ownership & boat & 814 & 1 & 3 & 2.460688 & 4 \\
\hline Income & inc & 773 & 1 & 11 & 6.230272 & 2.986371 \\
\hline Income-squared & incsq & 773 & 1 & 121 & 47.72316 & 40.81417 \\
\hline Income in Four Categories & inc4 & 773 & 1 & 4 & 2.575679 & 1.074205 \\
\hline Political Identity & pol & 803 & 0 & 5 & 2.694894 & 1.469664 \\
\hline Race & race & 804 & 1 & 7 & 1.507463 & 1.243141 \\
\hline Education & edu & 808 & 1 & 6 & 3.816832 & $\begin{array}{l}1.193171 \\
0.654863\end{array}$ \\
\hline Education in Three Categories & edu1 & 808 & 1 & 3 & 2.09901 & $\begin{array}{l}8 \\
0.444510\end{array}$ \\
\hline Degree in Science & degree & 507 & 0 & 1 & $\begin{array}{l}0.270217 \\
0.737684\end{array}$ & $\begin{array}{l}4 \\
0.440164\end{array}$ \\
\hline Donor to Environment & donor & 812 & 0 & 1 & 7 & 3 \\
\hline Donor Amount & donoramount & 592 & 1 & 6 & 3.280405 & 1.267485 \\
\hline
\end{tabular}

*not specified as limited to Florida

Figure 8: Age with K-density 


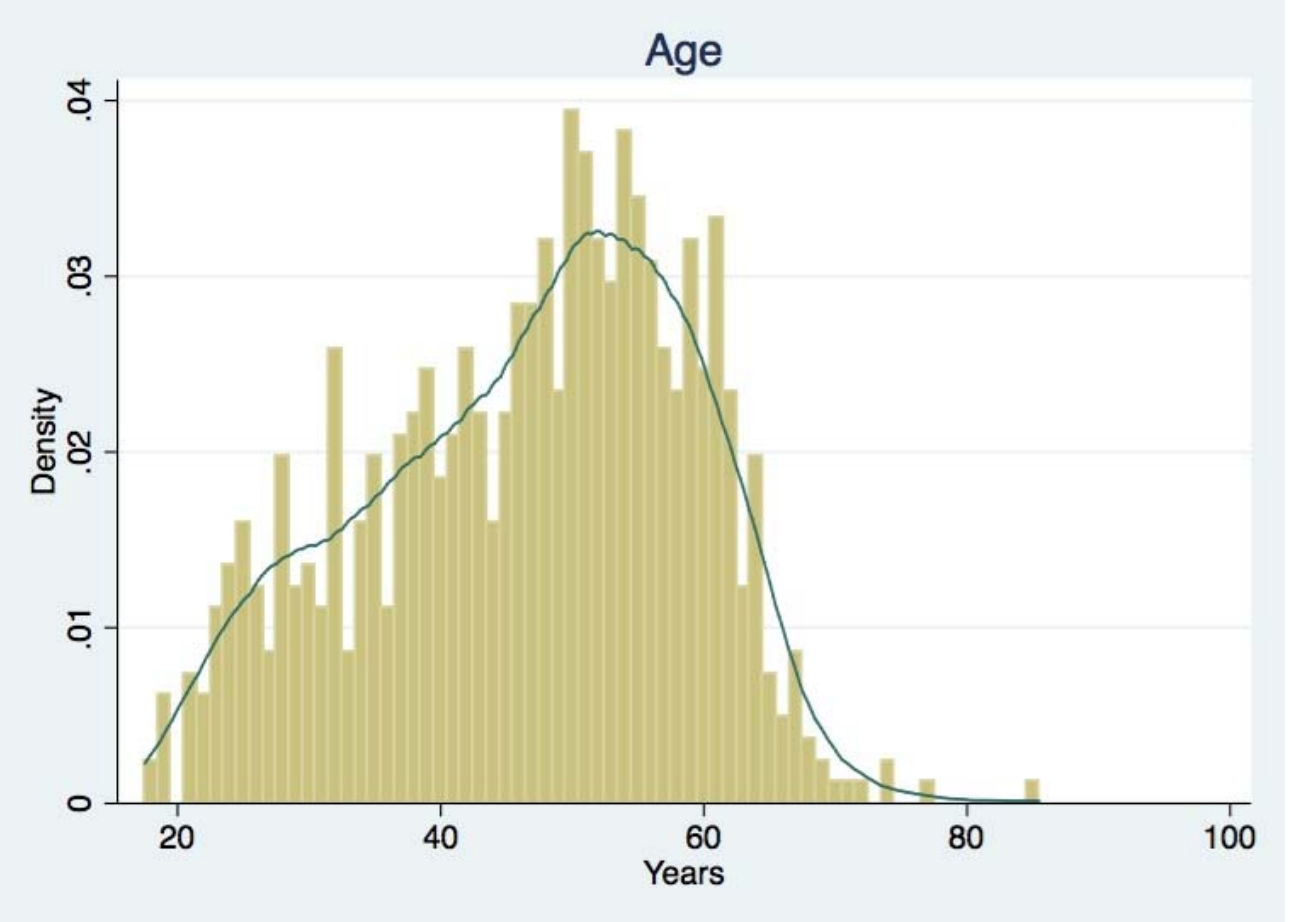

Figure 9: Household Annual Income

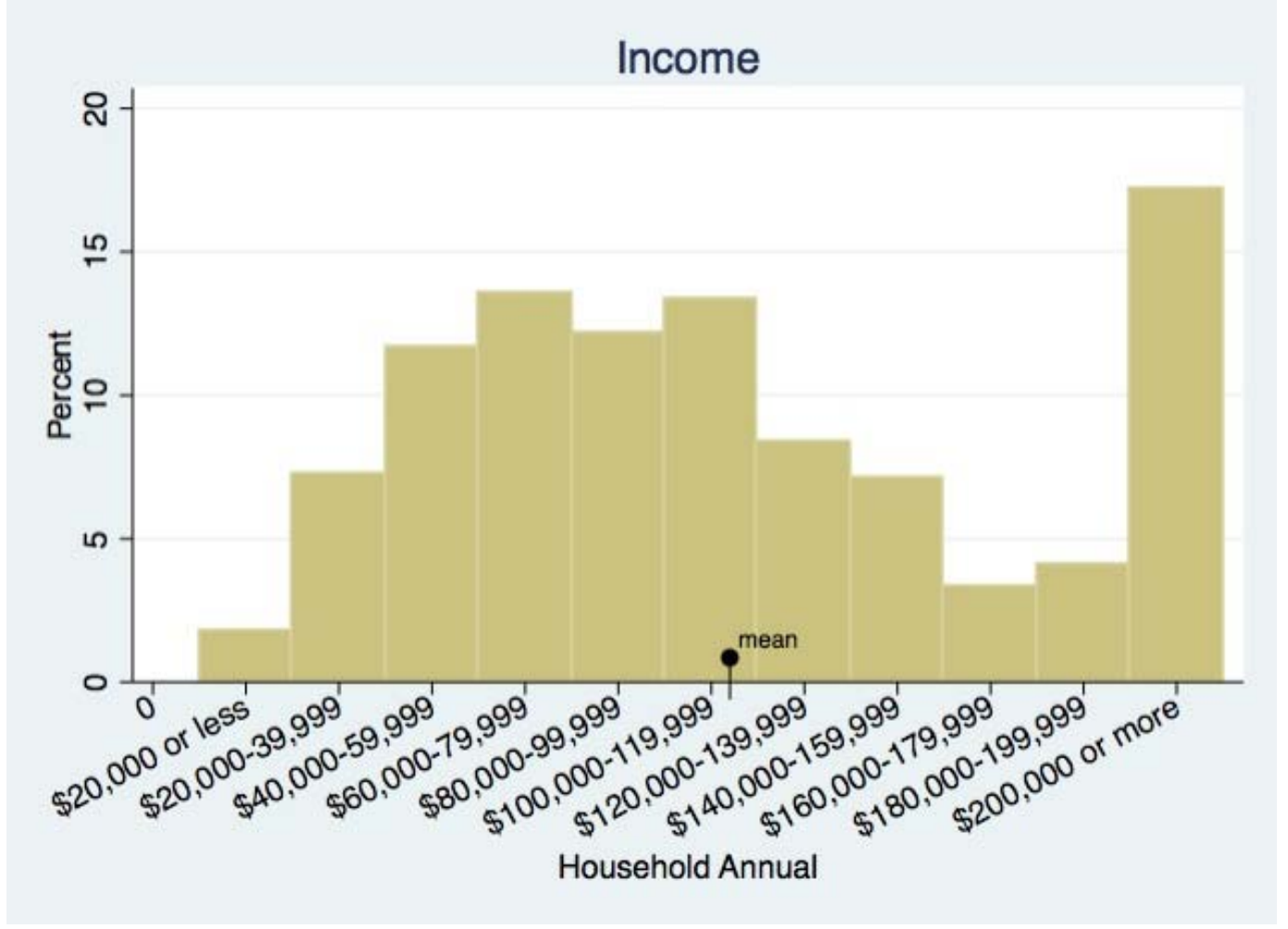


The mean for income falls near the high end of $\$ 100,000$ to $\$ 119,000$ per year. If this variable is transformed into four categories instead of eleven, the mean falls closer to the low end of between $\$ 100,000$ to $\$ 159,000$, as shown in Figure 10 .

Self-identified Hispanics were $12.3 \%$ of the sample; greater than $2 \%$ identified racially as Other, and less than $1 \%$ identified as Black.

For education, $83 \%$ had at least a two-year college degree, and nearly the entire sample had completed high school (see Figure 11).

Many residents of Florida have emigrated from other places, but it is still noteworthy that a majority of respondents were not born within the state. Of the $69.7 \%$ born outside of Florida, 58.4\% were born in another state and $11.3 \%$ were born abroad.

Figure 10: Income Variable Transformed

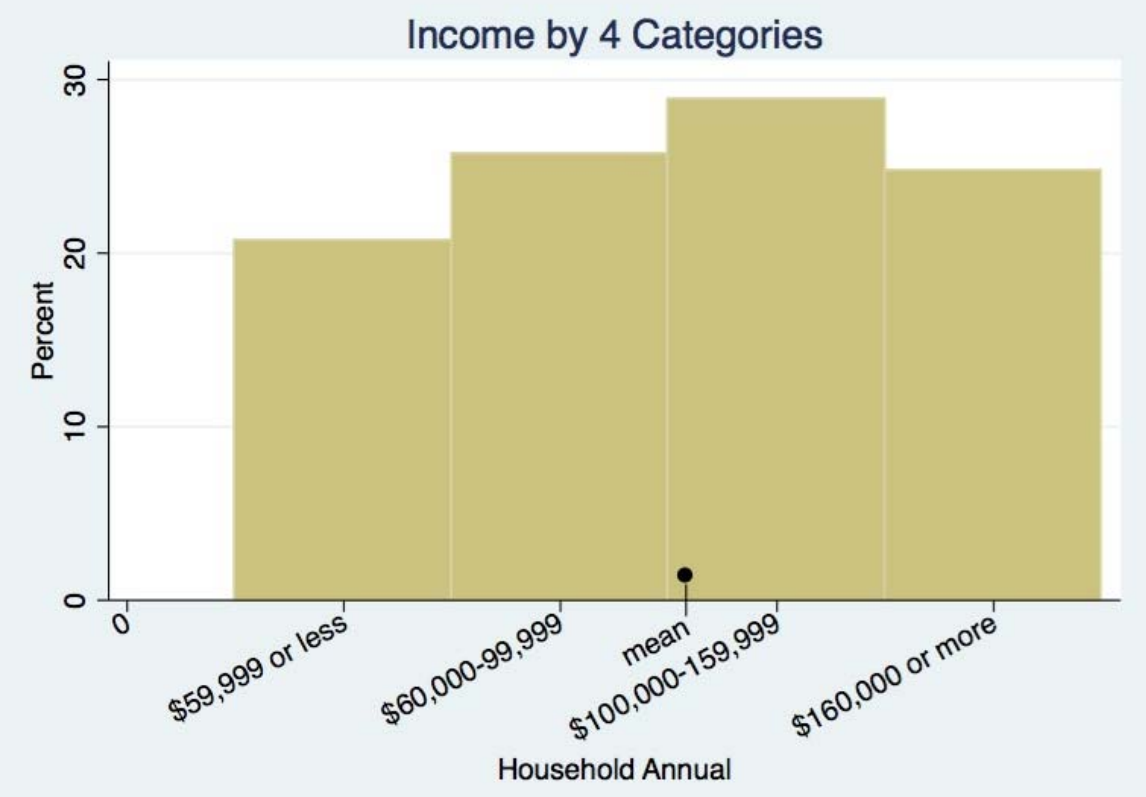

Figure 11: Educational Attainment 


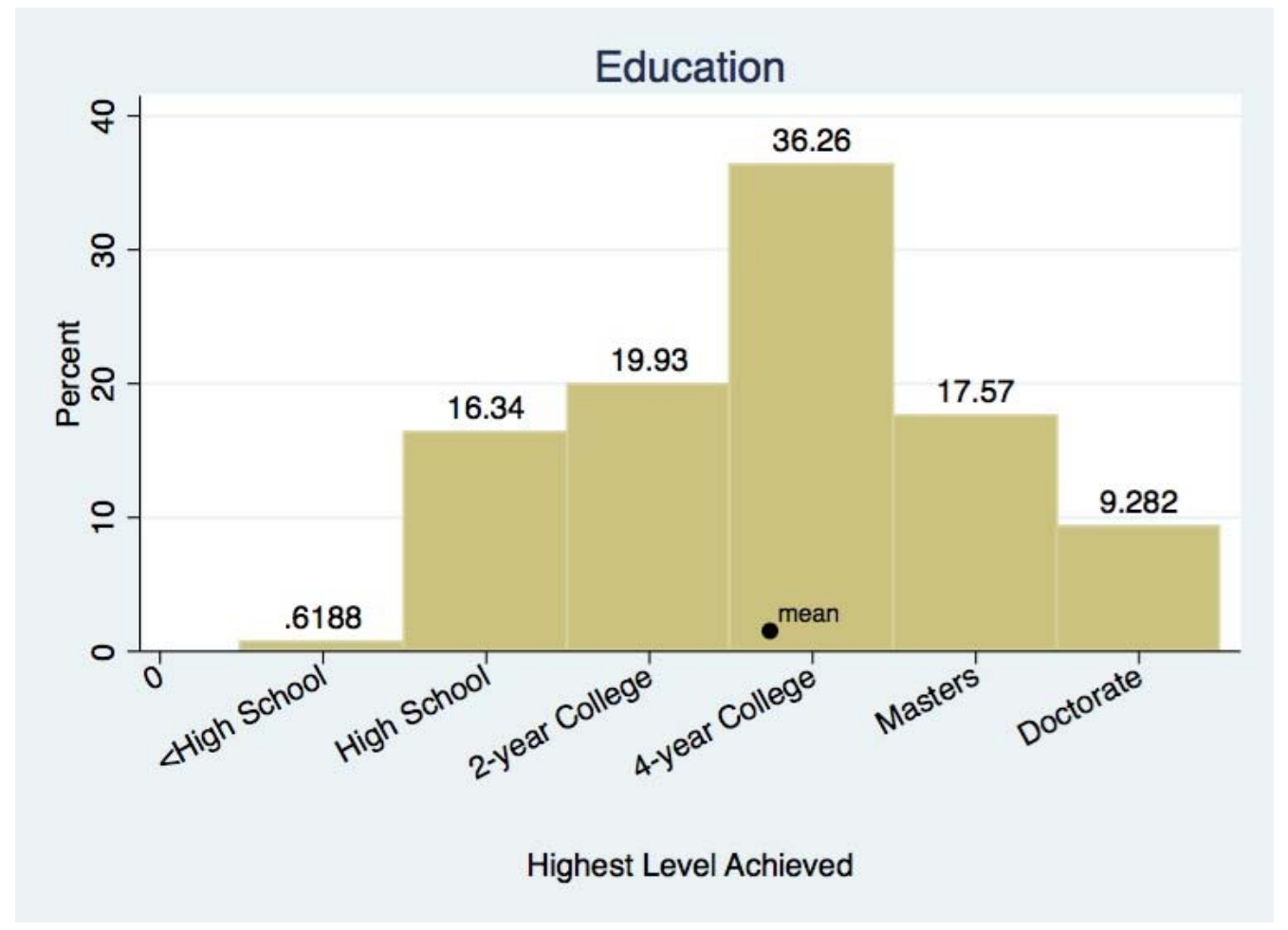

For political identity, the majority of $63.8 \%$ identify as Independent. The two dominant parties register as minorities in this sample: Republican (19.3\%) and Democrat (14.8\%). See Figure 12 for a display of all political categories offered.

Figure 12: Political Identification 


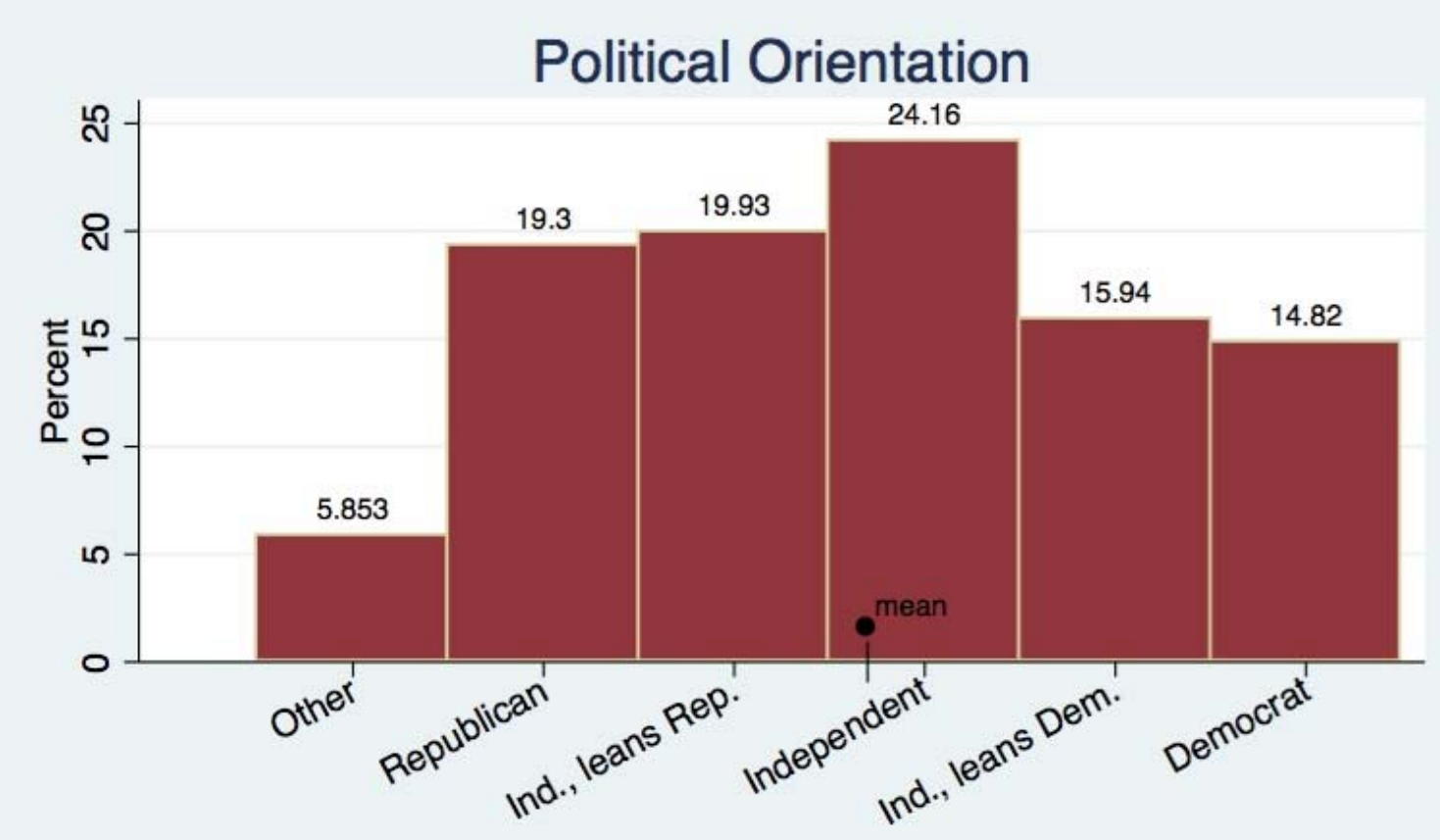

How do you identify yourself?

When combined into three categories instead of five, the political orientation appears skewed nearly $10 \%$ in the direction of Republican:

- Independent + Other: $30.1 \%$

- Democrat + Independent, leans Democrat: $\quad 30.8 \%$

- Republican + Independent, leans Republican: $\quad 39.2 \%$

These categories hold less explanatory power than the six divisions and will not be used for further analysis.

Below are some of the optional text comments provided by respondents who selected "Other" (frequency in parenthesis):

- Libertarian (7)

- Conservative (5) 
- None (3)

- American (2)

- Constitutionalist (2)

- All politicians are scoundrels

- Anarchist

- Fiscal Conservative

- Independent leans left of Democrat

- Neutral/Don't vote ever

- Pissed off at all parties

- Socialist

- Tea Party

- green party/liberal/votes democrat

- whomever lies least

Only this category offered a write-in option. Other political opinions were expressed by individuals who chose to send an unsolicited email with their comments, and these are compiled in Appendix 5.

\subsection{Ocean Interaction}

Regarding the sample's connection to coral reefs and the ocean in general, only 1 of 1,157 respondents claimed no activity in the ocean, and many respondents indicated participation in multiple activities. A composite Ocean Activity score produced a median of 12 out of a total possible 40 (based on 10 activities with a high score of 4 each). Average engagement for the 10 activities is presented in Figure 13. Boat ownership is presented in Figure 14, and nearly $78 \%$ owned a vessel that operated either with a motor $(68.3 \%)$ or without a motor $(9.5 \%)$.

Figure 13: Ocean Interaction 


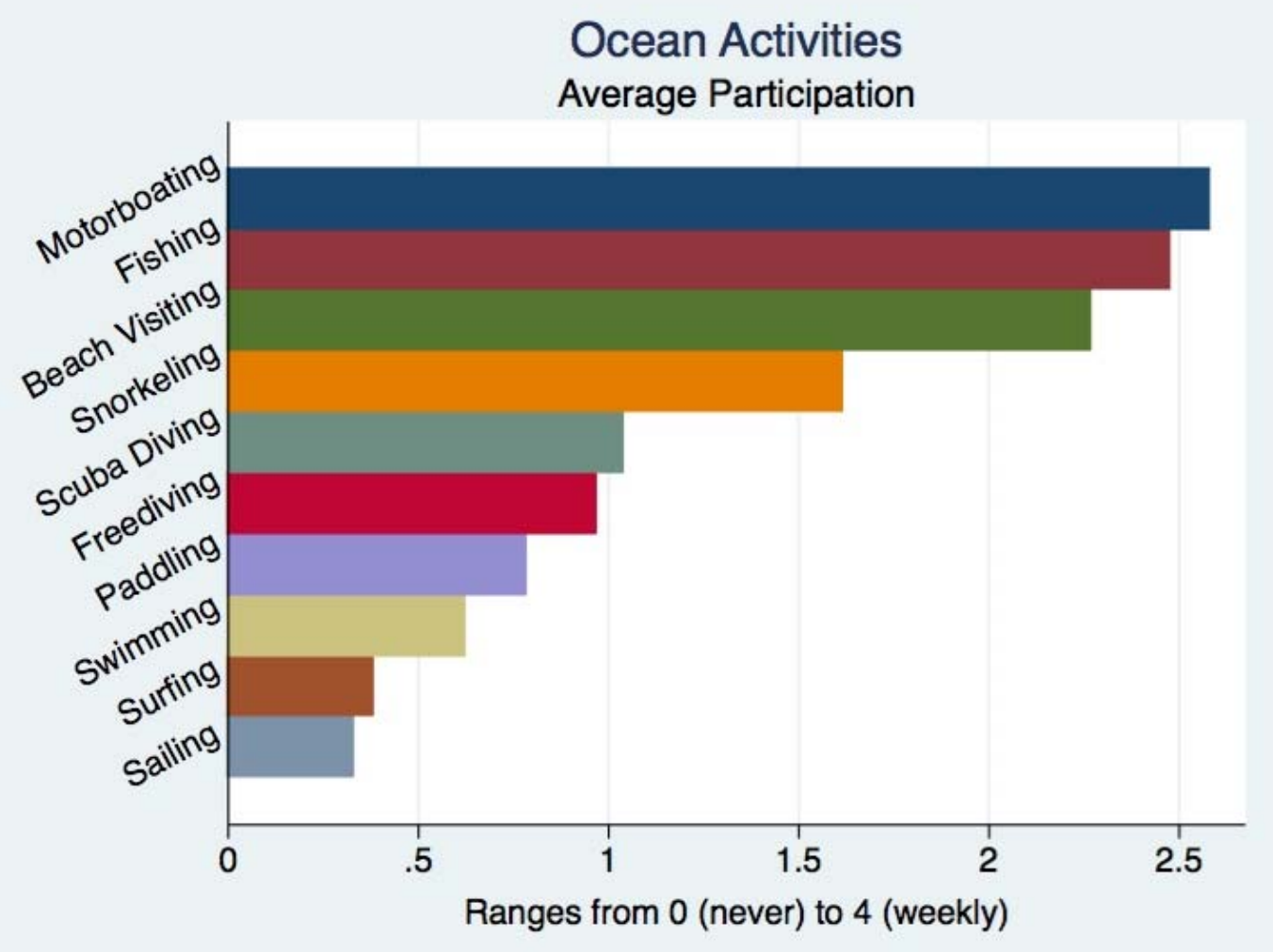

Of the ten activities surveyed, a majority practiced the top five at least annually. Therefore, most respondents spend time both "on the water" and "in the water." Boating with a motor was the most common activity, followed closely by fishing (no distinction was made between types of fishing). Motorboating, fishing, and beach visiting were practiced annually by greater than $94 \%$ of respondents. Snorkeling registered high participation at the annual rate but only moderate participation at the monthly rate, meaning that it is pervasive yet practiced infrequently by this sample.

Figure 14: Boat ownership 


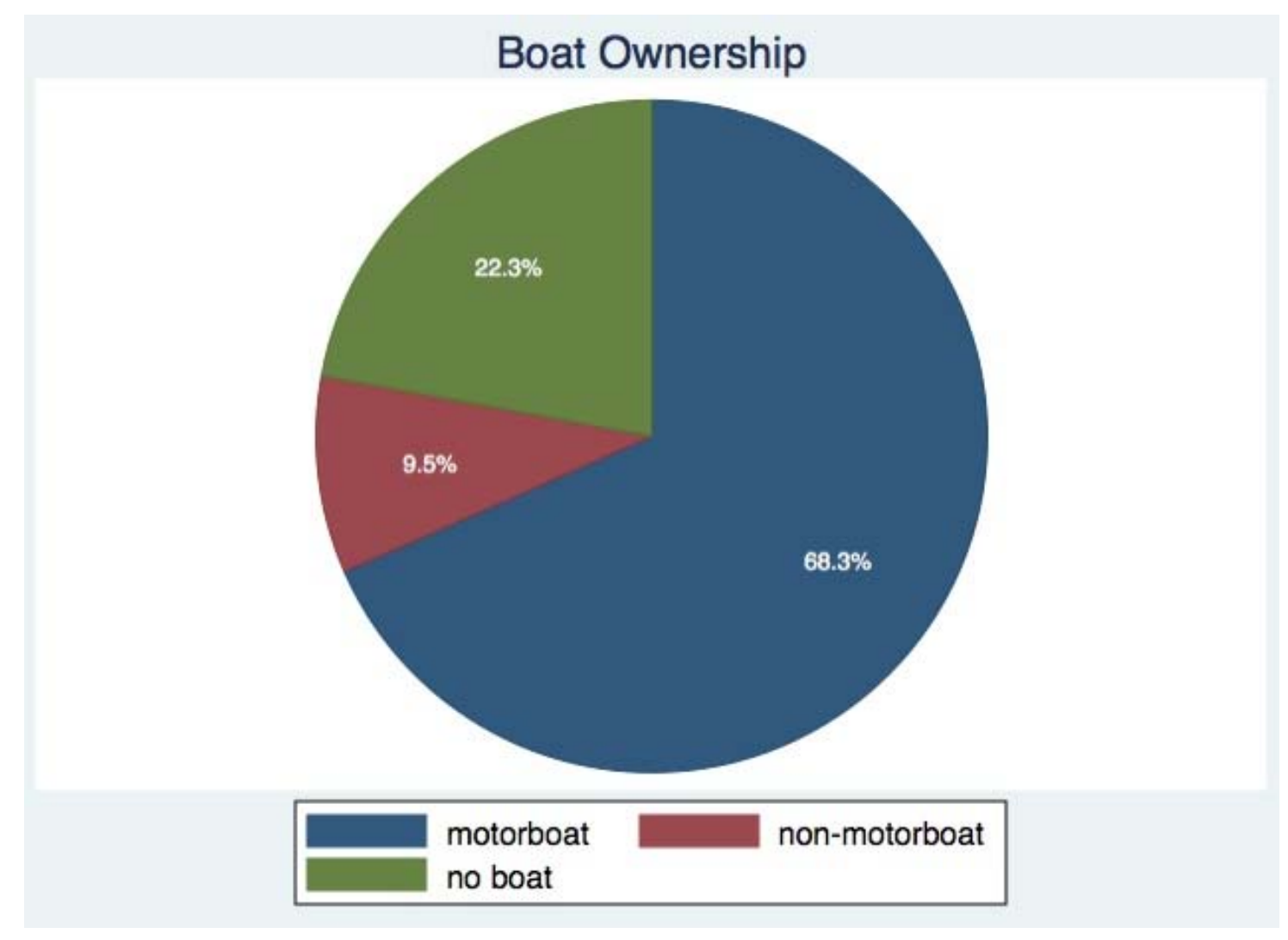

\subsection{Environmental Orientation}

Environmental orientation was assessed through several variables. The most

direct assessments asked respondents these three questions with the following results:

Question 27: Which is more important?

The Economy, even if it leads to environmental problems: $\quad 24.9 \%$

The Environment, even if it costs jobs or economic growth: $\quad 75.1 \%$

Question 39: In the past year, have you donated money or time to an environmental cause? $\quad$ Yes: $73.8 \%$

Question 41: On a 0 to 10 scale, where 0 means it does not describe you not at all and 10 means it describes you perfectly, how well does the word

"environmentalist" describe you? Mean: 6.1 
For question 41, Figure 15 shows the distribution for the 770 respondents. The choice of zero was the default setting and was not registered as a response.

Figure 15: Environmental Self-Identification

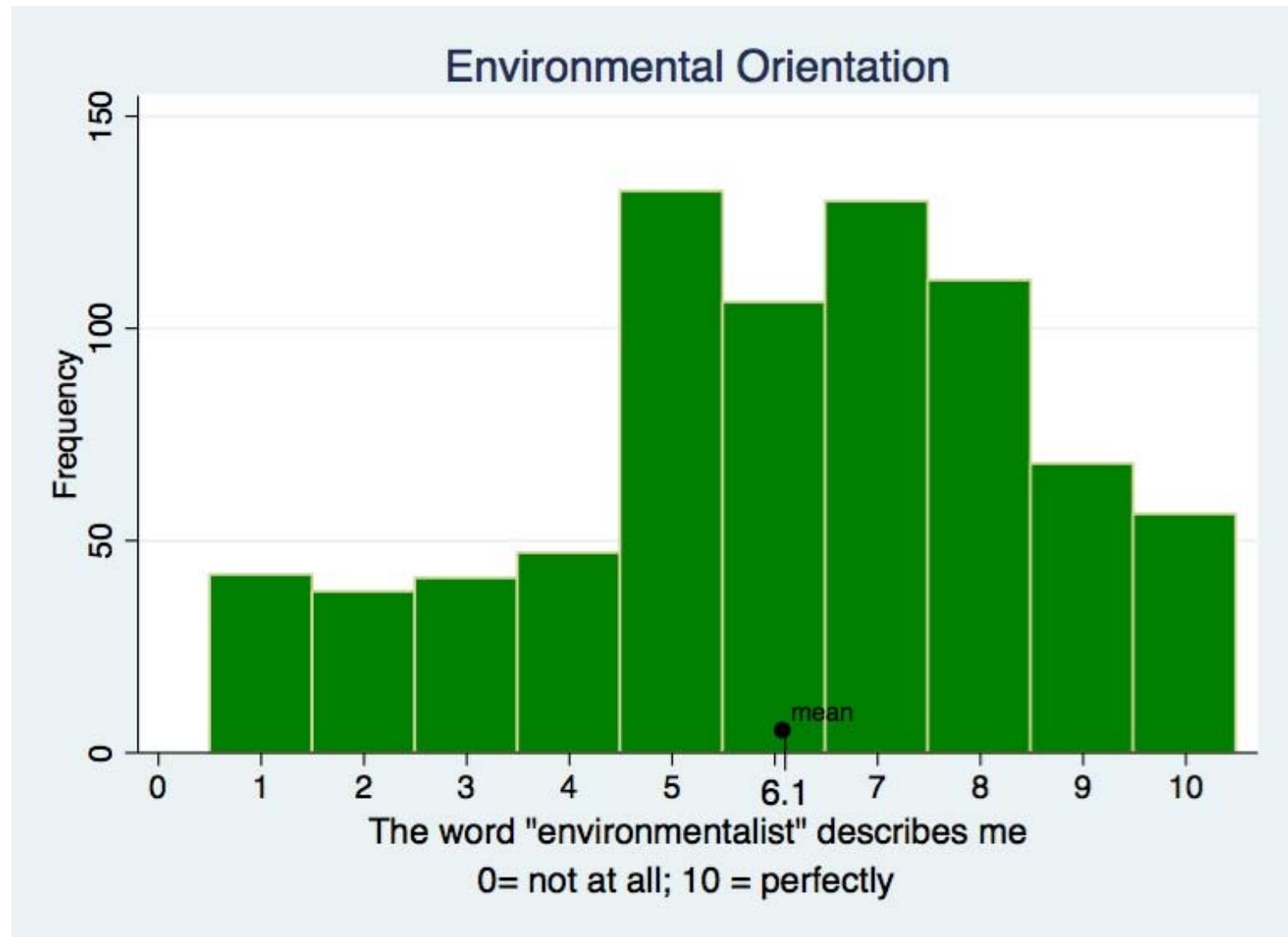

\subsection{Scales for Climate Concern and Coral Concern}

Two scales were created based on sets of responses: one set within question 20 about climate change, and one set within question 26 about coral reefs. The scale of Climate Concern combines five responses to statements on a five-point Likert scale that 
ranges from "none" to "extreme," and responses were coded so that high scores reveal high concern (see Appendix 6). Respondent totals ranged from 5 to 25, representing the full range of possible scores. Scores below 5 were dropped because they lacked all five responses, resulting in $\mathrm{N}=827$. As an example of one question represented by the scale, see Figure 16, which reports responses for "your concern about climate change."

Figure 16: One variable of 5 used in Scale of Climate Concern

\section{Question: Your concern about climate change}
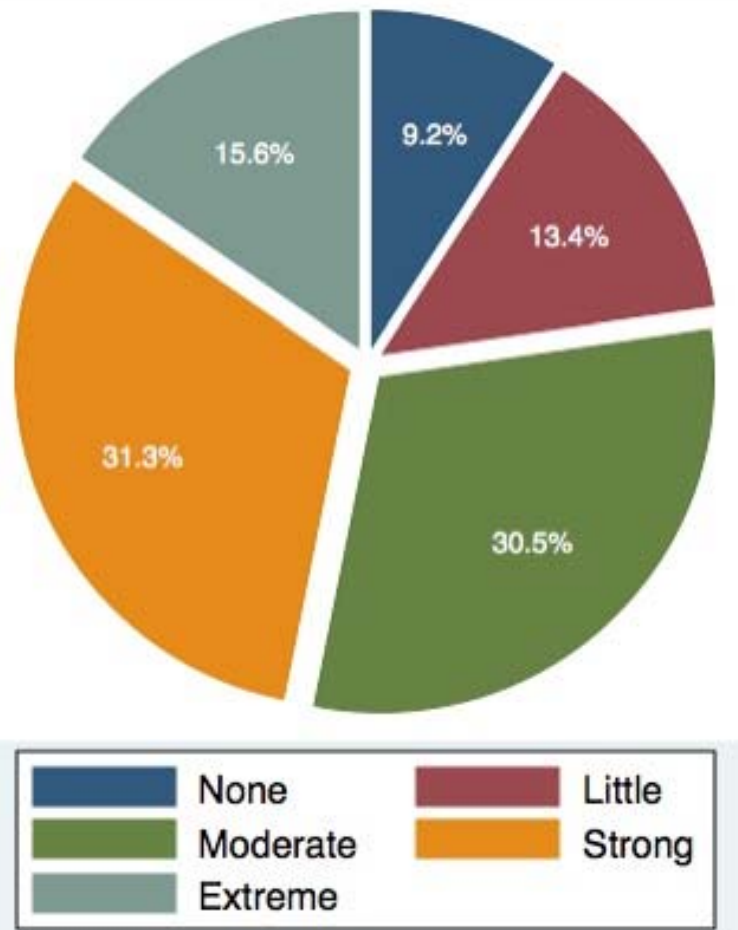

Factor analysis tests reliability by assessing the correlation of the scale items, and Climate Concern displayed strong reliability with the desired single factor. All five items scored above 0.8 , well above a basic standard of 0.4 (Acock 2012). An orthogonal 
rotation confirms this reliability with loading scores on factor 1 above the standard of 0.4 . Crombach's alpha, a test of both validity and reliability, registers at 0.93 , well above the standard of 0.8 .

The same tests were conducted for the Coral Concern scale, which combines seven responses on a five-point Likert scale that ranged from "strongly disagree" to "strongly agree" (see Appendix 6). No scores registered at the minimum of 7, and they ranged from 9 to the maximum of 35 , with $\mathrm{N}=816$. An example variable is reported in Figure 17; note that the combination of "Agree" and "Strongly Agree" is 64\%.

Figure 17: One variable of 7 used in Scale of Coral Concern

\section{Question: All coral reefs in Florida should be protected.}

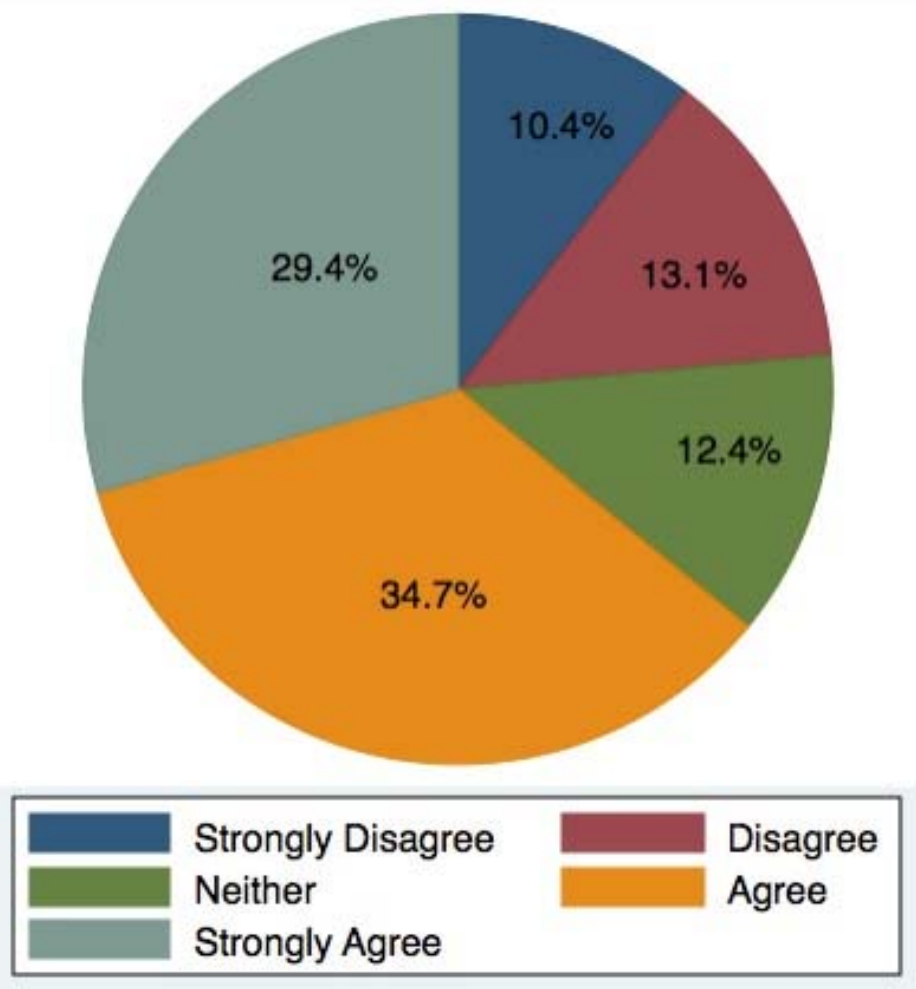


On single factor analysis, six of the seven question items scored above 0.5 , with the first item scoring 0.2 , below the standard of 0.4 . Orthogonal rotation on factor 1 produced four scores above the 0.4 standard, with the first item scoring the lowest. With all seven items, the Crombach's alpha score is 0.8 . When the scale was tested without the first item, scores showed little improvement; therefore, all items were retained.

Respondents demonstrated comparable concern for global climate change as for Florida's local coral reefs, albeit with more apparent variation within the scale for climate change (see Figure 18). The two scales and other variables related to these concepts are summarized in Table 11.

Other variables relate to these two concepts, but the six variables in Table 11 capture the trend that the majority of respondents have high and comparable levels of concern for both climate change and coral reefs. Modes tend towards the maximum, meaning that large percentages of respondents cluster around extreme concern. For example, $33 \%$ chose the maximum ("extremely destructive") for the threat from high water temperature to mainland reefs. Scores were comparable but slightly lower for a parallel question contained within the Climate Concern scale about how rising temperatures are affecting all reefs.

As for the question about when climate change impacts will arrive in Florida, the percent answering "now" is 55.7 (see Figure 19). 
Figure 18: Scales of Climate Concern and Coral Concern
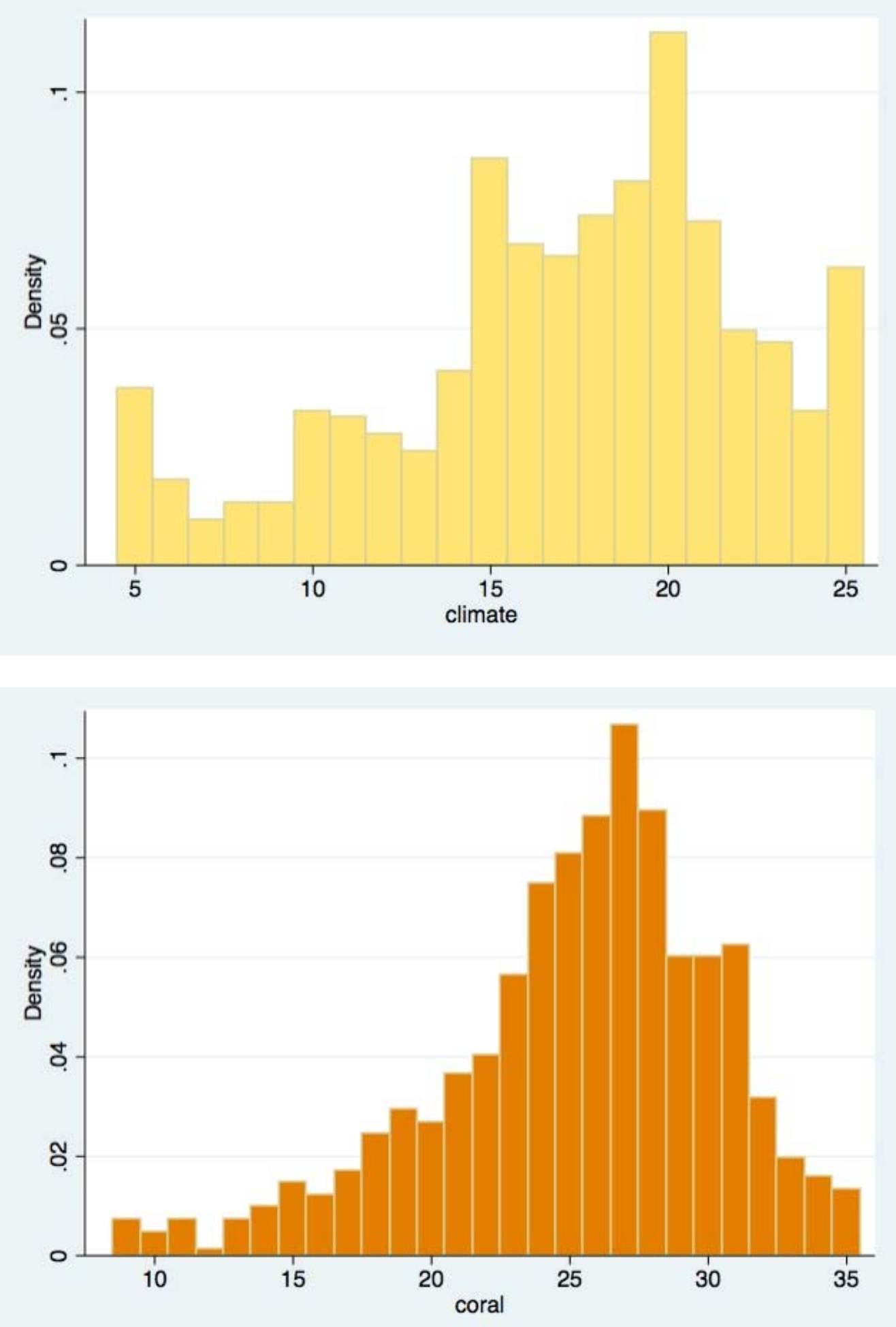
Table 11: Scales and Related Variables for Climate Change and Coral Reefs

\begin{tabular}{|l|l|l|l|l|l|l|l|}
\hline & N & Min & Max & Mean & St. Dev. & Mode \\
\hline \multicolumn{7}{|c|}{ Climate Change Variables } \\
\hline $\begin{array}{l}\text { 1. Climate Concern } \\
\text { Scale }\end{array}$ & 827 & 5 & 25 & 17.13785 & 5.121323 & 20 \\
\hline $\begin{array}{l}\text { 2. Climate Change } \\
\text { Arrives in Florida }\end{array}$ & 824 & 1 & 6 & 4.724515 & 1.752091 & 6 \\
\hline $\begin{array}{l}\text { 3. Threat [to reefs] } \\
\text { from High Water } \\
\text { Temperature }\end{array}$ & 1027 & 1 & 5 & 3.68 & 1.216274 & 5 \\
\hline $\begin{array}{l}\mid 7 \\
\text { 1. Coral Reef } \\
\text { Concern Scale }\end{array}$ & 816 & 9 & 35 & 25.30392 & 5.104146 & 27 \\
\hline $\begin{array}{l}\text { 2. Rate Health of } \\
\text { World Reefs }\end{array}$ & 943 & 1 & 5 & 3.552492 & .9867227 & 4 \\
\hline $\begin{array}{l}\text { 3. Rating of Reefs in } \\
\text { Mainland Florida }\end{array}$ & 936 & 1 & 5 & 3.202991 & .8892896 & 3 \\
\hline
\end{tabular}

Figure 19: Arrival of Climate Change Impacts

Question: When do you think climate change will start to have an impact in Florida?

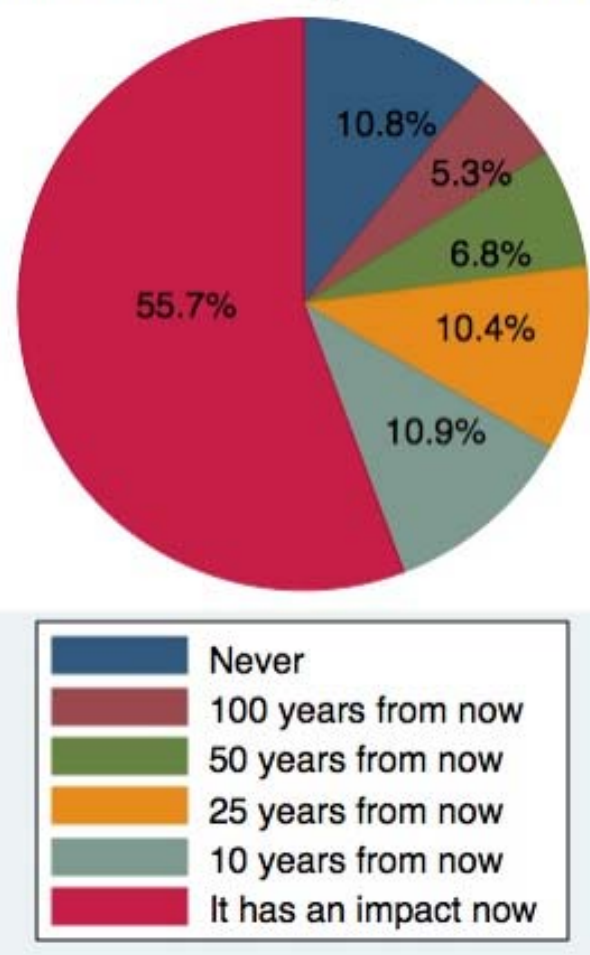




\subsection{Coral Reef Ratings and Threats}

As for the quality of mainland reefs, only $20.5 \%$ rated them above average, and $36.8 \%$ rated them below average (Figure 20 ).

In comparison, the health of reefs worldwide received more divergent and somewhat worse ratings. Even though it had a similar mean of 3.6 in comparison to the mainland reef's mean of 3.2 (higher indicating worse condition), the mode for reefs worldwide was 4, indicating "poor," and a larger percentage ranked them "terrible" as compared to Florida's mainland reefs.

\section{Figure 20: Rating of Mainland Reefs in Florida}

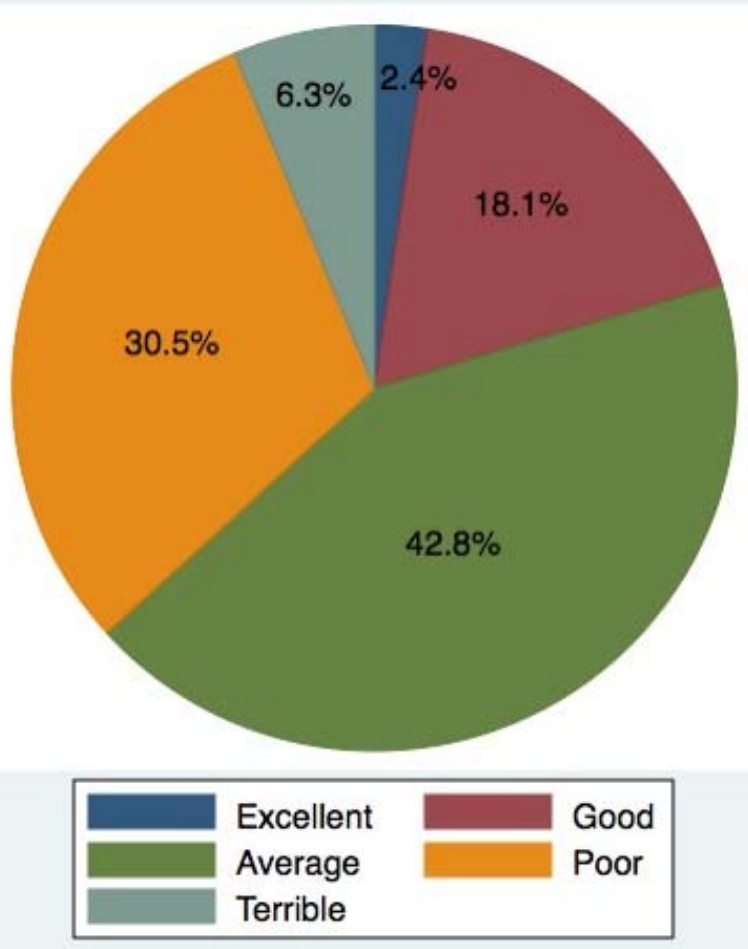


Additional variables assessed the perception of threats to coral reefs in Florida.

Figure 21 shows how respondents ranked the nine threats offered. Sewage \& Runoff ranks as the worst threat, and Scuba Diving \& Snorkeling ranks as the least threatening.

Figure 21: Ranked Threats to Florida's Coral Reefs

Note: Mean shown of scale of 1 (minimally destructive) to 5 (extremely destructive)

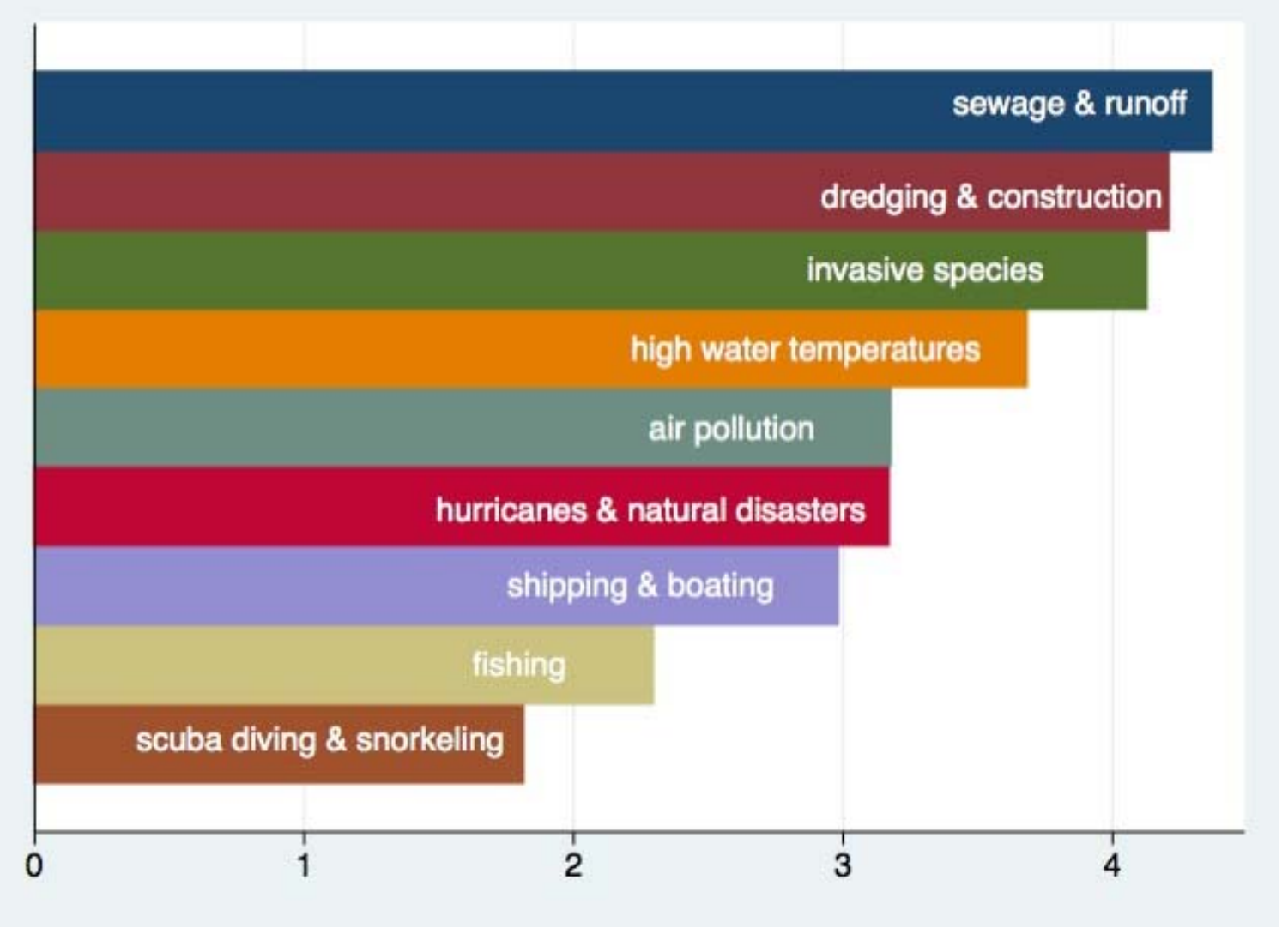

In the ranking of resources in relation to a map of the mainland region, the order from worst to best was: canals, coral reefs, wetlands, drinking water, beaches, and 
seafood. The means of these rankings had a small range from 2.5 to 3.3 , placing most of them close to "average."

As for information sources about coral reefs in Florida, the most popular choice was "Personal Experience." This choice was followed in order by: Scientific Literature, Magazines, Newspapers (print or online), Television, Email, Social Media, and Radio. In this regard, electronic media trails print media, and print media yields to direct experience. The prominence of Scientific Literature is curious, and it requires further investigation to clarify respondents' understanding of that term.

\subsection{Willingness To Pay}

How willing are stakeholders to pay for sustainability? Strong majorities express a willingness to pay in the three assessed scenario topics of seafood, management plans, and research funds (see Table 12). The highest WTP percentage is for management plans, where greater than $91 \%$ chose a plan with an associated fee. The lowest WTP percentage is for the first item tested, sustainable seafood, at $64.6 \%$, followed closely by the first research fund, at $65.6 \%$.

To calculate an average WTP amount per person, the percent favorable for each offer was multiplied by the offer amount, yielding a gross amount per offer, and those results were averaged. A slightly different average could be found by taking the average offer and multiplying by the total percent favorable. Average offers are presented in Table 12 for the sake of comparison. 
Table 12: Summary of Willingness to Pay (WTP) Scenarios

\begin{tabular}{|l|l|l|l|}
\hline & $\begin{array}{l}\text { Favorable } \\
\text { WTP }\end{array}$ & $\begin{array}{l}\text { Average WTP, } \\
\text { Per Person }\end{array}$ & Average Offer \\
\hline Sustainable Seafood & $64.6 \%$ & $\$ 3.40$ per week & $\$ 5.40$ \\
\hline Local Seafood & $80.5 \%$ & $\$ 2.18$ per week & $\$ 2.70$ \\
\hline Management Plan Choices & $91.1 \%$ & $\$ 6.11$ per month & $\$ 11.05$ \\
\hline Research Fund1 & $65.6 \%$ & $0.62 \%$ tax & $1.0 \%$ \\
\hline Research Fund2 (matched) & $73.2 \%$ & $0.70 \%$ tax & $1.0 \%$ \\
\hline
\end{tabular}

Combining the two seafood sub-scenarios creates a weekly WTP of $\$ 5.58$. Because Management Choice 1 and Management Choice 2 had the same favorable percentages of $91 \%$, they are reported in combination and result in a monthly WTP of $\$ 6.11$. A summary of favorability for the WTP outcome variables is displayed in Figure 22. The order corresponds to the order of the questions.

\section{Figure 22: Favorable Willingness to Pay}

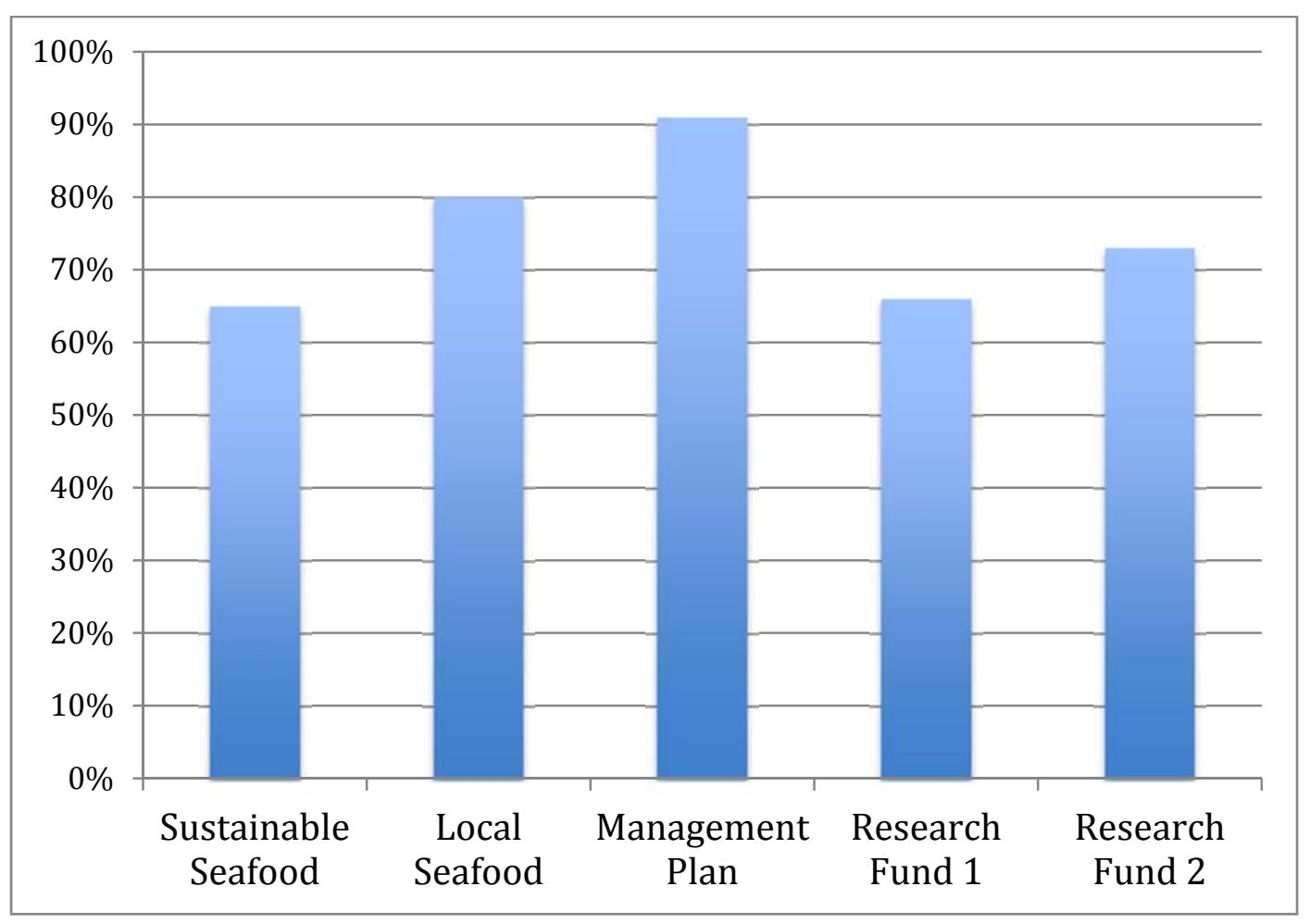


The two management choice questions had equivalent favorable levels of $91 \%$, and they are reported in combination. For the other two scenarios, when the two WTP questions per scenario are considered in combination, average WTP rises. For seafood, only $15 \%$ rejected both offers, meaning that $85 \%$ chose to pay for at least one offer. For the research fund taxes, the favorable percentage for at least one offer was $76 \%$. In combination, the three scenarios result in willingness to pay of $85 \%, 91 \%$, and $76 \%$.

\subsection{Seafood Preferences}

A series of eight seafood-related questions averaged more than 1,000 respondents per question, and more than $97 \%$ of respondents were eligible to answer them because they consume seafood. The financial framework employed for these questions was a weekly seafood budget, and a question about household spending registered a mean at greater than $\$ 30$ per week.

The premiums or offers for the sustainable and local seafood questions were matched so that every respondent saw a local seafood offer (second question) that equaled half of the sustainable seafood offer. For sustainable seafood, favorable responses ranged from $58.6 \%$ at the $\$ 10$ offer to $72.3 \%$ at the $\$ 2$ offer. For local seafood, $77.2 \%$ chose the $\$ 5$ offer, and $83.1 \%$ chose the $\$ 1$ offer. Figure 23 shows the responses per offer.

In Table 13, regarding seafood choices and education, education levels are aggregated into three categories instead of the six offered, because "less than high school" had only 5 respondents, and they had much higher WTP than "high school." The 
category of "4-year college" had higher WTP than "Masters" in both cases. Presented in the three categories, WTP for local seafood appears to rise with education, but it is not significant.

\section{Table 13: Seafood Choices and Education}

\begin{tabular}{|l|l|l|}
\hline Education & Sustainable WTP & Local WTP \\
\hline High School or less & $63.1 \%$ & $75.4 \%$ \\
\hline College & $68.7 \%$ & $82.6 \%$ \\
\hline Masters or more & $66.2 \%$ & $83.2 \%$ \\
\hline Mean & $64.7 \%$ & $80.5 \%$ \\
\hline Pearson Chi2 & $\begin{array}{l}\text { chi2(2)=1.5425 } \\
\operatorname{Pr}=0.462\end{array}$ & $\begin{array}{l}\text { chi2(2) }=3.9577 \\
\operatorname{Pr}=0.138\end{array}$ \\
\hline
\end{tabular}

Figure 23: Seafood Responses and Offers*

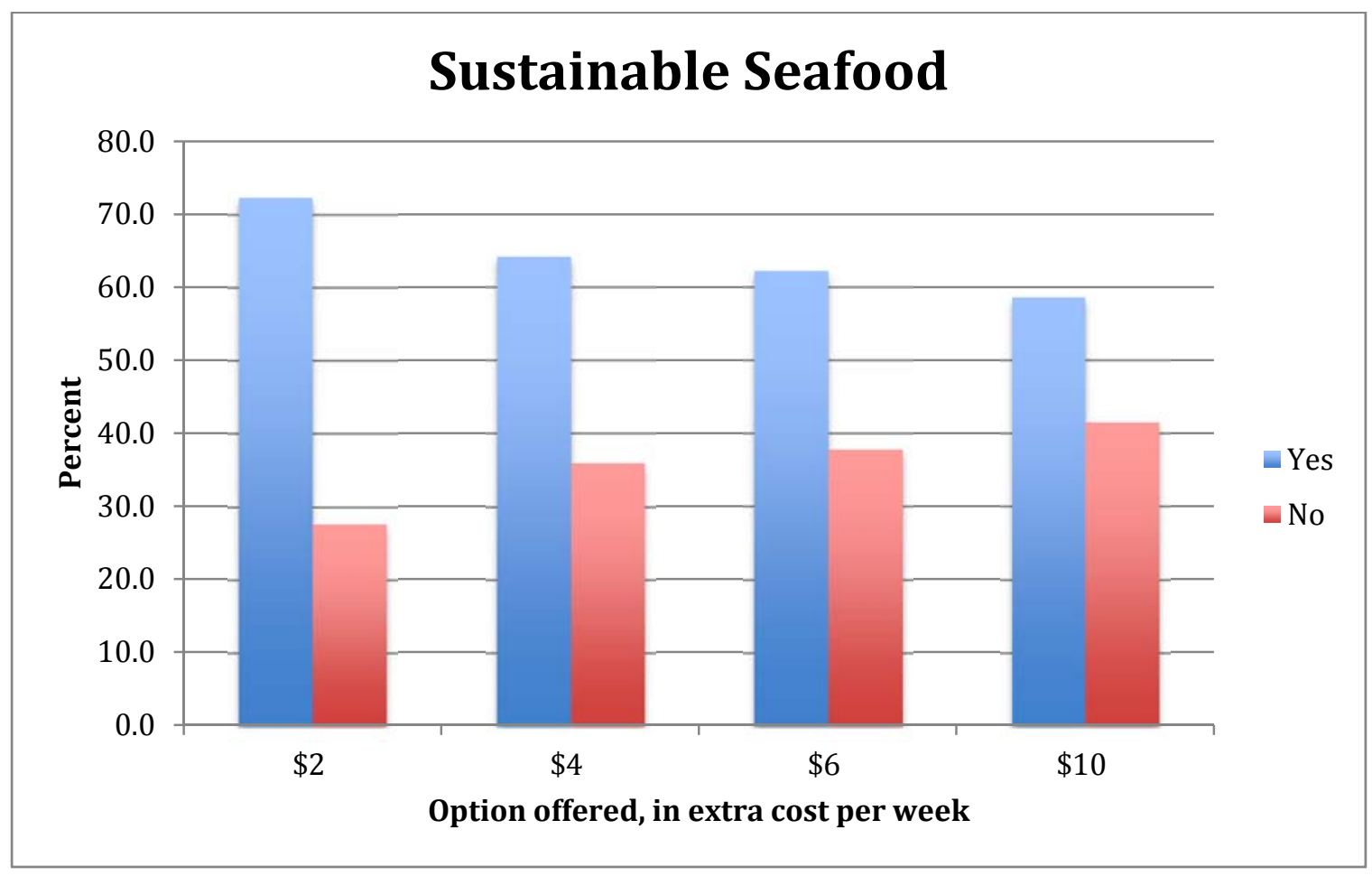




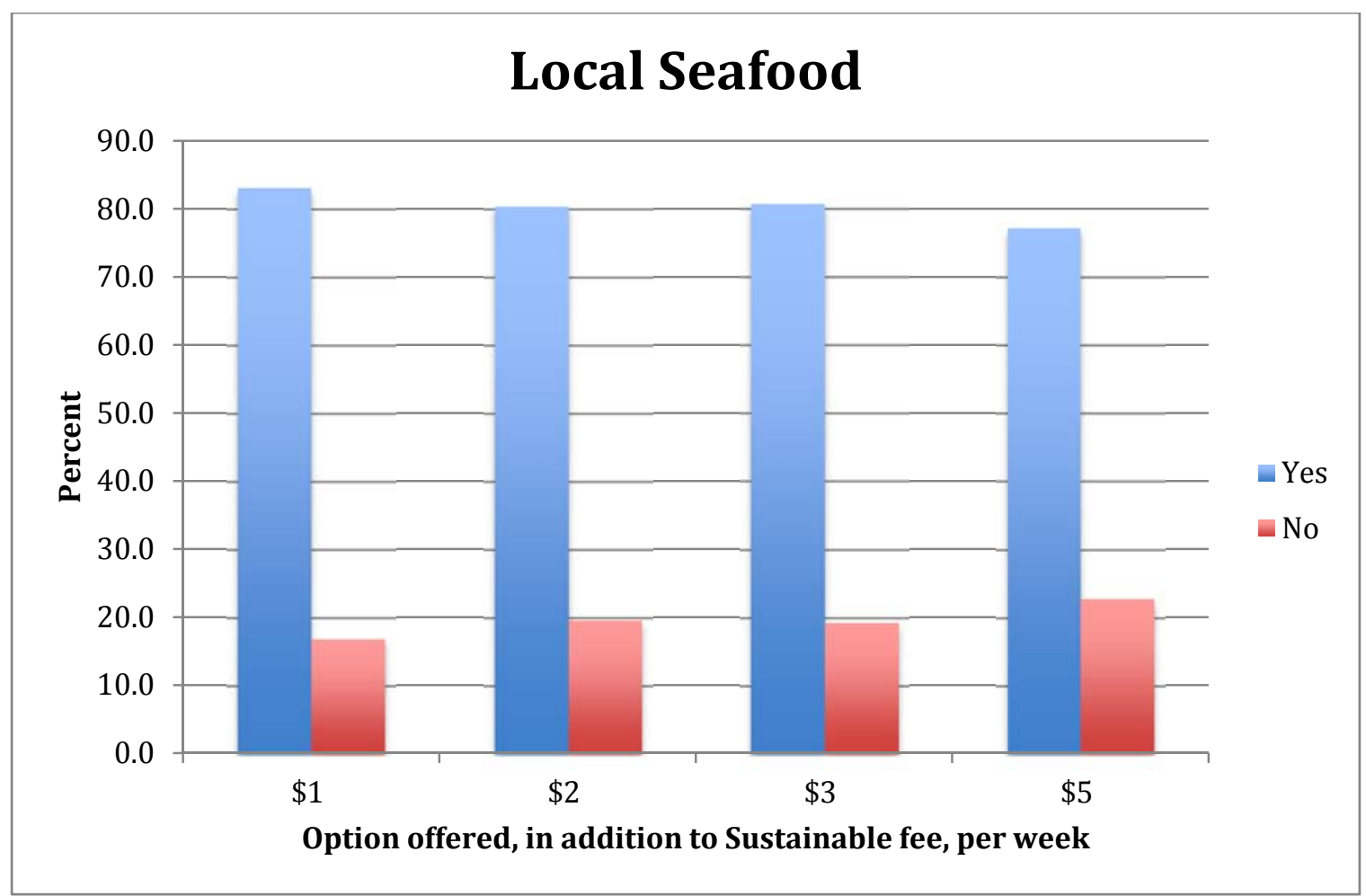

*Note: An error in online programming resulted in the removal of the penultimate offer, and additional data is being collected to address this gap.

Many respondents chose similarly for the sustainable and local seafood questions, with 93.1\% maintaining their affirmative answer for both. The question for sustainable seafood generated significant differences based on the offer (Pearson chi2 $(3)=12.1968$, $\operatorname{Pr}=0.007)$; but the differences by offer were not significant for local seafood.

Differences by income are presented in Figure 24. 
Figure 24: Seafood WTP Based on Income
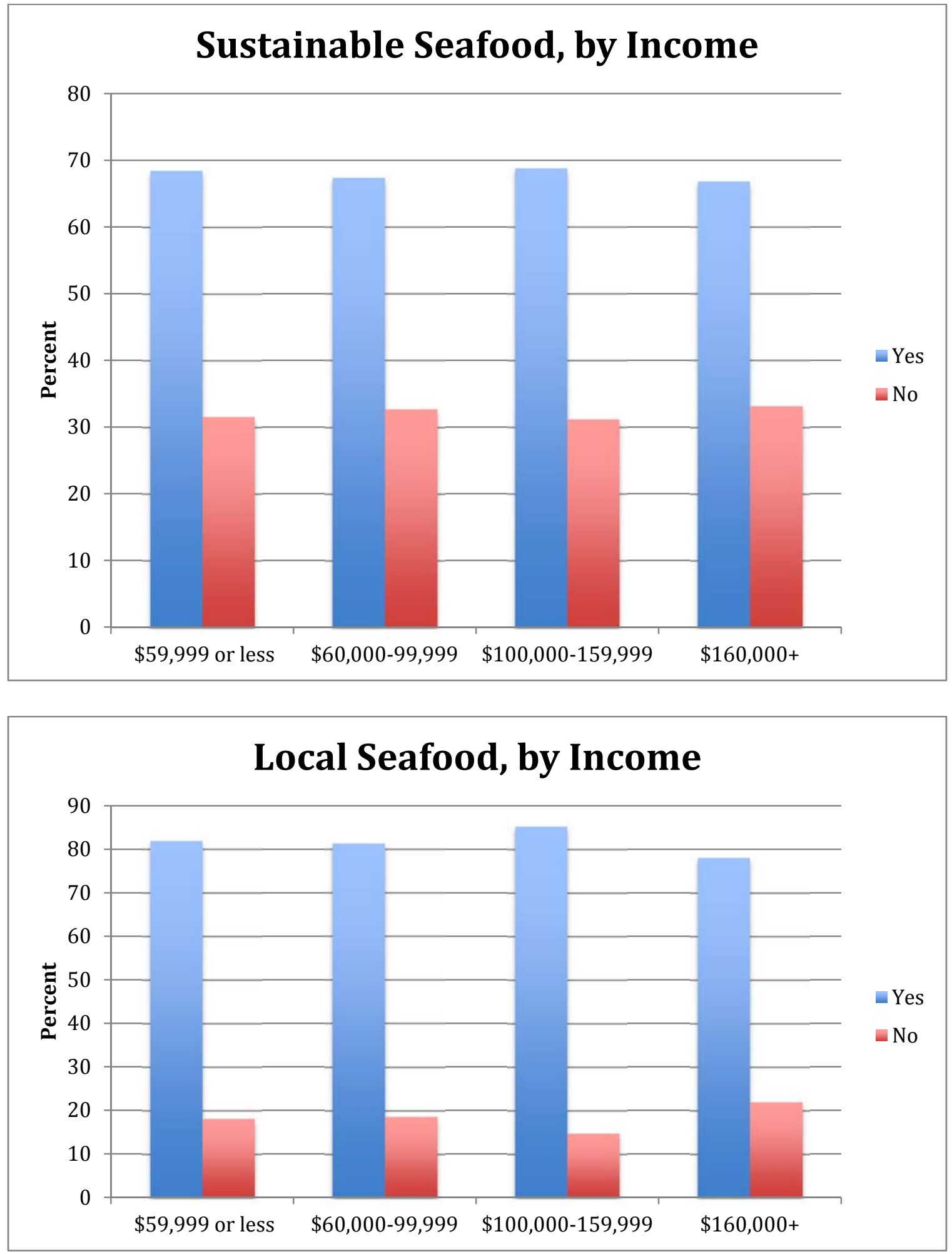


\subsection{Regression Analysis for Seafood}

Regressions were built from a parsimonious model to the extended model, and

they employed the two described scales of Climate Concern and Coral Concern instead of their sub-variables. The variable of Income did not prove significant; however, a proxy variable of Seafood Budget was significant in the expected direction. The two variables of Income and Seafood Budget are highly correlated $[\mathrm{r}=0.3$; chi2(100, $\mathrm{N}=702)=155.6524 ; \operatorname{Pr}=0.000]$.

For the sake of efficiency in regards to the two seafood scenarios, presented below is a table of the models followed directly by a table of diagnostics. The variable names are abbreviations as used in Stata, and these can be referenced in the summary of main variables in Table 10 or in Appendix 6.

For the choice of sustainable seafood, eight explanatory variables have significant differences at the 5\% level or higher. Age is the only variable in the negative direction besides the offer, meaning that as age increases, respondents are less likely to pay the premium for sustainable seafood. This significant, negative relationship remains consistent across various outcomes.

\subsubsection{Diagnostics for Seafood Regressions}

The diagnostics show that a high percentage of observations are correctly classified; however, for models 1 and 2, the report of significance for the Pearson chi2 
means that those models may be deficient. The Hosmer-Lemeshow statistic shows that the model is likely valid, because they pass that test of being non-significant.

Using the collinearity diagnostics command in Stata "collin," none of the variables has a high variance inflation factor, and multicollinearity does not appear to be problematic. The potential for outliers deserves further investigation; however, reviews of boxplots for the variables in the regression reveal few outliers. 
Table 14: Logit Models for Sustainable Seafood

\begin{tabular}{|c|c|c|c|c|}
\hline & \multicolumn{2}{|c|}{ model $1, \mathrm{~N}=655$} & \multicolumn{2}{|c|}{ model $2, \mathrm{~N}=642$} \\
\hline Variables & Coef. & $\mathrm{P}>|\mathrm{z}|$ & Coef. & $\mathrm{P}>|\mathrm{z}|$ \\
\hline foodoffer1 & -0.0780 & $0.018 * *$ & -0.0843 & $0.016^{* *}$ \\
\hline foodbudget & 0.1264 & $0.004 * * *$ & 0.1353 & $0.003 * * *$ \\
\hline inc & 0.0224 & 0.517 & --- & -- \\
\hline foodtrust & 0.2311 & $0.000 * * *$ & 0.2344 & $0.000 * * *$ \\
\hline age & -0.0335 & $0.000 * * *$ & -0.0395 & $0.000 * * *$ \\
\hline enviro & 0.1334 & $0.003 * * *$ & 0.0948 & $0.044 * *$ \\
\hline climate & 0.0495 & $0.035 * *$ & 0.0354 & 0.170 \\
\hline coral & 0.1028 & $0.000 * * *$ & 0.0902 & $0.000 * * *$ \\
\hline visit & 0.2114 & $0.011 * *$ & 0.2620 & $0.004 * * *$ \\
\hline Constant & -4.6085 & $0.000 * * *$ & --- & --- \\
\hline foodcert & & & 0.0581 & 0.226 \\
\hline incsq & & & 0.0013 & 0.615 \\
\hline edu & & & 0.0348 & 0.704 \\
\hline recboat & & & -0.2487 & $0.007 * * *$ \\
\hline efirst & & & 0.4347 & $0.08^{*}$ \\
\hline donor & & & 0.4195 & $0.061 *$ \\
\hline born US & & & 0.4572 & $0.056^{*}$ \\
\hline born foreign & & & 0.2725 & 0.445 \\
\hline Constant & & & -4.6310 & $0.000 * * *$ \\
\hline
\end{tabular}

Note: p values $*, * *, * * *$ denote $10 \%, 5 \%$, and $1 \%$ levels of significance respectively.

Table 15: Diagnostics for Regression on Sustainable Seafood

\begin{tabular}{|l|l|l|l|l|}
\hline Statistic & Model 1 & & Model 2 & \\
\hline $\begin{array}{l}\text { N covariate } \\
\text { patterns, or } \\
\text { groups }\end{array}$ & 655 & 10 & 642 & 10 \\
\hline $\begin{array}{l}\text { Chi-squared } \\
\text { test }\end{array}$ & $\begin{array}{l}\text { Pearson } \\
\text { chi2(645) } \\
=710.51\end{array}$ & $\begin{array}{l}\text { Hosmer- } \\
\text { Lemeshow } \\
\text { chi2(8)=4.11 }\end{array}$ & $\begin{array}{l}\text { Pearson } \\
\text { chi2(625) } \\
726.12\end{array}$ & $\begin{array}{l}\text { Hosmer- } \\
\text { Lemeshow } \\
\text { chi2(8) } \\
10.53\end{array}$ \\
\hline Prob>chi2 & 0.0372 & 0.8471 & 0.0031 & 0.2299 \\
\hline $\begin{array}{l}\text { Correctly } \\
\text { classified }\end{array}$ & $77.56 \%$ & --- & $79.28 \%$ & --- \\
\hline
\end{tabular}


Table 16: Logit Models for Local Seafood

\begin{tabular}{|c|c|c|c|c|}
\hline & \multicolumn{2}{|c|}{ model $3, \mathrm{~N}=654$} & \multicolumn{2}{|c|}{ model $4, \mathrm{~N}=675$} \\
\hline Variables & Coef. & $\mathrm{P}>|\mathrm{z}|$ & Coef. & $\mathrm{P}>|\mathrm{z}|$ \\
\hline foodoffer2 & -0.1390 & $0.071 *$ & -0.1471 & $0.059 *$ \\
\hline foodbudget & 0.0875 & $0.040 * *$ & 0.1122 & $0.008 * * *$ \\
\hline inc & -0.0027 & 0.948 & --- & --- \\
\hline foodtrust & 0.3203 & $0.000 * * *$ & 0.3131 & $0.000 * * *$ \\
\hline age & -0.0180 & $0.079 *$ & -0.0195 & $0.0700^{*}$ \\
\hline enviro & 0.0246 & 0.655 & --- & --- \\
\hline climate & 0.0754 & $0.010 * * *$ & 0.0925 & $0.001 * * *$ \\
\hline coral & 0.0276 & 0.321 & --- & --- \\
\hline visit & 0.3530 & $0.000 * * *$ & 0.3064 & $0.003 * * *$ \\
\hline Constant & -3.2788 & $0.001 * * *$ & --- & --- \\
\hline recboat & & & -0.1703 & 0.11 \\
\hline incsq & & & -0.0015 & 0.612 \\
\hline edu & & & 0.1379 & 0.214 \\
\hline sex & & & -0.4778 & 0.176 \\
\hline born US & & & 0.1469 & 0.608 \\
\hline born foreign & & & -0.7828 & $0.045 * *$ \\
\hline Constant & & & -2.3872 & $0.017 * *$ \\
\hline
\end{tabular}

Note: $\mathrm{p}$ values $* * *, * * *$ denote $10 \%, 5 \%$, and $1 \%$ levels of significance respectively.

Table 17: Diagnostics for Regression on Local Seafood

\begin{tabular}{|l|l|l|l|l|}
\hline Statistic & Model 3 & 10 & Model 4 \\
\hline $\begin{array}{l}\text { N covariate } \\
\text { patterns, or } \\
\text { groups }\end{array}$ & 654 & 675 & 10 \\
\hline $\begin{array}{l}\text { Chi-squared } \\
\text { test }\end{array}$ & $\begin{array}{l}\text { Pearson } \\
\text { chi2(644) }\end{array}$ & $\begin{array}{l}\text { Hosmer- } \\
\text { Lemeshow } \\
\text { chi2(8) } \\
6.28\end{array}$ & $\begin{array}{l}\text { Pearson } \\
\text { chi2(661) } \\
676.34\end{array}$ & $\begin{array}{l}\text { Hosmer- } \\
\text { Lemeshow } \\
\text { chi2(8) } \\
5.03\end{array}$ \\
\hline Prob $>$ chi2 & 695.82 & 0.6155 & 0.3311 & 0.7545 \\
\hline $\begin{array}{l}\text { Correctly } \\
\text { classified }\end{array}$ & 0.0770 & --- & $84.59 \%$ & -- \\
\hline
\end{tabular}




\subsection{Management Choice Preferences}

From a total set of twenty cards, each respondent was shown two choice cards, and the total number of responses recorded was 1,708 . The first set of ten cards earned 861 responses, and the second set earned 847 responses.

As a reminder, Plan B tended to have more favorable attributes than Plan A, except for water quality. With such biases, it is noteworthy that Plan A was selected much more often than the other two plans (see Figure 25):

- Plan A: 931

- Plan B: 625

- Plan C: 152

Figure 25: Preference for Plans

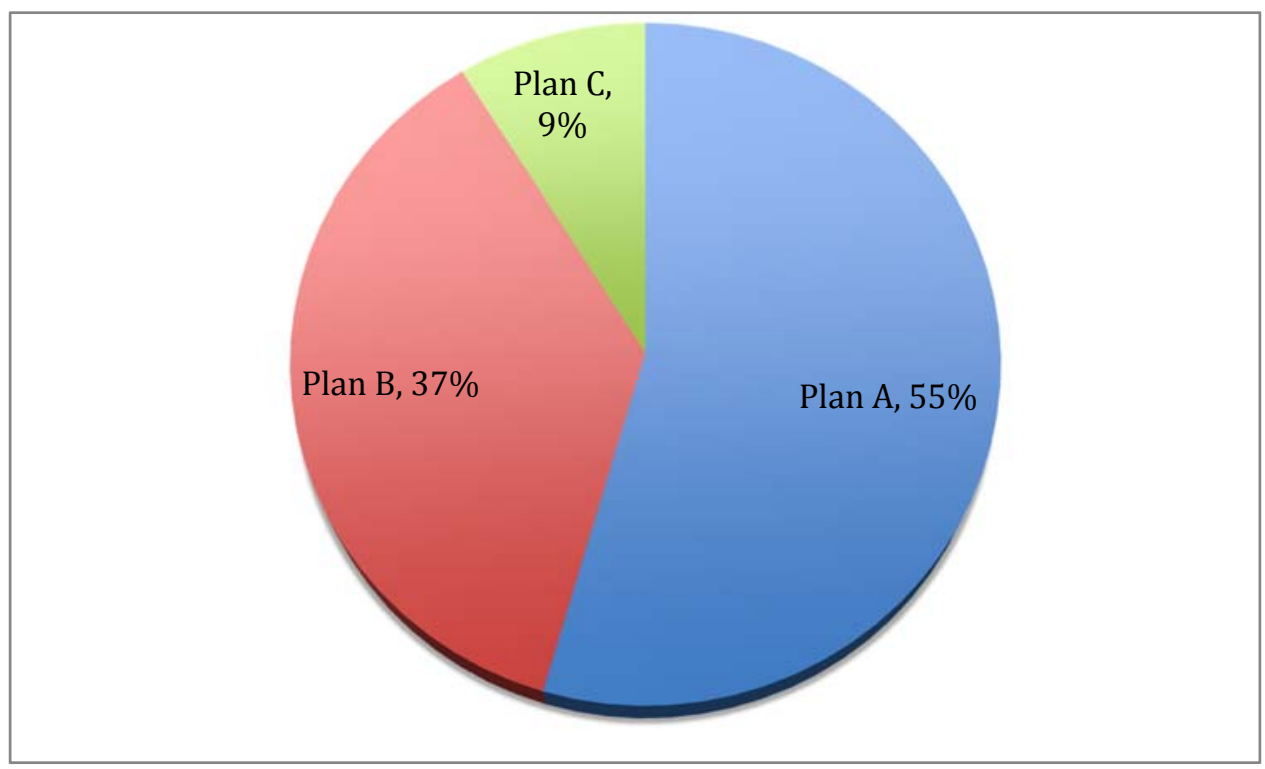

Respondents were asked to rank the four attributes within the management plans, and results appear in order in Table 18. 
Table 18: Importance of Attributes

Question: In choosing Plan A, B or C, how important were the following items to you?

\begin{tabular}{|l|l|l|l|l|l|}
\hline Attribute & $\mathrm{N}$ & Min & Max & Mean & Std. Dev. \\
\hline Water Quality & 834 & 1 & 5 & 4.414868 & .9196114 \\
\hline Coral Restoration & 834 & 1 & 5 & 4.374101 & .9783249 \\
\hline Monthly Fee & 834 & 1 & 5 & 3.079137 & 1.459652 \\
\hline Beach Size & 834 & 1 & 5 & 2.730216 & 1.261822 \\
\hline
\end{tabular}

The fee ranked as a less important attribute than Water Quality and Coral Restoration.

Responses by fee are summarized in Figure 26. The two fee levels favored by a majority were $\$ 10$ and $\$ 15$.

Figure 26: Management Plan Responses based on Fee Offered

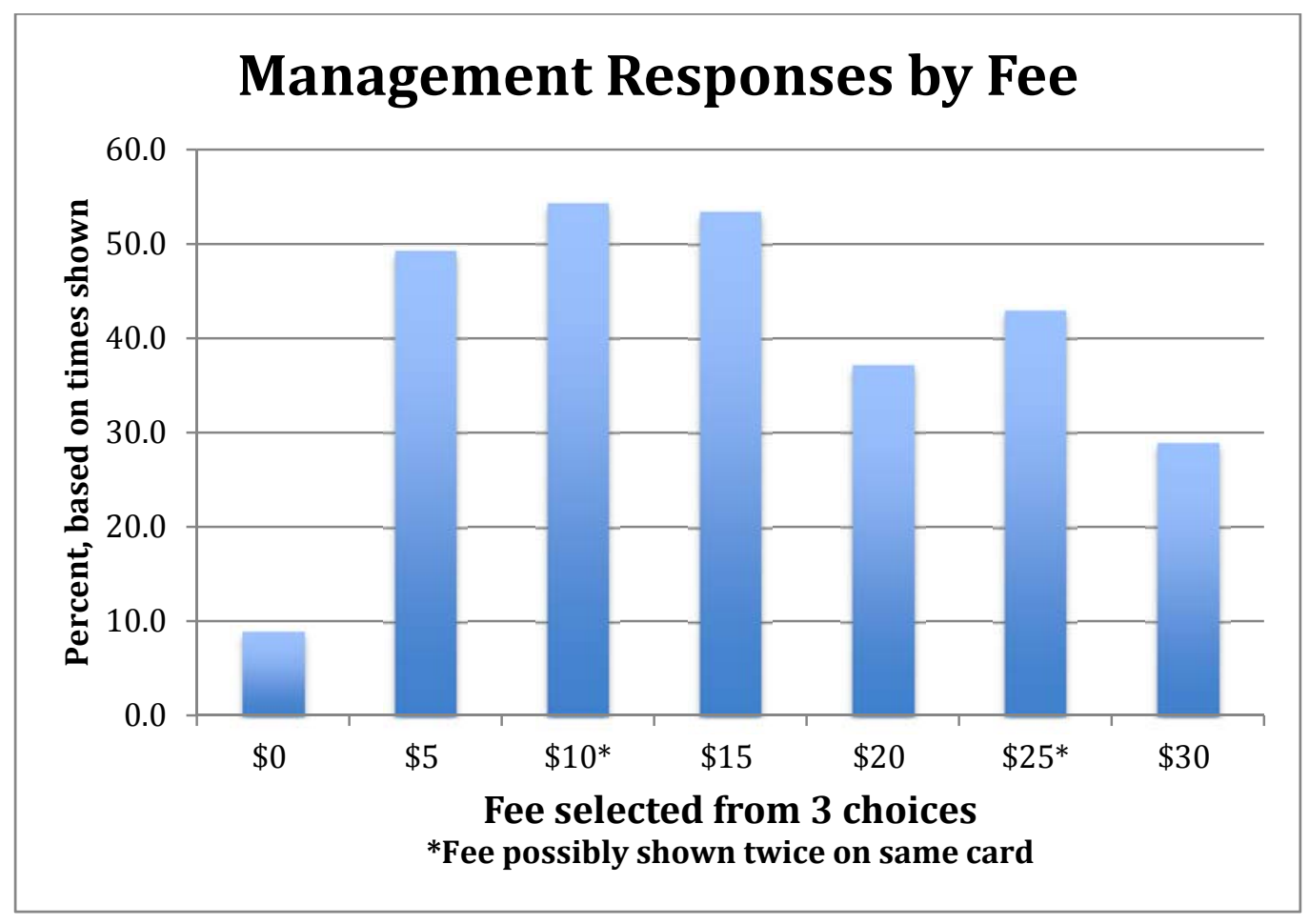


Based on political orientation, the $\$ 0$ fee status quo plan was selected by 3 Democrats and by 36 Republicans, and it was favored by Independents and Independents/lean Republican but not by Independents/lean Democrat. The $\$ 30$ highest fee was selected by 24 Democrats and 17 Republicans, and the other fees show a relatively even distribution by political orientation.

For respondents choosing the $\$ 0$ fee status quo plan, they were more likely to believe that climate change will never affect Florida ( 57 respondents) versus those who believe that climate change is affecting Florida now (40 respondents). Table 19 summarizes choices made at the fee levels of $\$ 0, \$ 10$, and $\$ 30$.

Table 19: Management Plan Choices by Variables Revealing Environmental Concern

\begin{tabular}{|l|l|l|l|l|}
\hline Variable & $\begin{array}{l}\text { Chose \$0 } \\
\text { Fee Plan }\end{array}$ & $\begin{array}{l}\text { Chose \$10 } \\
\text { Fee Plan }\end{array}$ & $\begin{array}{l}\text { Chose \$30 } \\
\text { Fee Plan }\end{array}$ & $\begin{array}{l}\text { Total \$10 + } \\
\text { \$30 Fee }\end{array}$ \\
\hline \multicolumn{4}{|c|}{ Lesser Environmental Concern } \\
\hline Republican & 36 & 67 & 17 & 84 \\
\hline Climate Change is Never & 57 & 28 & 7 & 35 \\
\hline Climate Concern<10 & 60 & 18 & 4 & 22 \\
\hline Coral Concern<20 & 73 & 37 & 7 & 44 \\
\hline Prioritize Economy & 87 & 78 & 23 & 101 \\
\hline Subtotal & 313 & \multicolumn{3}{|l|}{} \\
\hline \multicolumn{5}{|l|}{ Greater Environmental Concern } \\
\hline Democrat & 3 & 69 & 24 & 286 \\
\hline Climate Change is Now & 40 & 212 & 69 & 281 \\
\hline Climate Concern>10 & 79 & 349 & 116 & 465 \\
\hline Coral Concern>20 & 64 & 327 & 112 & 439 \\
\hline Prioritize Environment & 45 & 278 & 92 & 370 \\
\hline Subtotal & 231 & & 1648 \\
\hline
\end{tabular}


The variables in Table 19 listed under Lesser Environmental Concern show a lesser willingness to pay, and Great Environmental Concern variables show a greater willingness to pay. Those with Lesser Environmental Concern are more likely to choose the $\$ 0$ fee, and they are several times less likely to choose a plan with either the $\$ 10$ or $\$ 30$ fee (286 versus 1648). Choices are polarized based on the variables for climate change's proximity, the scales for concern for climate change and for coral reefs, and the prioritization of either the economy or the environment.

When asked a follow-up question about who should pay for the management of Florida's reefs, respondents favored citizen-based assessments instead of user fees (see Figure 27).

Figure 27: Who Should Pay?

\section{Responsibility to Pay}

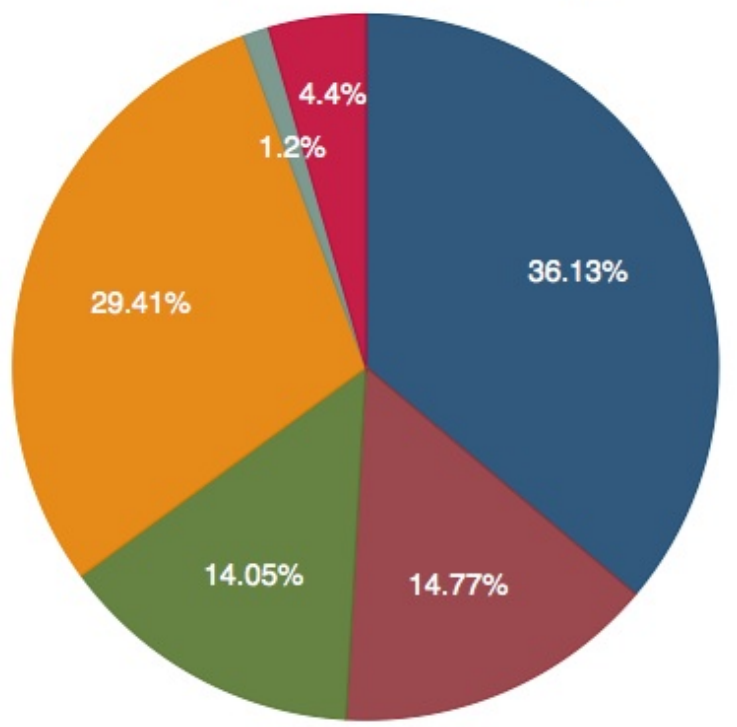

\begin{tabular}{|l|l|}
\hline All U.S. citizens & Tourists \\
\hline Users of Reefs & Residents of Florida \\
No one & Don't know \\
\hline
\end{tabular}

Who should be primarily reponsible to pay for the management and protection of Florida's coral reefs? 
In combination, "All U.S. Citizens" and "Residents of Florida" are favored by $66 \%$.

\subsection{Research Funding Preferences}

The method of analysis for the Research Fund scenarios was similar to the Seafood scenarios, and they are reported in a similar manner. See Figure 28 for associations with income. Recall that the first question about a tax, or Fund1, did not include matching funds, and the second question about a tax, Fund2, was explicit about including matching funds from the federal agency NOAA.

In the regressions reported below, neither income nor education proved to be significant, whereas variables related to environmental orientation proved to be influential.

\subsubsection{Regression Analysis for Research Funding}

For Research Fund1, six variables are significant at the 1\% level and one variable is significant at the 5\% level. Unlike in the seafood regression, the variable of visitation to coral reefs is no longer significant.

Two extremely influential variables are identification as a Republican and prioritization of the environment over the economy. Political party identification was significant only for Republicans and positive for WTP in reference to the category "Other." Yet there is a negative correlation between Republican identity and WTP for both Research Fund1 and Fund2, and they are always less likely to pay than the 
Figure 28: Research Fund 1 and Fund 2, by Income
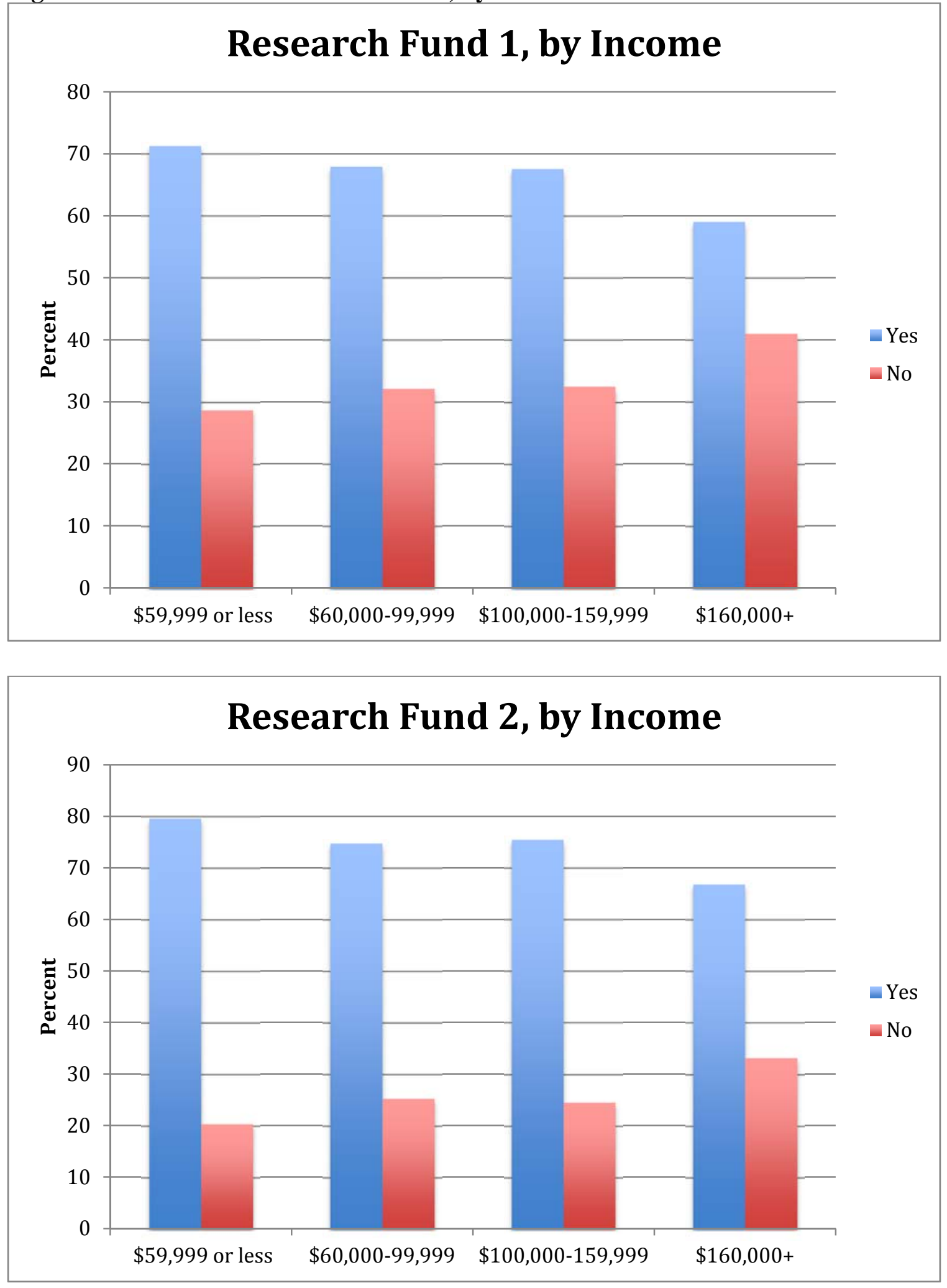
Table 20: Logit Models for Research Fund 1

\begin{tabular}{lrllc}
\multicolumn{3}{c}{ model 5, N=690 } & \multicolumn{3}{c}{ model 6, N=686 } \\
Variables & Coef. & \multicolumn{1}{c}{$\mathrm{P}>|\mathrm{z}|$} & Coef. & $\mathrm{P}>|\mathrm{z}|$ \\
taxoffer & -0.5922 & $0.000^{* * *}$ & -0.6587 & $0.000^{* * *}$ \\
inc & -0.0092 & 0.761 & -- & -- \\
coral & 0.0709 & $0.002^{* * *}$ & 0.0751 & $0.001^{* * *}$ \\
climate & 0.1072 & $0.000^{* * *}$ & 0.0973 & $0.000^{* * *}$ \\
age & -0.0261 & $0.001^{* * *}$ & -0.0155 & $0.063^{*}$ \\
republican & 0.8526 & $0.001^{* * *}$ & 1.0129 & $0.000^{* * *}$ \\
efirst & 0.8919 & $0.000^{* * *}$ & 0.8369 & $0.000^{* * *}$ \\
donor & 0.4565 & $0.032^{* *}$ & 0.3780 & 0.109 \\
visit & 0.0172 & 0.839 & -- & --- \\
Constant & -2.1990 & $0.008^{* * *}$ & -- & --- \\
incsq & & & -00009 & 0.970 \\
nonmotor boat & & & -0.7157 & $0.05^{* *}$ \\
motorboat & & & -0.0288 & 0.907 \\
edul & & & -0.1281 & 0.395 \\
flvisit & & & 0.9235 & $0.041^{* *}$ \\
recsurf & & & 0.3844 & $0.010^{* * *}$ \\
recsail & & & -0.3026 & $0.014^{* *}$ \\
tfish & & & 0.3368 & $0.003^{* * *}$ \\
tdredge & & & 0.1454 & 0.149 \\
Constant & & & -4.3559 & $0.000^{* * *}$ \\
& & & &
\end{tabular}

Table 21: Diagnostics for Regression on Research Fund 1

\begin{tabular}{|l|l|l|l|l|}
\hline Statistic & Model 5 & 10 & Model 6 & \\
\hline $\begin{array}{l}\text { N covariate } \\
\text { patterns, or } \\
\text { groups }\end{array}$ & 694 & 686 & 10 \\
\hline $\begin{array}{l}\text { Chi-squared } \\
\text { test }\end{array}$ & $\begin{array}{l}\text { Pearson } \\
\text { chi2(684) }\end{array}$ & $\begin{array}{l}\text { Hosmer- } \\
\text { Lemeshow } \\
\text { chi2(8) } \\
5.79\end{array}$ & $\begin{array}{l}\text { Pearson } \\
\text { chi2(669) } \\
682.26\end{array}$ & $\begin{array}{l}\text { Hosmer- } \\
\text { Lemeshow } \\
\text { chi2(8) } \\
3.94\end{array}$ \\
\hline Prob > chi2 & 0.3926 & 0.6703 & 0.3526 & 0.8621 \\
\hline $\begin{array}{l}\text { Correctly } \\
\text { classified }\end{array}$ & $74.78 \%$ & & $77.84 \%$ & \\
\hline
\end{tabular}


Table 22: Logit Models for Research Fund 2 (matched)

\begin{tabular}{lrlrc}
\multicolumn{1}{c}{ model 7, N=690 } & \multicolumn{3}{l}{ model $8, \mathrm{~N}=732$} \\
Variables & Coef. & $\mathrm{P}>|\mathrm{z}|$ & Coef. & $\mathrm{P}>|\mathrm{z}|$ \\
taxoffer & -0.8549 & $0.000^{* * *}$ & -0.8698 & $0.000^{* * *}$ \\
inc & -0.0305 & 0.372 & -- & --- \\
coral & 0.1056 & $0.000^{* * *}$ & 0.1084 & $0.000^{* * *}$ \\
climate & -0.0305 & $0.000^{* * *}$ & 0.1184 & $0.000^{* * *}$ \\
age & -0.0223 & $0.013^{* *}$ & -0.0051 & 0.609 \\
republican & 0.2960 & 0.264 & -- & --- \\
efirst & 0.4670 & $0.055^{*}$ & 0.3895 & 0.107 \\
donor & 0.7162 & $0.002^{* * *}$ & 0.5640 & $0.012^{* *}$ \\
visit & 0.0850 & 0.364 & -- & --- \\
Constant & -2.4813 & $0.008^{* * *}$ & & \\
incsq & & & 0.012 & 0.392 \\
born US & & & -0.4355 & $0.098^{*}$ \\
born foreign & & & -0.6535 & $0.08^{*}$ \\
non-motor & & & -0.9815 & $0.024 * *$ \\
motorboat & & & -0.3248 & 0.239 \\
edul & & & 0.0418 & 0.795 \\
recsurf & & & 0.2991 & $0.054^{*}$ \\
tdredge & & & 0.2507 & $0.009^{* * *}$ \\
Constant & & & -3.4700 & $0.000^{* * *}$
\end{tabular}

Table 23: Diagnostics for Regression on Research Fund 2

\begin{tabular}{|c|c|c|c|c|}
\hline Statistic & \multicolumn{2}{|l|}{ Model 7} & \multicolumn{2}{|l|}{ Model 8} \\
\hline $\begin{array}{l}\text { N covariate } \\
\text { patterns, or } \\
\text { groups }\end{array}$ & 689 & 10 & 732 & 10 \\
\hline $\begin{array}{l}\text { Chi-squared } \\
\text { test }\end{array}$ & $\begin{array}{l}\text { Pearson } \\
\text { chi2 }(679)= \\
669.34\end{array}$ & $\begin{array}{l}\text { Hosmer- } \\
\text { Lemeshow } \\
\text { chi2 }(8)= \\
5.38\end{array}$ & $\begin{array}{l}\text { Pearson } \\
\text { chi2 }(717)= \\
720.32\end{array}$ & $\begin{array}{l}\text { Hosmer- } \\
\text { Lemeshow } \\
\text { chi2 }(8)= \\
9.64\end{array}$ \\
\hline Prob $>$ chi2 & 0.5969 & 0.7166 & 0.4581 & 0.2916 \\
\hline $\begin{array}{l}\text { Correctly } \\
\text { classified }\end{array}$ & $81.71 \%$ & & $82.65 \%$ & \\
\hline
\end{tabular}


Democratic categories. A crosstab of political orientation and WTP for Research Fund1 is reported in Table 24, where the Republican WTP is similar to the overall average. In Table 25, a crosstab using Research Fund2, the differences across the political spectrum become clear. Favorable percentages for Research Fund 2 rise for all categories, and the change is small for "Republican" and particularly pronounced for "Independent/leans Republican" and for "Democrat."

Table 24: WTP for Research Fund 1 and Political Identity

$\begin{array}{lcr}\text { Political Identity } & \% \text { No } & \% \text { Yes } \\ \text { Other } & 50.00 & 50.00 \\ \text { Republican } & 35.06 & 64.94 \\ \text { Ind/leans Rep. } & 45.57 & 54.43 \\ \text { Independent } & 36.46 & 63.54 \\ \text { Ind/leans Dem. } & 22.22 & 77.78 \\ \text { Democrat } & 21.01 & 78.99 \\ \text { Total } & 34.21 & 65.79\end{array}$

Table 25: WTP for Research Fund 2 and Political Identity

$\begin{array}{lrr}\text { Political Identity } & \% \text { No } & \% \text { Yes } \\ \text { Other } & 45.65 & 54.35 \\ \text { Republican } & 34.42 & 65.58 \\ \text { Ind/leans Rep. } & 32.08 & 67.92 \\ \text { Independent } & 27.66 & 72.34 \\ \text { Ind/leans Dem. } & 16.54 & 83.46 \\ \text { Democrat } & 9.40 & 90.60 \\ \text { Total } & 26.42 & 73.58\end{array}$

Removing the variable Republican from the parsimonious regression does not change the significance of the other variables. 
In the extended model, the variables for Republican identity and visitation to reefs are removed, and income is replaced by income squared. This model maintains significance for the other parsimonious model variables except for donor status. Additional significant variables include boat ownership, sailing activity, and visitation to Florida's coral reefs at the 5\% level, and surfing activity and concern about fishing threats at the $1 \%$ level. Both variables related to sailing (owning a boat without a motor, and recreational sailing activity) demonstrate a strong negative impact. In contrast, surfing activity correlates with a higher WTP.

\subsubsection{Diagnostics for Research Funding Regressions}

All models pass the test of non-significance for both the Pearson chi2 and the Hosmer-Lemeshow chi2 statistic. Furthermore, a high percentage of observations are correctly classified.

Collinearity diagnostics show that none of the variables has a high variance inflation factor, and multicollinearity appears unproblematic. Reviews of boxplots for the variables in the regression reveal few outliers.

\subsection{Summary of Extended Regression Models}

The four graphics in Figure 29 summarize the four extended regression models by showing only their significant variables.

These illustrations show that many variables influence each decision, and different variables play different roles based on the scenario at hand. A significant 
negative influence appearing in three of the four models is Age. Positive factors appearing three times are Climate Change Concern and Coral Reef Concern.

For Seafood, three variables appear in preferences for both sustainable and local seafood: Seafood Budget, Trust in Labels, and Visitation to Reefs.

For the two Research Funds, the only reappearing negative influence was Nonmotorboat Owner (sailboat), and the three reappearing positive influences were Surfing Activity, Climate Change Concern, and Coral Reef Concern.

Two other positive variables appearing more than once were Environmental Donor, and Prioritization of Environment versus Economy. The additional negative influence of Foreign Birth appeared for Local Seafood and Research Fund2.

\section{Figure 29: Summary of Extended Models' Significant Variables}

Negative factors are shown under circle in red, dot pattern. Outlined boxes show model factors common between Sustainable and Local Seafood, and between Research Fund 1 and Research Fund 2. 

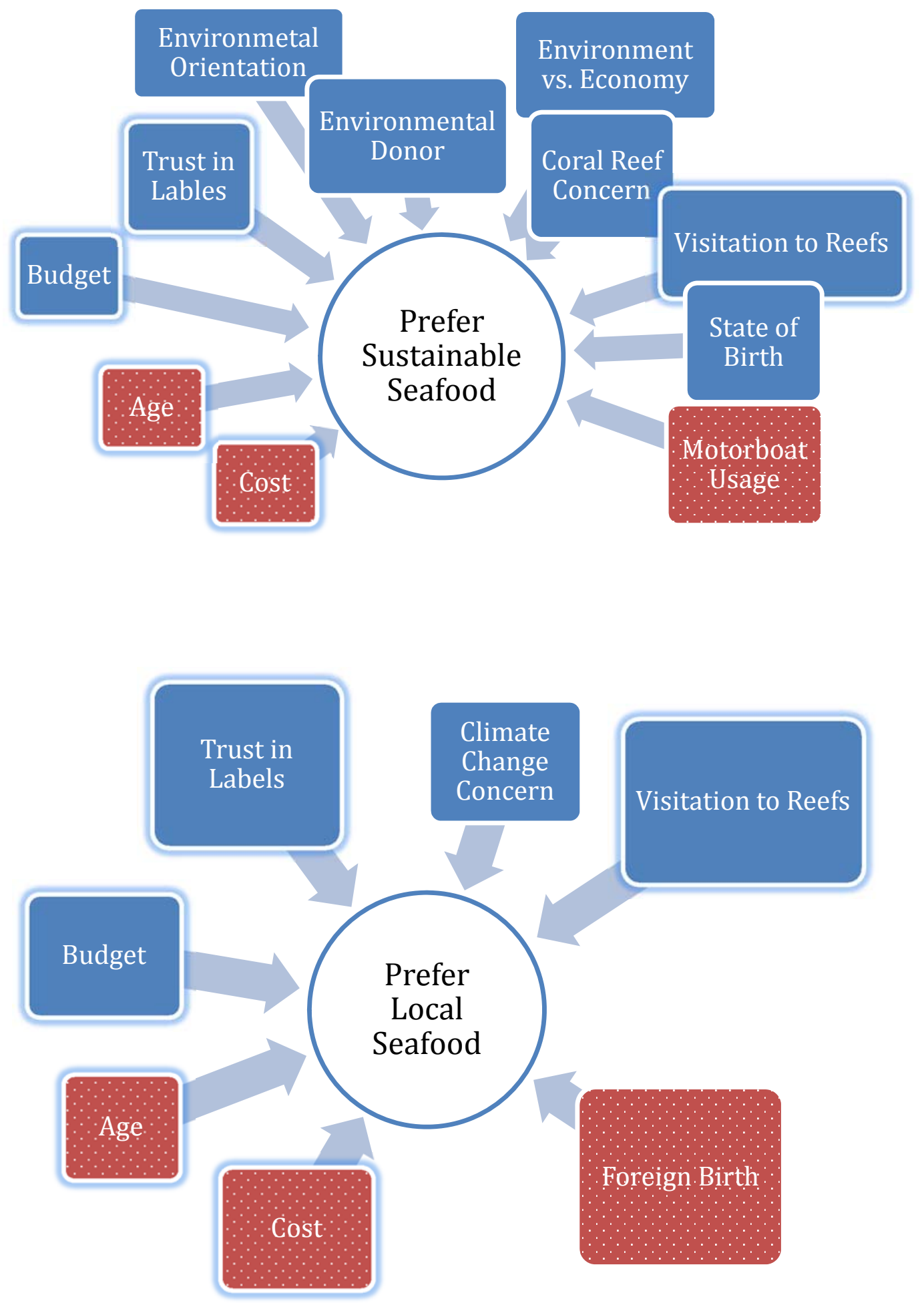

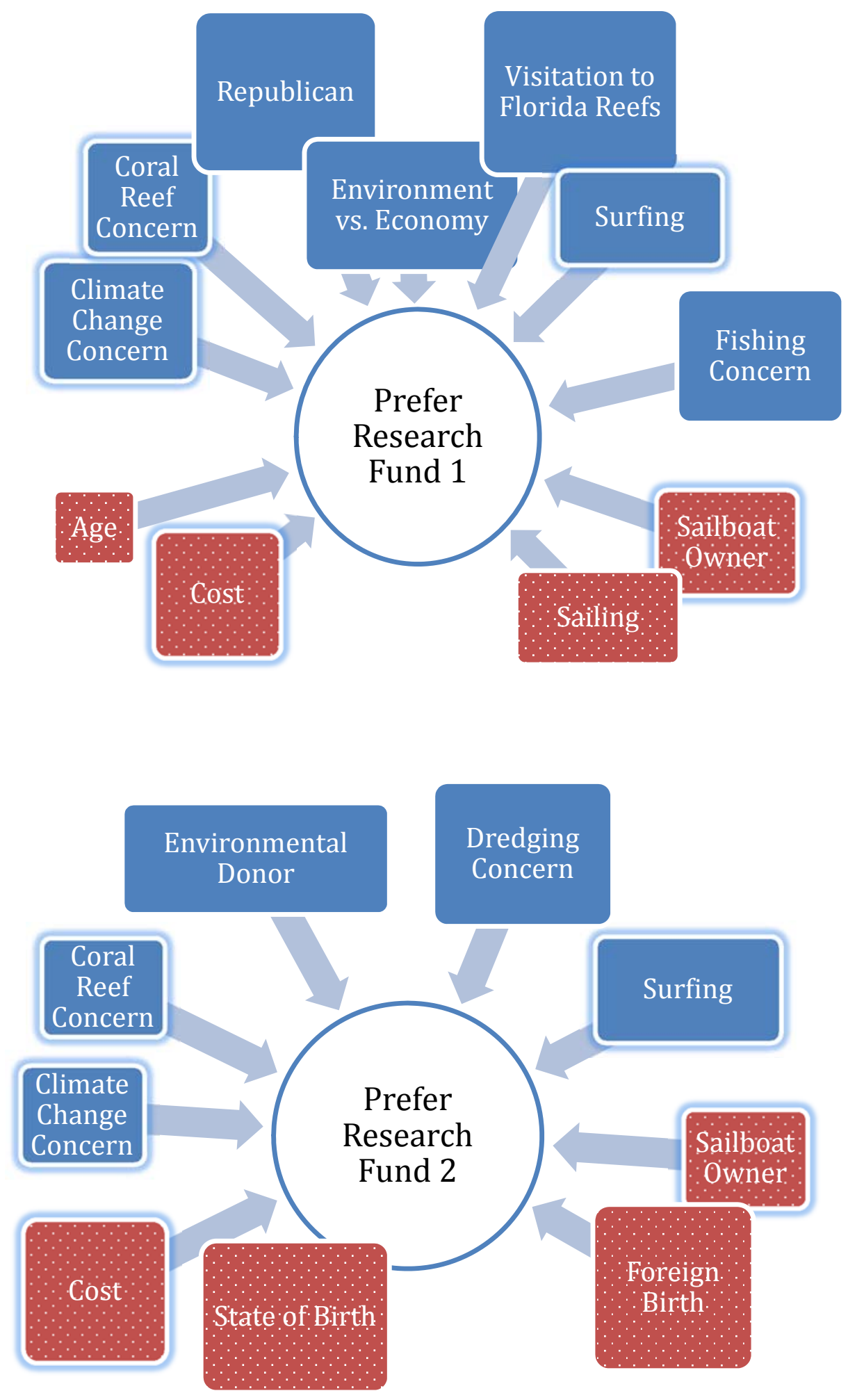


\section{CHAPTER 5: DISCUSSION}

\subsection{Analysis of Results}

The modest response rate of $2.6 \%$ likely relates to the survey's electronic, impersonal nature and lack of incentive. With email inundation and constant threats from spam a fact of daily life in the U.S., it stands to reason that the majority of individuals would ignore email solicitations from an unknown source. Without payment or other form of incentive, the individuals who opened the email lack an external motivation to click on the provided link. Then, after choosing to open the online survey, readers are confronted by a long disclaimer that may further inhibit their participation. Given these dis-incentives, the response rate appears quite reasonable.

Survey participants appear to represent the stakeholder population within southeastern Florida in a fair manner, yet surprises are noteworthy. Demographic findings, except for income, compare favorably with previous characterizations of resident coral reef users in southeastern Florida (Johns 2001). In comparison to previous studies of recreational anglers, this sample appears more educated and much more wealthy than would be expected (Cantrill 2004; Ditton 2003; Oh 2005; Shivlani 2011). For example, among specialized anglers of billfish in Florida, only 50\% had achieved a high school education (Ditton 2003), whereas in this study, the high school completion rate was above $99 \%$. The finding of a household income mode of greater than $\$ 200,000$ per year was very unexpected. 
The high income, high education, and relative homogeneity of respondents in comparison to the diversity of residents in southeastern Florida must be considered; however, these patterns likely emanate from the sample's emphasis on saltwater anglers. Access to offshore fishing requires access to a motorboat, and the segment of the population able to afford such a luxury item differs from the population at large. The finding that $68.3 \%$ of respondents own a motorboat emphasizes their relative wealth. Moreover, the survey's online format favors people with expendable time and income who are more likely to have access to technology and good computer skills, which could relate to their education.

Because the sample is quite wealthy, all findings must be considered from this perspective, and it may be instructive to compare income to other variables. Mean age and income are positively correlated (Pearson chi2 $(100)=7.7 \mathrm{e}+03, \operatorname{Pr}=0.000)$; Figure 30 shows the eleven income categories and their corresponding mean age. The upward trend appears across a range of mean ages from 41.5 years to 51.6 years. The four central income categories, inclusive from $\$ 60,000$ to $\$ 159,999$ annually, vary within a small range of 45.2 to 46.9 years. Respondents in the highest income category of $\$ 200,000$ or greater annually had a mean age of 49.8 years.

The mean category of $\$ 100,000$ to $\$ 119,999$ household income annually is more than double Florida's median household income of $\$ 47,309$ (U.S. Census 2014). In comparison, the stakeholder study by Johns (2003) found that reef users across four counties (excluding Martin County) had an annual household income of $\$ 55,000$ to $\$ 90,000$. As would be expected, respondents with a higher income are more likely to be boat owners. 
Figure 30: Mean Age by Income Category

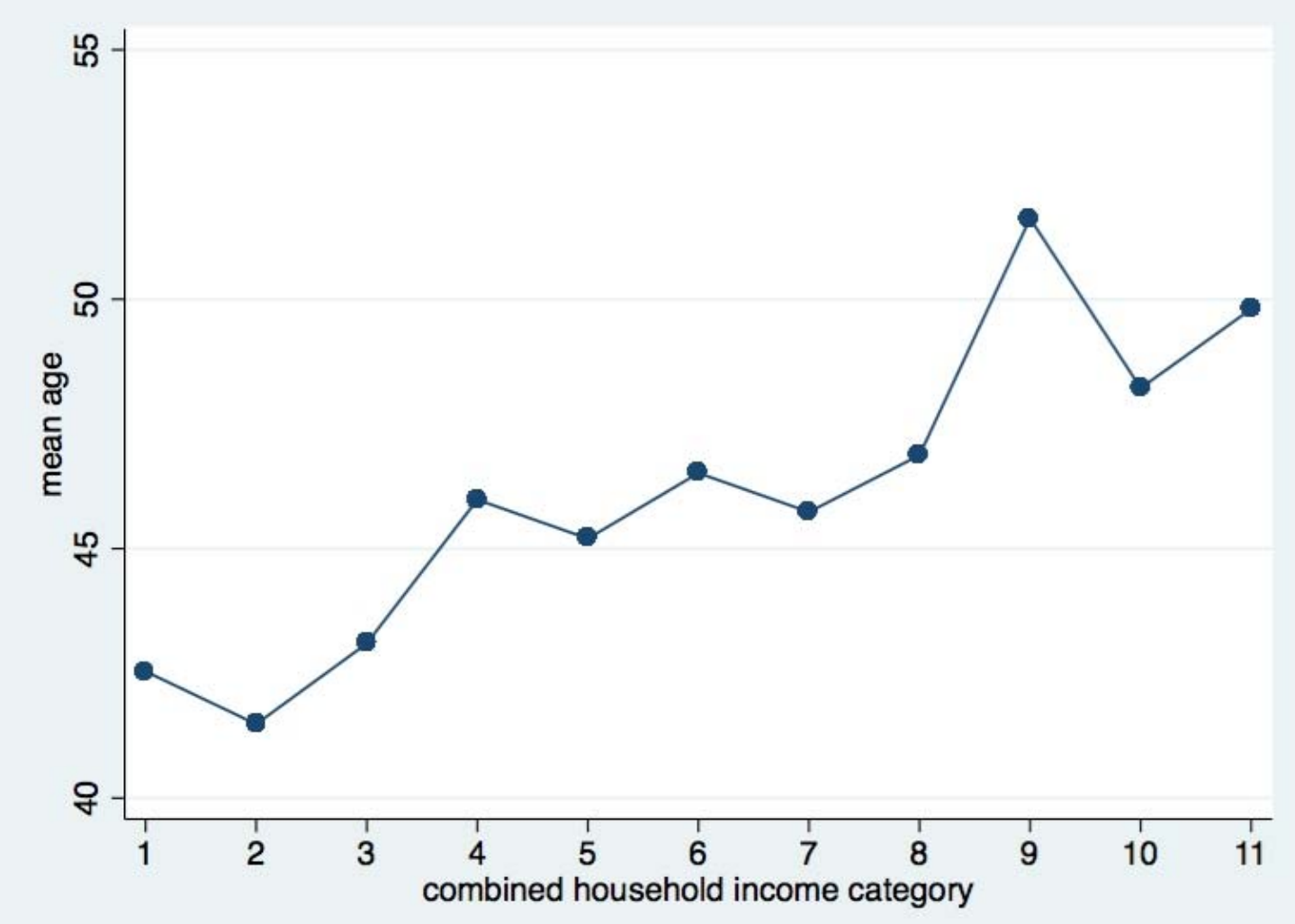

The sample shows higher education levels than the state average, with $36.3 \%$ having a bachelor's degree as compared to $26.2 \%$ for Florida (U.S. Census 2014). As expected, stakeholders with higher income also have more education.

The gender gap is not altogether surprising, considering that commercial and recreational fishing remain male-dominated domains, and a similar if less pronounced effect may be observed in other coral reef-related industries such as scuba diving and marine science (Cooke 2006; Johns 2001; Shivlani 2011). The mean age of 46.6 years 
appears reasonable, but if considered somewhat high, it may reflect a lack of expendable time for younger, fully-employed individuals and/or parents of minors in comparison to elder or retired individuals who could apply their less-burdened time to completing a survey without incentives or compensation.

Along with income, another unexpectedly high result is the political orientation of "Independent." This trend follows similar changes observed in the two national coral reef attitude surveys (Edge 2002; Edge 2008). While dominated by Independents, the sample skews slightly toward Republican. As an alternate strategy, the questionnaire could have asked for one's voting record, which would have eliminated the identity choices of "Independent, leans Republican" (19.9\%) or "Independent, leans Democrat" (15.9\%). With such high response rates, these distinctions appear useful.

The text responses from those choosing the category of "Other" show little reverence for conventional political parties. Similar discontent is evident in the email responses in Appendix 5. Overall, these stakeholders represent movement away from the traditional two-party system and an unorthodox spirit in regards to political identity. In addition, because these stakeholders are relatively wealthy, it could be inferred that they have higher than average political influence. The choice of an Independent identity by the majority could portend a coming shift in state and national politics.

The sample's connection to coral reefs, and the ocean in general, is very high. Snorkeling, scuba diving, and freediving represent the activities that bring stakeholders into the closest interactions with coral reefs. They are the eyewitnesses with the highest credibility, and they are strongly represented in this sample. It is somewhat surprising that nearly a majority practiced freediving, although freedivers commonly practice 
spearfishing, a sub-category of fishing. In southeastern Florida, spearfishers are especially active during lobster season, and a fishing license is required for this activity. This noteworthy community deserves further investigation.

More than $77 \%$ never practiced surfing or sailing; however, these minority stakeholder communities have intense associations with the ocean. The international environmental organization Surfrider is active in southeastern Florida, and surfers in general are known for their strong subculture and connection to nature. Sailors may also have environmental affiliations ranging from the local to the international, and their culture based on the use of wind power may foster strong environmental ethics. In the regressions, however, these two communities represented opposite sides of willingness to pay: active surfers are more willing to pay, and active sailors are less willing to pay. A possible hypothesis based on this finding is that the full-immersion experience of surfing inspires a stronger bond with the ocean than non-immersive activities, such as sailing. As with speafishers, these communities deserve further investigation.

As for environmental orientation, Question 27 comes directly from a national study of attitudes about climate change, and that study's results were quite different: $45 \%$ prioritized The Economy, and 55\% prioritized The Environment (Maibach 2009). This study's results were $25 \%$ and $75 \%$ respectively. This difference could be partially attributed to the so-called Great Recession, which technically ended in the U.S. in 2009 (U.S. Labor 2010). With an improving economy, respondents may feel more comfortable choosing to prioritize the environment. Moreover, the wealth of stakeholders gives them greater autonomy than the average U.S. citizen. 
Yet other results indicate that stakeholders have a similar self-identified environmental orientation as the general public. The wording for Question 41, about affinity for the word "environmentalist," comes directly from the Edge 2002 national study of coral reef attitudes, and that study found a mean of 6.3 that is nearly identical to this study's finding of 6.1 (see Figure 15). This question and other direct measures of environmental inclinations indicate a fairly high level of environmental concern and involvement among stakeholders.

\subsubsection{Comparison to Previous WTP Studies}

The results from the Research Fund scenarios are most readily comparable to previous studies, as discussed below. The closest parallel to the current study is the Shivlani study (2006), which reports results from five projects with 3,218 respondents. It concluded "that an overwhelming majority of respondents from all survey projects are in favor of protecting corals and a large percentage is willing to pay either additional sales taxes (as residents) or bed taxes (as visitors) to ensure the protection of coral reefs in southeastern Florida." These projects covered four counties and excluded Monroe County from its definition of southeastern Florida.

Similar to the current study, the survey questions in Shivlani (2006) proposed an additional sales tax for a coral reef protection fund, and it found lower WTP than the current study's results. For residents, 50.5 percent accepted the first offer of a sales tax of

$1 \%$ percent, 32.1 percent accepted the offer of $2 \%$, and 26.1 percent accepted the offer of 3\% (Shivlani 2006). For the latter two categories, majorities agreed to pay a tax at new levels that they suggested, which equated to tax rates of $0.74 \%$ and $0.87 \%$ respectively. 
Boat owners demonstrated somewhat higher willingness to pay. Overall, it was estimated that nearly one-third of residents agreed to pay a sales tax that averaged $0.65 \%$.

In contrast, nearly two-thirds or more of stakeholders in the current study agreed to pay the offered sales tax. The current study capped the highest sales tax offer at $2 \%$, yet even that highest offer earned favorability from 62.3 percent, for Research Fund 1, and 75.4 percent, for Research Fund 2. For both Research Fund 1 and Research Fund 2, a majority favored each of its nine offers (see Figure 31). A simple explanation for this difference between studies is that the Shivlani 2006 report surveyed the general public for some of its projects, but its boat-owner intercept survey targeted stakeholders. Moreover, one project to interview coral reef stakeholders in each county found that the majority rejected the idea of new fees--a direct contrast to the current study. Although differing methodologies could explain these discrepencies, it is also possible that a change of opinion has occurred that is more favorable to taxation.

The preferred rate of a sales tax is more comparable between studies. For Shivlani (2006), preferred tax rates averaged from a low of $0.26 \%$ to a high of $0.95 \%$, with an average for residents calculated at $0.65 \%$. Using the current study, a favored average percent can be calculated by multiplying the nine offers by the percent answering "yes," and such averages result in rates of $0.62 \%$ for Research Fund 1 and $0.70 \%$ for Research Fund 2. Therefore, both studies find a preferred coral reef research fund sales tax rate of close to $0.65 \%$. Such a rate is favored by supermajorities in the current study. 
Figure 31: Research Fund Choices per Offer
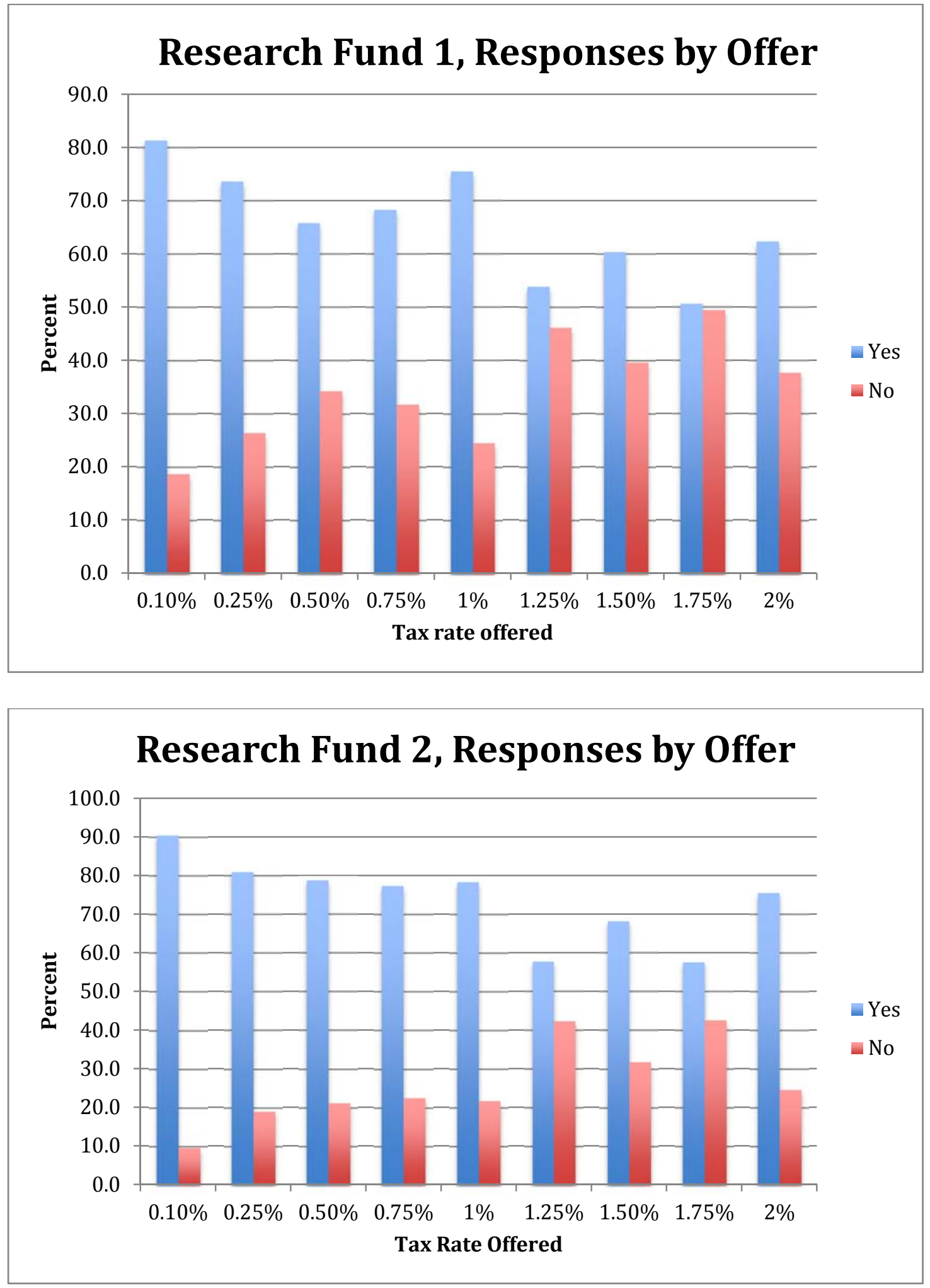
Another comparable study of stakeholders is by Johns (2003), and its proposal of a fee on boat registrations to fund artificial reefs was rejected by more than $75 \%$ of respondents. This study's proposal appears constricted by the wide range and high values of its offers, ranging from $\$ 10$ to $\$ 2,000$. For combined funding to maintain both artificial and natural reefs in their existing condition, residents in four counties (excluding Martin County) expressed WTP of \$256 million per year, or the equivalent of \$9 "Use Value Per Person-Day." While difficult to compare directly to the current study, the pledge of \$256 million per year is similar to the projected annual revenue from Research Fund 2 of $\$ 235$ million per year (see below).

In the Leiserowitz study (2008) of WTP for climate change remediation in Florida, majorities agreed to pay all proposed increases of fees: $\$ 100 /$ year for utilities, $\$ 5 /$ month in taxes, $\$ 2.50 /$ month on electricity, and unspecified increases to fund solar panels on state buildings. This favorability may relate to the modest fees, particularly when compared to the fees offered by Johns (2003). Even so, the highest favorability in Leiserowitz (2008) was 65\%, whereas the current study reached favorability levels as high as $81 \%$ and $91 \%$. These comparisons suggest that future studies could employ a larger range or higher fee values.

In the two national coral reef attitude studies by Edge (2002, 2008), majorities of the general public agreed to pay modest fees of $\$ 10$ per vacation, although a fee of $\$ 50$ was favored by only $51 \%$ in 2002 and by $33 \%$ in 2007 . In international studies, an average recreational WTP by contingent valuation methods registered at $\$ 59.80$ per year and by choice experiments at $\$ 94.30$ per year (Ghermandi 2011). The latter value falls 
within a range from the current study's finding that $91 \%$ of stakeholders agreed to a choice experiment fee that ranged from $\$ 5 /$ month to $\$ 30 /$ month, or $\$ 60$ to $\$ 360$ per year. For the Research Fund scenarios, income from a proposed sales tax varies depending on assumptions. If we assume a sales tax rate of $0.65 \%$ on annual taxable spending of $\$ 4,731$ ( $10 \%$ of median household income in Florida), then the calculated annual amount generated per Florida taxpayer would be $\$ 30.75$. For higher income individuals, such as those within the current study, annual taxable spending of $\$ 11,000(10 \%$ of an $\$ 110,000$ household income) would result in $\$ 71.50$.

Calculations of potential income are not real numbers; they provide hypothetical benchmarks to judge the value of particular methods and policies. Yet the current study may have underestimated values by using contingent valuation methods (Ghermandi 2011). Alternately, it could have overestimated values by proposing general fees and taxes instead of direct reef user fees, which are unpopular among Florida's coral reef stakeholders (Shivalani 2011). One internal benchmark of the study's validity is the novel approach of including a purely market-based but relevant product, namely seafood, alongside the non-market values of ecosystem research, protection and restoration. Both the market-based and non-market fees were favored by similar percentages of supermajorities.

\subsubsection{Climate Change and Other Perceptions}

For the two scales of Climate Concern and Coral Concern, both demonstrate solid reliability, and their validity comes mainly from the replication of questions and statements from previous surveys. Overall, the findings relating to climate change show 
much greater concern and angst than previous findings from regional and national surveys. For example, in a 2009 national survey (Maibach), a slightly reworded question with the same response metric as this study asked: "When do you think global warming will start to harm people in the United States?" Only 34\% responded "now," and 15\% choose "never." In comparison, the current study found respective responses of $55.7 \%$ and $10.8 \%$. In both studies, the majority display concern and belief in climate change, while a minority divides into several brackets of relatively lesser concern and doubt.

The finding of high concern about climate change indicates a noteworthy shift in attitudes among stakeholders within the past few years. For the five recent studies of coral reef stakeholders in southeastern Florida, they recognized coral reefs as deteriorating, but climate change did not register as a major concern (Berry 2011; Shivlani 2011; Shivlani 2008; Shivlani 2007; Shivlani 2006). The shift to high concern could be attributed to many factors that deserve further investigation, such as: the effect of Superstorm Sandy in 2013, increased media coverage of climate change, increased attention on southern Florida as extremely vulnerable to sea level rise, and generally mild winter temperatures.

The angst over climate change also contrasts with national surveys that find limited and stagnating concern for climate change (Barker 2013). As for the 2008 study of climate change attitudes across Florida, those findings appear similar or lower than the current study's findings (Leiserowitz). In that study, 30\% agreed that "dangerous impacts" from global warming were happening now; the current study finds $55.7 \%$ agree that climate change impacts are happening now (without the word "dangerous"). As for impacts never occurring in Florida, that study registered $14 \%$ and this study reports 
$10.8 \%$. That study's finding that $61 \%$ of Floridians agree that global warming is worsening damage to coral reefs was not directly replicated, yet a similar question about the threat of high temperatures registered the mode at the highest level (5), a mean of 3.68 , and only $17 \%$ expressing disagreement with this threat. Overall, the stakeholders in the current study demonstrate greater concern about climate change than general Florida residents assessed in 2008.

Regarding perceived threats to Florida's coral reefs, the three that were ranked with a mean above 4 (out of 5) must be considered very worrisome to respondents: Sewage \& Runoff, Dredging and Construction, and Invasive Species. The next four threats rank moderately high, and only two threats register below the midpoint: Fishing, and Scuba Diving \& Snorkeling. Considering that the vast majority of respondents are fishers, it comes as little surprise that they would consider fishing a minor threat. One surprise is the high ranking of invasive species, although this issue has gained prominence in local media due to the rapid spread of the Pacific lionfish across Florida and the greater Caribbean region. While this invasion is real, its relative threat to Florida's reefs remains unknown. Within the literature on U.S. coral reefs, invasive species rank so low that it has been categorized as "negligible-low" in a recent assessment of threatened corals (Brainard 2011). That assessment ranked the top four threats as ocean warming, disease, ocean acidification, and reef fishing, and the 14 other threats all ranked below "medium." The perception of threats in southeastern Florida is quite different than scientific assessments (see Table 26). 
Table 26: Contrast of Assessment and Perception of Reef Threats

List for NOAA constructed from Brainard (2011).

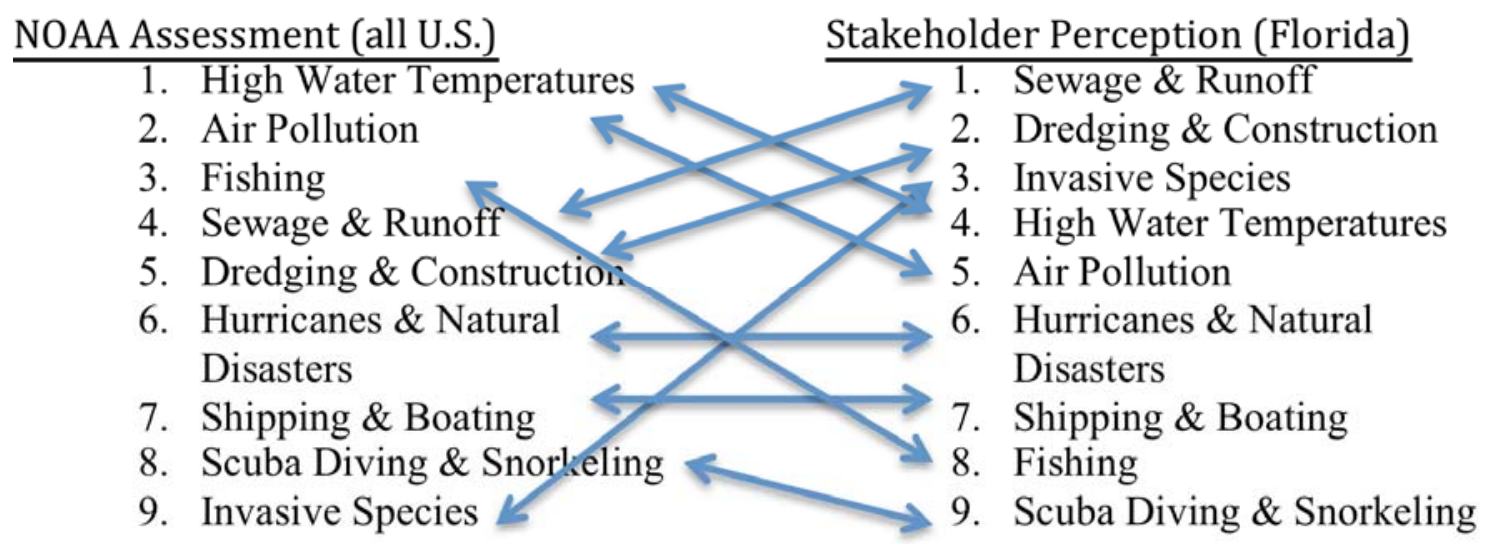

Respondents do seem aware of the threat of ocean acidification, as it ranked highest among the seven factors in the scale of Coral Concern. It was followed by concern for carbon dioxide. In contrast, concern for high water temperatures was moderate. These differences may relate to distinct understandings of the terms "climate change" and "global warming." Notably, it appears that non-temperature related effects of climate change register as more worrisome than rising temperatures. From another perspective, the choice of "high water temperature" may have confounded respondents who recall the damage of cold water temperatures in Florida in 2010 (ONMS 2011). The many nuances in understanding and perception of the term "climate change," while beyond the scope of this study, deserve further study.

\subsubsection{Economic Surprises}

One of the most striking findings from this study is the opaque influence of financial issues. For the seafood and research fund scenarios, the range of offers was 
much less influential than expected, and in some cases it was negligible. Household income's influence was even more surprising, because it showed no trend for seafood choices and an unexpected negative trend for research fund choices. In that case, stakeholders with greater income were less willing to support research.

One possible explanation for these unusual associations with income is the phenomenon of an inferior good (Mankiw 2001). An inferior good is regarded as less desireable as wealth increases, and examples could include low-quality clothing or transportation. Sustainable seafood should not qualify as an inferior good, because its standards should guarantee a high-quality product. The finding for research funds, based on taxation, seems more logical if one considers taxation as an inferior method of income. Wealthier people contribute more and receive relatively fewer benefits from public taxation than poorer people; in this regard, greater wealth creates a dis-incentive to approve taxation. On the other hand, recreation related to coral reefs requires wealth, and it could be argued that taxation for coral reef research would disproportionately favor upper classes. A clear and concise explanation remains elusive.

The results violate the conceptions of a normal good and of the law of demand to some degree, because higher prices (offers) did not dampen demand in a clear and consistent manner. The effect of income also violates theory regarding consumer choice (Mankiw 2001). Such contradictions of theory require further investigation. In the model explained at the end of this section, it is theorized that motivations from an environmental perspective could be overwhelming traditional financial motivations. 


\subsubsection{Trust in Seafood}

As for seafood choices, local seafood earned much greater support than sustainable seafood. The question about local seafood explained that this premium would be added to the premium for sustainable seafood. Respondents may not have read the question carefully enough to realize this cumulative effect, and they may have misinterpreted the lower premiums to indicate that the local seafood would cost less. If there were no misunderstanding, the result indicates a much greater respect and demand for seafood with local origination.

The supply of local seafood in Florida is decreasing, and this scarcity may be influencing an increase in demand (Florida Ocean Alliance 2013). Research of sustainable seafood is too thin to offer much guidance. One study of labeled seafood purchases in California supermarkets found that seafood sales declined when sustainability labels were introduced; it also found education levels to be influential (Hallstein 2013). In the current study, education shows no consistent, significant pattern, and this curious finding appears across the WTP variables.

In contrast to the expectations of intuition and theory, the seafood results show no significant correlation with income or education. A person with low status (income, education) is equally likely to pay the premium as a person with high status. This finding is surprising. Confusion over the questions does not provide an explanation, as respondents reported a high level of certainly in their answers for this section $(80.8 \%$ at 8 or above on a scale of 1 to 11 for certainty). One possible explanation comes from the follow-up question that asked them about their trust in sustainability labels. Although the 
mode was the top category of "highly credible," the range of responses and a moderate mean of 7.3 (on a scale of 1 to 11) indicate disparities in trust among these consumers. This variable proved significant and influential in the regressions.

This trust-choice relationship may result from the novelty of seafood labeling schemes and the term "sustainable seafood." Even aggressive educational campaigns about sustainable seafood have failed to prove a significant effect (Hallstein 2013); furthermore, the use of such labels in Florida remains anomalous (personal observation). Moreover, generational differences, and particularly a baby boomer effect, may influence willingness to pay for an item that could be interpreted as a luxury.

In the sustainable seafood regression models, all of the significant variables in the positive direction have greater explanatory power than age, with climate change exerting somewhat lesser influence than the other variables. Based on the log-odds ratio, the variable of trust in seafood labels accounts for $25 \%$ of the difference. The next variable in order of influence is the number of visitations to coral reefs, and this association may be interpreted as very direct and personal interactions with ocean ecosystems that engender greater concern. This variable implies access, experience, and personal knowledge of an ecosystem that may be influencing purchasing decisions. In comparison, the more specific sub-variables for ocean interaction, such as scuba diving or sailing, were not significant.

Nearly equal in influence to the variable of weekly seafood budget, the variable of self-identification as an environmentalist underscores the importance of identity. With each unit of increase in this scale, respondents were $15 \%$ more willing to purchase sustainable seafood. Alongside concern for climate change and for coral reefs, this 
variable reflects the importance of an environmental orientation. The influence of these variables appears to equal or surpass the influence of financial considerations. If accurate, this pattern demonstrates that stakeholders are making decisions fundamentally with their ethical, environmental values and secondarily based on disposable income.

For the extended model for sustainable seafood, all parsimonious model variables except for climate change concern remain significant. A highly significant variable in the negative direction is the activity of recreational motorboating. Because this activity requires disposable income and leisure time, it implies a wealthier stratum of stakeholders. Surprisingly, this stratum is less willing to pay for sustainable seafood, even though its designation indicates a superior, better-regulated product. Trust in sustainability labels is not their issue, as this variable and recreational boating are very weakly correlated. Because other recreational activities were not significant, the possibility exists that this relationship is spurious.

An additional three variables in the extended model are significant at the $10 \%$ level, and each one's influence registers above $50 \%$ according to the log-odds ratio. Prioritizing the environment over the economy, while a simplistic measure of environmental orientation, adds weight to the emerging picture of the importance of environmental values, as does the dichotomous variable of donating to environmental causes. The variable of birthplace in a state outside of Florida, in reference to stakeholders born within Florida, has a positive influence on willingness to pay. This variable could be interacting with other factors such as environmental orientation and education. Southeastern Florida has traditionally not been held in high esteem for either 
factor, and U.S. citizens relocating from other states to Florida may bring greater awareness to the region.

For local seafood, which had a much higher percentage of favorability, two variables did not remain significant when the same parsimonious model for sustainable seafood was applied. Environmental orientation and concern for coral reefs became insignificant, yet concern for climate change remained significant at the 5\% level. Other variables exert a similar influence as for sustainable seafood, with age becoming less influential and trust in seafood labels becoming more influential. This emphasis on trust implies that consumers are highly willing to pay for seafood products that can be confirmed as originating from a local source. Another increasingly influential variable is visitation to coral reefs. Something in the term "local" appeals to these stakeholders; they potentially represent the growing movement of "locavores" or people who prefer to obtain their food from local sources.

In the extended regression model for local seafood, the two insignificant variables from the parsimonious model were dropped, and those remaining were significant. An additional significant variable is foreign birth, yet this variable was not significant for sustainable seafood. In short, stakeholders born in a foreign country are much less likely to purchase seafood marketed as "local." This finding may relate to the Caribbean roots for the majority of the foreign-born population of southeastern Florida, and they may maintain a bias that seafood from Florida is not preferable to seafood from other countries of origin. 


\subsubsection{High Fees Supported in Choice Modeling}

For the choice experiment of management plans, choices align with the stated importance that respondents gave to the attributes in making their decision. Respondents ranked water quality as the most important attribute, and Plan A always represented the best water quality option. The attribute of coral restoration ranked a close second. These two attributes appear to play a much stronger role in decision-making than the attributes of beach size and fee. Because the least important attribute to respondents was beach size, it conferred a diminishing advantage to Plan B.

The question of the fee's importance is intriguing. The status quo plan with no fee was rejected by greater than $90 \%$. This rejection demonstrates that respondents are not satisfied with the status quo, and overwhelmingly they are willing to pay for improvements. A review of responses by fee shows that the mid-range to lower fees were preferred over the higher fees, which meets expectations. Even so, the lowest fee associated with improvements, $\$ 5$, was less preferred than plans with fees of $\$ 10$ and $\$ 15$, and the $\$ 20$ fee was less preferable than the $\$ 25$ fee. The $\$ 30$ fee, as expected, was least preferred. This variation in the fee's influence reinforces the finding that financial considerations are not dictating stakeholders' choices.

Political orientation is a muddy issue, although it is clear that this population is trending towards Independent. A recent study shows that U.S. political orientation and climate change attitudes are correlated (McCright 2013). Yet in this study, the regression models mostly did not find significance for political orientation. Independents, true to their identity, show inconsistent patterns in willingness to pay. Democrats trend higher 
and Republicans trend lower in willingness to pay, and this preference aligns with the Republican Party's strong stance against expanded governance and new taxes of any kind. But the lowest WTP is within the category Other. This minority of $6 \%$ demonstrates a strong resistance to governmental institutions and cooperative behavior.

\subsubsection{Matching Funds Engenders Support}

In the regression models for Research Fund1, the influence of the variable of frequency of visiting reefs in Florida is not surprising, as those with greater familiarity with the resource are expected to demonstrate greater support. The variable of the threat

of fishing to coral reefs in Florida shows that as respondents have greater recognition of this threat, they have more WTP for this fund.

The second question about a tax for a coral reef research fund, Fund2, deliberately emphasized that this fund would receive matching funds from a federal agency, and it engendered much higher support. Using the same parsimonious model as for Fund1, the variable of Republican is no longer significant, and the variable of Environmental Donor appears to replace Environment vs. Economy. In the extended model for Fund2, the variable age is no longer significant, even though in other regressions with other outcomes it appeared to be important. In this extended regression, the variables of concern about coral reefs and about climate change remain significant at the $1 \%$ level.

Another variable at the $1 \%$ level is the threat from Dredging \& Construction, which stakeholders identified as the second greatest threat to coral reefs in Florida after the first threat of Sewage \& Runoff. Essentially, respondents with greater concern about dredging are more willing to pay for this tax, and a reasonable hypothesis is that they are 
responding to the high visibility of this issue. Similarly as for Fund1, surfers showed greater WTP. Significant variables indicating a lesser WTP are: birthplace in a state outside of Florida, foreign birthplace, and ownership of a non-motorized boat (most likely a sailboat).

Given that stakeholders in the current study hold comparable, complementary concern about both the global issue of climate change and the more localized issue of Florida's coral reefs, they may be perceiving them as connected issues or as less spatially differentiated than expected. This finding contrasts with the expectations of a process called "environmental hyperopia," whereby people perceive distant or global problems to be worse than local problems (Devine-Wright 2013). Further investigation could measure the extent to which stakeholders cast these issues in localized or globalized contexts.

\subsection{Interpretation}

When confronting unpleasant information, such as extinction or death, people may react initially with denial and then move through stages towards acceptance. Studies of attitudes toward death, based on the Kubler-Ross model, show that these stages can be quantified into five categories: Denial, Anger, Bargaining, Depression, and Acceptance (Maciejewski 2007). Because information about coral reef degradation is highly unpleasant, it is proposed that people are dealing with this information in ways similar to this model.

Denial is a powerful force, but its opposite is equally if not more powerful. Acceptance of the degradation of coral reefs and of the impact of climate change is the norm for this population of stakeholders. Those who deny these realities are relegated to 
a small minority, and this minority is considered the most likely to avoid a payment to improve the environment. Other stakeholders who accept environmental degradation may join the deniers in choosing to avoid the sacrifice of a payment, and their decision may result from a detachment instead of strict denial. By removing themselves emotionally from an attachment to the issue at hand, people can avoid the dissonance of understanding the problem yet refusing to address it.

Attachments to the issue at hand appear to inspire the vast majority of stakeholders. Fully $91 \%$ of stakeholders are willing to pay a fee for the improved management of coral reefs in Florida. The 9\% of non-payers offers an approximation of the minority of stakeholders that deny the degradation of coral reefs, and this percentage shows affinity with the $10.8 \%$ of respondents who believe that climate change will never impact Florida. These two essential groups, either attached or detached from the issue, may expand or contract in their willingness to pay based on a variety of factors, but it is proposed that this fluctuation depends upon their relative levels of acceptance of degradation and of attachment to the environment. The following percentages from this study represent increasing levels of acceptance and of attachment to environmental issues:

- $65 \%$ : WTP for Sustainable Seafood

- 66\%: WTP for Research Fund1

- 73\%: WTP for Research Rund2 (matched)

- 75\%: Prioritize the Environment over the Economy

- 76\%: WTP for a Research Fund

- $\quad 80 \%$ : WTP for Local Seafood

- $\quad 85 \%$ : WTP for Sustainable or Local seafood

- $89 \%$ : Climate Change will eventually impact Florida

- 91\%: WTP for Management Plans 
In every case, a strong majority expressed WTP or an attachment to environmental issues. Similarly, the high means of many variables related to environmental issues demonstrates high concern. In particular, the scales of concern about climate change and of coral reefs are skewed in the direction of extreme concern.

The range of willingness to pay, however, shows that issues resonate differently. A proposed explanation is that the respondent is expressing relatively lesser or greater levels of attachment to that issue. The attachment to sustainable seafood, for example, appears much less than the attachment to local seafood or to management choices. For the latter choices, respondents expressed a high attachment to the attribute of water quality, followed closely by attachment to coral restoration. They expressed lesser attachments to monthly fees and to beach size.

Greater explanation of attachment and detachment is provided by the multiple regressions for the four scenarios of Sustainable Seafood, Local Seafood, Research Fund (unmatched), and Matched Research Fund.

Across the regression models of the four scenarios, the only consistently significant variable is the cost or offer value, and this negative association affirms the economic theory that consumers are less willing to pay as costs increase. Conspicuously absent from these models are the expected variables of income and education. For income, associations appear so flat or consistent across income levels that prediction becomes impossible, and in the case of the tax scenarios for the Research Funds, the association appears negative. A possible explanation emerges from a comparison of political orientation and willingness to pay, as there are consistent patterns of correlation across the scenarios, with Republicans less willing to pay than Democrats. 
More puzzling than income, however, is education, as patterns remain elusive, even though theory would tend to predict that a higher education would result in both higher income and a higher willingness to pay (Mankiw 2011). Perhaps that pattern would hold within the general population, but within this sample of stakeholders, who presumably have high levels of knowledge about marine resources, the effect of education is negligible.

Instead of these expected influences, the concept of environmental concern appears to hold high explanatory power. Higher environmental concern tends to positively influence willingness to pay, and this concern may be expressed in different ways. For the Research Fund taxes, it appears consistently as concern for both climate change and for coral reefs. Across the scenarios, it variously appears as self-identification as an environmentalist, as a donor to environmental causes, and a prioritization of the environment over the economy.

Another consistently influential variable across the scenarios is age. With its negative association, it infers that older generations have less willingness to pay premiums for seafood or taxes for research funds, and the inverse suggests that younger generations have greater willingness to pay. This association may relate to the relative novelty of the concepts of sustainable food and coral reef degradation. A few decades ago, these issues were given scant attention.

Returning to the hypotheses, here are the conclusions.

Hypothesis 1: Willingness to pay to protect coral reefs is moderately high.

The null hypothesis would be that WTP would show little difference from a random choice of $50 \%$ yes to $50 \%$ no. This null hypothesis should be rejected, as all 
scenarios measured were different than this ratio. With all means above $64 \%$ or twothirds favorable, the willingness to pay does appear moderately-high to high. It appears higher when each scenario is considered in combination: 76\% WTP for either the unmatched or matched research fund, $85 \%$ WTP for either sustainable or local seafood, and $91 \%$ WTP for either management plan. The more direct measures of WTP for reef protection, the Research Funds, showed similar levels to the less direct measures for Seafood. For six of the eight regression models, with the exception of the two models for local seafood, the scale of Concern for Corals was positive and significant, lending additional weight to the assertion that stakeholders are translating their concern about reefs into a willingness to pay.

Hypothesis 2: Local concern for coral reef conservation influences willingness to pay.

The null hypothesis that concern for reefs does not influence WTP should be rejected. For the direct measure of coral reef conservation through the Research Funds, all four models displayed significant influence from the variable Concern for Corals. For Fund2, the matched tax for a Research Fund, Concern for Coral registers more than 11\% influence per unit change of the scale.

Hypothesis 3: Global concern for climate change does not influence willingness to pay.

The null hypothesis cannot be rejected, as it would state that Concern for Climate is influential. Indeed, it seems that this hypothesis was poorly formed, as Concern for Climate is significant in every regression model except for the extended model for Sustainable Seafood. Yet the parsimonious model for Research Fund2 shows significance 
in the negative direction, while all other models are in the positive direction. In this case, the variable Republican causes distortions, because Republicans are more likely to answer yes than three of the other political orientations (Other, Independent/leans Republican, and Independent), and the removal of any political variable in the extended model results in a very significant, positive relationship.

In addition to these hypotheses, the results are quite surprising in terms of the lack of influence of education and income on willingness to pay. It could be hypothesized that these variables are interacting with other variables and maintain an influence through indirect instead of direct relationships. These variables, along with political orientation, require further investigation.

\subsection{Conclusion}

In conclusion, how are stakeholders making their decisions? Borrowing the theory of grief from psychology and its continuum of "denial" to "acceptance," we can substitute these terms with "detachment" to "attachment." For environmental decisions, the guiding principle appears as a relative attachment or detachment to the issue, and this principle can be imagined as a continuum ranging from full attachment to full detachment. These concepts are similar to the emotional range of full acceptance to full denial.

Based on this study's findings, it is hypothesized that three main lenses of perception are informing one's relative attachment to an environmental issue, and these lenses consolidate a number of sub-attachments: Environmental Attachments, Emotional Attachments, and Financial Attachments. The three lenses interact, and they are proposed to have the relative influence as demonstrated in Figure 30, Lenses of Attachment. 
Figure 32. Lenses of Attachment

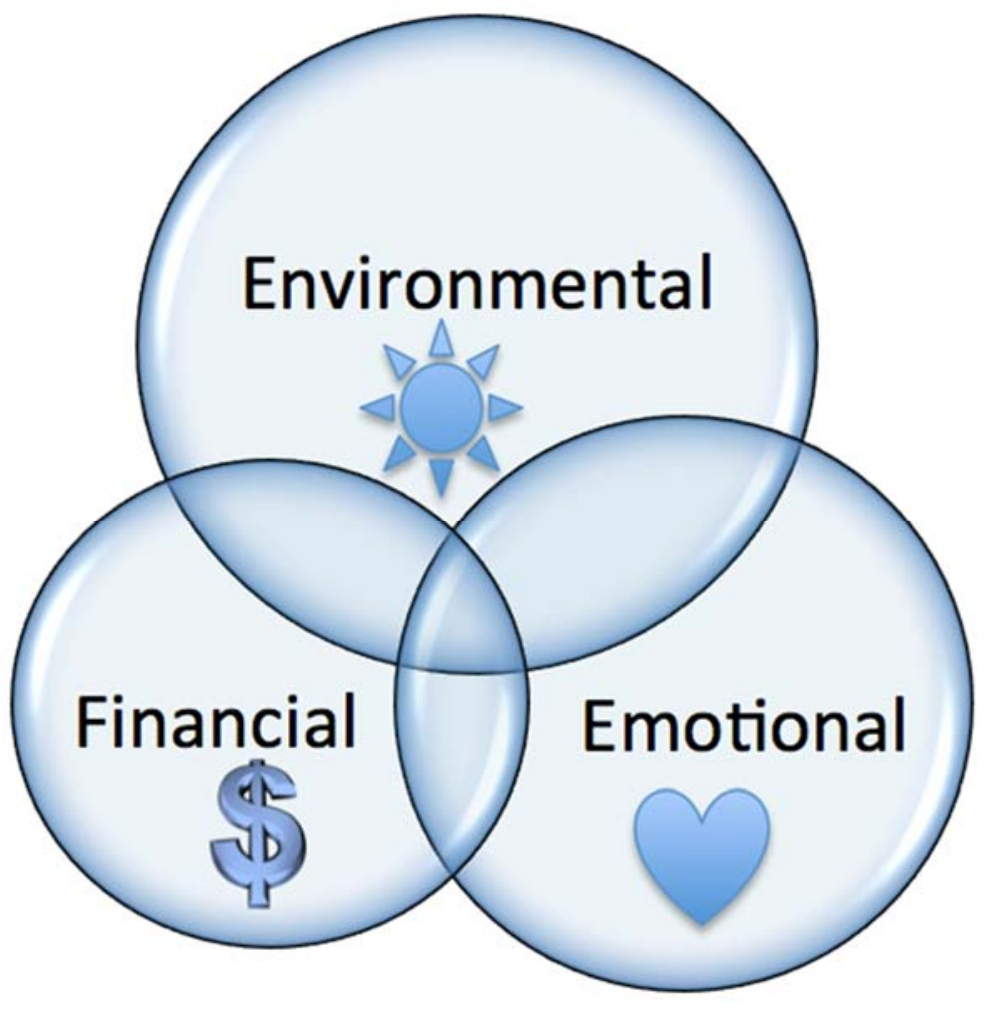

Supporting this conceptual model are many variables of influence (see Figure 31).

In this study, a central variable is Age, which seems to influence all three lenses and to interact with many other variables. For the most prominent lens of Environmental Attachment and the secondary lens of Emotional Attachment, major influential concepts include Witness to Eco-Loss and Water Immersion. These two concepts encompass many of the significant variables found in the regression models, such as concern about coral reef degradation and climate change, personal visitation and experience with coral reefs, and activities within the ocean-with surfers demonstrating the highest attachment. With 
immersive or in-the-water activities tending to show high concern, we can extrapolate and hypothesize that these in-the-water activities inspire close attachments.

Of somewhat lesser influence are concepts related to boating activity and birthplace, which demonstrated negative associations in the regressions (except for State of Birth in Sustainable Seafood). These two concepts are considered more emotional in nature. Stakeholders born outside of Florida may detach emotionally from issues considered more local in nature, and stakeholders who own and operate vessels may detach from their potential impacts on the environment.

The three variables not touching the circles occupy an uneasy position within this model. Differing from the literature, education's influence is murky, and it floats outside the model at the greatest distance. Politics lies closer and conceivably influences many variables, but its direct interactions are unclear. Income is shown as interacting with the related concepts of Discretionary Budget and Donor Inclination.

This model is highly conceptual and based on the researcher's understanding of the data. It proposes that a consumer's environmental decisions, such as willingness to pay for a product or policy, are processed through three lenses of increasing influence: the financial lens, the emotional lens, and the environmental lens. In this study, the larger emotional and environmental lenses appears to overwhelm the financial lens and its many associated concepts. The strongest lens of environmental attachment is a complex concept with likely interactions with political orientation, and it has a strong connection with an acceptance of environmental degradation. Such acceptance includes concern about climate change. 
Figure 33: How Attachments Interact to Influence Decisions

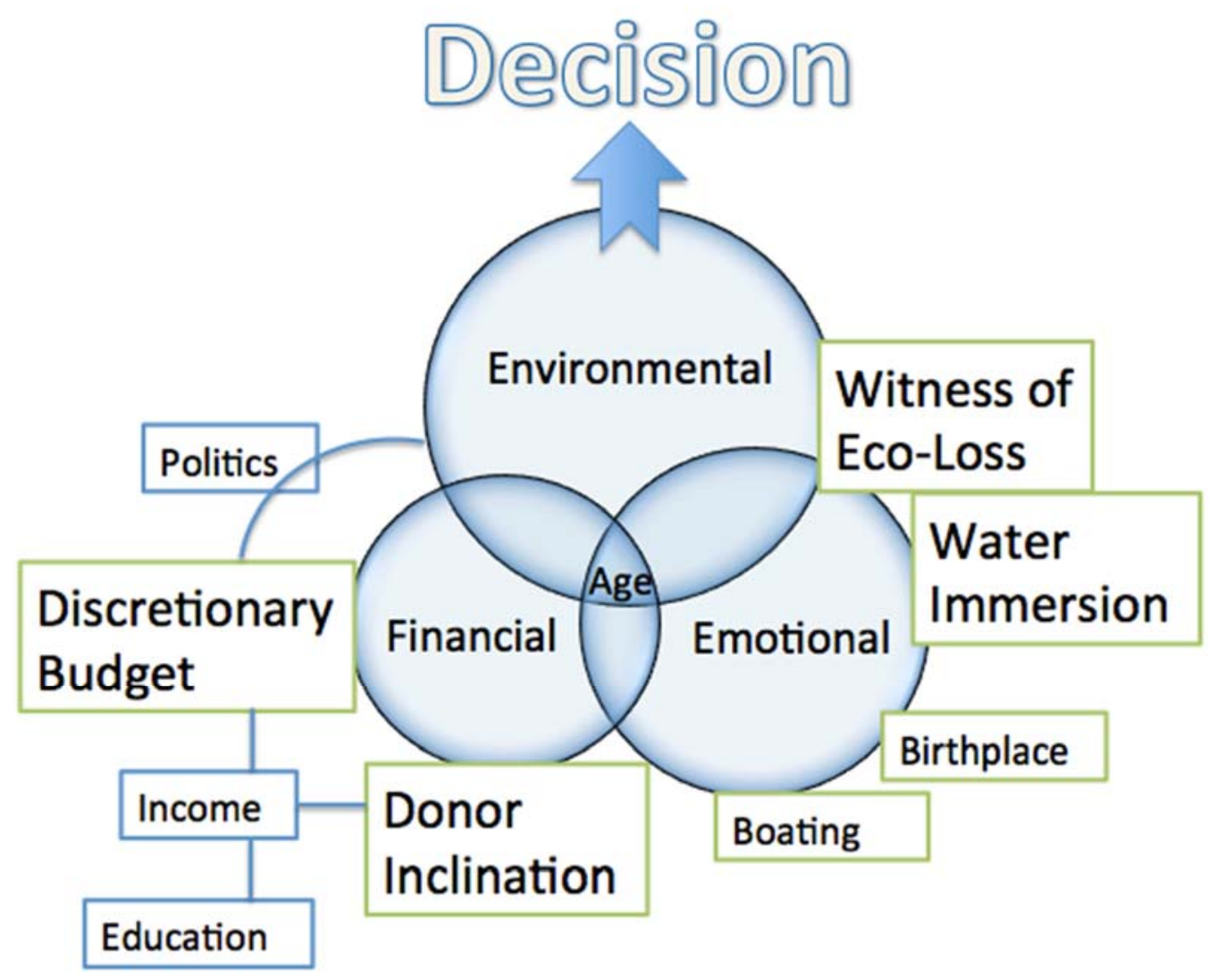




\subsection{Implications for Management}

Due to the widespread degradation of the Florida Reef during the past fifty years, any attempt to restore the system will be very costly. The good news is that residents of southeastern Florida who use the coral reefs and nearby ocean habitats, the stakeholders, are very prepared to support taxes and other means of raising revenue to improve the quality of Florida's coral reefs. It is unknown how widely such support extends to parts of the state outside of southeastern Florida and to the general public, but these groups would likely be influenced by the opinions of direct users who have intimate knowledge of the system. Perhaps the most hopeful precedent comes from another highly degraded ecosystem in southeastern Florida: the Everglades. Broad support from local, national and even international levels is evident in the multi-billion dollar Comprehensive Everglades Restoration Plan, and the links between the two systems have been widely established (Keller 2005). A system-wide restoration effort of the Florida Reef could also embrace the principles of ecosystem-based management.

Water quality in the ocean is a strong motivating factor for these stakeholders, and the scenarios that addressed the issue directly received this study's highest support. In addition, stakeholders have the highest concern about threats that affect coastal water quality, including sewage and dredging. It would be prudent for any management plan to emphasize its ability to improve coastal water quality.

Managers of coral reefs and related ecosystems have many allies within various stakeholder communities who recognize the severity of the coral reef crisis and who are prepared to support new initiatives. The status quo is not acceptable to them. The 
exceptionally large stakeholder community of recreational anglers may represent an untapped resource for managers who have tended to focus on researchers, scuba divers, and commercial fishers. The approximately 1 million saltwater anglers within Florida represent greater than $5 \%$ of the state's population, and because they form the vast majority of this study's sample, the findings apply particularly well to this community. Their support stands in stark contrast to sub-populations and interest groups of fishers who opposed the creation of the Florida Keys National Marine Sanctuary and who promote the "right to fish" above all else. These oppositional groups appear to be minorities, albeit vocal ones, who do not represent the will of the majority.

These and other implications for management are summarized below.

1. Florida Reef stakeholders express strong support for new management and funding mechanisms to improve the reef.

2. Water quality ranks as the most important factor.

3. Recreational anglers are a very large and very supportive community.

4. Both climate change and coral reef issues engender high concern. Concern about climate change appears to have risen steeply in recent years.

5. Local seafood is a very desirable, but consumers may remain unaware of its scarcity in comparison to imported seafood.

6. Status lacks influence. Instead of wealth and knowledge, motivation to support coral reef sustainability and restoration derives from emotional and environmental attachments.

As for the amount of funding that could be generated from the scenarios tested in this study, it cannot be assumed in practice that all respondents would pay these amounts or vote in favor of them. Even so, it is worthwhile to consider the financial implications if 
these scenarios were adopted by the state of Florida. The 2014 U.S. Census estimates 7.1 million households in Florida and a median household income of $\$ 47,309$, which is less than half of the median income within this study. Combining a portion of households with Table 12's Summary of WTP Scenarios, the following projections are generated.

- $\quad($ Local + Sustainable Seafood average WTP $) \times($ Half of Florida households $)=$ $\$ 5.58 /$ week x 3,550,000 households $=\$ 19.8$ million/week, or $\$ 1$ billion/year.

- $\quad($ Management Plan average WTP) $x($ All Florida households $)=\$ 6.11 /$ month $\mathrm{x}$ $7,100,000$ households $=\$ 43.4$ million $/$ month, or $\$ 520$ million/year.

- (Research Fund 2 average WTP) x (10\% of Florida median household income) $\mathrm{x}$ (All Florida households $)=(0.7 \%$ tax $\times \$ 4,731) \times 7,100,000=\$ 235$ million $/$ year. These projections make many assumptions, particularly that the responses of stakeholders would apply to all Florida residents, and they must be considered crude estimates, but they demonstrate that statewide implementation of any scenario would generate substantial income. The seafood scenario does not fund coral reef restoration directly, although this mechanism would likely generate some restoration income through conservation mechanisms. The other two scenarios are competitors for taxation, and the implementation of one would likely prohibit the other. Research Fund2's amount would receive matching federal funds for an annual total of $\$ 470$ million. If implemented over ten years, this scenario would generate $\$ 4.7$ billion. This amount is within the realm but lower than estimates for the completion of the Comprehensive Everglades Restoration Plan (Keller 2008). 


\subsection{Limitations}

Because participants are solicited online, the sample excludes people without an available email address or sufficient computer access. This exclusion would tend to eliminate people with a low-income or with a high protection of privacy. It also lacks the confirmation of identity and the immediacy of a survey conducted in person. Although some respondents may assume false identities online, it is assumed that those participants are very few and that their responses are sufficiently inconsistent to avoid tainted results.

The fishing community has exhibited resistance to previous surveys (Suman 2008); thus, they have been over-sampled to accommodate this concern. Even so, those willing to complete the survey may not be representative of the population of fishers.

The concern about a lack of basic awareness about coral reefs is overcome by the sampling of stakeholders, who are assumed to have higher knowledge than the general public.

This survey assesses awareness without providing much information that could be informative for the respondent. Albeit necessary, this limitation is regrettable, considering that coral reefs face dire threats that are expected to have great impacts on society within the coming decades.

\subsection{Areas for Further Research}

The current study's data has potential to be analyzed further, and each scenario deserves further investigation and consideration for standalone studies. A plan has been 
developed to investigate the choice experiment's data and to analyze it in a similar manner to the other two scenarios.

Future research could replicate and extend the current study to a broader population, such as the state of Florida or the United States. For the sake of comparison with the current findings of stated preferences, a new study could seek revealed preferences, particularly for seafood, and it could replicate in Florida the supermarket experiment conducted in California by Hallstein (2013).

As mentioned previously, the total economic value of the Florida Reef remains unknown, and this research gap should be of the highest priority. The meta-analysis by Brander (2013) found that Florida lacked a single study for six of the twelve main ecosystem service areas for coral reef valuation.

The Florida Reef deserves the same level of attention and research that has been applied to the Florida Everglades, and the history of Everglades' research provides a good model. Many studies of the Everglades have benefited from an interdisciplinary, teambased approach, and the Florida Reef is sufficiently large and complex to necessitate such collaboration.

A major research question has developed from the current study: why does status lack influence in stakeholders' decisions? Environmental researchers cannot assume that that education and income affect environmental decisions in the same manner as they affect other consumer decisions. Does the general public form decisions differently than stakeholders?

Other studies could look more closely at the psychology behind relationships with ocean environments, because these are located outside of human habitation and therefore 
require higher levels of imagination or conceptualization than terrestrial habitats that are more easily explored and interpreted. The lack of understanding and awareness of the ocean remains a hindrance to all such studies.

"Climate change" may have displaced "global warming" as the most common umbrella term used within the scientific literature, but this change may not have been adopted by the public. Limited studies indicate that some confusion exists about these terms, and it would be useful to clarify the limitations relating to both.

Finally, the large-scale processes of climate change and ecosystem degradation may be difficult for stakeholders to process and analyze. In comparison to the decline of a single species, such as the bald eagle, the shift of a complex system such as a rainforest or a coral reef may be overly nuanced or dependent on so many factors as to render it indigestible, even to specialized scientists. Yet the same could be said for "society" and "gender" and other complex concepts that are routinely investigated. It is worth this risk to find greater understanding. 


\section{REFERENCES}

Acock, A.C. (2012). A Gentle Introduction to Stata. Revised 3rd Edition. College Station, Texas: Stata Press.

Appeltans, W., Ahyong, S. T., Anderson, G., Angel, M. V., Artois, T., Bailly, N., et al. (2012). The magnitude of global marine species diversity. Current Biology, 22(23), 2189-2202.

Baker, A.C., Glynn, P.W., and Riegl, B. (2008) Climate change and coral reef bleaching: An ecological assessment of long-term impacts, recovery trends and future outlook. Estuarine, Coastal and Shelf Science, 80, 435-471.

Banks, K.W. et al. (2008). The Reef Tract of Continental Southeast Florida. Coral Reefs of the USA. Dordrecht, NLD: Springer. E-book: http://site.ebrary.com/ id/10223642?ppg=192

Barker, C. (2013). U.S. stands out as among the least concerned about climate change. Pew Research Center. Website. http://www.pewresearch.org/facttank/2013/09/27/u-s-stands-out-as-among-the-least-concerned-about-climatechange/

Berry, L., Boukerrou, L., Mehallis, M., Lirman, D., Grecsek, C., \& Lambright, D. (2011). FDOU Project 23: Evaluation of the Potential for a Marine Zoning Area for Southeast Florida. Florida Department of Environmental Protection. Miami, FL. 209 pp.

Bhat, M. (2003). Application of non-market valuation to the Florida Keys marine reserve management. Journal of Environmental Management, 67(4), 315-325. doi:10.1016/S0301-4797(02)00207-4

Bradbury, R.H. and Seymour, R.M. (2009). Coral reef science and the new commons. Coral Reefs, 28(4), 831-837.

Brainard, R.E., Birkeland, C., Eakin, C.M., McElhany, P., Miller, M.W., Patterson, M., and Piniak, G.A. (2011). Status review report of 82 candidate coral species petitioned under the U.S. Endangered Species Act. U.S. Dep. Of Commerce, NOAA Tech. Memo., NOAA-TM-NMFS-PIFSC-27. Available at: http://www.nmfs.noaa.gov/stories/2012/05/07_coral_documents_page.html

Brander, L. and van Beukering, P. (2013). The Total Economic Value of U.S. Coral Reefs: A Review of the Literature. NOAA Coral Reef Conservation Program. Silver Spring, MD: NOAA. 
Brevard County Natural Resources Management Office (2009). The Apportionment of Probable Benefits and Fees Under a Proposed MSBU for Brevard County's South Beaches. Prepared by PRÆCIPIO EFS, Inc., PMG Associates Inc., Olsen Associates Inc. Available at: http://www.brevardcounty.us/ NaturalResources/Beaches/RestorationProjects

Brown, L.R. (2012). Full planet, empty plates: The new geopolitics of food scarcity. New York: W.W. Norton \& Company.

Burke, L., Reytar, K., Spalding, M., and Perry, A. (2011). Reefs at Risk Revisited. World Resources Institute, Washington, DC.

Campling, L., Havice, E., and Howard, P.M. (2012). The Political Economy and Ecology of Capture Fisheries: Market Dynamics, Resource Access and Relations of Exploitation and Resistance. Journal of Agrarian Change, 12(2-3), 177-203.

Cantrell, R.N., Garcia, M., Leung, P., and Ziemann, D. (2004). Recreational anglers' willingness to pay for increased catch rates of Pacific threadfin (Polydactylus sexfilis) in Hawaii. Fisheries Research, 68, 149-158.

doi:10.1016/j.fishres.2004.01.003

Cinner, J.E. et al. (2012). Comanagement of coral reef social-ecological systems. Proceedings of the National Academy of Sciences, 109(14), 5219-5222.

Cocking, S. (2014). National recreational policy in works. Miami Herald, April 6. http://www.miamiherald.com/2014/04/06/4041747/national-recreational-policyin.html

Cooke, S.J. and Cowx, I.G. (2006). Contrasting recreational and commercial fishing: Searching for common issues to promote unified conservation of fisheries resources and aquatic environments. Biological Conservation, 128, 93-108. doi:10.1016/j.biocon.2005.09.019

Costanza, R. et al. (1997). The value of the world's ecosystem services and natural capital. Nature, 387, 253-260.

Costanza, R. et al. (2014). Changes in the global value of ecosystem services. Global Environmental Change, 26, 152-158.

Crabbe, M.J.C. (2009). Climate change and tropical marine agriculture. Journal of Experimental Botany, 60, 2839-2844.

DeHaven-Smith, L. (1991). Environmental concern in Florida and the nation. Gainesville: University of Florida Press. 
Devine-Wright, P. (2013). Think global, act local? The relevance of place attachments and place identities in a climate changed world. Global Environmental Change, 23, 61-69.

Ditton, R., and Stoll, J. Social and economic perspective on recreational billfish fisheries. (2003). Marine and Freshwater Research, 54(4), 545-554.

Edge Research (2002). Public knowledge and attitudes about coral reefs: Results of a national survey of U.S. adults. Conducted By Edge Research on behalf of CRF, The Munson and Henry Foundations, and SeaWeb.

Edge Research (2008). Coral 2007: Americans' awareness and attitudes toward coral threats: Report of national survey findings.

Fenner, D. (2012). Challenges for Managing Fisheries on Diverse Coral Reefs. Diversity, 4, 105-160. doi: $10.3390 / \mathrm{d} 4010105$

Florida Department Of Environmental Protection (2008). Session 2008 Legislative Summary. Wastewater Disposal/Ocean Outfalls, Senate Bill 1302. Available at: http://www.dep.state.fl.us/secretary/leg/2008\%20_legis_summ2.pdf

Florida Fish and Wildlife Conservation Commission (FFWCC). (2014). Recreational Saltwater Licenses \& Permits (Available at: http://myfwc.com/license/ recreational/saltwater-fishing/). Fishing licenses downloaded from Explorer database, October 2013.

Florida Fish and Wildlife Conservation Commission, Fish and Wildlife Research Institute (FWRI). (2013). Unified Florida Coral Reef Tract Map. Available at: http://www.arcgis.com/home/item.html?id=6837a60d7b294016b6250b7bdea4dd43

Florida Keys National Marine Sanctuary (2007). Revised management plan. Key West, Florida: U.S. Department of Commerce, National Oceanic and Atmospheric Administration, National Ocean Service, National Marine Sanctuary Program. http://floridakeys.noaa.gov/mgmtplans/2007_man_plan.pdf

Florida Ocean Alliance (2013). Florida's Oceans and Coasts: An Economic and Cluster Analysis. Available at: http://www.floridaoceanalliance.org

Flugman, E., Mozumder, P., and Randhir, T. (2012). Facilitating adaptation to global climate change: Perspectives from experts and decision makers serving the Florida Keys. Climatic Change, 112(3-4), 1015-1035.

Fogarty, N.D. (2012). Caribbean Acroporid coral hybrids are viable across life history stages. Marine Ecology-Progress Series, 446. doi:10.3354/meps09469 
Frieler, K., Meinshausen, M., Golly, A., Mengel, M., Lebek, K., Donner, S.D., and Hoegh-Guldberg, O. (2013). Limiting global warming to 2 degrees $\mathrm{C}$ is unlikely to save most coral reefs. Nature Climate Change, 3(2), 165-170. doi:10.1038/NCLIMATE1674

Gazzani, F., \& Marinova, D. (2007). Using choice modelling to account for biodiversity conservation: Non-use value for Ningaloo reef. MODSIM07 - Land, Water and Environmental Management: Integrated Systems for Sustainability. Modelling and Simulation Society of Australia and New Zealand, Christchurch, pp. 2721.

Ghermandi, A., Nunes, P.A.L.D., Portela, R., Nalini, R. and Teelucksingh, S.S. (2011). Recreational, Cultural and Aesthetic Services from Estuarine and Coastal Ecosystems. 12.11, 217-237. Elsevier Inc.

Gilliam, D.S. (2010). Southeast Florida Coral Reef Evaluation and Monitoring Project 2009 Year 7 Final Report. Florida DEP report \#RM085. Miami Beach, FL: FDEP.

George, P. (1996). Miami: One Hundred Years Of History. South Florida History, 24(2). Available at: http://www.historymiami.org/research-miami/topics/history-ofmiami/

Gregg, K. (2013). Literature review and synthesis of land-based sources of pollution affecting essential fish habitats in southeast Florida. West Palm Beach, FL: NOAA.

Guber, D. L. 2003. The Grassroots of a green revolution: polling America on the environment. Cambridge, Mass: MIT Press.

Hallstein, E. and Villas-Boas, S.B. (2013). Can household consumers save the wild fish? Lessons from a sustainable seafood advisory. Journal of Environmental Economics and Management, 66, 52-71.

Hannah, L.J. (2012). Saving a million species: Extinction risk from climate change. Washington, DC: Island Press.

Hardin, G. (1968). The Tragedy of the Commons. Science, 162, 1243-8.

Harnik, P.G. et al. (2012). Extinctions in ancient and modern seas. Trends in Ecology \& Evolution, 27(11), 608-617.

Hilborn, R., and Hilborn, U. (2012). Overfishing: What Everyone Needs to Know. Oxford: Oxford University Press.

Hoegh-Guldberg, O. (2011). Coral reef ecosystems and anthropogenic climate change. Regional Environmental Change, 11, S215-S227. doi:10.1007/s10113-010-0189-2 
Huang, D. (2012). Threatened Reef Corals of the World. PLoS ONE 7(3): e34459. doi:10.1371/journal.pone.0034459

IUCN Red List Summary Statistics (2013). Trends in the status of biodiversity. Available at: www.iucnredlist.org/about/summary-statistics\#TrendsInBiodiversityStatus

Johns, G.M., Leeworthy, V.R., Bell, F.W., and Bonn, M.A. (2003). Socioeconomic Study of Reefs in Southeast Florida. Final Report. Hazen and Sawyer Environmental Engineers \& Scientists.

Johns, G.M., Milon, J.W. and Sayers, D. (2004). Socioeconomic Study of Reefs in Martin County, FL. Final Report. Hazen and Sawyer Environmental Engineers \& Scientists.

Keith, D. et al. (2013). Scientific Foundations for an IUCN Red List of Ecosystems. PLoS ONE 8(5):e62111. doi:10.1371/journal.pone.0062111

Keith, D. and Spalding, M. (2013). Caribbean Coral Reefs, 167-171. Supplementary Material Appendix S2. Scientific Foundations for an IUCN Red List of Ecosystems. PloS ONE, 8(5):e62111.

Keller, B.D. and Causey, B.D. (2005). Linkages between the Florida Keys National Marine Sanctuary and the South Florida Ecosystem Restoration Initiative. Ocean \& Coastal Management, 48, 69-90.

Kellison, G.T. et al. (2012). Coral Reef Fish Assemblage shifts and declines in Biscayne National Park, Florida, USA. Bulletin of Marine Science 88(1), 147-182.

Kittinger, J.N., Finkbeiner, E.M., Glazier, E.W., and Crowder, L.B. (2012). Human dimensions of coral reef social-ecological systems. Ecology and Society, 17(4). http://dx.doi.org/10.5751/ES-05115-170417

Koopman, B., Heaney, J. P. (2006). Ocean Outfall Study: Final Report. Department of Environmental Engineering Sciences, University of Florida. Available at: http://www.dep.state.fl.us/water/reuse/docs/OceanOutfallStudy.pdf

Leiserowitz, A., and Broad, K. (2008). Florida: Public opinion on climate change. A Yale University / University of Miami / Columbia University Poll. New Haven, CT: Yale Project on Climate Change. Available at: http://environment.yale.edu/leiserowitz/climatechange/US.html

Londoño, L.M., and Johnston, R.J. (2012). Enhancing the reliability of benefit transfer over heterogeneous sites: A meta-analysis of international coral reef values. Ecological Economics, 78, 80-89. doi:10.1016/j.ecolecon.2012.03.016 
Lovell, S., Steinback, S. and Hilger, J. (2013). The Economic Contribution of Marine Angler Expenditures in the United States, 2011. U.S. Dep. Commerce, NOAA Tech. Memo. NMFS-F/SPO-134, 188 p.

Maciejewski, P.K., Zhang, B., Block, S.D., and Prigerson, H.G. (2007). An Empirical Examination of the Stage Theory of Grief. JAMA, 297(7), 716-723. doi:10.1001/jama.297.7.716.

Maibach, E., Roser-Renouf, C., and Leiserowitz, A. (2009). Global Warming's Six Americas 2009: An audience segmentation analysis. Yale Project on Climate Change and the George Mason University Center for Climate Change Communication.

Mankiw, N. G. (2001). Principles of economics. Fort Worth, TX: Harcourt College Publishers.

McClenachan, L. (2009). Documenting loss of large trophy fish from the Florida Keys with historical photographs. Conservation Biology, 23(3), 636-643. doi:10.1111/j.1523-1739.2008.01152.x

McClenachan, L. (2013). Recreation and the "right to fish" movement: Anglers and ecological degradation in the Florida Keys. Environmental History, 18(1), 76-87. doi:10.1093/envhis/ems110

McClenachan, L., Ferretti, F., and Baum, J.K. (2012). From archives to conservation: Why historical data are needed to set baselines for marine animals and ecosystems. Conservation Letters, 5(5), 349-359. doi:10.1111/j.1755263X.2012.00253.x

McCright, A.M., Dunlap, R.E., \& Xiao, C. (2013). Perceived scientific agreement and support for government action on climate change in the USA. Climatic Change, 119(2), 511-518 DOI 10.1007/s10584-013-0704-9

McDonald's (2014). Sustainable Fisheries. Website. Available at: http://www.mcdonalds.com/us/en/supplierstories.html\#/fish

Mendenhall, W. and Sincich, T. (2012). A Second Course in Statistics: Regression Analysis, 7th ed. Boston: Prentice Hall.

Miller, G. T., \& Spoolman, S. (2008) Environmental Science: Problems, Concepts, and Solutions. Twelfth Ed. Belmont, CA: Brooks/Cole.

Monterey Bay Aquarium (2014). Seafood Watch National Sustainable Seafood Guide. Available at: http://www.seafoodwatch.org/cr/seafoodwatch.aspx 
Mote Marine Laboratory (2014). Protect Our Reefs Grant Program. Tropical Research Laboratory, Summerland Key, Florida. Website:

http://isurus.mote.org/Keys/reef_plate.phtml

National Marine Fisheries Service (2010). Fisheries Economics of the United States, 2009. U.S. Dept. Commerce, NOAA. Tech. Memo. NMFS-F/SPO-118, 172p. Available at: https://www.st.nmfs.noaa.gov/st5/publication/index.html.

NOAA Coral Reef Conservation Program (2008). A Classification Scheme for Mapping the Shallow-water Coral Ecosystems of Southern Florida, Version 3.2. http://ccma.nos.noaa.gov/ecosystems/coralreef/fl_mapping/FLClassScheme.pdf

NOAA Coral Reef Conservation Program (2011). Implementation Of The National Coral Reef Action Strategy. U.S. Department Of Commerce.

NOAA Fisheries (2012). Endangered Species Act recovery outline: elkhorn \& staghorn corals. http://sero.nmfs.noaa.gov/pr/endangered $\% 20$ species/ Updated\%20Recovery\%20Outline.pdf

Office of National Marine Sanctuaries (ONMS) (2011). Florida Keys National Marine Sanctuary Condition Report 2011. U.S. Department of Commerce, National Oceanic and Atmospheric Administration, Office of National Marine Sanctuaries, Silver Spring, MD. 105 pp. Available at:

http://Floridakeys.noaa.gov/scipublications/condition.html

Oh, C., Ditton, R., Anderson, D., Scott, D., and Stoll, J. (2005). Understanding differences in nonmarket valuation by angler specialization level. Leisure Sciences, 27(3), 263-277.

Ohashi, T. (2010) Challenges Faced by the U.S. Fishery Policy in Overcoming Overfishing in Federally Managed Waters: Shifting from Traditional to Responsible Fishery Management for Sustainable Seafood. The Japanese Journal of American Studies, 21, 189-210.

Ostrom, E. (2000). Collective Action and the Evolution of Social Norms. The Journal of Economic Perspectives, 14(3), 137-158.

Ostrom, E. (1990). Governing the commons: the evolution of institutions for collective action. Cambridge: Cambridge University Press.

Palumbi, S. et al. (2012). Support the consensus statement on climate change and coral reefs. Twelfth International Coral Reef Symposium. Center for Ocean Solutions working group. Available at: http://www.icrs2012.com/Consensus_Statement.htm 
Pandolfi, J.M., Connolly, S.R., Marshall, D.J., \& Cohen, A.L. (2011). Projecting coral reef futures under global warming and ocean acidification. Science, 333(6041).

Park, T., Bowker, J.M., \& Leeworthy, V.R. (2002). Valuing snorkeling visits to the Florida Keys with stated and revealed preference models. Journal of Environmental Management, 65, 301-312.

Parkes, G., et al. (2009). Review of Fish Sustainability Information Schemes Final Report. MRAG Ltd. Marine Resources Assessment Group. Available at: www.mrga.co.uk

Pita, C., Pierce, G.J., Theodossiou, I., and Macpherson, K. (2011). An overview of commercial fishers' attitudes towards marine protected areas. Hydrobiologia, 670(1), 289-306. doi:10.1007/s10750-011-0665-9

Ponte, S. (2012). The Marine Stewardship Council (MSC) and the Making of a Market for 'Sustainable Fish'. Journal of Agrarian Change, 12(2-3), 300-315.

Precht, W.F. (2006). Coral reef restoration handbook. Boca Raton, FL: CRC/Taylor \& Francis.

Qualtrics 2013. Survey Software. Provo, UT. Website:

http://www.qualtrics.com/university/researchsuite

Rau, G.H., McLeod, E.L., \& Hoegh-Guldberg, O. (2012). The need for new ocean conservation strategies in a high-carbon dioxide world. Nature Climate Change, 2(10), 720-724. doi:10.1038/NCLIMATE1555

Riegl, B.M. \& Purkis, S. (2011). Methods to preserve coral reef futures. E-letter, Science. Available at: http://www.sciencemag.org/content/333/6041/418/reply\#sci_el_15719

Roney, J.M. (2012). Taking Stock: World Fish Catch Falls to 90 Million Tons in 2012. Washington, DC: Earth Policy Institute. Website. Available at: http://www.earth-policy.org/indicators/C55/fish_catch_2012

Ropicki, A.J., Larkin, S.L., and Adams, C.M. (2010). Seafood substitution and mislabeling: WTP for a locally caught grouper labeling program in Florida. Marine Resource Economics, 25, 77-92.

Ruttenberg, B.I., and Granek, E.F. (2011). Bridging the marine-terrestrial disconnect to improve marine coastal zone science and management. Marine Ecology Progress Series, 434, 203-212. doi:10.3354/meps09132 
Salz, R.J., and Loomis, D.K. (2004). Saltwater Anglers' Attitudes towards Marine Protected Areas. Fisheries, 29(6), 10-17. doi: 10.1577/1548-

8446(2004)29[10:saatmp]2.0.co;2

Scannell, L. and Gifford, R. (2013). Personally Relevant Climate Change: The Role of Place Attachment and Local Versus Global Message Framing in Engagement. Environment and Behavior, 45(1) 60-85.

Shivlani, M. (2006). Florida department of environmental protection (DEP) coral reef needs assessment study. Miami, FL: Florida Department of Environmental Protection.

Shivlani, M. and Estevanez, M. (2011). Development of management alternatives for the southeast Florida region according to stakeholder working panels. Miami Beach, FL: Florida Department of Environmental Protection.

Shivlani, M., Leeworthy, V.R., Murray, T.J., Suman, D.O., and Tonioli, F. (2008). Knowledge, attitudes and perceptions of management strategies and regulations of the Florida Keys National Marine Sanctuary by commercial fishers, dive operators, and environmental group members: A baseline characterization and 10year comparison. Silver Spring, Maryland: U.S. Department of Commerce, National Oceanic and Atmospheric Administration, Office of National Marine Sanctuaries.

Shivlani, M., Letson, D. and Theis, M. (2003). Visitor Preferences for Public Beach Amenities and Beach Restoration in South Florida, Coastal Management, 31(4), 367-385. doi: 10.1080/08920750390232974

Shivlani, M. and Villanueva, M. (2007). A compilation and comparison of social perceptions on reef conditions and use in southeast Florida. Miami, FL: Florida Department of Environmental Protection.

Shoyama, K., Managi, S. \& Yamagata,Y. (2013). Public preferences for biodiversity conservation and climate-change mitigation: A choice experiment using ecosystem services indicators. Land Use Policy, 34, 282-293. http://dx.doi.org/10.1016/j.landusepol.2013.04.003

Southeast Florida Coral Reef Initiative (SEFCRI) (2014). Coral Reef Protection Act. Website: http://www.southeastfloridareefs.net/coral-relief/coral-reef-protection-act/

StataCorp (2013). Stata: Release 13. Statistical Software. College Station, TX: StataCorp LP. 
Street, D.J., Burgess, L. \& Louviere J.J. (2005). Quick and easy choice sets: Constructing optimal and nearly optimal stated choice experiments. International Journal of Research in Marketing, 22(4),459-470. http://dx.doi.org/10.1016/j.jiresmar.2005.09.003

Suman, D., Shivlani, M., and Milon, J. (1999). Perceptions and attitudes regarding marine reserves: A comparison of stakeholder groups in the Florida Keys National Marine Sanctuary. Ocean \& Coastal Management, 42(12), 1019-1040.

Tans, P. (2014). Trends in Atmospheric Carbon Dioxide. NOAA Earth System Research Laboratory. Accessed May 2014. Website: www.esrl.noaa.gov/gmd/ccgg/trends/

Tawfik, R. T., \& Turner, R. K. (2010). Visitor preferences for coral reef conservation in Ras Mohammed National Park. Norwich: United Kingdom: Centre for Social and Economic Research on the Global Environment, University of East Anglia.

Tietenberg, T. H. (2000). Environmental and natural resource economics. Reading, MA: Addison-Wesley.

Trenor, C. (2011). Carting Away the Oceans V. Greenpeace. Available at: http://www.greenpeace.org/usa/en/media-center/reports/Carting-Away-theOceans-V

Turvey, S., ed. (2009). Holocene extinctions. Oxford: Oxford University Press.

United Nations (2005). Graphic Resources, Millennium Ecosystem Assessment. Available at: http://www.millenniumassessment.org/en/GraphicResources.html

United Nations (2012). World Review of Fisheries and Aquaculture Part I. The State of World Fisheries and Aquaculture. FAO Fisheries and Aquaculture Department. Available at: http://www.fao.org/docrep/016/i2727e/i2727e01.pdf

URI Sustainable Seafood Initiative. (2012). Seafood Guides. University of Rhode Island Website. Available at: http://seagrant.gso.uri.edu/sustainable_seafood/guides.html

U.S. Bureau of Labor Statistics (2010). The Recession of 2007-2009. BLS Spotlight on Statistics. Available at: http://www.bls.gov/spotlight/2012/recession/ pdf/recession_bls_spotlight.pdf

U.S. Census Bureau (2014). State \& County QuickFacts. Accessed April 2014. Website: http://quickfacts.census.gov/qfd/states/12000.html

Van Beukering, P., Brander, L., van Zanten, B., Verbrugge, E., and Lems, K. (2011). The Economic Value of the Coral Reef Ecosystems of the United States Virgin Islands. Report number: R-11/06. IVM Institute for Environmental Studies. 
Van Lange, P.A.M., Joireman, J., Parks, C.D., and Van Dijk, E. (2013). The psychology of social dilemmas: A review. Organizational Behavior and Human Decision Processes, 120, 125-141.

Veron, J.E.N. (2008). A reef in time: the Great Barrier Reef from beginning to end. Cambridge, Mass: Belknap Press of Harvard University Press.

Veron, J.E.N., et al. (2009). The coral reef crisis: the critical importance of $<350 \mathrm{ppm}$ CO2. Marine Pollution Bulletin, 58, 1428-1436.

Wadlow, K. (2014). County Commission tells Biscayne National Park chief that proposed fishing limits are unacceptable. Keysinfonet. February 22. Available at: http://www.keysnet.com/2014/02/22/494811/county-commission-tellsbiscayne.html

Waite, R., et al. (2014). Coastal Capital: Ecosystem Valuation for Decision Making in the Caribbean. Washington, DC: World Resources Institute. Accessible at: http://www.wri.org/coastal-capital

Watson, R. and Howell, B. (2013). Closing the Coral Commons to Support Reef Restoration in Florida. In Conservation \& the Environment: Conservative Values, New Solutions. Property and Environment Research Center. Website: http://perc.org/articles/closing-coral-commons-support-reef-restoration-florida

Wilkinson, C., and Salvat, B. (2012). Coastal resource degradation in the tropics: Does the tragedy of the commons apply for coral reefs, mangrove forests and seagrass beds. Marine Pollution Bulletin, 64(6), 1096-1105. doi:10.1016/j.marpolbul.2012.01.041

Williams, D.E. and Miller, M.W. (2012). Attributing mortality among drivers of population decline in Acropora palmata in the Florida Keys (USA). Coral Reefs, 31, 369-382.

Zander, K.K., Garnett, S.T., and Straton, A. (2010). Trade-offs between development, culture and conservation -- Willingness to pay for tropical river management among urban Australians. Journal of Environmental Management, 91, 2519-2528. doi:10.1016/j.jenvman.2010.07.01

Zwerdling, D. and Williams, M. (2013). For A Florida Fishery, 'Sustainable' Success After Complex Process. National Public Radio. February 11. Available at: http://www.npr.org/2013/02/12/171376575/for-a-florida-fishery-sustainablesuccess-after-complex-process 


\section{APPENDICES}

Appendix 1: Stakeholder Sample Creation

Appendix 2: Email Invitation

Appendix 3: Survey Instrument

Appendix 4: Emails from Respondents

Appendix 5: Sub-Variables related to Main Variables 


\section{Appendix 1}

Stakeholder Sample Creation:

Compilation of the Stakeholder Sample for

Diving, Boating, and Education and Other

The four main strata of Fishing, Diving, Boating, and Education and Other were compiled using the steps below. Because the survey was distributed only by email, contacts without available email addresses were eliminated.

A foundational list of highly-engaged stakeholders was obtained from the database of the Southeast Florida Coral Reef Initiative (SEFCRI), and this list was supplemented through online searches and direct calls to contacts.

Fishing

1. A public records request was sent to the Florida Fish and Wildlife Conservation Commission to obtain a list of commercial and recreational fishing licenses.

2. A list of known fishing clubs and tournaments in the SEFCRI region was generated from SEFCRI contacts.

a. Fishing clubs and tournaments were contacted by a general email address and asked to provide the email addresses for five individuals affiliated with that operation. Response rates were low.

Diving

1. Recreational: A list of all known recreational diving operations in the SEFCRI region was generated from SEFCRI contacts.

a. Each recreational diving operation was contacted by email and asked to provide the email addresses for five individuals affiliated with that operation. Response rates were low.

2. Commercial: A list of at least 26 commercial divers was generated for email solicitation. The list was obtain by an online search on http://www.yellowpages.com for: ["commercial diving companies" near "south florida fl"], resulting in 82 businesses from this website: http://www.yellowpages.com/south-florida-fl/commercial-diving-companies

a. Selected top ten (10) of this search

b. Selected top two (2) each of revised searches, using location as near "Miami," "Fort Lauderdale," and "West Palm Beach."

3. Clubs: Selected first 10 results from Google search of: [scuba organizations "south florida"].

Boating

1. A list of known boating clubs and tournaments was generated from SEFCRI and updated from online sources. 
Education and Other:

1. A list of universities, nonprofits, and highly-engaged stakeholders was generated from SEFCRI and updated from online sources.

a. This list included 92 citizens who attended a community meeting in the summer of 2013, sponsored by SEFCRI, to launch its new outreach program, Our Florida Reefs.

b. Many individuals had served in a volunteer capacity for SEFCRI.

2. A list of media from personal sources was created to represent news outlets across the region, with an emphasis on identifying reporters who cover the environment, outdoors, fishing, or marine-related activity.

Lists of contacts were uploaded into the online system Qualtrics, and its email system was used to distribute invitational emails. 


\section{Appendix 2}

\section{Email Invitation}

Subject: Your opinions needed on S. Florida coastal economy

Dear [insert email address or name],

You have been selected to complete an important new survey about South Florida's coastal resources, especially coral reefs. Our tourism-based economy depends on South Florida's natural beauty and resources.

This survey gives you an opportunity to express your ideas and concerns about these resources. Findings will be shared with coastal experts and with state and national decision-makers.

This interesting and anonymous survey should take approximately 15 minutes to complete. Your participation is vital and sincerely appreciated.

\section{Follow this link to the Survey:}

$\$\{1: / /$ SurveyLink? $\mathrm{d}=$ Take the Survey $\}$

Or copy and paste the URL below into your internet browser:

$\$\{1: / /$ SurveyURL $\}$

Thank you for supporting this timely research.

Sincerely,

James W. Harper

jharp002@fiu.edu

Follow the link to opt out of future emails:

$\$\{1: / /$ OptOutLink?d=Click here to unsubscribe $\}$ 


\title{
Appendix 3
}

Survey Instrument

\begin{abstract}
ADULT CONSENT TO PARTICIPATE IN A RESEARCH STUDY
Attitudes about Coral Reefs and Levels of Environmental Concern in Urban Southeastern Florida
\end{abstract}

\section{PURPOSE OF THE STUDY}

You are being asked to be in a research study. The purpose of this study is to investigate current concerns about the environment and coral reefs in southeastern Florida.

NUMBER OF STUDY PARTICIPANTS

If you decide to be in this study, you will be one of 350 people in this research study.

\section{DURATION OF THE STUDY}

Your participation will require approximately 15 to 25 minutes.

\section{PROCEDURES}

If you agree to be in the study, you will be asked to do the following things: 1 . Complete the online survey one time with honest answers.

\section{RISKS AND/OR DISCOMFORTS}

There are no known risks associated with your participation in this study.

\section{BENEFITS}

There are no known benefits may be associated with your participation in this study.

\section{ALTERNATIVES}

There are no known alternatives available to you other than not taking part in this study. However, any significant new findings developed during the course of the research that may relate to your willingness to continue participation will be provided.

\section{CONFIDENTIALITY}

The records of this study will be kept private and will be protected to the fullest extent provided by law. In any sort of report we might publish, we will not include any information that will make it possible to identify a subject. Research records will be stored securely and only the researcher team will have access to the records. However, 
your records may be reviewed for audit purposes by authorized University or other agents who will be bound by the same provisions of confidentiality.

\section{COMPENSATION \& COSTS}

There is no payment for your participation. You will not be responsible for any costs to participate in this study.

\section{RIGHT TO DECLINE OR WITHDRAW}

Your participation in this study is voluntary. You are free to participate in the study or withdraw your consent at any time during the study. Your withdrawal or lack of participation will not affect any benefits to which you are otherwise entitled. The investigator reserves the right to remove you without your consent at such time that they feel it is in the best interest.

\section{RESEARCHER CONTACT INFORMATION}

If you have any questions about the purpose, procedures, or any other issues relating to this research study you may contact James Harper at Florida International University, 305-893-6214,jharp002@fiu.edu.

\section{IRB CONTACT INFORMATION}

If you would like to talk with someone about your rights of being a subject in this research study or about ethical issues with this research study, you may contact the FIU Office of Research Integrity by phone at 305-348-2494 or by email at ori@fiu.edu.

\section{PARTICIPANT AGREEMENT}

I have read the information in this consent form and agree to participate in this study. I have had a chance to ask any questions I have about this study, and they have been answered for me. I understand that I am entitled to a copy of this form after it has been read and signed.

Consent I have read, understood, and printed or copied the above consent form (if desired), and desire of my own free will to participate in this study.

O Yes (1)*

No (2)

If No Is Selected, Then Skip To End of Survey

* Original codes are in parentheses. 
Intro $\rightarrow$ Directions: Please answer each question as honestly as possible. If unsure, choose the first answer you think of. You will not be able to go backwards to change answers.

\section{Your Opinions Matter}

Tourism in South Florida drives the economy and affects every resident. To remain strong, tourism here depends on clean air, waterways, and beaches.

Today, South Florida faces many threats to its unique coastal areas, including its beaches, coral reefs, and other habitats in the ocean. The choices we face are not easy. You have an opportunity with this survey to make your voice heard and to influence the leaders and decision-makers who manage the vital coastal habitats in South Florida. Your opinions are important.

\section{Section 1: Recreation and Ocean Resources}

1 How often do you participate in the following activities in or near the ocean? Select all that apply during the past 12 months.

\begin{tabular}{|c|c|c|c|c|c|}
\hline & $\begin{array}{c}\text { More than } \\
\text { once a week } \\
(1)\end{array}$ & $\begin{array}{c}\text { More than } \\
\text { once a month } \\
(2)\end{array}$ & $\begin{array}{c}6-12 \text { times a } \\
\text { year (3) }\end{array}$ & $\begin{array}{c}1-6 \text { times a } \\
\text { year (4) }\end{array}$ & Never (5) \\
\hline Fishing (1) & $\square$ & $\square$ & $\square$ & $\square$ & $\square$ \\
Scuba diving & $\square$ & $\square$ & $\square$ & $\square$ & $\square$ \\
(2) & $\square$ & $\square$ & $\square$ & $\square$ & $\square$ \\
Snorkeling (3) & $\square$ & $\square$ & $\square$ & $\square$ & $\square$ \\
Freediving (4) & $\square$ & $\square$ & $\square$ & $\square$ & $\square$ \\
Boating, by & $\square$ & $\square$ & $\square$ & $\square$ & $\square$ \\
motor (5) & $\square$ & $\square$ & $\square$ & $\square$ \\
Surfing (6) & $\square$ & $\square$ & $\square$ & $\square$ & $\square$ \\
Paddling (7) & $\square$ & $\square$ & $\square$ & $\square$ \\
Distance & & $\square$ & $\square$ & $\square$ & $\square$ \\
swimming or \\
other exercise
\end{tabular}


2 Do you eat seafood (fish, oysters, crabs, etc.)?

O Yes (9)

O No (10)

If No Is Selected, Then Skip To How many times have you visited a cor...

3 Approximately what is your household's weekly seafood budget?

$\mathrm{O}$ under $\$ 10(1)$

O $\$ 10-\$ 19(2)$

O $\$ 20-\$ 29(3)$

O $\$ 30-\$ 39(4)$

O $\$ 40-\$ 49(5)$

O $\$ 50-\$ 59(6)$

O $\$ 60-\$ 69(7)$

O $\$ 70-\$ 79(8)$

O $\$ 80-\$ 89(9)$

O $\$ 90-\$ 99(10)$

O over $\$ 100(11)$

4 A growing number of seafood consumers want to know if seafood is harvested in a sustainable way. Concerns about the consequences of fishing operations, such as overfishing, unmarketable bycatch, and habitat impacts are all considerations that can enter into the buying habits of consumers.

In answering the question below, please consider your household budget as if you are making actual seafood purchase decisions in a real

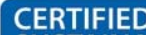
SUSTAINABLE SEAFOOD MSC www.msc.org

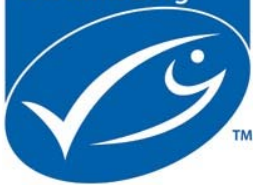
payment situation.

When comparing conventional seafood products, would you be willing to pay an extra amount of $\$ 8$ per week* in your seafood budget if those purchases are certified by a credible agency as being harvested in a sustainable way?

O Yes (18)

O Don't know (19)

O No (20)

* Sample offer shown; see Table 6 for all options. 


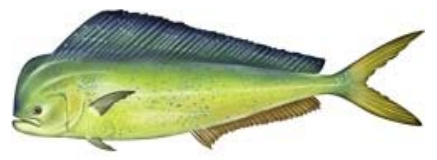

5 Seafood harvested in a sustainable way could come from distant sources; however, locally caught seafood ensures sustainability through compliance with U.S. laws and regulations, and it creates employment, boosts income, and fosters resilient local fishing communities.

In answering the question below, please consider your household budget as if you are making actual seafood purchase decisions in a real payment situation.

When comparing sustainable seafood products, would you be willing to pay an extra amount (above and beyond the amount listed in the previous question) of $\$ 4$ per week* in your seafood budget if it is certified by a credible agency that the seafood you are buying is locally harvested in compliance with U.S. laws and regulations and creates employment, boosts income, and fosters resilient local fishing communities?

O Yes (10)

No (11)

* Sample offer shown; see Table 6 for all options.

6 On a scale from 0 to 10 , how certain are you of the answer you just gave in the previous question about your willingness to pay for seafood that is certified as both sustainable and local?

Completely uncertain (0) (1)

○ 1 (2)

○ 2 (3)

○ 3 (4)

○ $4(5)$

○ $5(6)$

○ $6(7)$

○ 7 (8)

○ 8 (9)

○ (10)

Completely certain (10) (11) 
7 Do you think that seafood certification (shown on labels such as "Sustainably Harvested Seafood" and "Local Seafood") offers a credible signal about seafood products?

O Not at all credible (0) (1)

O $1(2)$

O $2(3)$

O $3(4)$

O $4(5)$

O $5(6)$

O $6(7)$

O $7(8)$

O 8 (9)

O $9(10)$

O Highly credible (10) (11)

8 How many times have you visited a coral reef, at any location?

O Never (1)

O $1-5$ times (2)

O 6-10 times (3)

O $10-20$ times (4)

O 21 or more times (5)

9 From your perspective, what do you think is the present condition (or health) of coral reefs around the world?

Slide the tab under the face to change its expression.

Terrible Poor Mediocre Good Great

(Big Frown) (Frown) (Flat) (Smile) (Big Smile)

O $1(1)$

O $2(2)$

O 3 (3)

O 4 (4)

O 5 (5) 
II Section 2: Coral Reefs in Florida

Intro $\rightarrow$ Directions: All questions that follow address coral reefs in naturally warm, shallow waters (not in aquariums or museums). The photograph shows an example of a coral reef in Florida.

Why are reefs important?

Coral reefs exist near human populations around the world and contain $25 \%$ of all species in the ocean. They rank as one of the earth's most valuable ecosystems, and they provide seafood, recreation, sand creation for beaches, and a buffer against severe storms. They have become one of the most threatened ecosystems on earth, with rapid declines documented worldwide during the past 30 years.

In South Florida, coral reefs are credited with creating 94,000 jobs and generating $\$ 8$ billion annually.

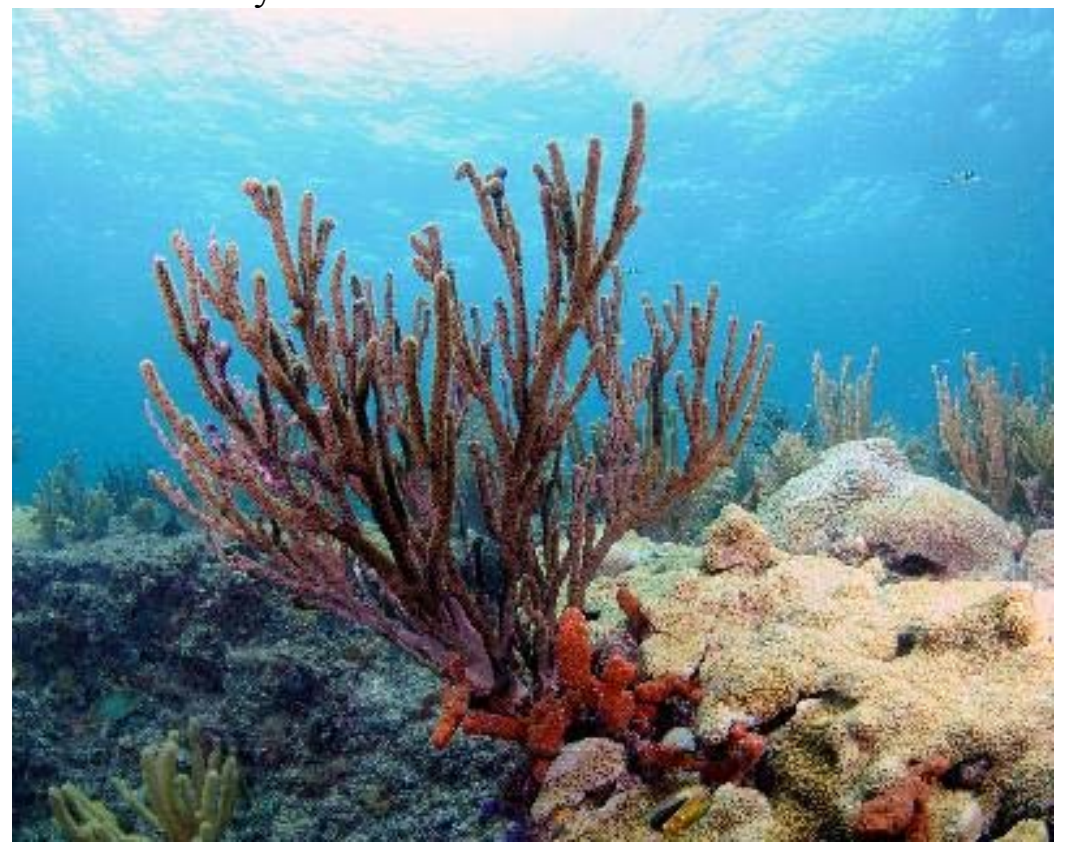

10 In the past 5 years, have you visited a coral reef in Florida? A visit could include fishing or other activities at the surface (such as snorkeling, surfing, or paddling) where you knew that reefs existed in that location.

O Yes (1)

No (2)

Don't know (3) 
11 Rank the following threats to coral reefs in Florida. From your perspective, how destructive is each one?

\begin{tabular}{|c|c|c|c|c|c|}
\hline & $\begin{array}{c}\text { Extremely } \\
\text { Destructive } \\
(1)\end{array}$ & $\begin{array}{c}\text { Very } \\
\text { Destructive } \\
(2)\end{array}$ & $\begin{array}{c}\text { Moderately } \\
\text { Destructive } \\
(3)\end{array}$ & $\begin{array}{c}\text { Slightly } \\
\text { Destructive } \\
(4)\end{array}$ & $\begin{array}{c}\text { Minimally } \\
\text { Destructive } \\
(5)\end{array}$ \\
\hline $\begin{array}{c}\text { Scuba Diving } \\
\text { \& Snorkeling } \\
\text { (1) }\end{array}$ & 0 & 0 & 0 & 0 & 0 \\
$\begin{array}{c}\text { Hurricanes \& } \\
\text { Natural } \\
\text { Disasters (2) }\end{array}$ & 0 & 0 & 0 & 0 & 0 \\
$\begin{array}{c}\text { Dredging \& } \\
\text { Construction } \\
\text { (3) }\end{array}$ & 0 & 0 & 0 & 0 & 0 \\
$\begin{array}{c}\text { Air Pollution } \\
\text { (4) }\end{array}$ & 0 & 0 & 0 & 0 & 0 \\
$\begin{array}{c}\text { Shipping \& } \\
\text { Boating (5) }\end{array}$ & 0 & 0 & 0 & 0 & 0 \\
$\begin{array}{c}\text { Fishing (6) } \\
\text { Sewage \& }\end{array}$ & 0 & 0 & 0 & 0 & 0 \\
$\begin{array}{c}\text { Runoff (7) } \\
\text { Invasive }\end{array}$ & 0 & 0 & 0 & 0 & 0 \\
$\begin{array}{c}\text { Species (8) } \\
\text { High Water }\end{array}$ & 0 & 0 & 0 & 0 & 0 \\
Temperatures \\
(9)
\end{tabular}


12 Where are coral reefs in Florida located? The state is divided into 9 general regions. Scroll over the map and click on a box to include that region. Select at least one box.

\begin{tabular}{|c|c|c|}
\hline Click to write Region 1 (81) & Off (1) & \\
Click to write Region 2 (82) & & \\
Click to write Region 4 (84) & & \\
Click to write Region 5 (85) & & \\
Click to write Region 6 (86) & & \\
Click to write Region 7 (87) & & \\
Click to write Region 8 (88) & & \\
Click to write Region 9 (89) & \\
Region \#10 (90) & \\
\hline
\end{tabular}

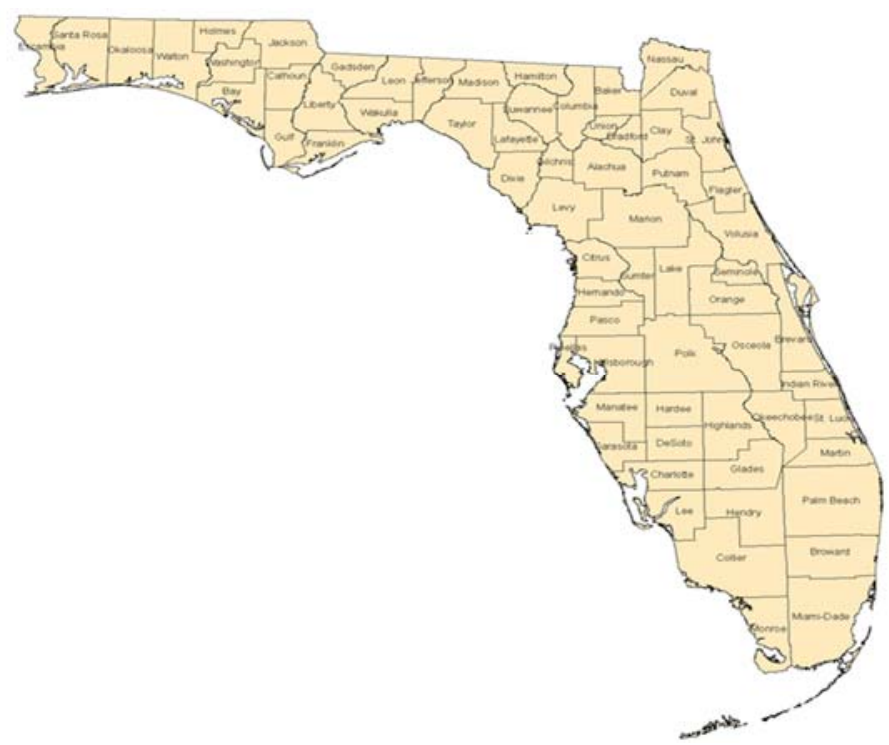

13 How do you currently obtain information and learn more about coral reefs?

Rank the most important source as "1," the second most important as "2," and continue to rank all the sources that provide you with useful information about coral reefs.

Personal experience (1)

Email (2)

Newspapers (print or online) (3)

Social Media (4)

Television (5)

Magazines and Newsletters (6)

Radio (7)

Scientific literature (9) 
14 Most of the nearly 6 million people in South Florida live in the region shown on this map. This region has extensive beaches and coral reefs near each other.

Rank the present condition of each listed resource, in the region on this map, as you understand it. You can respond based on the area where you live or that you know the best.

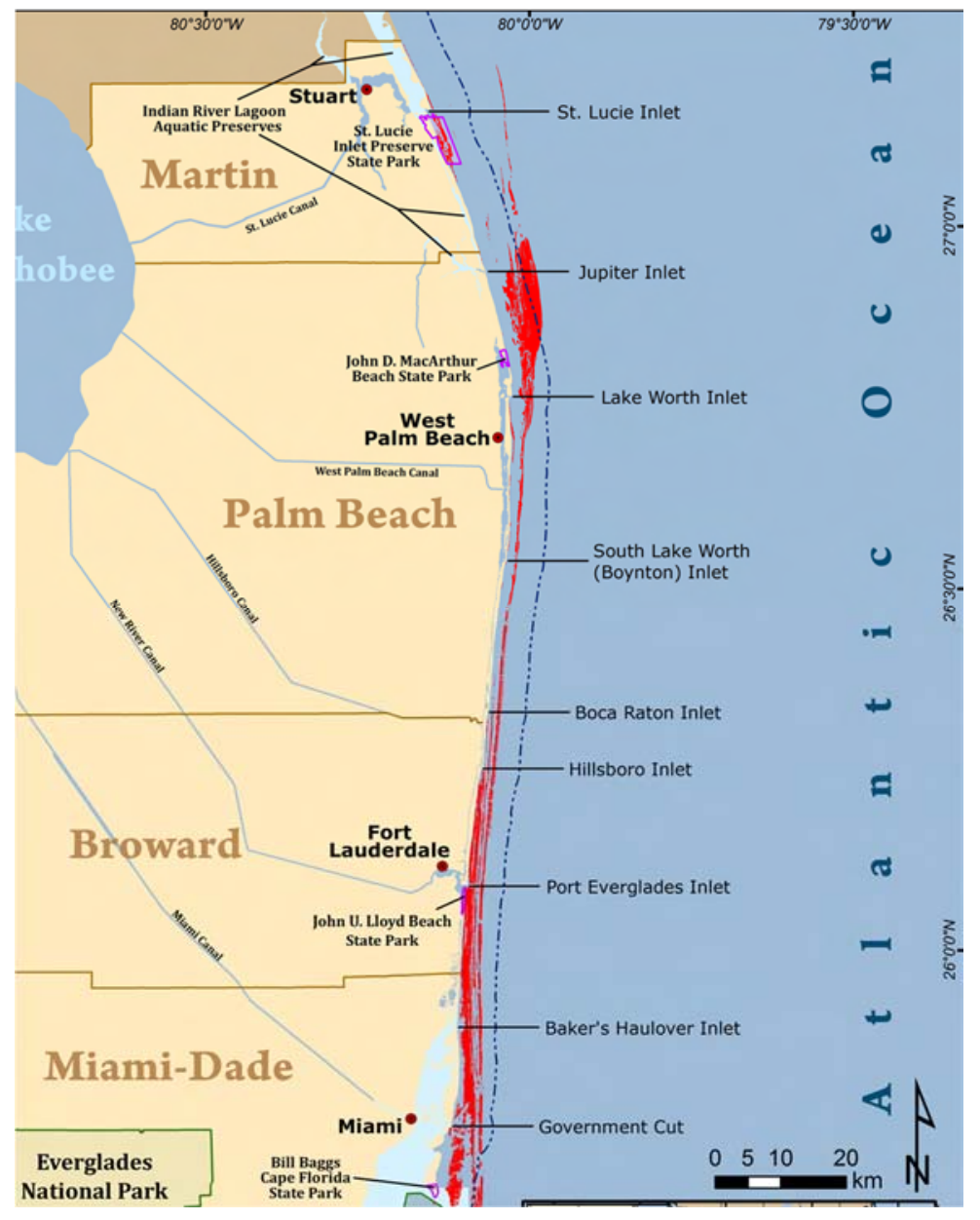

\begin{tabular}{|c|c|c|c|c|c|}
\hline & Excellent (1) & Good (2) & Average (3) & Poor (4) & Terrible (5) \\
\hline $\begin{array}{l}\text { Coral Reefs } \\
\text { (in red) (1) }\end{array}$ & O & 0 & O & O & $\mathrm{O}$ \\
\hline Beaches (2) & 0 & $\mathrm{O}$ & 0 & 0 & $\mathrm{O}$ \\
\hline Seafood (3) & O & 0 & O & O & 0 \\
\hline Wetlands (4) & O & O & O & O & O \\
\hline Canals (5) & O & O & O & O & O \\
\hline $\begin{array}{c}\text { Drinking } \\
\text { Water (6) }\end{array}$ & O & O & 0 & 0 & O \\
\hline
\end{tabular}




\section{Section 3: Coastal Management Choices}

Intro $\rightarrow$ Directions: This section allows you to express your preference for how coastal resources should be managed in the future. Pay close attention to this explanation, and do not move forward until you understand it.

The next 2 questions will show a table with 3 plans (under column A, B, C). Each plan is a complete package that has an associated monthly fee that you would be charged for 5 years. You will choose one combination that you prefer and that you are willing to pay for.

Here is an example:

\begin{tabular}{|c|c|c|c|}
\hline & $\begin{array}{c}\text { Plan A } \\
\Downarrow\end{array}$ & $\begin{array}{c}\text { Plan B } \\
\Downarrow\end{array}$ & $\begin{array}{c}\text { Plan C } \\
\text { (no change) } \\
\Downarrow\end{array}$ \\
\hline $\begin{array}{l}\text { Beach } \\
\text { size: }\end{array}$ & $10 \%$ Smaller & $\underbrace{}_{\text {Current }}$ & $10 \%$ Smaller \\
\hline $\begin{array}{l}\text { Water } \\
\text { quality: }\end{array}$ & $\begin{array}{c}\text { Significant }(30 \%) \\
\text { Improvement }\end{array}$ & $\begin{array}{l}\text { Slight (10\%) } \\
\text { Improvement }\end{array}$ & Poor \\
\hline $\begin{array}{l}\text { Coral } \\
\text { restoration: }\end{array}$ & $\begin{array}{c}\text { Significant (30\%) } \\
\text { Improvement }\end{array}$ & $\begin{array}{c}\text { (1) } \\
\text { Current } \\
\text { Level }\end{array}$ & $\begin{array}{c}\text { Dint } \\
\text { Current } \\
\text { Level }\end{array}$ \\
\hline $\begin{array}{c}\text { Fee } \\
\text { per month: }\end{array}$ & $+\$ 15$ & $+\$ 30$ & $+\$ 0$ \\
\hline
\end{tabular}

\section{Which plan do you prefer?}

Plans A and B include improvements for at least one coastal resource. Plan C represents the status quo and what can be expected with "no change" to management. For Plan C, notice that beaches will become smaller, because natural erosion and loss of sand is expected to be faster than current rates of beach expansion projects. 
"Water quality" refers to the clarity and cleanliness of seawater near the coastline, and "coral restoration" refers to direct action on reefs that supports their growth.

Before making your choice, consider the following: Clean, clear water is necessary for coral reefs to develop. Problems that foul the water include sewage pipes and construction projects, and managing them can be costly. One major new cost involves the state's decision to remove South Florida's six pipes that send partially-treated sewage into the ocean. Other new management solutions could include limitations on pumping sand onto beaches and / or expansion of coral restoration projects.

IIIa Management Choices 1*

15.1 Which plan do you prefer?

O A (1)

$\mathrm{B}(2)$

$\mathrm{O}$ C (3)

*Note: The choice cards, and question versions 15.2-15.10 are not shown. See Appendix 4.

\section{IIIb Management Choices 2*}

Answer If Which package do you prefer? A Is Displayed

16.1 This card is different than the previous card. Consider it carefully. Now which plan do you prefer?

O A (1)

O B (2)

O C (3)

*Note: The choice cards, and question versions 16.2-16.10 are not shown. See Appendix 4.

17 For the plan you selected with the highest fee, how certain are you that you will pay that fee for the next 5 years? You can assume that your selected plan is being 
implemented by Florida management agencies, and the new monthly fee will appear on your next utility bill.

Move the tab under the dial to select a number between 0 to 10 , with 0 meaning "not at all willing to pay" and 10 meaning "perfectly willing to pay."
O $0(0)$
O $1(1)$
O $2(2)$
O $3(3)$
O $4(4)$
O $5(5)$
O $6(6)$
O $7(7)$
O $8(8)$
O $9(9)$
O $10(10)$

18 In choosing Plan A, B or C, how important were the following items to you?

\begin{tabular}{|c|c|c|c|c|c|}
\hline & $\begin{array}{l}\text { Not important } \\
\text { (1) (1) }\end{array}$ & (2) (2) & (3) (3) & (4) (4) & $\begin{array}{c}\text { Very } \\
\text { important (5) } \\
\text { (5) }\end{array}$ \\
\hline Fee (1) & 0 & O & O & 0 & O \\
\hline $\begin{array}{c}\text { Coral } \\
\text { restoration (2) }\end{array}$ & 0 & O & O & 0 & O \\
\hline $\begin{array}{l}\text { Water quality } \\
\text { (3) }\end{array}$ & $\mathrm{O}$ & O & $\mathrm{O}$ & O & O \\
\hline Beach size (4) & 0 & O & O & 0 & 0 \\
\hline
\end{tabular}

19 Who should be primarily responsible to pay for the management and protection of Florida's coral reefs?

O All U.S. citizens (1)

Tourists in Florida (2)

O People who use Florida's reefs (3)

O Residents of Florida (4)

O No one (5)

O Don't know (6)

IV Section 4: Climate Change and Reef Values 
20 Rank each statement by choosing the label that best reflects your perspective.

\begin{tabular}{|c|c|c|c|c|c|}
\hline $\begin{array}{c}\text { Your concern } \\
\text { about climate } \\
\text { change: (1) } \\
\begin{array}{c}\text { Human } \\
\text { influence on } \\
\text { climate } \\
\text { change: (2) }\end{array}\end{array}$ & 0 & 0 & 0 & 0 & 0 \\
$\begin{array}{c}\text { The effect of } \\
\text { climate } \\
\text { change on } \\
\text { hurricanes: } \\
\text { (3) }\end{array}$ & 0 & 0 & 0 & 0 & 0 \\
$\begin{array}{c}\text { The effect of } \\
\text { climate } \\
\text { change on } \\
\text { coral reefs: } \\
\text { (4) }\end{array}$ & 0 & 0 & 0 & 0 & 0 \\
$\begin{array}{c}\text { Your concern } \\
\text { about sea } \\
\text { level rise: (5) }\end{array}$ & 0 & 0 & 0 & 0 & 0 \\
\hline
\end{tabular}

21 When do you think climate change will start to have an impact in Florida?

O It has an impact now (1)

O 10 years from now (2)

O 25 years from now (3)

O 50 years from now (4)

O 100 years from now (5)

O Never (6) 
22 A specialty Florida license plate called "Protect Our Reefs" costs an additional \$25 and supports only one nonprofit research center.

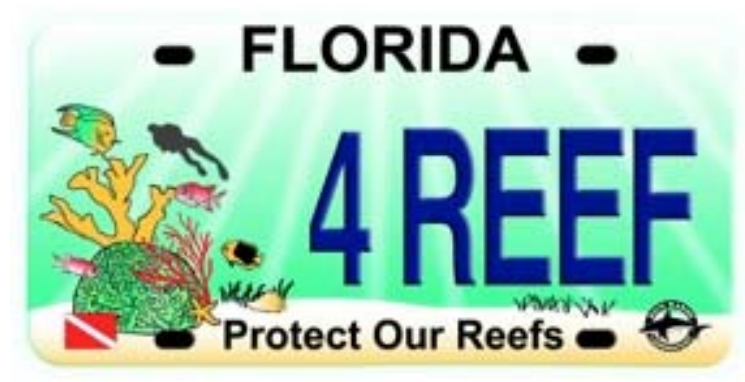

Suppose that a referendum were held for financing a Florida Coral Reef Research Fund using additional local sales tax to support all coral reef research centers in Florida. The referendum would need a majority vote (more than $50 \%$ ) to pass.

How would you vote if this referendum proposes $\$\{\text { e://Field/blank1 }\}^{*}$ additional local sales tax $\$\{\mathrm{e}: / /$ Field/blank 2$\}$ for the Florida Coral Reef Research Fund?

Yes, in favor of Florida Coral Reef Research Fund (1)

No, against the Florida Coral Reef Research Fund (2)

* See Table 8 for all offers.

23 On a scale from 0 to 10 , how certain are you of the answer you just gave about raising local sales tax for the Florida Coral Reef Research Fund?

O Completely uncertain (1)

O $1(2)$

O $2(3)$

O $3(4)$

O $4(5)$

O $5(6)$

O $6(7)$

O $7(8)$

O 8 (9)

O $9(10)$

O Completely certain (11)

24 Now suppose that an alternative referendum were held in which the Florida Coral Reef Research Fund Program (as described above) was cosponsored. In this case, the program costs are shared by the National Oceanic and Atmospheric Administration (NOAA) on a dollar to dollar match (for each dollar raised locally, 
NOAA provides an additional dollar on top of what it spends now on coral reef research in Florida). Again, the referendum would need a majority vote (more than $50 \%$ ) to pass.

Now how would you vote if this alternative referendum proposes $\$\{\mathrm{e}: / \text { Field/blank } 1\}^{*}$ additional local sales tax $\$\{$ e://Field/blank2\}* for the Florida Coral Reef Research Fund? - Yes, in favor of Florida Coral Reef Research Fund, cosponsored by the Federal Agency (1)

No, against the Florida Coral Reef Research Fund, cosponsored by the Federal Agency (2)

* See Table 8 for all offers.

25 On a scale from 0 to 10 , how certain are you of the answer you just gave about raising local sales tax for the Florida Coral Reef Research Fund?

Completely uncertain (1)

O 1 (2)

O $2(3)$

O 3 (4)

O $4(5)$

O $5(6)$

O $6(7)$

O $7(8)$

О 8 (9)

O $9(10)$

O Completely certain (11) 
26 To what extent do you agree or disagree with each of the following statements?

\begin{tabular}{|c|c|c|c|c|c|}
\hline & $\begin{array}{l}\text { Strongly } \\
\text { Agree (1) }\end{array}$ & Agree (2) & $\begin{array}{c}\text { Neither } \\
\text { Agree nor } \\
\text { Disagree (3) }\end{array}$ & Disagree (4) & $\begin{array}{c}\text { Strongly } \\
\text { Disagree (5) }\end{array}$ \\
\hline $\begin{array}{l}\text { The primary } \\
\text { value of coral } \\
\text { reef areas is to } \\
\text { provide the } \\
\text { needs of } \\
\text { humans. (1) }\end{array}$ & 0 & 0 & 0 & 0 & 0 \\
\hline $\begin{array}{l}\text { Human use of } \\
\text { coral reef } \\
\text { areas should } \\
\text { not be allowed } \\
\text { if it damages } \\
\text { these areas. } \\
\text { (2) }\end{array}$ & O & 0 & $\mathrm{O}$ & 0 & $\mathrm{O}$ \\
\hline $\begin{array}{l}\text { All coral reefs } \\
\text { in Florida } \\
\text { should be } \\
\text { protected. (3) }\end{array}$ & 0 & 0 & 0 & 0 & O \\
\hline $\begin{array}{l}\text { Increasing } \\
\text { carbon } \\
\text { dioxide is a } \\
\text { threat to } \\
\text { corals. (4) }\end{array}$ & 0 & 0 & O & 0 & O \\
\hline $\begin{array}{l}\text { The increasing } \\
\text { acidification } \\
\text { of sea water } \\
\text { threatens } \\
\text { corals. (5) }\end{array}$ & O & O & $\mathrm{O}$ & 0 & $\mathrm{O}$ \\
\hline $\begin{array}{l}\text { Water } \\
\text { temperatures } \\
\text { are rising too } \\
\text { quickly for } \\
\text { corals to } \\
\text { adapt. (6) }\end{array}$ & 0 & 0 & 0 & 0 & $\mathrm{O}$ \\
\hline $\begin{array}{l}\text { Coral reefs are } \\
\text { more } \\
\text { endangered } \\
\text { than } \\
\text { rainforests. (7) }\end{array}$ & 0 & 0 & 0 & 0 & 0 \\
\hline
\end{tabular}


27 Consider the two items below. Which is more important? While both are important, choose the one that seems more important than the other.

The Economy, even if it leads to environmental problems (1)

The Environment, even if it costs jobs or economic growth (2)

V Section 5: About You

28 What year were you born?

O 19

29 Where were you born?

Florida (1)

Other U.S. state or territory (2)

Other country (3)

301 . What is your gender?

Male (1)

Female (2)

31 What is your zip code?

32 Does anyone in your household own a boat?

Yes, with a motor (1)

Yes, but without a motor (2)

No (3)

33 What is your approximate combined household income, annually and before taxes?

under $\$ 20,000$ (1)

O $\$ 20,000-39,999$ (2)

O $\$ 40,000-59,999$ (3)

O \$60,000-79,999 (4)

O $\$ 80,000-99,999(5)$

○ $\$ 100,000-119,999$ (6)

○ $\$ 120,000-139,999$ (7)

O $\$ 140,000-159,999(8)$

○ $\$ 160,000-179,999$ (9)

○ $\$ 180,000-199,999$ (10)

○ $\$ 200,000$ or more (11) 
34 What percent (\%) of your household income comes from beach or ocean-related 1) tourism, 2) hospitality, 3) resources (such as fishing and boating), and 4) other environmental science and management jobs?

Drag the tabs to the right to select a percentage for each of the 4 categories that applies to your household. Tourism (1) Hospitality (2) Ocean resources (3) Environmental Fields (4)

35 In terms of politics, how do you identify yourself?

O Republican (1)

O Independent, leans Republican (2)

O Independent (3)

O Independent, leans Democrat (4)

O Democrat (5)

O Other: (6)

36 What is your race?

White/Caucasian (1)

A African American (2)

- Hispanic (3)

Asian (4)

a Native American (5)

口 Pacific Islander (6)

Other (7)

37 What is the highest level of education you have completed?

O Less than High School (1)

O High School / GED (2)

O 2-year College Degree (4)

4-year College Degree (5)

O Masters Degree (6)

O Doctoral Degree (7)

Answer If What is the highest level of education you have completed? 4-year College Degree Is Selected Or Masters Degree Is Selected Or Doctoral Degree Is Selected

38 Do you hold a degree related to the environment or the physical sciences?

Y Yes (1)

No (2) 
39 In the past year, have you donated money or time to an environmental cause?

Y Yes (1)

No (2)

Don't know (3)

Answer If In the past few years, have you donated money or time to ... Yes Is Selected

40 Approximately how much money did you donate within the past 12 months?

$\square \$ 0(1)$

口 $\$ 1-\$ 49(2)$

口\$50 - \$199(3)

口 $\$ 200-\$ 499(4)$

$\square \$ 500-\$ 999(5)$

$\square$ more than $\$ 1,000(6)$

41 On a 0 to 10 scale, where 0 means it does not describe you at all and 10 means it describes you perfectly, how well does the word "environmentalist" describe you?

○ $0(0)$

○ $1(1)$

○ $2(2)$

○ $3(3)$

○ (4)

○ $5(5)$

O $6(6)$

○ 7 (7)

○ $8(8)$

○ $9(9)$

○ $10(10)$

End Thank You! You have completed the survey. 


\section{Appendix 4}

Emails from Respondents:

Sample emails sent from survey participants, Nov. 13- Jan. 7

Email is identified by date and respondent ID.

1. Nov. 13, ID R_dbSzscSTnSgeT9b

This survey is bogus. I'm a commercial fisherman in the Florida keys and I started reading it and it does not work for me. Those questions are going to be answered with out any direct knowledge on the industry. NOAA and national marine fisheries are destroying our culture. And on top of everything you have FWC enforcement on laws that shouldn't exist making it harder to make a living. Sustainable seafood is every where. The ocean is larger than all the continents put together. I've never seen better fishing in my life and thank god for it everyday. You can't ask people questions that they don't even understand and expect to call that research. Get your ass out from under a desk and be a real scientist like the rest of the commercial fisherman. The ones that nobody respects or listens to the real research being done everyday of our lives. All you idiots make up numbers and call it a day and take away from our hungry families. Commercial fisherman not only are fisherman. We are scientist, meteorologist, teachers, students, mechanics, and salesman ect. Even though most of us are high school and college drop outs that's what it takes to do the job we love. You have to be out of your fucking mind to do the job but there is no place I'd rather be but on the sea. Take all that into consideration that the real research that takes place nobody listens to.

Sent from my iPhone

2. Dec. 3, ID R_e9CP4rvV2ZxXKMR

I have lived here my entire life and have seen dramatic changes to our resources.

3. Dec. 4, ID R_bE1Szb7SeylVdFX

Survey too long for non paid participants, After section three you lost my attention.

4. Dec. 9, ID R_5zitE8H4LDG9Zgp

Relevant survey but the questions were not specific enough.

For example, the question asked whether or not fishing damaged the reefs. What kind of fishing? Commercial fishing using drag nets - definitely YES. Recreational fishing by informed locals - not really. Fishing by tourists or the uninformed - probably.

Also, one question asked how much more would I be willing to spend on certified fish. It should have asked how much of a percentage more rather than a definite dollar amount. Say my weekly seafood budget is only about $\$ 10$, so paying an additional $\$ 10$ is $100 \%$ that's ridiculous. For someone who has a budget of $\$ 100 / \mathrm{wk}$, an additional $\$ 10$ is only $10 \%$. 
Preservation of the coral reefs is extremely important. At least your survey also aimed to educate as well.

5. Dec. 19, ID R_8eNBGd8pVHfIp7v

I am very disappointed that no space was set aside for my thoughts on Government run programs. I don't like them. They are to top heavy. So Everything in your study shows federal or state run studies ...Not good.. The private sector could and would do a much better job. Have a blessed day and a very Merry Christmas.. $<@$ ) $\}\}\}><$

6. Dec. 19, ID R_79WtsM0MxxpSU17

James - regarding the survey question about a sales tax (local) to benefit the reefs - good idea bit the percentage was too high and the survey did not allow any adjustments.

Consequently I voted against even though I wanted to vote "for" . I feel our reefs and fish populations (Although dwindling) are a NATIONAL resource so I liked the idea of "codollars" from NOAA. Net/net, I'd suggest a state-wide tax option with the NOAA codollars but keep the percentage small so you have a chance of getting the needed votes to pass. Thanks for including me in the survey.

7. Dec. 26, ID R_exnkXCXqZWNjPN3

James,

I just finished taking your survey which I found very interesting. I think there was one question missing that would help with insight of peoples opinions. That question would relate to peoples confidence in moneys actually being implemented towards reef improvements. The state's record in using moneys for their stated purpose is not so good. Florida's water management (paid for by the tax payers) also does not have a good track record. Example:

How certain are you that the fees to the state will be used as proposed and in an efficient manor? How much does that effect your answers?

8. Dec. 28, ID R_beGIUR3dFWlzS6x

Hey James,

I just took the survey and I wanted to let you guys know that I go spearfishing and kayak fishing, every chance I can. I spend a lot of time in the water off broward county in between 20-70 feet of water. If you have further questions about anything reef related please let me know!

Sent from my iPhone

9. Dec. 30, ID R_8czVpWhoO8yXjgN

The problem with the fishing in florida is over regulation for the general public and over fishing for the commercial guys. Your survey is so slanted that I stopped filling it out. 
Why would anyone in this economy who loves to fish pay more to support an industry that has been collectively stealing the rights of weekend boaters for years. Ex: the red snapper fleet in the panhandle. How many jobs does the marine industry support? I bet you it's a hell of a lot more than commercial fishing in florida. Boat sales, tourism, tackle shops, guides, ext.... I know many and am related to a few commercial guys and know they are getting record low prices for fish that are supposedly harder to find and catch. So we pay more money to who? Let the private boaters keep more fish!! Support a larger industry including the largest (tourism) and the most important which would be family bonding time instead of a select small group of people who don't give a poop about the environment.

In ending I would like to invite you to take a small road trip to stuart. Just south of the inlet you will find pecks lake. It's a beautiful reef about a mile off the beach. Right now the mackerel are running. Just watch the commercial guys... Listen... Then get your dive gear on and swim down to the reef and look...

Then rewrite your slanted survey.

\section{Jan. 3, ID R cMeFVaio4Zy2X7n}

James,

Your survey is too long. I'd suggest shorter 3/5 min surveys spread out rather than trying to 'boil the ocean' with one all encompassing survey. I started but did not finish...I suspect you'll get a lot of that.

\section{Jan. 4, ID R_cOVnwkhfhJZ8T6B James,}

We obviously need to be responsible with our actions as a society when balancing human wants and needs with the environment. But I'm worried today that too many of the current environmentalists are turning global warming/climate change into a cult or pseudo religion.

As one example, a lot of environmentalists today have no deference to the economy with how they want to impose their version of environmentalism on the world. One of your questions even had the immaturity to ask if the economy should be a consideration with environmental improvements. This is illogical for one very simple reason: if you destroy the economy to the point where too many people cannot provide for their family in meaningful ways, one must remember that a father/husband or a wife/mother has no moral dilemma with burning down an entire forest in one evening if it means the difference between keeping their kids warm or not.

If your motivation (and others at FIU) is to take a lead in environmentalism, that's wonderful. Just never forget the paragraph directly above. I am all about cleaner air and water and healthy coral reefs. I am all about as many forms of energy that can usefully compete with oil as possible. Besides the environmental concerns, and besides the country drilling a ton of oil recently in the Dakotas and elsewhere, having a mostly oilbased energy structure is, at the end of the day, a national security concern. 
As another example, I'm an airline pilot. When I first started labor costs were the number one expenditure for my airline ... as it should be. Once oil got above \$75-80ppb, fuel became the \#1 expenditure. Airplanes, even large jet airplanes, have been tested flying with fuels other than petroleum. This is exciting to me and I hope advancements in this area continue. But if we have to artificially reduce the number of flights in this country to adhere to some contrived schedule of improvements in this area, and it causes me to lose my job, instead of congratulating and shaking the hands of the people who were responsible for this environmental feat, I'd put my knee in their crotch with an unusual amount of force.

So as you go forward, do things smart. Always maintain deference for the economy. The economy is a natural beast and if you try to manipulate it and put it in a corner, it will just come back and bite you as explained above. That doesn't mean something can't cost slightly more, but you obviously can't do it with taxes because politicians (of both parties) will just take environmental dollars and use them for their own purposes. Thanks for the survey and good luck with your sane environmental efforts going forward. 
Appendix 5

Sub-Variables related to Main Variables (see Table 10)

Description

Boating, by motor

Fishing

Visit Beach

Snorkeling

Scuba diving

Freediving

Paddling

Swimming

Surfing

Sailing

Canals

Reefs

Wetlands

Drinking Water

Beaches

Seafood
Mi Ma

$\begin{array}{ccccc}\mathrm{N} & \mathrm{n} & \mathrm{M} & \mathrm{Ma} & \\ \text { Ocean Interaction } & & \text { Mean }\end{array}$

1152

1155

1141

1138

1137

1130

1126

1129

04

4

2.582465

2.47619

1.159019

1.125602

1.169771

1.103666

1.616872

1.616872

1.041337

1.237279

1.260113

1.075554

1.118436

0.845249

$\begin{array}{llll}1130 & 0 & 4 & 0.3814159\end{array}$

0.739370
2

6

\section{Rate Mainland Resources}

$93 \quad 3.26923$

$\begin{array}{lllll}6 & 1 & 5 & 1 & 1.04352 \\ 93 & & & 3.20149 & 0.891629 \\ 8 & 1 & 5 & 3 & 5\end{array}$

$\begin{array}{lllll}8 & 1 & 5 & 3 & 5\end{array}$

$\begin{array}{lll}93 & 2.91201 & 0.977065\end{array}$

$\begin{array}{lllll}2 & 1 & 5 & 7 & 4\end{array}$

$93 \quad 2.73212 \quad 0.994516$

$\begin{array}{lllll}7 & 1 & 5 & 4 & 5\end{array}$

$\begin{array}{lll}93 & 2.53248 & 0.861247\end{array}$

$\begin{array}{lllll}9 & 1 & 5 & 1 & 7\end{array}$

$93 \quad 2.50374$

$\begin{array}{lllll}5 & 1 & 5 & 3 & 0.934548\end{array}$

\section{Coral Concern Scale Factors}

Coral and acidification

Coral and carbon dioxide

Coral not only human needs

Coral protection in Florida

Coral and temperature

Coral worse than rainforests

Coral use prevention if damaging

$\begin{array}{rrrrr}815 & 1 & 5 & 4.065031 & 0.9735781 \\ 815 & 1 & 5 & 3.746012 & 1.111932 \\ 816 & 1 & 5 & 3.669118 & 1.122367 \\ 817 & 1 & 5 & 3.597307 & 1.311018 \\ 814 & 1 & 5 & 3.461916 & 1.074311 \\ 815 & 1 & 5 & 3.420859 & 0.9422159 \\ 816 & 1 & 5 & 3.367647 & 1.247184\end{array}$

Reef Threats 
Threat from Sewage \& Runoff

$\begin{array}{rrrrr}1025 & 1 & 5 & 4.369756 & 0.8920561 \\ 1027 & 1 & 5 & 4.212269 & 1.037186 \\ 1028 & 1 & 5 & 4.125486 & 1.016328 \\ 1028 & 1 & 5 & 3.683852 & 1.215869 \\ 1025 & 1 & 5 & 3.180488 & 1.241223 \\ 1028 & 1 & 5 & 3.174125 & 1.160797 \\ 1027 & 1 & 5 & 2.986368 & 1.083191 \\ 1028 & 1 & 5 & 2.292802 & 1.036278 \\ 1028 & 1 & 5 & 1.814202 & 0.9379548\end{array}$

\section{Climate Concern Scale Factors}

$\begin{array}{llllrr}\text { Climate's Reef Effect } & 828 & 1 & 5 & 3.722222 & 1.109545 \\ \text { Climate's Human Influence } & 828 & 1 & 5 & 3.568841 & 1.174639 \\ \text { Sea Level Rise Concern } & 828 & 1 & 5 & 3.31401 & 1.199737 \\ \text { Climate Change Concern } & 829 & 1 & 5 & 3.302774 & 1.16252 \\ \text { Climate's Hurricane Effect } & 828 & 1 & 5 & 3.218599 & 1.155102\end{array}$

\section{Information Source}

$\begin{array}{llllrr}\text { Personal Experience } & 878 & 1 & 8 & 6.002278 & 2.276747 \\ \text { Scientific Literature } & 827 & 1 & 8 & 5.325272 & 2.296302 \\ \text { Magazines } & 771 & 1 & 8 & 5.201038 & 1.857886 \\ \text { Newspapers (print or online) } & 766 & 1 & 8 & 4.930809 & 2.219148 \\ \text { Television } & 789 & 1 & 8 & 4.66033 & 2.020507 \\ \text { Email } & 759 & 1 & 8 & 3.814229 & 2.002244 \\ \text { Social Media } & 771 & 1 & 8 & 3.522698 & 2.27532 \\ \text { Radio } & 754 & 1 & 8 & 3.208223 & 1.911143\end{array}$

